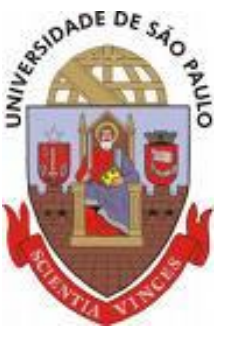

\author{
Universidade de São Paulo \\ Faculdade de Odontologia de Ribeirão Preto
}

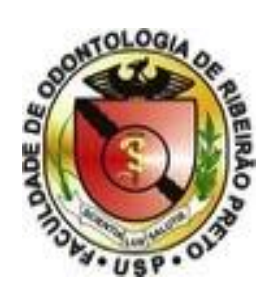

FRANCIELLE ALVES MENDES

Avaliação da adaptação marginal e interna, da resistência à fratura após ciclagem termomecânica e das tensões nos implantes por correlação de imagens digitais em próteses parciais fixas sobre implantes com pilares e copings em zircônia com diferentes sistemas CAD/CAM 



\section{Avaliação da adaptação marginal e interna, da resistência à fratura após ciclagem termomecânica e das tensões nos implantes por correlação de imagens digitais em próteses parciais fixas sobre implantes com pilares e copings em zircônia com diferentes sistemas CAD/CAM}

Tese apresentada à Faculdade de Odontologia de Ribeirão Preto da Universidade de São Paulo para obtenção do Título de Doutor em Reabilitação Oral

Área de Concentração: Reabilitação Oral

Orientador: Prof.Dr. Ricardo Faria Ribeiro

Co-orientador: Prof. Dr. Flávio Domingues das Neves

\section{VERSÃO CORRIGIDA}

\section{Ribeirão Preto}




\section{FICHA CATALOGRÁFICA}

Mendes, Francielle Alves

Avaliação da adaptação marginal e interna, da resistência à fratura após ciclagem termomecânica e das tensões nos implantes por correlação de imagens digitais em próteses parciais fixas sobre implantes com pilares e copings em zircônia com diferentes sistemas CAD/CAM, 2015.

224p.: il. ; $30 \mathrm{~cm}$

Versão Corrigida da Tese de doutorado, apresentada à Faculdade de Odontologia de Ribeirão Preto/USP. Área de Concentração: Reabilitação Oral.

Orientador: Ribeiro, Ricardo Faria Ribeiro

Co-orientador: Neves, Flávio Domingues das

1.CAD/CAM. 2.Adaptação marginal. 3. Resistência à fratura. 4.Ciclagem termomecânica. 5.Zircônia. 6.Análise por correlação digital de imagens. 7.MEV. 


\section{FOLHA DE APROVAÇÃO}

Francielle Alves Mendes. Avaliação da adaptação marginal e interna, da resistência à fratura após ciclagem termomecânica e das tensões nos implantes por correlação de imagens digitais em próteses parciais fixas sobre implantes com pilares e copings em zircônia com diferentes sistemas CAD/CAM

Tese apresentada à Faculdade de Odontologia de Ribeirão Preto da Universidade de São Paulo para obtenção do grau de Doutor em Reabilitação Oral

Data da defesa:

\section{Banca Examinadora}

Prof. Dr.

Julgamento: Assinatura:

Prof. Dr.

Julgamento: Assinatura:

Prof. Dr.

Julgamento: Assinatura:

Prof. Dr.

Julgamento: Assinatura:

Prof. Dr.

Julgamento: Assinatura: 

“Ora, àquele que é poderoso para fazer infinitamente mais do que tudo quanto pedimos ou pensamos, conforme o seu poder que opera em nós, a ele seja a glória, na igreja e em Cristo Jesus, por todas as gerações, para todo o sempre. Amém!" 



\section{Dedico eSTe TrabalHo}

A Deus, meu melhor amigo, por me fortalecer nos momentos em que estive fraca e me animar nos momentos em que quis fraquejar. Obrigada pela presença constante em minha vida!

Aos meus pais, Norvandir e Nilde, por todo amor, dedicação e incentivo aos estudos. Vocês serão sempre meus maiores exemplos. Sinto muita saudade, pai! Mãe, minha maior ajudadora durante esse processo. Obrigada por tudo, pelas noites mal dormidas, pela companhia nas viagens, pelo cuidado com a Marina, pelas orações, pelo colo, palavras de incentivo, enfim, Deus não poderia ter me dado mãe melhor.

À minha filha Marina, que foi meu melhor presente e alegria! Veio trazer um novo sentido à minha vida. Obrigada filhinha, pela companhia nas viagens, por cada sorriso que me sustenta e me inspira a continuar a caminhada. Mamãe te ama muito!

Ao meu querido esposo, Pedro, meu eterno companheiro. Muito obrigado é pouco para agradecer todo carinho, ajuda e incentivo. Obrigada pela companhia em todos os momentos e por me incentivar a continuar a caminhada acadêmica. Sem você eu não teria conseguido chegar até o fim.

À minha irmã, Simone e meu cunhado Denilson, por toda preocupação, ajuda e incentivo. Vocês são meu alicerce, minha maior referência. Irmãzinha, mesmo longe sempre se faz presente. Você é meu grande exemplo. A sua força é essencial ao meu caminhar. Obrigado por tudo!

Às minhas sobrinhas Isabelle e Beatriz, que são presentes de Deus na nossa vida. Cada sorriso, cada cartinha, cada telefonema, me faz muito feliz. Obrigada por terem me ajudado com a Marina nas viagens. 



\section{AgRADECIMENTO ESPECIAL}

Ao meu orientador Prof. Dr. Ricardo Faria Ribeiro, pessoa e profissional com conhecimento e postura exemplares, por toda dedicação e ajuda durante todas as fases desse trabalho. Obrigado por todos os ensinamentos, por estar sempre disponível, por entender minha ausência e por acreditar nesse trabalho. Muito obrigado!!! 



\section{AgRadecimentos}

Ao Prof. Dr. Flávio Domingues das Neves, meu co-orientador, por ter ajudado a delinear esse trabalho e compartilhado os seus conhecimentos sobre o sistema CAD/CAM. Obrigado pela amizade, respeito, disponibilidade e oportunidades durante todos esses anos.

À Profa. Dra. Renata Cristina Silveira Rodrigues Ferracioli e à Profa. Dra. Rossana Pereira de Almeida por terem participado da minha banca de qualificação e terem contribuído com o projeto.

À Profa. Dra. Maria da Gloria Chiarello de Mattos pela amizade, convívio e ensinamentos.

Aos professores da pós graduação, por todos os ensinamentos e experiências compartilhadas.

À Dra. Adriana Cláudia Lápria Faria por todo conhecimento transmitido, amizade, paciência, atenção e ajuda durante todas as etapas desse trabalho. A sua presença no laboratório fez toda a diferença durante o desenvolvimento deste trabalho. Muito obrigado!

À Ana Paula Macedo, pela ajuda, principalmente durante os testes de resistência a fratura e microscopia eletrônica de varredura. Muito obrigado pela companhia, amizade e dinamismo durante todas as fases.

À Izabela, pela amizade, ajuda em todos os momentos, pelas risadas, companheirismo, ensinamentos e por ter sido sempre tão prestativa. Muito obrigado!

Ao Danilo pela disponibilidade, sempre com seu jeito calmo e alegre. Obrigado principalmente pela ajuda durante a preparação das amostras para a visualização no MEV.

À Talita, parceira durante as clínicas, aulas, viagens e congressos. Obrigado pela amizade e por ter me ensinado um pouco com seu jeito único de ser.

Ao Serginho, pela amizade, alegria ao me cumprimentar e por toda ajuda.

A todos os colegas da pós-graduação, pela companhia e conhecimentos compartilhados. Ficaram boas recordações e ensinamentos! 
Aos colegas do laboratório de prótese, principalmente ao Lício e Marcelo, por terem me ajudado durante a preparação do enceramento dos pilares.

Às secretárias do Departamento e da Pós-Graduação: Ana Paula Xavier, Fernanda Talita de Freitas, Isabel Cristina Galino Sola, Regiane de Cássia Tirado Damasceno e Regiane Cristina Moi Sacilotto, pela atenção e paciência.

Ao Prof. Dr. Antônio Carlos Shimano e aos técnicos Carlos Alberto Moro e Reginaldo Trevilato Silva, do laboratório de Bioengenharia da FMUSP-RP, por ter disponibilizado o laboratório e ajudado durante a avaliação da resistência à fratura e MEV.

Ao Rodrigo Ferreira Silva, pela educação e presteza em realizar o banho de ouro das amostras para avaliação no MEV.

Às funcionárias da Casa de Hóspedes, em especial à Shirlene, por terem me acolhido tão bem. Obrigada pelo cuidado e amizade.

À Renata, obrigado pela companhia na casa de hóspedes e nas viagens de volta pra casa. Você me ensinou muito com sua humildade e simplicidade. Ficarão boas e alegres lembranças.

À Protécnica, especialmente ao Lício, Douglas e Débora, pela amizade, paciência e pelo bom relacionamento durante os procedimentos de escaneamento dos pilares e infraestruturas Lava.

Ao Marco Aurélio Dias Galbiati e seus funcionários do laboratório MADG, pela confecção do grupo controle e prensagem das próteses. Obrigado pelo cuidado, profissionalismo e por terem me acolhido tão bem. Agradeço de coração!

Ao João Felipe Bonatto Bruniera, por ter realizado os escaneamentos das próteses por meio do microCT. Muito obrigado pela grande ajuda!

A Profa. Dra. Yara T. C. Silva Sousa (UNAERP), por ter sido tão prestativa e ter nos dado a oportunidade de realizar os escaneamentos no microCT. Muito obrigada!

Ao Thiago (Neodent) pela ajuda e boa comunicação durante os procedimentos com o sistema Neodent digital. 
À Erica por ter permitido acompanhar as suas etapas finais de pós-doutorado e por ter me ajudado a delinear meu projeto.

À Tânia de Freitas Borges, pela disponibilidade em sempre me ajudar. Obrigado por todo incentivo, oportunidades, companhia nas viagens e amizade sincera.

À Faculdade Patos de Minas, em especial ao amigo e coordenador, Fernando Nascimento, obrigado pelo incentivo, compreensão e pelo afastamento durante o curso.

À Suleimy, por ter realizado parte da análise estatística desse trabalho.

Ao Programa de Pós Graduação em Reabilitação Oral, do Departamento de Materiais Dentários e Prótese, pela oportunidade.

À Neodent que prontamente nos forneceu os implantes e componentes usados nesse trabalho.

À Capes por ter concedido a bolsa de doutorado no primeiro semestre do curso.

À FAPESP por ter concedido o auxílio e a bolsa de estudos para realização do curso de doutorado (Processos 2012/13115-8 e 2012/08003-6).

À Faculdade de Odontologia de Ribeirão Preto da Universidade de São Paulo, na pessoa do seu diretor Prof. Dr. Valdemar Mallet da Rocha Barros pela sua competência.

A todos que direta e indiretamente contribuíram com esse trabalho e com meu crescimento acadêmico. 

MENDES, F. A. Avaliação da adaptação marginal e interna, da resistência à fratura após ciclagem termomecânica e das tensões nos implantes por correlação de imagens digitais em próteses parciais fixas sobre implantes com pilares e copings em zircônia com diferentes sistemas CAD/CAM. Ribeirão Preto, 2015. 224p. Tese (Doutorado em Reabilitação Oral). Faculdade de Odontologia de Ribeirão Preto, Universidade de São Paulo.

\section{RESUMO}

Considerando a crescente exigência estética, o desenvolvimento da zircônia e o incremento da tecnologia CAD/CAM o objetivo deste trabalho foi avaliar a adaptação marginal e interna, as tensões nos implantes e a resistência à fratura após prensagem da porcelana e termociclagem mecânica em próteses parciais fixas sobre implantes com pilares e infraestrutura em zircônia com dois sistemas CAD/CAM (Neodent digital -Neodent e Lava - 3M ESPE) comparados com o método convencional $(\mathrm{n}=10)$. A adaptação marginal e interna foi analisada por meio de um microtomógrafo computadorizado (microCT). Cada prótese foi digitalizada e os arquivos foram processadas utilizando o software NRecon e CTAN. Foi utilizado o programa Dataview para aferição das medidas. Para a realização da ciclagem termomecânica as próteses foram posicionadas na máquina de fadiga mecânica por mastigação e foi aplicada a carga de $120 \mathrm{~N}$ com uma ponta que simula a oclusão antagonista simulando 2.000 .000 ciclos. Durante o ensaio, as próteses foram mantidas em água destilada e termocicladas com variação de temperatura entre $5^{\circ}-55^{\circ} \mathrm{C}$. Para a verificação das tensões geradas pelas próteses parciais fixas em torno dos implantes foi realizada a análise por correlação de imagens digitais. Foram selecionados cinco modelos de cada um dos sistemas CAD/CAM e um antagonista e aplicada uma carga de $250 \mathrm{~N}$, com velocidade de $0,1 \mathrm{~mm} / \mathrm{min}$, em máquina universal de ensaios. Para avaliação da resistência à fratura foi aplicada uma força perpendicular ao longo eixo da peça protética, no pôntico, até que devido à fratura não houvesse mais resistência. Após esse teste foi avaliado o relacionamento entre os componentes da prótese em microscópio eletrônico de varredura (MEV). A análise estatística mostrou que houve diferença significativa na adaptação pilar-implante dos molares entre os grupos Lava e ZirNeo, Lava e Controle $(p=0,008)$. Para a desadaptação vertical e horizontal antes e após a prensagem e ciclagem não houve diferença significante $(p>0,005)$. A desadaptação interna axial mostrou diferença significante antes e após para os molares dos grupos Lava e ZirNeo $(p<0,001)$. A desadaptação interna oclusal mostrou diferença significante para os PM dos grupos TiNeo e Controle e para os molares dos grupos Lava e Zir Neo $(p<0,005)$. Houve diferença significante de tensão na região cervical dos molares dos grupos ZirNeo e Lava $(p=0,015)$ com maiores valores de tensão para o grupo Lava. O grupo TiNeo teve maior resistência à fratura que os demais $(p=0,022)$. O relacionamento entre os componentes da prótese permaneceu favorável para todos os grupos. Os resultados deste trabalho permitem concluir que a prensagem da porcelana e a termociclagem mecânica não influenciou os resultados da desadaptação marginal e melhorou a adaptação interna. O grupo usinado pelo sistema Neodent digital em zircônia teve maior concentração de tensão na região cervical podendo ter maior perda óssea nessa região. O grupo TiNeo foi o que mais resistiu à fratura. Entre fresar em zircônia pelo sistema Neodent digital ou Lava, o sistema Lava distribui melhor a tensão ao longo do implante, porém teve maiores valores de desadaptação interna. Entre fresar em titânio ou confeccionar a prótese pelo sistema convencional, melhor fresar.

Palavras-Chave: CAD/CAM; adaptação marginal; resistência a fratura; ciclagem termomecânica; zircônia; análise por correlação digital de imagens; MEV. 

MENDES, F. A. Evaluation of the marginal and internal fit, resistance to fracture after thermomechanical cycling and tensions in the implants by correlation of digital images in fixed partial dentures on implants with abutments and copings in zirconia with different CAD/CAM systems. Ribeirão Preto, 2015. 224p. Tese (Doutorado em Reabilitação Oral). Faculdade de Odontologia de Ribeirão Preto, Universidade de São Paulo.

\begin{abstract}
Considering the growing aesthetic requirements, the development of zirconia and the increase of CAD/CAM technology, the aim of this study was to evaluate the marginal and internal fit, tensions in implants and fracture resistance after pressing porcelain and thermomechanical cycling in FPDs on implants with abutments and infrastructure in zirconia with two CAD/CAM systems (Neodent digital -Neodent and Lava - 3M ESPE) compared with the conventional method $(\mathrm{n}=10)$. The marginal and internal fit was analyzed by a computerized microtomograph (microCT). Each prosthesis was scanned and the files were processed using the NRecon and CTAN software. Dataview program was used for the assessment of the measures. To carry out the thermomechanical cycling, prostheses were placed in mechanical fatigue machine for chewing and $120 \mathrm{~N}$ load was applied with a tip that simulates the antagonist occlusion simulating 2,000,000 cycles. During the test, the prostheses were kept in distilled water and thermocycled with temperatures between $5^{\circ}-55^{\circ}$ C. Digital image correlation analysis was performed to check the load transfer by implant-supported restoration. Five models were selected from each of the CAD/CAM systems and an antagonist and a load of $250 \mathrm{~N}$ was applied, with $0.1 \mathrm{~mm} / \mathrm{min}$ speed using a universal testing machine. The fracture resistance was verified with force applied perpendicular to the long axis of the prosthesis, at pontic, until there were no more fracture resistance. After this test was evaluated the relationship between the components of the prosthesis in a scanning electron microscope (SEM). The statistical analysis showed significant difference in abutment-implant fit of molars between Lava and ZirNeo, Lava and control groups $(p=.008)$. For vertical and horizontal fit there was no significant difference $(p>.005)$ before and after pressing and thermomechanical cycling. The axial internal gap was significantly different before and after for molar ZirNeo groups $(p<.001)$. The occlusal internal fit was significantly different to the PM of TiNeo and Control, and the molars of Lava and ZirNeo $(p<.005)$. There were significant difference for tension in the cervical region of the molars of ZirNeo and Lava $(p=.015)$ with higher values for the Lava group. TiNeo group had higher resistance to fracture than others $(p=.022)$. The relationship between the prosthesis components remained positive for all groups. The results of this study showed that the pressing of porcelain and thermomechanical cycling did not influence the results of marginal gap and improved internal fit. The zirconia group machined by Neodent digital system had higher concentration of tension in the cervical and may have greater bone loss in this region. TiNeo group was the most resistant to fracture. Between the zirconia milling by Neodent digital or Lava system, the Lava system distributes better strain throughout the implant, but had greater internal fit values. Between milling titanium or fabricate the prosthesis by the conventional system, better milling.
\end{abstract}

Keywords: CAD/CAM; marginal fit; fracture resistance; thermomechanical cycling; zirconia; digital image correlation analysis; SEM. 



\section{SUMÁRIO}

1. INTRODUÇÃO 23

2. REVISÃO DA LITERATURA

2.1 Adaptação protética e CAD/CAM 31

2.2 Tensão nos implantes e perda óssea

2.3 Resistência a fratura

3. PROPOSIÇÃO

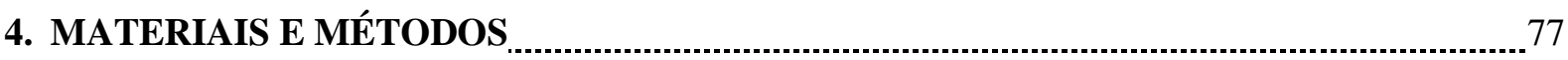

4.1 Obtenção dos modelos

4.2 Confecção dos pilares - TiNeo e ZirNeo 81

4.3 Confecção dos pilares - Grupo Lava

4.4 Confecção dos pilares - Grupo Controle $\quad 84$

4.5 Confecção das infraestruturas - ZirNeo e TiNeo _..._. 86

4.6 Confecção das infraestruturas - Lava

4.7 Confecção das infraestruturas - Controle

4.8 Cimentação provisória das infraestruturas

4.9 Prensagem da porcelana

4.9.1 Aplicação do Opaco (Grupos TiNeo e Controle) _ 94

4.9.2 Aplicação do ZirLiner (Grupos ZirNeo e Lava) _ 95

4.9.3 Recobrimento estético das infraestruturas 96

4.10. Tratamento interno da superfície, prévio à cimentação 101

4.11. Confecção dos antagonistas _ 102

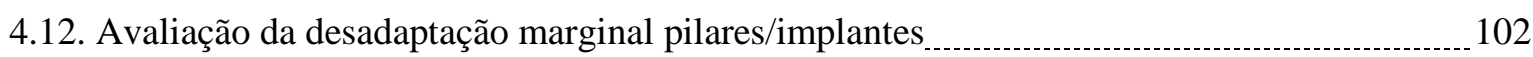

4.13. Avaliação da desadaptação infraestruturas/pilares antes ciclagem $\ldots$

4.14. Ensaio de ciclagem termomecânica

4.15. Avaliação da adaptação das próteses após ciclagem

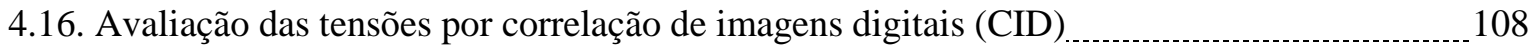

4.17 Ensaio mecânico de resistência à fratura 110

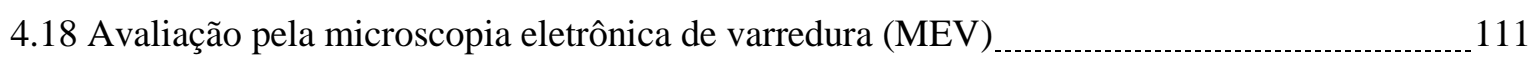

5. RESULTADOS

5.1 Adaptação marginal vertical entre pilares/implante (Lupa estereoscópica) _ $\quad 115$

5.2 Adaptação marginal e interna entre infraestrutura/pilares (MicroCT)

5.3 Adaptação marginal e interna entre a prótese fixa e pilares após prensagem da porcelana e ciclagem (MicroCT)

5.4 Adaptação marginal e interna antes e após prensagem da porcelana e ciclagem

(MicroCT) 
5.5 Correlação de imagens digitais 146

5.6 Resistência a fratura 152

5.7 Microscopia eletrônica de varredura 159

6. DISCUSSÃO 173

7. CONCLUSÕES 189

REFERENCIAS BIBLIOGRÁFICAS 193

ANEXOS 203 
1. Introducão 

A utilização de próteses implantossuportadas para reabilitação de pacientes desdentados posteriores aumentou significativamente nos últimos anos. Além disso, houve crescente interesse pela odontologia estética levando ao aumento do uso de restaurações metal free também nessa região. Por causa da estética e biocompatibilidade muitos pacientes preferem coroas de cerâmica pura em detrimento de coroas metalocerâmicas (Fahmy, 2010).

Entretanto, apesar da cerâmica ser um material estético com ótimas propriedades, é frágil por natureza e quando se discute a possibilidade de confecção de próteses parciais fixas e pilares para implantes, há de se considerar sua baixa resistência à fratura, aliada à baixa resistência à flexão (Picone e Maccauro, 1999). Isto se torna ainda mais crítico na região posterior da boca, onde as forças mastigatórias são maiores e há a necessidade de materiais cerâmicos mais resistentes para apoiar o revestimento cerâmico mais fraco. A necessidade de melhores propriedades mecânicas em regiões sujeitas a maiores cargas mastigatórias levou à introdução da zircônia na odontologia (Andreiuolo, 2013).

Em comparação com as ligas de metais, a zircônia é uma cerâmica que oferece boa estética, excelente biocompatibilidade, estabilidade química e dimensional, baixo acúmulo de placa, baixa condutividade térmica e radioatividade, alta radiopacidade, resistência mecânica, dureza e módulo de Young da mesma magnitude que o do aço inoxidável (Guess, 2012). Além disso, é cada vez mais utilizada para restaurações unitárias ou múltiplas na região anterior ou posterior da boca (Kollar et al., 2008).

Entretanto a zircônia é um material que não pode ser usado facilmente sem uso da tecnologia CAD/CAM (Abduo, 2014). O método CAD/CAM surgiu na odontologia há aproximadamente 20 anos com o objetivo de otimizar a produção de estruturas protéticas (Heymann et al, 1996). O método se define resumidamente por um escaneamento do modelo/boca seguido pelo desenho da estrutura protética no computador e conseguinte confecção por uma máquina de fresagem. 
As vantagens do sistema CAD/CAM são rapidez, reprodutibilidade, durabilidade, previsibilidade e precisão dimensional. Além disso, o sistema CAD/CAM minimiza a distorção inerente da técnica convencional. O sistema Cerec (Sirona Dental Systems GmbH, Benshein, Alemanha) foi o pioneiro a usar essa tecnologia para confecção das próteses dentárias, entretanto no mercado brasileiro também existem vários outros sistemas como: Lava (3M), Neodent digital (Neodent), VIPI, Amann Girbach, Zirkonzhan (Talmax), entre outros. Estudos recentes têm mostrado que a fabricação de próteses fixas de múltiplos elementos pelos sistemas CAD/CAM tem maior precisão do que com técnicas tradicionais de fabricação, como fundição (Beuer, 2009; Kohorst, 2011).

Entretanto, a maior durabilidade das restaurações dentais não depende somente de suas propriedades mecânicas (Karatasli et al., 2011). Segundo Beuer (2008), um dos fatores que determinam o sucesso em longo prazo das restaurações dentais é a adaptação marginal. A combinação de desajustes horizontais e verticais na interface pilar-implante pode resultar em efeitos adversos, incluindo afrouxamento do parafuso e rotação e/ou fratura do pilar (Kano et al., 2007). Além disso, pode ocorrer também infiltração bacteriana ocasionando inflamação gengival devido ao desenvolvimento da microflora na região do gap, com grandes riscos de periimplantite e de reabsorção óssea, bem como posterior fratura do parafuso (Barbosa et al., 2008).

Diferentes técnicas têm sido usadas para avaliar a adaptação marginal de coroas entre elas a microtomografia computadorizada, a qual tem a vantagem de não ser destrutiva (Borba et al., 2011; Krasanaki et al., 2012, Pelekanos et al., 2009). Essa técnica possibilita a avaliação da adaptação em 3D o que garante a leitura mais precisa da desadaptação.

Outro fator a ser avaliado é a tensão nos implantes. Não existe consenso na literatura quanto ao melhor planejamento protético para reabilitações parciais com múltiplos implantes adjacentes a fim de minimizar as tensões geradas na interface osso-implante (Tiossi, 2012). 
Uma prótese é considerada passiva quando há contato circular simultâneo com seus respectivos pilares sobre implantes. O encaixe passivo é assumido como sendo um dos mais importantes pré-requisitos para a manutenção da interface osso-implante. Para fornecer o ajuste passivo a prótese deveria, teoricamente, não induzir tensão sobre os componentes do implante e o osso circundante na ausência de uma força externa aplicada (Sahin e Cehreli, 2001).

$\mathrm{Na}$ escolha entre cimentar ou parafusar uma prótese, Piascik et al. (2009) afirmam que a cimentação adesiva é preferível por assegurar maior retenção e adaptação marginal, garantindo maior resistência à fratura. Além disso, Alkumru et al. (1988) afirmaram que a redução da resistência à fratura de restaurações totalmente cerâmicas pode ser devida a discrepâncias internas acentuadas.

Diferentes métodos vêm sendo empregados para avaliar as tensões geradas na interface osso-implante e a influência dos materiais utilizados na confecção das próteses implantossuportadas. Dentre eles, podemos destacar métodos experimentais como a fotoelasticidade e a extensiometria além dos métodos de simulação computacional como o de elementos finitos tridimensionais (Tiossi et al., 2011). O método de correlação de imagens digitais (CID) foi inicialmente proposto para monitorar o fluxo de fluidos e a deformação de superfícies sólidas em engenharia. Também já foi utilizado na Odontologia para analisar a distribuição e direção de tensões superficiais geradas pela contração de polimerização de resinas compostas ( $\mathrm{Li}$ et al., 2009). O método consiste na tomada de uma série de imagens digitais da superfície que será analisada, previamente pintada com pequenas partículas de tinta preta, usando uma câmera CCD (Charged-Coupled Device). As tensões na superfície do modelo são calculadas por software específico, a partir do deslocamento das partículas durante a aplicação de carga. Este método é capaz de proporcionar a análise qualitativa e quantitativa das tensões, além de analisar todo o campo do modelo em estudo, em vez de 
apenas uma pequena parte de sua superfície. Este método também apresentou maior precisão na detecção de tensões quando comparado ao método extensométrico ( $\mathrm{Li}$ et al., 2009). Comparado aos métodos mais utilizados para análise de tensões (fotoelasticidade e extensometria), o método CID é mais completo e, portanto, mais indicado para a comparação e validação direta do modelo matemático computacional (MEF-3D). Há ainda a possibilidade de adicionar mais uma câmera para captura das imagens, transformando o método em um sistema 3D de análise de tensões (CID-3D).

Assim, esse estudo teve como propósito comparar dois sistemas CAD/CAM ao sistema convencional de confecção de próteses fixas sobre implantes, de três elementos, com um pôntico intermediário. 
2. ReVisÃo da Literatura 



\subsection{Adaptação protética e CAD/CAM}

Hung et al. (1990) avaliaram a adaptação marginal de coroas Dicor, Cerestore e metalocerâmicas sobre dez pré molares hígidos preparados. As desadaptações marginais verticais foram medidas antes da cimentação, após a cimentação e após a termociclagem. Foram observadas diferenças significativas entre as três condições de teste em cada tipo de coroa, entre coroas Dicor e metalocerâmica após a cimentação e após a termociclagem, e entre coroas Cerestore e metalocerâmica após a termociclagem. Todas as 30 coroas cimentadas foram então incluídas em resina acrílica e cortadas para a mensuração da desadaptação marginal absoluta. Diferenças significativas entre coroas Dicor e Cerestore e entre coroas Cerestore e metalocerâmicas foram encontradas. Concluiu-se que a desadaptação marginal aumentou após a cimentação e termociclagem e coroas metalocerâmicas tiveram adaptação marginal significativamente melhor do que as coroas Dicor e Cerestore.

Jacobs e Windeler (1991) investigaram a taxa de solubilidade do cimento de fosfato de zinco comparado com o tamanho da fenda marginal. Teste padronizado com as amostras foi construído para simular lacunas marginais clinicamente relevantes de 25, 50, 75 e $150 \mu \mathrm{m}$ e suas linhas de cimento subsequentes. $\mathrm{O}$ estudo foi dividido em duas fases: a Fase 1 avaliou os efeitos da difusão simples da solubilidade do cimento num ambiente estático, enquanto a Fase 2 investigou os efeitos de forças convectivas sobre dissolução do cimento em ambiente dinâmico. Os resultados demonstraram aumento significativo entre os quatro grupos da fase 1 . O grupo D teve menor cimento remanescente do que os grupos A, B e C. Não houve diferença significativa entre as áreas de cimento remanescente no grupo $\mathrm{A}, \mathrm{B}, \mathrm{C}$ e amostras teste. Linhas de cimento são inevitáveis em prótese fixa porque sempre existirá algum grau de discrepância marginal. Isto é significativo porque todos os cimentos comumente utilizados dissolvem no ambiente bucal. Idealmente, a discrepância marginal deve estar ligada à espessura do filme do cimento. 
Por outro lado, o objetivo do estudo de Jemt (1996) foi medir e comparar a precisão da adaptação de próteses implantossuportadas na maxila desdentada utilizando réplicas em modelos e implantes intraorais. Sete próteses maxilares e 10 mandibulares foram selecionadas aleatoriamente e medidas por meio de uma técnica de imagem tridimensional (3-D). Os resultados indicaram que as próteses rotineiramente parafusadas a implantes osseointegrados poderiam demonstrar a desadaptação de até várias centenas de microns. Quando modelos mestres foram utilizados como referência, a distorção média 3-D do ponto central do cilindro de ouro foi de $37 \mu \mathrm{m}$ e $75 \mu \mathrm{m}$ para próteses mandibulares e maxilares, respectivamente. $\mathrm{O}$ correspondente deslocamento significativo foi de $90 \mu \mathrm{m}$ e $111 \mu \mathrm{m}$, respectivamente, quando os implantes intraorais foram utilizados como referências. A distorção média 3-D foi significativamente maior para as medidas intraorais em ambos os arcos. Além disso, a desadaptação foi significativamente mais elevada para as próteses superiores quando os modelos mestres foram utilizados como referência. No entanto, para as medidas intraorais não foi possível observar diferença significativa de adaptação entre as arcadas, o que pode ser devido ao tamanho relativamente pequeno da amostra.

Heymann et al. (1996) realizaram estudo clínico em longo prazo com 50 restaurações inlay CEREC (Siemens AG) em 28 pacientes. Após quatro anos encontraram que as inlays tiveram comportamento altamente favorável na manutenção da cor, cáries secundárias, contorno anatômico, adaptação marginal, textura de superfície e sensibilidade pós-operatória. Monitoraram a perda de cimento ao longo das margens oclusais e encontraram diminuição incomum na mensuração do desgaste do cimento do terceiro para o quarto ano. Os resultados favoráveis das restaurações $\mathrm{CAD} / \mathrm{CAM}$ deste estudo clínico em longo prazo prevêem significante sucesso dessa abordagem restauradora e otimização da produção de estruturas protéticas. 
Em 2001, Gratton et al. avaliaram o efeito da pré-carga aplicada aos parafusos do pilar de liga de ouro no micromovimento e fadiga da interface implante/pilar/parafuso do pilar. Quinze restaurações de implantes unitários com liga nobre, cada um contendo um UCLA hexagonal com cilindro de ouro, foram divididas aleatoriamente em três grupos com pré-carga (16, 32 e 48 N.cm). Cada grupo foi composto por cinco implantes (3,75 x $15 \mathrm{~mm})$ e cinco parafusos quadrados de liga de ouro. A máquina de ensaios mecânicos aplicou carga compressiva cíclica entre 20 e $130 \mathrm{~N}$ a $6 \mathrm{~Hz}$ em um ponto de contato em cada coroa sobre implante. A micromovimentação da interface parafuso/pilar foi medida após 100, 500, 1000, $5.000,10.000,50.000$ e 100.000 ciclos. Houve diferença significativa no torque de pré-carga. No entanto, não houve diferença significativa entre a pré-carga e o número de ciclos. O grupo 16 N.cm apresentou maior micromovimento que ambos os grupos 32 e 48 N.cm em todos os intervalos do ciclo. Dentro dos limites desse estudo pode-se concluir que o micromovimento da interface pilar/implante/parafuso do pilar permaneceu constante ao longo 100.000 ciclos com pré carga de 16, 32 e 48 N.cm, indicando assim que não ocorreu fadiga da interface da junta parafusada. A utilização de parafusos com pré-carga adequada exibiu maior micromovimento na interface pilar/implante. Isto foi evidenciado pelo grupo $16 \mathrm{~N} . \mathrm{cm}$ que exibiu maior micromovimento em comparação com os grupos 32 e 48 N.cm. Interfaces parafusadas utilizando parafusos que foram demasiadamente apertados (pré-carga de 48 N.cm de torque) exibiram menor quantidade de micromovimento sem aparente comprometimento do sistema como resultado do aperto excessivo. A abertura máxima na interface pilar/implante foi de $17 \mu \mathrm{m}$ quando o parafuso do pilar foi apertado a $16 \mathrm{~N} . \mathrm{cm}$ e carga de $130 \mathrm{~N}$ foi aplicada.

Também em 2001, Sahin e Çehreli, analisaram o significado clínico de ajuste passivo e os fatores que afetam o ajuste de próteses sobre implantes. Afirmaram que os procedimentos clínicos e laboratoriais utilizados para confecção da estrutura são inadequados para fornecer ajuste passivo absoluto para próteses fixas implantossuportadas. Uma prótese é considerada 
passiva quando há contato circular simultâneo de seus respectivos pilares sobre os implantes. O encaixe passivo é assumido como sendo um dos mais importantes pré-requisitos para a manutenção da interface osso-implante. Para fornecer o ajuste passivo a prótese deveria, teoricamente, não induzir tensão sobre os componentes do implante e osso circundante na ausência de uma força externa aplicada. As complicações protéticas são atribuídas à falta de ajuste passivo, causando efeito questionável sobre o sucesso do implante. No entanto, o uso de tecnologia avançada pode melhorar a adaptação das próteses.

Cibirka et al. (2001) examinaram a hipótese nula de que não há diferença nos valores de destorque dos parafusos dos pilares após teste de fadiga quando as dimensões entre hexágono do implante e hexágono do pilar são alterados ou a forma hexagonal do implante é eliminada. Três sub-grupos de implantes NobelBiocare foram avaliados $(n=10)$ : hexágono externo $(\mathrm{R})$, hexágono modificado $(\mathrm{H})$, e plataforma geométrica circular $(\mathrm{C})$ com pilares usinados Procera com angulação de $25^{\circ}$. Não houve nenhum afrouxamento do parafuso do pilar ou deslocamento rotativo na interface pilar/implante avaliados sob alta resolução $(25 \mathrm{x})$. Exame radiográfico não demonstrou indicação de parafuso quebrado ou deslocado após testes de fadiga. $\mathrm{O}$ espaço foi confirmado visualmente entre o implante e as paredes dos pilares no momento da avaliação radiográfica para todas as amostras. Para o grupo R, a média de destorque foi 14,40 N.cm; para o grupo M, o valor médio foi de 14,70 N.cm e para o grupo C foi de 16,40 N.cm.

Khraisat et al. (2004) investigaram o efeito do carregamento cíclico lateral com carga em diferentes posições no afrouxamento do parafuso do pilar de um sistema de implante hexágono externo. Para isso, o destorque do parafuso do pilar foi medido antes e após carregamento. A diminuição do destorque foi comparada entre as aplicações de carga cêntricas e excêntricas. Além disso, o deslocamento rotativo do pilar e as alterações microscópicas nas superfícies de contato das roscas foram examinados. Quinze implantes 
Branemark foram divididos igualmente em três grupos: A, B, e C. Cada conjunto consistiu de um implante Mark IV (4 x $10 \mathrm{~mm}$ ) montado em um bloco, um pilar CeraOne (3 mm) e uma infraestrutura cimentada. Para o grupo A, carga cíclica de $50 \mathrm{~N}$ foi aplicada centralizada e perpendicular ao longo eixo do implante, enquanto que para o grupo B a mesma carga foi aplicada excentricamente (à distância de $4 \mathrm{~mm}$ ) no sentido de desaparafusar. A meta de $1 \mathrm{x}$ $10^{6}$ ciclos (40 meses de função simulada) foi definida. Grupo C (controle) foi deixado sem carga pelo mesmo período de tempo de carregamento como os grupos A e B. O destorque foi registrado antes e após o carregamento e a diferença foi calculada. Os resultados demonstraram que para todas as amostras, nenhuma decementação ou afrouxamento do parafuso foi observado por inspeção tátil ou visual durante ou após o carregamento. O grupo A exibiu diferença significativa nos valores de destorque em comparação com os grupos B e C. Os grupos B e C não foram significativamente diferentes um do outro. Dentro das limitações deste estudo in vitro, os valores de destorque foram preservados sob carga lateral excêntrica em relação às cargas laterais cêntricas.

Em seu trabalho, Reich et al. (2005) avaliaram a adaptação marginal clínica e interna de várias unidades de prótese parcial fixa posterior, totalmente em cerâmica e utilizando três sistemas CAD/CAM. Os resultados foram comparados com os de próteses metalocerâmica convencionais. Vinte e quatro próteses de cerâmica pura foram fabricadas e aleatoriamente subdivididas em três grupos. Foram oito próteses usando o sistema Digident CAD/CAM (DIGI), oito usando o sistema Cerec Inlab (IN LA); Zircônia Vita InCeram foi usada para ambos os grupos. Num terceiro grupo foram fresadas as próteses a partir de blocos de zircônia estabilizada com ítrio, usando o sistema Lava (LAVA). Todas as próteses foram recobertas com material de revestimento cerâmico. Além disso, 6 próteses parciais fixas metalocerâmicas de 3 elementos serviram como grupo controle. Todas as próteses foram avaliadas ao microscópio, usando réplicas. A mediana da desadaptação marginal do sistema 
Digident foi $75 \mu \mathrm{m}$, do Lava e Cerec Inlab $65 \mu \mathrm{m}$ e das próteses metalocerâmicas $54 \mu \mathrm{m}$. No ponto médio das paredes axiais, a mediana da desadaptação foi $94 \mu \mathrm{m}$ para Digident, $105 \mu \mathrm{m}$ para Lava, $154 \mu \mathrm{m}$ para Cerec Inlab e $75 \mu \mathrm{m}$ para próteses convencionais. Na transição entre a parede axial e a oclusal, os valores da mediana da desadaptação foram: $197 \mu \mathrm{m}$ para Digident, $162 \mu \mathrm{m}$ para Lava, $198 \mu \mathrm{m}$ para Cerec Inlab e $116 \mu \mathrm{m}$ para as restaurações metalocerâmicas. A espessura das réplicas na área oclusal foi $326 \mu \mathrm{m}$ para Digident, $198 \mu \mathrm{m}$ para Lava, $359 \mu \mathrm{m}$ para Cerec Inlab e $287 \mu \mathrm{m}$ para as próteses metalocerâmicas. As desadaptações marginais do sistema Digident diferiram significativamente das próteses metalocerâmicas. As desadaptações na parede axial do sistema convencional foram significativamente menores que as dos sistemas CAD/CAM. Os resultados desse estudo indicaram que as desdaptações das restaurações metalocerâmicas foram semelhantes principalmente aos sistemas Lava e Cerec Inlab. Dentro dos limites desse trabalho confirmouse que é possível usar o sistema CAD/CAM e alcançar bons resultados de adaptação clínica com as vantagens de padronização dos materiais. Quanto aos materiais, os resultados mostraram que o sistema Lava é confiável para calcular a contração de sinterização da zircônia.

Kano et al. (2007) afirmaram que grande desadaptação na interface pilar/implante tem sido relatada e resultado em efeitos adversos, incluindo afrouxamento do parafuso, rotação e fratura do pilar. Os objetivos deste estudo foram (1) propor um sistema de classificação baseado no microgap horizontal e vertical da interface pilar/implante e (2) comparar a interface pilar/implante em 4 grupos de pilares. Quarenta e oito implantes hexágono externo selecionados aleatoriamente foram pareados com (1) pilares usinados de titânio, (2) pilares pré-fabricados com liga de paládio, (3) pilares de plástico com cinta de liga de níquel-cromo e (4) pilares de plástico com cinta de liga de cobalto-cromo. A comparação dos microgaps horizontais e verticais na interface pilar/implante foi feita em 8 posições em 
cada amostra utilizando microscópio óptico sob ampliação de 150x. Não houve diferença significativa entre os grupos em relação ao desajuste vertical. Pilares pré-fabricados de titânio apresentaram desajuste horizontal significativamente maior em comparação com outros grupos. Pilares pré-fabricados tiveram desajuste horizontal significativamente maior do que pilares de Ni-Cr. No sistema de classificação proposto, $23 \%$ de todos os lugares medidos na interface pilar/implante tinham relacionamento ideal, 34\% tinham apenas discrepância horizontal, 4\% tinham apenas discrepância vertical e 39\% tinham ambas as discrepâncias, verticais e horizontais. O sistema de classificação pilar/implante proposto demonstrou a maneira de caracterizar e comparar a desadaptação na interface pilar/implante.

Em 2008, Barbosa et al. investigaram se existia correlação direta entre o nível de desajuste vertical na interface pilar/implante e perda de torque no parafuso do pilar. Foi discutido que a desadaptação marginal pode ocasionar infiltração bacteriana, ocasionando inflamação com grandes riscos de periimplantite e de reabsorção óssea, bem como posterior fratura do parafuso. Os resultados mostraram que todos os valores de desajuste foram acima de $10 \mu \mathrm{m}$. Houve alto nível de perda de torque, às vezes aproximando-se de $70 \%$ do torque inicial. Dentro das limitações desse estudo, pode ser concluído que não necessariamente grandes valores de desajustes verticais implicarão em grandes perdas de torque.

Estudo de Gonzalo et al. (2008) objetivou investigar a adaptação marginal de prótese parcial fixa (PPF) confeccionada por dois sistemas CAD/CAM - Procera (Nobel Biocare) e Lava (3M ESPE) e analisar as diferenças entre pilares e entre superfícies vestibular e lingual. Vinte amostras padronizadas foram preparadas para receber prótese fixa de 3 elementos. Microscópio com aumento de 1000x foi usado para as mensurações. Procera demonstrou menor desadaptação $(26 \pm 19 \mu \mathrm{m})$. Não houve diferença significante entre pilar e superfície e nenhuma interação foi observada entre sistema cerâmico, pilares e superfícies. A precisão da 
adaptação alcançada pelos sistemas foi dentro da média de aceitabilidade clinica, sendo que Procera demonstrou melhor adaptação marginal.

Beuer et al. (2008), em seu estudo in vitro, examinaram a influência dos ângulos de preparo sobre a precisão da adaptação da zircônia em coroas unitárias. As hipóteses a serem testadas neste estudo foram: (1) o ângulo de preparo não exerce qualquer influência sobre a precisão da adaptação de infraestruturas de zircônia, (2) o local de confecção exerce alguma influência sobre a precisão da adaptação de infraestruturas de zircônia e (3) todos os grupos experimentais possuem desadaptaçãoes marginais clinicamente aceitáveis. O ângulo do preparo e local de medição exibiram significativa influência sobre a precisão da adaptação. Por outro lado, não foram detectadas influências significativas entre infraestruturas preparadas usando laboratório e sistema CAD/CAM. Todos os grupos mostraram desadaptações marginais que variaram entre 36,6 e 45,5 $\mu \mathrm{m}$. Dentro das limitações deste estudo, concluiu-se que o ângulo de preparação não teve influência na adaptação marginal. Sobre a influência do local de confecção, tanto no laboratório como pelos sistemas CAD/CAM a precisão é igual. Com relação à aceitabilidade clínica, as coroas à base de zircônia fabricadas pelo sistema CAD/CAM podem ser prescritas com confiança, uma vez que as desadaptações marginais foram inferiores a $50 \mu \mathrm{m}$.

Beuer et al., em um de seus estudos de 2009, compararam a precisão da adaptação de próteses fixas de três elementos posteriores fabricadas a partir de blocos de zircônia semisinterizados que foram projetados e usinados por dois sistemas CAD/CAM e um sistema CAM. As próteses foram fabricadas por um sistema CAD/CAM (Etkon), um sistema de laboratório CAD/CAM (Cerec InLab) e um sistema CAM (laboratório Cercon). Após a adaptação por um técnico dental, as próteses foram cimentadas, embutidas e seccionadas. As desadaptações marginal e interna foram medidas com microscópio óptico (50x). Houve diferença significante entre os sistemas para a desadaptação marginal e interna. Todos os 
sistemas apresentaram desadaptações marginais abaixo de $120 \mu \mathrm{m}$ e, portanto, foram considerados clinicamente aceitáveis. Os sistemas CAD/CAM foram mais precisos do que o sistema CAM.

Já em outro estudo, também em 2009, Beuer et al. mediram a desadaptação marginal e interna de dois sistemas de confecção (Lava e Procera) de restaurações à base de zircônia. A hipótese desse estudo foi que ambos os sistemas produzem desadaptações marginais abaixo de $120 \mu \mathrm{m}$ e não há diferença na desadaptação marginal e interna de ambos os sistemas testados. O sistema Procera teve melhor adaptação marginal que o sistema Lava, o que pode ter sido influenciado pelo maior espaço de cimentação desse sistema, permitindo melhor assentamento da peça. Ambos os sistemas CAD/CAM demonstraram, in vitro, adaptações marginais aceitáveis. O sistema Procera mostrou desadaptações marginais significativamente inferiores que o sistema Lava. As diferenças de ajuste entre ambos os sistemas estudados dependiam da região do retentor sendo avaliada.

Seo et al., também em 2009, investigaram os efeitos de três diferentes preparações de coroas parciais de cerâmica pura Cerec 3 na adaptação marginal e interna utilizando microtomógrafo SkyScan 1172 (microCT). Foram confeccionados 3 diferentes preparos para Cerec $(\mathrm{n}=20)$ : Grupo I- cobertura da cúspide funcional convencional e preparação ombro, Grupo II- redução horizontal das cúspides e Grupo III- completa redução das cúspides e preparação em ombro. Após a fixação das coroas foi realizado o escaneamento por meio do microCT e os cortes foram reconstruídos tridimensionalmente. As desadaptações foram medidas em cada ponto de referência. Para a técnica de reconstrução 3D, a média da desadaptação interna foi: Grupo I (197,3 \pm 48,2 $\mu \mathrm{m})$, Grupo II $(171,2 \pm 45,1 \mu \mathrm{m})$ e Grupo III $(152,7 \pm 27,1 \mu \mathrm{m})$. Para a técnica $2 \mathrm{D}$, as desadaptações de cada grupo foram menores sobre as margens $(35,4 \pm 32,2 \mu \mathrm{m})$ a $(128,4 \pm 69,5 \mu \mathrm{m})$ e maiores na horizontal ou ângulo das paredes $(184,5 \pm 41,2 \mu \mathrm{m})$ a $(406,5 \pm 176,1 \mu \mathrm{m})$. O Grupo I apresentou desadaptações marginais e 
internas maiores do que os outros grupos. Dentro dos limites deste estudo, coroas parciais totalmente cerâmicas fabricadas usando o sistema Cerec mostraram diferença significativa nos valores das médias das desadaptações marginais internas, dependendo do preparo. Em todos os grupos as desadaptações marginais foram menores do que as desadaptações internas. O microCT utilizado neste estudo foi muito eficaz para a medição da desadaptação marginal e interna.

Pelekanos et al. (2009) avaliaram a adaptação marginal de diferentes núcleos de alumina In-Ceram (Vita, Bad Säckingen, Alemanha) com técnicas desenvolvidas por quatro diferentes fabricantes. Quatro grupos de quatro amostras de núcleos de alumina In-Ceram (VITA), cada uma com 0,6 mm de espessura, foram fabricados a partir de um modelo mestre usando quatro diferentes técnicas: Grupo SL (Sistema In Ceram), Grupo CL (Sistema Celay), Grupo CR (Sistema CAD/CAM Cerec InLab) e grupo WO (Cerâmica Wol). Após os núcleos serem adaptados no modelo mestre, foram escaneados usando microtomógrafo (1072 SkyScan) e os dados foram processados pelo software Tview e foram geradas 10 cortes verticais de cada núcleo. Os dados foram processados e o gap e discrepância marginal absoluta foram medidos em $\mu \mathrm{m}$. Os grupos SL e WO apresentaram os melhores resultados de gap marginal, 22 e $35 \mu \mathrm{m}$, respectivamente. O sistema CAD/CAM apresentou gap marginal de $55 \mu \mathrm{m}$. Além disso, os grupos SL e WO apresentaram os melhores valores de discrepância marginal, com $50 \mu \mathrm{m}$ e $60 \mu \mathrm{m}$, respectivamente. A técnica SL e WO apresentaram as melhores discrepâncias marginais, seguidas pelo Cerec In Lab, o qual apresentou clinicamente os melhores resultados. Análise microtomográfica demonstrou ser um método confiável para avaliação da adaptação marginal de restaurações dentais.

Al-Amleh et al. (2010) afirmaram que a zircônia é única em sua composição polimórfica cristalina e sensível aos processos de fabricação e manipulação, e há discussões sobre qual método de processamento é menos prejudicial para o produto final. Atualmente, as 
restaurações em zircônia são fabricadas quer por processos de fresagem moles ou duro, com o fabricante de cada um reivindicando vantagens sobre o outro. Lascamentos da porcelana de revestimento são relatados como sendo problema comum e têm sido rotulados como a principal desvantagem clínica. O objetivo desta revisão sistemática foi informar sobre o sucesso clínico das restaurações à base de zircônia. Uma ampla revisão da literatura foi concluída para ensaios in vivo em restaurações de zircônia em MEDLINE e PubMed, entre 1950 e 2009. Dezessete estudos clínicos envolvendo restaurações à base de zircônia foram encontrados, 13 foram realizados em próteses parciais fixas, dois em coroas individuais e dois em pilares de implantes de zircônia, dos quais 11 foram baseados em fresagem da zircônia macia e seis na fresagem da zircônia dura. Lascamentos da cerâmica de revestimento foram ocorrência comum e fratura da prótese só foi observada na fresagem da zircônia macia. Com base no número de estudos in vivo limitados em curto prazo, a zircônia parece ser adequada para a fabricação de coroas individuais, próteses parciais fixas e pilares de implante que oferecem protocolos rígidos que sejam respeitados durante o processo de fabricação e entrega. Novos estudos prospectivos de longo prazo são necessários para estabelecer o melhor processo de fabricação de restaurações à base de zircônia.

O objetivo de Pak et al. (2010) foi investigar e comparar a adaptação marginal de 2 diferentes sistemas CAD/CAM com coroas totalmente em cerâmica antes e após aplicação da cerâmica de revestimento. Além disso, verificar a adaptação marginal de coroas de zircônia tetragonal com óxido de ítrio parcialmente sinterizadas seguido por um processo de sinterização (Lava CAD/CAM) e (Digident CAD/CAM) e com blocos de zircônia totalmente sinterizados. Foram confeccionadas 20 coroas para cada sistema e a adaptação marginal foi avaliada por meio de um microscópio de luz com processamento de imagem (Acura 2000) com 50 pontos que foram escolhidos ao acaso. Cada coroa foi medida duas vezes: a primeira medida foi feita com uma infraestrutura de 0,5 milímetros e a segunda medição foi feita 
depois da cobertura cerâmica. As médias e desvios padrão do ajuste marginal foram 61,52 \pm 2,88 $\mu \mathrm{m}$ (Digident antes revestimento cerâmico) e 83,15 $\pm 3.51 \mu \mathrm{m}$ (Digident após o recobrimento de porcelana), 62,22 $\pm 1,78 \mu \mathrm{m}$ (Lava antes do recobrimento cerâmico) e 82,03 $\pm 1,85 \mu \mathrm{m}$ (Lava após o recobrimento de porcelana). Não foram encontradas diferenças significativas entre os grupos, antes e após recobrimento de porcelana. Analisando a desadaptação marginal dentro de cada grupo, antes e após a aplicação de porcelana, houve diferença significante. Dentro das limitações deste estudo, pode-se concluir que não houve diferença significativa na desadaptação marginal entre os dois sistemas CAD/CAM de confecção de coroas de cerâmica pura e o recobrimento de porcelana mostrou ter influência significativa na adaptação marginal dos dois sistemas de cerâmica pura.

No estudo de Elias e Santos (2010) foi realizada revisão da literatura referente à zircônia. Há décadas as restaurações metalocerâmicas têm sido a escolha ideal para a fabricação de próteses fixas sobre dentes e implantes. Recentemente, novos sistemas cerâmicos foram desenvolvidos para desempenhar este papel devido à inerente desvantagem estética de uma infraestrutura metálica. Este trabalho descreve as principais características dos sistemas CAD/CAM, analisa as propriedades mecânicas da zircônia, apresenta resultados de ensaios com blocos de zircônia produzidos no Brasil e compara as propriedades dos blocos nacionais e importados. A cerâmica é um material frágil por natureza, e sua baixa resistência à fratura aliada à baixa resistência à flexão vem à tona quando se discute a possibilidade de confecção de próteses parciais fixas e pilares para implantes. Isto se torna ainda mais crítico na região posterior, onde as forças mastigatórias são maiores. A zircônia é um material comprovadamente indicado para uso restaurador sob os aspectos biológicos, funcionais e estéticos. Cabe ao cirurgião-dentista estar informado quanto às suas propriedades, sistemas disponíveis e seu processamento, assim como dos estudos laboratoriais e clínicos para indicar sua utilização de forma correta, extraindo o máximo proveito de suas características. Os 
resultados obtidos mostram que não existem diferenças significativas entre as propriedades dos blocos nacionais e importados.

Tiossi et al. (2010) tiveram como objetivo verificar o efeito da solda a laser na adaptação de próteses mal adaptadas de titânio comercialmente puro e liga de $\mathrm{Ni}-\mathrm{Cr}$ em próteses de peça única. Dois conjuntos de próteses implantossuportadas semelhantes foram construídos. Ambos os grupos de seis próteses parciais fixas sobre implantes de 3 elementos foram fundidos como peça única e avaliadas quanto à adaptação passiva em microscópio óptico com ambos os parafusos apertados e com apenas um parafuso apertado. Posteriormente, todas as estruturas foram seccionadas no sentido diagonal, na região do pôntico, posicionadas em uma matriz com torque de 10 N.cm e soldadas a laser. A adaptação passiva foi avaliada pela segunda vez. Com ambos os parafusos apertados, a prótese em peça única demonstrou maiores valores de desadaptação que os outros grupos. Com o teste do parafuso único, avaliando a adaptação no lado oposto ao apertado, o grupo $\mathrm{Ni}$-Cr em peça única foi significativamente diferente do titânio comercialmente puro. No lado apertado nenhuma diferença significante foi encontrada entre os grupos. Os resultados demonstraram que estruturas de titânio comercialmente puro soldadas a laser tiveram menor desadaptação e melhoraram a passividade das estruturas quando comparadas com estruturas em peça única.

Heintze e Rousson (2010) avaliaram de forma sistemática e compararam a frequência de lascamento do recobrimento e fratura da infraestrutura de próteses parcial fixa em zircônia e metalocerâmica. Foram utilizados a base de dados Scopus e os resumos da Associação Internacional de Pesquisa Odontológica procurando por estudos clínicos envolvendo zircônia e prótese parcial fixa em metalocerâmica (PPF MC). Além disso, estudos que foram integrados em revisões sistemáticas sobre PPF MC também foram avaliados. Os principais pesquisadores de quaisquer estudos clínicos sobre PPF em zircônia foram contatados para fornecer informações adicionais. Com base na informação disponível para cada PPF, um 
ficheiro de dados foi construído. Lascamento da porcelana foi dividido em três graus (grau 1 = polimento, grau 2 = reparação, grau 3 = substituição). Para avaliar a frequência de lascamento da porcelana e os possíveis fatores que influenciam, um modelo exponencial foi usado. Quando todos os estudos foram incluídos, 142 lascamentos de porcelana foram registrados para zircônia (24\%) e 43 para metalocerâmica (34\%). Se apenas os estudos que avaliaram os dois tipos de materiais da infraestrutura fossem incluídos, a frequência de lascamento seria de 54\% para os PPF em zircônia e 34\% para PPF em metal. Ao ajustar a taxa de sobrevivência para efeito do estudo, a diferença entre a zircônia e metal foi significativa para todos os tipos de fratura, bem como para lascamento grau 3. Se todos os tipos de lascamentos da porcelana de cobertura fossem levados em consideração, a sobrevivência de PPF metalocerâmica seria de 97\%, enquanto que a taxa de sobrevivência dos PPF em zircônia foi de $90 \%$ após 3 anos para um estudo típico. Para ambos os materiais, a frequência de graus 1 e 2 da porcelana de cobertura foi consideravelmente superior ao grau 3. Lascamentos de porcelana foi significativamente menos frequente em materiais prensados do que em materiais esculpidos à mão para zircônia e metal. Como a frequência de lascamentos da porcelana de cobertura foi significativamente maior nas PPF em zircônia que em metal e como os processos de transformação refinados começaram a produzir melhores resultados em laboratório, novos estudos clínicos com esses novos procedimentos devem confirmar se a frequência de fratura pode ser reduzida ao nível da zircônia.

Estudo de Karatasli et al. (2011) comparou a adaptação marginal de quatro diferentes materiais de infraestrutura criadas por MAD/CAM (desenho manual e usinagem no computador) ou CAD/CAM (desenho e usinagem no computador). Infraestruturas de metal fundidas convencionalmente foram utilizadas no grupo controle. Foi levantada a hipótese de que infraestruturas fabricadas por $\mathrm{CAD} / \mathrm{CAM}$ utilizando tecnologia computacional estaria associada com menor desadaptação marginal. Neste estudo, foram analisadas adaptações 
marginais de diferentes infraestruturas fabricadas com CAD/CAM ou MAD/CAM. Grupos Celay e Zirkonzahn foram fabricados por MAD/CAM e Lava e DC-Zircon foram fabricadas por CAD/CAM. Foram utilizadas infraestruturas metálicas fundidas como grupo controle. Dezesseis pontos anteriormente estabelecidos foram marcados e as medições foram realizadas com microscópio estereoscópico (150x). A adaptação marginal das amostras foi avaliada através do cálculo das médias dos valores dos 16 pontos. Os grupos podem ser resumidos como se segue em termos de fenda marginal, a partir do menor para o maior: Lava $(24,6 \pm$ $14,0 \mu \mathrm{m})<$ Celay $(64,9 \pm 25,2 \mu \mathrm{m})<$ DC-Zirconia $(110,1 \pm 36,5 \mu \mathrm{m})<$ Zirkonzahn $(112,11 \pm$ 22,6 $\mu \mathrm{m})<$ metal $(120,1 \pm 33,1 \mu \mathrm{m})$. O uso de sistemas CAD/CAM ou MAD/CAM não pode ser o fator mais importante para a adaptação marginal. A dificuldade de fresagem de materiais duros pode aumentar clinicamente a desadaptação marginal das restaurações.

Borba et al. (2011) mediram a adaptação marginal e interna de prótese parcial fixa de três elementos utilizando a técnica do microCT e testaram a hipótese nula de que não há nenhuma diferença na adaptação entre os sistemas cerâmicos estudados. Os valores médios para desadaptação marginal, área de chanfro, parede axial, área occlusal e discrepância marginal horizontal foram significativamente diferentes para todos grupos testados. O sistema Vita In Ceram YZ apresentou valores médios maiores do que Vita In Ceram Zircônia para todos os locais de medição, exceto para parede axial e área de transição axio-oclusal. A área oclusal apresentou os maiores valores médios de desadaptação para os dois sistemas cerâmicos. As médias dos valores de desadaptação marginal e na parede axial foram baixas para ambos os sistemas. Os sistemas cerâmicos avaliados apresentaram diferentes níveis de adaptação interna e marginal, rejeitando a primeira hipótese do estudo. O Sistema Vita In Ceram YZ apresentou valores mais baixos de desadaptação do que o Sistema Vita In Ceram Zircônia para a maioria dos locais de medição. A segunda hipótese do estudo também foi rejeitada, uma vez que havia diferença entre os valores de desadaptação medidos em locais 
diferentes para esses sistemas cerâmicos. Apesar das diferenças, ambos os sistemas cerâmicos foram clinicamente aceitáveis, tanto na adaptação marginal quanto interna.

Kohorst et al. (2011), em estudo in vitro, avaliaram a influência de diferentes meios de processamento sobre a precisão da adaptação de próteses fixas de quatro elementos em zircônia (PPF), fabricados pelo sistema (CAD/CAM). Três grupos de 10 amostras cada, em zircônia, foram fabricados. Infraestruturas de um grupo (Cercon CAM) foram produzidas por meio de um sistema unicamente CAM de laboratório. As outras infraestuturas foram feitas com diferentes sistemas CAD/CAM: laboratório de produção (Cercon CAD/CAM) e pela produção centralizada em centro de usinagem (Compartis), após o envio dos dados geométricos. As infraestruturas foram, então, revestidas com a cerâmica recomendada e a adaptação marginal foi determinada pela utilização de uma réplica. Discrepâncias marginais horizontal, vertical e absoluta, e gap marginal foram avaliados. A média de discrepâncias horizontais variou entre $22 \mu \mathrm{m}$ (Cercon CAM) e $58 \mu \mathrm{m}$ (Compartis), as discrepâncias verticais variaram entre $63 \mu \mathrm{m}$ (Cercon CAD/CAM) e $162 \mu \mathrm{m}$ (Cercon CAM) e as discrepâncias marginais absolutas variaram entre $94 \mu \mathrm{m}$ (Cercon CAD/CAM) e $181 \mu \mathrm{m}$ (Cercon CAM). A diferença marginal variou entre $72 \mu \mathrm{m}$ (Cercon CAD/CAM) e $112 \mu \mathrm{m}$ (Cercon CAM, Compartis). Em todas as medições, a adaptação marginal foi significativamente influenciada pelo sistema utilizado. Dentro das limitações deste estudo, todas as restaurações demonstraram adaptação marginal clinicamente aceitável. No entanto, os resultados sugerem que os sistemas CAD/CAM são mais precisos do que o sistema só CAM para a fabricação de PPF de quatro unidades.

Nissan et al. (2011) compararam o resultado em longo prazo e as complicações das próteses parafusadas sobre implantes contra protéses cimentadas em pacientes parcialmente desdentados. Pacientes com edentulismo posterior parcial bilateral compuseram o grupo de estudo. Os implantes foram colocados e próteses cimentadas ou parafusadas foram 
aleatoriamente designadas para os pacientes em um desenho de boca dividida. Em acompanhamento de até 15 anos, exames foram realizados a cada 6 meses no primeiro ano e cada 12 meses nos anos subsequentes. Os seguintes parâmetros foram avaliados e registrados em cada acompanhamento: fratura de cerâmica, afrouxamento de parafuso de pilar, fratura da infraestrutura de metal, índice gengival e perda óssea marginal. Trinta e oito pacientes foram tratados com 221 implantes para suportar próteses parciais. Nenhum implante fraturou durante o período de acompanhamento (média de follow-up: $66 \pm 47$ meses para restaurações parafusadas e $61 \pm 40$ meses para restaurações cimentadas). Fratura da cerâmica ocorreu significativamente com mais frequência em restaurações parafusadas do que em cimentadas. Afrouxamento do parafuso de pilar ocorreu significativamente mais vezes em restaurações parafusadas do que em cimentadas. Não houve fraturas da infraestrutura de metal em qualquer tipo de restauração. A média das pontuações do Índice Gengival foi significativamente maior para restaurações parafusadas do que para cimentadas. A perda óssea média marginal foi significativamente maior para parafusada do que para restaurações cimentadas. O resultado em longo prazo das restaurações implantossuportadas cimentadas foi superior ao de restaurações parafusadas, clínica e biologicamente.

Em 2012, Krasanaki et al. avaliaram a influência de dois diferentes tipos de preparação (90 graus - chanfro ou ombro) na adaptação marginal de infraestruturas de alumina com desenho e fabricação assistido por computador (CAD/CAM). Foi utilizada microtomografia de raios-X, que é um método não destrutivo que permite medições em diferentes cortes e distâncias ao longo da área marginal, proporcionando confiáveis reconstruções tridimensionais. A hipótese nula era que não haveria diferença significativa entre gap e discrepância marginal para ambos os tipos de preparação. Dois subgrupos de quatro infraestruturas de alumina cada foram fabricados usando um molde mestre em alumina com preparo de 90 graus em chanfro ou em ombro. as infraestruturas foram escaneadas por 
um microtomógrafo e a adaptação marginal foi avaliada. Os valores médios da desadaptação marginal para o chanfro $(22,52 \mu \mathrm{m})$ e ombro $(21,00 \mu \mathrm{m})$ não tiveram efeito significativo sobre a desadaptação marginal. Os valores médios da desadaptação marginal na região bucolingual foi maior que na mésio-distal, tanto para o chanfro quanto para o ombro. $\mathrm{O}$ preparo em ombro apresentou diferença significante entre vestíbulolingual e mésiodistal. Os valores médios para o preparo em chanfro foram maiores do que para em ombro, mas não houve diferença significante. A média dos valores da desadaptação marginal vestíbulolingual foram maiores do que mesiodistal, tanto para chanfro quanto para ombro. Infraestruturas com preparo em chanfro exibiram $15 \%$ de subextensão, $6,25 \%$ de sobreextensão e $78,8 \%$ extensão das margens. Já as infraestruturas com preparos em ombro demonstraram $17,5 \%$ de subextensão, $10 \%$ sobreextensão e $72,5 \%$ extensão das margens. Nem preparo em chanfro nem em ombro influenciaram a adaptação marginal de infraestruturas de cerâmica reforçada com alumina pelo sistema CAD/CAM, os quais estavam dentro da faixa de aceitação clínica. As infraestruturas tanto em chanfro quanto em ombro não apresentaram diferença significante quanto a sub ou sobreextensão.

Guess et al. (2012) afirmaram que a tecnologia CAD/CAM em combinação com a zircônia tem aumentado a popularidade na implantodontia. Este trabalho apresenta o conhecimento atual sobre zircônia como infraestrutura para restaurações suportadas por implantes e pilares de implantes, evolução dos exames laboratoriais, desempenho clínico e as possíveis tendências futuras para a implantodontia. Foi realizada uma revisão da literatura de 1990 até 2010, utilizando os termos de pesquisa "zircônia", "implantes", “encosto", "coroa" e "prótese fixa" usando bancos de dados eletrônicos (PubMed) e busca manual. A pesquisa mostrou que as últimas aplicações da zircônia na implantodontia incluem pilares de implantes, estururas múltiplas e de arco completo, bem como barras personalizadas para suportar próteses fixas e removíveis. Elevada biocompatibilidade, baixa adesão de superfície 
bacteriana, bem como propriedades químicas favoráveis da zircônia foram relatados pelos autores. Zircônia estabilizada com óxido de ítrio possui alta resistência à flexão e tenacidade à fratura devido a um mecanismo transformador de endurecimento. Dados clínicos preliminares confirmaram a alta estabilidade da zircônia para pilares e como material de estrutura para coroas e próteses fixas sobre implantes. Danos no pilar ou infraestrutura de zircônia têm sido raramente encontrados. No entanto, fratura do recobrimento de porcelana é a complicação técnica mais comum em restaurações de próteses sobre implantes em zircônia. Estas falhas na porcelana levaram a preocupações sobre diferenças de coeficiente de expansão térmica entre o material da infraestrutura e revestimento de porcelana e suas respectivas técnicas de processamento. Como atualmente não há evidência clinica de longo prazo, recomenda-se cautela no que diz respeito ao uso de extensas estruturas de zircônia.

Andreiuolo et al. (2013) descreveram técnica alternativa para a personalização das próteses $\mathrm{CAD} / \mathrm{CAM}$ através de um processo de duplo escaneamento. Apesar das inúmeras vantagens da tecnologia CAD/CAM, alguns clínicos e técnicos de laboratório começaram a prestar menos atenção aos princípios básicos do projeto da infraestrutura da prótese fixa. Neste trabalho, inicialmente o modelo foi digitalizado. Depois, o padrão de cera foi selado no modelo e novamente digitalizado. Este procedimento fornece suporte adequado à espessura da porcelana de maneira previsível com pouco esforço e custo adicional para clínicos e laboratórios. Esta técnica representa uma opção à tradicional fabricação pela digitalização única pelo método CAD/CAM. Ele permite a individualização das infraestruturas de maneira previsível e, possivelmente, melhora a longevidade das coroas de cerâmica pura, dado que a espessura da infraestrutura e da porcelana pode ser controlada. A espessura adequada da infraestrutura e da porcelana pode diminuir o estresse interno e reduzir a falha mecânica. Autores relataram que esta técnica precisa ser mais estudada por meio de ensaio clínico para determinar a eficácia da modificação controlada da infraestrutura. 
Abduo, em 2014, avaliou a literatura pertinente à adaptação de próteses fixas sobre implantes fabricadas pelo método CAD/CAM. Após uma busca eletrônica abrangente através do PubMed (Medline), foram identificados 14 artigos relevantes. Os resultados indicaram que a precisão da adaptação de estruturas de próteses CAD/CAM excede a adaptação de próteses unitárias e estruturas soldadas a laser e é similar à de próteses confeccionadas com cilindros pré-fabricados. A influência do sistema CAD/CAM sobre a adaptação é mínima, porém o sistema $\mathrm{CAD} / \mathrm{CAM}$ é o único meio de produzir restaurações dentais em cerâmica de alta resistência como dióxido de zircônia.

Estudo de Harish et al. (2014) foi realizado para comparar a discrepância interna e marginal de copings de cobalto-cromo sinterizados a laser e cobalto-cromo fundidos convencionalmente. Vinte amostras de aço inoxidável de dimensão 15 x $10 \mathrm{~mm}$, foram fabricadas utilizando a tecnologia CAD/CAM e posteriormente divididas em dois grupos: Grupo 1 e Grupo 2 contendo 10 amostras cada. Todas as 20 amostras foram escaneadas usando o escaner LAVA $3 \mathrm{M}$ e os dados foram usados para fabricar copings metálicos utilizando a técnica de sinterização a laser (Grupo 1) e técnica de fundição convencional (Grupo 2). Copings foram cimentados sobre as respectivas matrizes e foi realizado corte e acabamento. Os modelos cortados foram digitalizados sob lupa com ampliação de 50x para avaliação da adaptação interna e marginal. A discrepância interna e marginal média de copings metálicos sinterizados a laser foi $107,6 \mu \mathrm{m}$ e $102,15 \mu \mathrm{m}$, respectivamente. As discrepâncias internas e marginais médias para copings metálicos fundidos convencionalmente foi $187,09 \mu \mathrm{m}$ e $176,5 \mu \mathrm{m}$, respectivamente. Dentro das limitações do estudo, os resultados são conclusivos, de que copings fabricados pela técnica de sinterização a laser mostraram melhor adaptação interna e marginal do que os fabricados pela técnica convencional. Assim, a qualidade da técnica de sinterização a laser supera as falhas. 
Katsoulis et al. (2014) analisaram a precisão da adaptação de infraestruturas de zircônia escaneadas a laser e manualmente, de próteses fixas totais implantossuportadas parafusadas e compararam com estruturas CAD/CAM em titânio e fundidas convencionalmente. Infraestruturas fabricadas pelo sistema CAD/CAM em zircônia (Procera, Nobel) para reconstrução implantossuportada de 10 elementos parafusadas em seis implantes (posições: 15, 13, 11, 21, 23, 25) foram fabricadas usando um escaner a laser $(\mathrm{ZrO}-\mathrm{G}, \mathrm{N}=6)$ e um escaner mecânico (ZrO-M, N = 5) para escaneamento da plataforma do implante e da prótese em resina. Grupo controle em liga de $\mathrm{Co}-\mathrm{Cr}(\mathrm{n}=5)$ foi fabricado no mesmo modelo concebido e semelhante ao de $\mathrm{ZrO}$. Teste com parafuso único (implante 25 parafusado) foi aplicado para avaliar o microespaço vertical entre implante e infraestrutura em microscópio eletrônico de varredura. Não foi observada diferença significante entre a adaptação vertical das infraestruturas em zircônia escaneadas a laser, pelo escaner mecânico e em titânio pelo escaner a laser, enquanto os valores do grupo controle foram significativamente maiores que os outros três grupos CAD/CAM. A tendência de valores crescentes do implante 23-15 foi observada em todos os grupos. Dentro das limitações deste estudo laboratorial, pôde-se concluir que os escaners a laser e manual com tecnologia CAD/CAM facilitam a fabricação de reconstruções longas parafusadas sobre implantes confeccionadas a partir de dióxido de zircônia. As estruturas CAD/CAM de titânio escaneadas a laser demonstraram maior precisão, enquanto a desadaptação de arco completo do grupo controle foi clinicamente inaceitável.

Já em 2015, Katsoulis et al. compararam a precisão da adaptação de próteses implantossuportadas parafusadas (PPF), espaço longo e espaço curto, confeccionadas pelo sistema CAD/CAM de titânio e revestidas com cerâmica. Estruturas de titânio em CAD/CAM para próteses implantossuportadas maxilares foram confeccionadas em um único modelo de trabalho. O grupo A consistiu de seis PPF de dez unidades ligada a seis implantes (posições $15,13,11,21,23,25)$ e o grupo B de 6 próteses PPF de 5 unidades ligadas a três implantes 
(posições 21, 23, 25). O sistema CAD/CAM - Biodenta Swiss AG (Berneck, Suíça) foi utilizado para a escaneamento do modelo mestre e de cada prótese separadamente (CAD). As próteses foram usinadas (CAM) a partir de um bloco de titânio e revestidas com porcelana. A mediana da distância vertical mesial, distal e vestibular entre a plataforma do implante e a prótese pelo teste do parafuso único no implante 25 foi realizada com uso do microscópio eletrônico de varredura. Todas as medidas apresentaram valores $<40 \mu \mathrm{m}$. A mediana das desadaptações verticais foi $23 \mu \mathrm{m}$ para o grupo A e $7 \mu \mathrm{m}$ para o grupo B. A diferença entre os grupos foi significativa no implante 21 e não significante no implante 23 . O escaneamento e confecção da prótese pelo sistema CAD/CAM, incluindo a queima da porcelana, foi altamente preciso e reproduzível para todos as PPF longas e curtas. Todas as PPFs mostraram valores clinicamente aceitáveis, as PPF curto espaço foram significativamente mais precisas que PPF espaço longo.

Lins et al., em 2015, avaliaram a adaptação interna e marginal de copings de zircônia sobre implantes cone Morse fabricados pelos sistemas CAD/CAM Neodent digital, Ceramill e Lava. Vinte e quatro pilares anatômicos pré-fabricados (Neodent) foram utilizados para fabricar copings de zircônia $(\mathrm{n}=8)$ em Ceramill, Lava e Neodent digital. Todos foram cimentados e cortados em cortadeira de precisão para obter 5 superfícies (mesial, distal, vestibular, palatina, e incisal) e regiões dos ângulos (axiogengival interno e axioincisais). Medições foram obtidas a partir de imagens com ampliação de 100x e 200x, feitas com câmara digital ligada a um microscópio óptico e adaptado com dispositivo de medição. Foi encontrada diferença significativa para a superfície palatina entre os sistemas Ceramill e Lava e entre Lava e Neodent digital. Para as regiões dos ângulos, diferenças significativas foram encontradas entre Ceramill e Neodent digital e para Lava e Neodent digital. Para a superfície incisal, também foram encontradas diferenças significativas entre Ceramill e Lava, Ceramill e Neodent digital e Lava e Neodent digital. Nenhuma diferença estatística foi encontrada entre 
as outras superfícies. Quando os valores médios foram comparados uns com os outros, diferença significativa foi encontrada entre Lava e Neodent digital. Nenhuma diferença estatística foi encontrada entre Ceramill e Neodent digital ou entre Ceramill e Lava. Nenhuma diferença significativa foi encontrada para discrepância marginal entre o Ceramill e Lava, Ceramill e Neodent digital e Lava e Neodent digital. Para desadaptação marginal absoluta, nenhuma diferença significativa foi encontrada entre os sistemas Ceramill e Lava, entre Ceramill e Neodent digital ou Lava e Neodent digital. Algumas limitações nesse estudo são relatadas: os copings foram confeccionados em diferentes laboratórios, por diferentes técnicos e o espaço interno necessário para fabricação dos copings foi determinado por cada sistema. Além disso, foram testados em condições laboratoriais que não refletem as condições clínicas. Entretanto, apesar de todos esses limites, o sistema Lava demonstrou menores desadaptações internas que o sistema Neodent digital, embora os valores encontrados para os três sistemas, tanto para desadaptação marginal quanto interna, estivessem dentro dos níveis de aceitabilidade clinica.

\subsection{Tensões nos implantes e perda óssea}

Meijer et al. (1993) calcularam a distribuição de tensões por meio de três diferentes modelos de elementos finitos em mandíbula desdentada com dois implantes na região interforaminal. Os implantes foram conectados com uma barra ou permaneceram sozinhos. O primeiro modelo foi uma representação tridimensional da mandíbula inteira, o segundo modelo da região interforaminal dessa mesma mandíbula, enquanto que o terceiro modelo foi uma representação bidimensional da região interforaminal. A diferença na distribuição de tensões ao redor dos implantes e nos implantes sozinhos foi analisada. Pôde-se concluir que, para os parâmetros do estudo, a distribuição de tensões ao redor dos implantes seguindo o modelo de elementos finitos tridimensional na região interforaminal de uma mandíbula 
desdentada pode ser usada. Para cada estudo, entretanto, os benefícios podem ser ganhos pelas vantagens da redução do modelo e cálculo do tempo.

Papavasiliou et al. (1996) afirmaram que o limite de elasticidade do osso ao redor dos implantes pode ser superado e, só assim, produz microfraturas no osso. O objetivo deste estudo foi usar simulações de computador para analisar situações clinicas com implantes IMZ em mandíbulas desdentadas e identificar as condições de carga que poderia levar a microfraturas no osso. Modelos tridimensionais de análise de elementos finitos foram usados para examinar os efeitos de: (1) tipos de mandíbulas desdentadas, (2) materiais de revestimento, (3) ausência de osso cortical, (4) diferentes elementos intramobile (5) direções de carga e (6) níveis de carga. Padrões de distribuição de tensões e estresses interfaciais foram monitorados especificamente em quatro diferentes alturas ao longo da interface ossoimplante. Estresse foi concentrado em direção ao osso cortical (0,8-15,0 MPa). Não houve diferença entre os tipos de materiais de revestimento e ausência de osso cortical. Aumento do estresse foi associado com mandíbulas menores. Cargas oblíquas aumentaram o estresse em 15 vezes e $200 \mathrm{~N}$ aumentou 10 vezes. Condições de microfratura no osso foram associadas a cargas oblíquas, alto estresse occlusal e à ausência de osso cortical.

Ciftci e Canay (2000) avaliaram o efeito de diversos materiais utilizados na confecção de infraestruturas de próteses parciais fixas implantossuportadas na distribuição de tensões em torno dos implantes. Cinco diferentes modelos matemáticos foram construídos para estudar porcelana, liga de ouro, resina composta, resina composta reforçada e resina acrílica utilizando o método de análise de elementos finitos 3D, usando o software MARC K7.2/Mentat 3.2 para a análise. Os pontos de referência foram determinados no osso cortical e foram aplicadas forças perpendiculares, oblíquas e horizontais. Valores de tensão criados pelas forças oblíquas e horizontais pareciam ser mais elevados que os criados pelas forças verticais. $\mathrm{O}$ estresse foi mais concentrado no osso cortical ao redor da região cervical do 
implante. Liga de ouro e porcelana produziram valores mais altos de tensão na região cervical do implante. $\mathrm{O}$ estresse criado pela resina acrílica e pela resina composta reforçada foram $25 \%$ e $15 \%$ menor, respectivamente, que o estresse criado pela porcelana na região lingual dos implantes, que atingiu os valores máximos de resistência do osso cortical.

Oh et al., em 2002, afirmaram que o sucesso dos implantes dentários é altamente dependente da integração entre o implante e tecidos moles e duros intraorais. O objetivo deste artigo foi revisar e discutir, com base na literatura disponível no momento, os fatores que poderiam ser as causas mais prováveis para o início de perda óssea ao redor dos implantes. Além disso, é importante notar que outros fatores, como trauma cirúrgico e periimplantites, também poderiam desempenhar papel no processo de início de perda óssea ao redor do implante. A perda precoce da crista óssea é observada muitas vezes após o primeiro ano de função, seguida de perda óssea mínima $(\leq 0,2 \mathrm{~mm})$, anualmente. Seis fatores etiológicos plausíveis são hipoteticamente tratados, incluindo trauma cirúrgico, sobrecarga oclusal, periimplantite, microgap, espaço biológico e distância da crista ao implante. Ensaios clínicos controlados e randomizados são necessários para comparar o efeito plausível de cada fator para esclarecer as causas do início de perda óssea ao redor do implante.

Natali et al. (2006) usaram a análise numérica para avaliar a relevância dos estados de tensão induzida no tecido ósseo peri-implantar por desajuste em prótese fixa. Desadaptações, tanto na direção mésio-distal quanto vestíbulo-lingual, foram consideradas para investigar a realidade do problema. Foi usado modelo de elementos finitos de uma porção da mandíbula com dois implantes conectados por uma barra de liga de ouro, na base de dados morfométricos de um paciente desdentado parcial. A análise numérica do desajuste implante/prótese mostrou efeitos significativos de estresse sobre o tecido ósseo periimplantar. Para a configuração específica da prótese considerada, a tensão de compressão máxima foi 40-60 MPa, dependendo do desajuste considerado. O nível de estresse foi 
amplamente afetado pelas características axiais e rigidez à flexão do conjunto implante/barra. Pela análise de tensões usando métodos numéricos foi possível estimar o estado de tensão com alta precisão em termos de intensidade e localização. Para o caso considerado, o estresse induzido pelo desajuste foi comparável às forças oclusais relacionadas. Portanto, o possível desajuste implante/barra deve ser cuidadosamente considerado para garantir a confiabilidade do sistema protético.

Li e Fok (2009) mediram a contração de polimerização de resinas compostas, utilizando o método de correlação de imagens digitais. Para isso espécimes de barra com secção 4 x $2 \mathrm{~mm}$ e comprimento de $10 \mathrm{~mm}$, aproximadamente, foram fotopolimerizadas com dois níveis de irradiância, $450 \mathrm{~mW} / \mathrm{cm}$ (2) e $180 \mathrm{~mW} / \mathrm{cm}$ (2), respectivamente. A luz foi gerada com Optilux 501 (Kerr) e as duas irradiâncias diferentes foram obtidas através do ajuste da distância entre a ponteira e a espécime. Um sistema de medição 2D com câmera única foi usado para registar a deformação da amostra durante 30 min a uma frequência de 0,1 Hz. A superfície da amostra em observação foi pulverizada com tinta para produzir um contraste suficiente para permitir o rastreamento de pontos individuais na superfície. A fotopolimerização ocorreu em uma extremidade da amostra na qual a superfície pintada foi totalmente coberta por 40 segundos. Após a polimerização, a tampa foi removida imediatamente para que a deformação da superfície pintada pudesse ser gravada pela câmera. As imagens foram então analisadas com software especializado e a contração volumétrica determinada ao longo do comprimento da viga. Resultados demonstraram possível heterogeneidade na composição do material e comportamento de encolhimento no compósito. O encolhimento volumétrico máximo ocorreu a uma distância de cerca de $1 \mathrm{~mm}$ abaixo da superfície ao invés de na superfície de irradiação. Depois de alcançar o seu valor de pico, o encolhimento, gradualmente, diminuiu com o aumento da distância ao longo do comprimento da barra, antes de se estabilizar em um valor de cerca de $0,2 \%$ a uma distância de $4-5 \mathrm{~mm}$. A 
contração volumétrica máxima obtida concordou muito bem com o valor de $1,6 \%$ relatado pelo fabricante para o composto examinado neste trabalho. Em comparação com os outros métodos de medição, o método de correlação de imagem é capaz de produzir informações sobre o comportamento da contração de polimerização das resinas compostas.

No estudo de Moretti Neto et al. (2011) o objetivo foi validar um modelo experimental baseado no módulo de elasticidade para simular a performance do osso humano in vivo em estudos biomecânicos de próteses implantossuportadas. Para isso, cinco grupos de poliuretano F16, Axson ( $\mathrm{n}=8)$ diferindo em sua composição de reagentes (parte $\mathrm{A} /$ parte $\mathrm{B}$ ): Grupo A $(0,5 / 1,0)$, Grupo B $(0,8 / 1,0)$, Grupo C $(1,0 / 1,0)$, Grupo D $(1,2 / 1,0)$, Grupo E $(1,5 / 1,0)$ testaram a hipótese nula de que nenhum dos grupos testados teria o módulo de elasticidade compatível com o osso para ser usado em modelos de testes biomecânicos. Foi utilizada máquina universal de testes (Kratos modelo K - $2000 \mathrm{MP}$ ) para mensurar os valores do módulo de elasticidade de cada amostra. Os valores do módulo de elasticidade variaram de

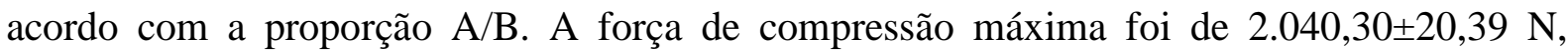
$2.410,51 \pm 30,60 \mathrm{~N}, 2.430,15 \pm 60,84 \mathrm{~N}, 2.200,84 \pm 90,55 \mathrm{~N}$ e $1.900,33 \pm 30,22 \mathrm{~N}$ e os valores do módulo de elasticidade foram $389,72 \pm 18,58,529,19 \pm 61,91,571,11 \pm 58,17,470,35 \pm 32,81$ e

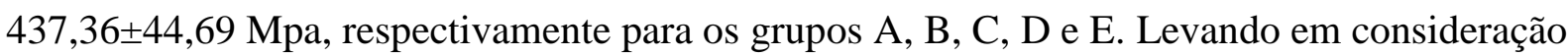
as limitações dos dados obtidos, pareceu válido concluir que o módulo de elasticidade variou de acordo com a relação A/B. A relação A/B 1:1 proporcionou as melhores características mecânicas e módulo de elasticidade semelhante ao do osso trabecular para simular osso em testes in vitro.

Tiossi et al. (2011) utilizaram o método de correlação de imagens digitais para analisar as tensões geradas pelos implantes no osso de suporte simulado de dois diferentes desenhos protéticos (esplintado e não esplintado) sob duas situações clínicas (presença ou ausência de contato interproximal na distal). Para isso foi utilizado um modelo de resina epóxi 
feita com réplicas de resina acrílica de um primeiro pré molar inferior e segundo molar e com implantes parafusados substituindo o segundo pré molar e primeiro molar. Coroas esplintadas e não esplintadas foram fabricadas e carregadas, com e sem a presença do segundo molar. Um sistema de medição de câmara única foi usado para registar a deformação no plano na superfície do modelo em frequência de $1,0 \mathrm{~Hz}$ sob cargas entre 0 e $250 \mathrm{~N}$. As imagens foram então analisadas com software especializado para determinar a direção (horizontal) e as tensões de cisalhamento ao longo do modelo. Coroas esplintadas com a presença do segundo molar geraram menor tensão quando comparadas com coroas não esplintadas sem o segundo molar. Nenhuma diferença significativa foi encontrada entre os outros grupos não esplintados com molar e esplintados sem o molar. Analisando as tensões entre os dois implantes (entre segundo pré-molar e primeiro molar), coroas esplintadas com segundo molar também produziram, significativamente, menores valores de tensão quando comparadas com coroas não esplintadas com ausência do molar. A tensão de cisalhamento (Exx) também foi calculada e os resultados encontrados entre os molares demonstraram que a tensão foi significativamente maior quando o segundo molar estava ausente, independentemente das coroas estarem esplintadas ou não. Analisando a região entre implantes o oposto foi encontrado, maiores valores de tensão de cisalhamento foram encontrados quando o segundo molar estava presente, tanto para coroas esplintadas quanto não esplintadas.

Papaspyridakos., em 2012, realizaram revisão sistemática da literatura para avaliar a incidência e os tipos de complicações técnicas e biológicas associadas a próteses totais fixas sobre implantes para pacientes desdentados. Busca eletrônica no Medline/PubMed foi realizada para identificar ensaios clínicos randomizados controlados e estudos prospectivos de coorte com próteses totais fixas sobre implantes para pacientes desdentados. Foram selecionados estudos com pelo menos 5 anos de acompanhamento após a colocação da prótese. De um total de 281 próteses (tempo médio de uso de 9,5 anos), a taxa de 
complicações foi estimada em 24,6\%. As taxas cumulativas de "prótese livre de complicações" após 5 e 10 anos foram 29,3\% e 8,6\%, respectivamente. A complicação mais comum foi perda óssea periimplantar (> $2 \mathrm{~mm}$ ), com taxas de 20,1\% após 5 anos e 40,3\% após 10 anos. A complicação técnica mais frequente relacionada aos implantes foi fratura do parafuso, rendendo taxa de complicação aos 5 anos de $10,4 \%$ e taxa de $20,8 \%$ aos 10 anos. A complicação biológica mais frequente relacionada à prótese foi hipertrofia ou hiperplasia de tecido ao redor das próteses $(13,0 \%$ e $26,0 \%$, após 5 e 10 anos, respectivamente). A complicação técnica mais comum relacionada às próteses foi lascamento ou fratura dos materiais de revestimento (33,3\% em 5 anos e 66,6\% em 10 anos). Complicações biológicas e técnicas após a colocação das próteses ocorreram de forma contínua ao longo do tempo como resultado de fadiga e estresse. Esses eventos não podem ocasionar falhas dos implantes protéticos, mas são significativos em relação à quantidade de reparação e manutenção necessárias, tempo e custo tanto para o dentista quanto para o paciente.

Qian et al. (2012) analisaram a evidência e as razões por trás da perda óssea marginal ao redor dos implantes orais em longo prazo. A pesquisa informatizada foi realizada no PubMed em abril de 2011, com as seguintes palavras-chave: implantes orais e reabsorção óssea marginal, reabsorção da crista e perda óssea, perda óssea e osso. Os autores concluíram que existe evidência clínica de que fatores como o sistema de implante, manejo clínico e características dos pacientes, podem causar perda óssea marginal ou mesmo falha do implante. É possível que o mecanismo por detrás de microfraturas ósseas ou de outros tipos de lesão óssea combinados podem levar à inflamação, que por sua vez estimula a reabsorção óssea. Nesta revisão, não foi encontrada nenhuma evidência da razão para a perda ossea primária - periimplantite. Com os dados, não se pôde provar que a sobrecarga pode resultar em perda de osso marginal ao redor dos implantes. Reações de corpo estranho (por exemplo, 
devidas ao acúmulo de partículas de cimento nos tecidos moles) podem resultar em perda óssea marginal e devido a fatores combinados, resultar em periimplantite secundária.

Vigolo. (2012) compararam a evolução clínica em longo prazo de coroas unitárias implantossuportadas cimentadas e parafusadas. Para isso, dezoito pacientes que se apresentaram com região desdentada bilateral em região de canino ou molar, com largura óssea adequada, altura óssea semelhante nos locais de implante, e esquema oclusal que permitiu o estabelecimento de contatos oclusais cúspides/fossa idênticos. Cada paciente recebeu dois implantes idênticos, de acordo com um desenho de boca dividida. Um lado foi sorteado para ser restaurado com uma coroa unitária implantossuportada cimentada e o outro foi restaurado com uma coroa unitária implantossuportada parafusada. Os parâmetros adotados foram: sucesso, complicações, níveis de osso marginal de implantes e saúde periimplantar de tecido mole. Dois implantes colocados em um mesmo paciente falharam 5 anos após a inserção; os restantes 30 implantes sobreviveram, resultando numa taxa cumulativa de sucesso de 93,7\%. Nenhuma complicação ocorreu. A reabsorção óssea marginal média em 10 anos após a colocação do implante, medida por meio de radiografias intraorais, foi de 1,1 $\pm 0,2 \mathrm{~mm}$ para ambos os tipos de restaurações. Não houve diferenças significativas entre os dois grupos com relação ao nível ósseo marginal nos 10 anos de acompanhento. No $4^{\circ}$ ano de avaliação foi observada diferença significativa, mas isso não foi considerado clinicamente relevante. Os tecidos moles ao redor dos implantes permaneceram estáveis durante o período de avaliação. Dentro das limitações deste estudo, os resultados indicaram que não houve diferença significativa no comportamento clínico do osso marginal e tecidos moles periimplantares quando restaurações unitárias foram cimentadas ou parafusadas ao implante.

Tiossi et al., em 2012, usando o método de correlação digital de imagens mediram as tensões geradas por implantes com dois materiais de revestimento diferentes (cerâmica e 
resina) em osso de suporte simulado sob 2 situações clínicas: presença ou ausência de um contato proximal distal à restauração. As características de transferência de carga das diferentes reabilitações protéticas foram analisadas e comparadas. Foi usado um modelo de resina epóxi de um bloco ósseo com réplicas de um primeiro pré-molar inferior e segundo molar, confeccionados em resina acrílica, e os implantes parafusados, substituindo o segundo pré-molar e o primeiro molar. Recobrimento de porcelana (G1 e G3) e de resina (G2 e G4) com coroas esplintadas parafusadas foram carregados com (G1 e G2) e sem (G3 e G4) a presença da réplica do segundo molar. Método de medição bidimensional de correlação digital de imagens foi usado para registar a deformação da superfície do modelo em frequência de $1,0 \mathrm{~Hz}$ durante a aplicação de carga de $250 \mathrm{~N}$. A tensão máxima compressiva (Exx) foi encontrada nas seguintes regiões: entre molares e entre implantes. A magnitude das tensões na simulação do bloco ósseo com coroas com recobrimento de resina foi menor que com porcelana, independente se com ou sem segundo molar. Dentro das limitações desse estudo pôde se concluir que o recobrimento da resina, mais macia, ajudou a distribuir a carga de forma mais uniforme entre os dentes de apoio e os implantes, reduzindo, assim, as tensões na simulação do bloco ósseo. Por outro lado, usando o recobrimento de porcelana, mais duro, resultou na concentração de carga em um ou dois dentes, conduzindo, assim, a valores mais altos de tensão no bloco ósseo. Em todos os grupos analisados os valores de deformação foram mais elevados na região da plataforma do implante, abaixo da crista óssea, com valores menores no ápice do implante.

\subsection{Resistência à fratura}

Tuntiprawon e Wilson (1995) avaliaram o efeito do aumento da espessura do cimento na resistência à fratura de coroas de alumina com revestimento de porcelana. Trinta e três coroas de porcelana foram divididas em três grupos. No Grupo 1, só folha de platina foi 
utilizada para proporcionar espaço de cimentação. No Grupo 2, duas camadas de espaçador e no grupo 3 quatro camadas foram pintadas na matriz de metal antes da tomada de impressão. Cada coroa foi cimentada com cimento de fosfato de zinco sobre um modelo de metal e carregado até a fratura. A força máxima para romper cada coroa foi gravada. A resistência média da fratura foi de $408 \mathrm{~N}$ para o Grupo 1, $365 \mathrm{~N}$ para o Grupo 2 e $324 \mathrm{~N}$ para o Grupo 3. Houve diferença significativa entre os grupos 1 e 3 . Conclui-se que o aumento da espessura do cimento acima de $70 \mu \mathrm{m}$ reduziu a resistência à fratura de coroas de porcelana.

O objetivo do estudo de Chen et al. (1999) foi determinar a resistência à fratura de coroas totais de cerâmica pura, com e sem carga cíclica anterior. Molares padronizados foram fabricados ( $\mathrm{n}=40)$ em máquina CAD/CAM (Cerec 2), com materiais cerâmicos (Vita Mark II e ProCad) e também pelo método convencional por prensagem (Coroas IPS Empress). Cargas cíclicas que simulavam condições bucais foram realizadas em metade de cada grupo. Depois disso, todas as coroas foram carregadas até a falha catastrófica. Quatro coroas IPS Empress fraturaram durante o carregamento cíclico. Houve diferença significativa entre a média da resistência à fratura dos cinco grupos, tanto com quanto sem fadiga. Dentro de cada grupo, a diferença na resistência à fratura entre as coroas com e sem carga cíclica foi significativa. A resistência à fratura de coroas ProCad foi significativamente maior do que coroas Vita Mark II. Coroas IPS Empress revelaram resultados significativamente diferentes. Não houve diferença significativa na resistência à fratura entre coroas Vita Mark II e IPS Empress, coroas ProCad e IPS Empress e coroas ProCad e IPS Empress. Dentro dos limites deste estudo in vitro, pôde-se constatar que coroas Cerec ProCad demonstraram maior resistência à fratura do que coroas Vita Mark II, melhores propriedades de fadiga e menor probabilidade de falha que coroas IPS Empress fabricadas em laboratório. A carga cíclica diminuiu significativamente a resistência à fratura de coroas de cerâmica pura, mas teve menos efeito sobre coroas ProCad 
Cerec que sobre coroas IPS Empress. Coroas Procad glazeadas tiveram maior resistência e propriedades de fadiga e, portanto, o polimento de superfície é recomendado para uso clínico.

Já em 2004, Guazzato et al. avaliaram a resistência à flexão biaxial, confiabilidade e o modo de fratura da porcelana de camada dupla ou discos de zircônia. Para isso, 80 amostras foram confeccionadas com porcelana convencional e infraestrutura cerâmica de zircônia e divididas em quatro grupos: espécimes de porcelana monolítica, espécimes com material da infraestrutura monolítica, camada dupla com porcelana em cima e camada dupla com material da infraestrutura em cima. A carga máxima de ruptura foi calculada e análise de elementos finitos foi utilizada para estimar o máximo de tensão na tração de ruptura. Os resultados demonstraram que espécies de infraestruturas monolíticas e amostras de camada dupla com o material da infraestrutura na parte inferior tiveram diferença significativamente mais forte do que porcelana monolítica. Dessa forma, este estudo, como investigações anteriores sobre diferentes materiais, indica que as propriedades da camada inferior da bicamada é que dita pelas propriedades da peça. As duas possíveis configurações são comparáveis com a situação clínica de uma coroa (quando o material da infraestrutura está sob tensão) e de um conector de PPF (quando a porcelana está sob tensão). No caso da coroa, o presente estudo indica que a contribuição de uma infraestrutura com material mais resistente é significativa e seu uso é altamente recomendável. No entanto, na situação de uma PPF, a mais fraca cerâmica de revestimento é superada pelo fortalecimento da zircônia. A fim de melhorar a variabilidade de todas as próteses de cerâmica pura, o material da infraestrutura deve ser questionado e novos estudos devem se concentrar naqueles fatores que podem afetar o desempenho clínico em longo prazo, por exemplo, o comportamento de fadiga, tratamento de superfície e tratamento térmico e otimização do estresse.

Rekow e Thompson, em 2005, afirmaram que próteses obtidas pelo sistema CAD/CAM foram introduzidas e, em paralelo, a resistência dos materiais cerâmicos utilizados 
na fabricação de coroas dentárias têm melhorado. No entanto, coroas de cerâmica pura sofrem danos na superfície, limitando o seu sucesso clínico. Fatores diretamente associados à fabricação de CAD/CAM que contribuem para o sucesso incluem a seleção de materiais, parâmetros e estratégias de usinagem $\mathrm{O}$ desafio é compreender os locais e mecanismos de início dos danos, limitações impostas pela estética e restrições biológicas relacionadas. No entanto, uma série de fatores adicionais também pode levar a falhas catastróficas da coroa. Tais fatores incluem manipulações pós-fabricação, em laboratório ou pelo clínico, fadiga associada com a função oclusal fisiológica, locais de tensão criados pelo comprimento ou distorção dentro da estrutura do dente de apoio e/ou materiais adesivos utilizados para cimentar a coroa. Qualquer dano que reduz a resistência de uma coroa aumenta a probabilidade de falha catastrófica. Há evidências de que o espaço excessivo de cimento poderia ser relacionado a falhas do material de revestimento.

Sundh e Sjogren (2006) avaliaram a resistência à fratura de próteses parciais fixas de três elementos fabricadas com blocos de zircônia pré-sinterizados, sinterizados após fresagem e encolhidos para as dimensões finais desejadas. Após o carregamento dinâmico em água, a resistência à fratura das próteses confeccionadas com blocos pré fabricados de zircônia estabilizada com ítria (Vita YZ) ou de magnésio parcialmente sinterizado (Mg-PSZ) foi determinada: (I) tal como é fornecido pelo fabricante, (II) após tratamento térmico de maneira semelhante ao revestimento, e (III) após o recobrimento com cerâmica feldspática. Todas as amostras sobreviveram 100.000 ciclos e nenhuma delas apresentou quaisquer sinais de defeitos após o carregamento dinâmico. Depois do recobrimento, a carga de ruptura dos corpos de prova Vita YZ foi significativamente maior do que as de Denzir-M. Não houve diferença significativa entre espécimes tratados termicamente e recobertos com Denzir-M. As fraturas foram localizadas entre o ponto de carga e um dos conectores. As formas de propagação de trincas eram, na maioria, oblíqua gêngivo-oclusal através do conector e 
pôntico e paralela bucolingual para a superfície oclusal ao longo da superfície oclusal. Com base nos resultados, Denzir-M e Vita YZ parecem ser alternativas interessantes para uso em todas as restaurações de cerâmica pura. Estudos clínicos com períodos maiores de acompanhamento são necessários para avaliar o desempenho clínico desses sistemas restauradores cerâmicos.

Kollar et al. (2008) relataram uma série de casos sobre a utilização da cerâmica pura de alta resistência sem sílica para diferentes indicações protéticas. Cinquenta e dois pacientes receberam reconstruções de zircônia sobre dentes ou sobre implantes durante um período de 2 anos. O período de observação para um novo exame foi de 12 a 30 meses. As mais frequentes indicações foram coroas unitárias e próteses parciais fixas curtas. Todas as restaurações foram cimentadas nos remanescentes dentários ou nos pilares de zircônia. O exame clínico incluiu parâmetros biológicos (Índice Papila), bem como complicações técnicas (profundidade e sangramento à sondagem) e estética. Nenhum implante foi perdido ou causou problemas, mas dois dentes foram perdidos após fratura horizontal. No geral, os parâmetros periodontais foram favoráveis. Fraturas de infraestruturas ou pilares de implantes não foram observadas. Afrouxamento de parafuso de pilar ocorreu uma vez para um pré molar unitário. Além disso, cinco coroas sobre implantes na região posterior exibiram lascamento da porcelana de revestimento. No que diz respeito à estética, nenhuma reconstrução foi considerada inaceitável, mas três coroas foram refeitas pouco tempo após a entrega. Neste estudo de curto prazo, observou-se que propriedades biológicas, estéticas e mecânicas da zircônia foram favoráveis e o material pode ser utilizado em várias indicações sobre dentes ou implantes.

O trabalho de Piascik et al. (2009) teve como objetivo desenvolver e avaliar um método químico prático de alta resistência para modificação da superfície de cerâmicas odontológicas (como zircônia), para facilitar a cimentação adesiva usando silanos e cimentos resinosos disponíveis no mercado. A adesão foi medida usando microtração e testes de 
resistência de união. A investigação focou em uma nova abordagem para tratamento da superfície da zircônia com uma camada de $\mathrm{Si}_{\mathrm{x}} \mathrm{O}_{\mathrm{y}}$ "semente química" que iria promover a ligação com silanos tradicionais. Blocos ProCAD e ZirCAD foram ligados a um bloco composto dimensionalmente similar usando técnicas padrão concebidas para materiais contendo sílica (silano e cimento resinoso). Blocos ZirCAD foram tratados com $\mathrm{SiCl}_{4}$ por deposição de vapor sob duas condições diferentes, antes da cimentação. Barras para microtração foram preparadas e submetidas a forças de tração à velocidade de $1 \mathrm{~mm} / \mathrm{min}$ em microscopia eletrônica de varredura para analisar superfícies de fratura e determinar o modo de falha ou qualquer falha coesiva no compósito (falha coesiva parcial ou completa dentro do compósito) ou falhas do adesivo (falha adesiva parcial ou completa). A zircônia não tratada teve valores de resistência mais baixos, sendo o único grupo a mostrar falhas durante o corte (aproximadamente $40 \%$ falharam). As amostras com tratamento de superfície apresentaram maior força de adesão e nenhuma falha durante o corte. Os valores médios do pico de tensão das amostras com superficie tratada tiveram desvio padrão maior do que grupo controle devido a variações no modo de falha. Esses grupos incluíram casos de falhas coesivas (maior resistência de união) e combinação de falhas coesivas e adesivas. Análise em microscopia eletrônica de varredura das barras fraturadas após microtração revelou vários tipos de falhas: falha adesiva, modo misto de falha adesiva e coesiva e falha coesiva. Pelo uso do clorosilano como pré-tratamento foi criada uma camada de sílica na zircônia, usada para aumentar os locais de aplicação dos subsequentes primers organosilanos. Os dados mecânicos deste estudo apoiam o conceito de que a modificação química da superfície pode melhorar a adesão do cimento resinoso à zirconia usando técnicas de silanização e cimentação tradicionais.

Vásquez et al. (2009) compararam o efeito da ciclagem termomecânica sobre a resistência ao cisalhamento de três cerâmicas de baixa fusão com titânio comercialmente puro, com cerâmica feldspática convencional e com liga de ouro para avaliar os tipos de 
falhas na interface da cerâmica, e analisaram a composição química desta interface. Quatro grupos experimentais foram formados: Gr1 (grupo controle): Vita Omega 900- liga Au-Pd; Gr2: Triceram-Ticp; Gr3: Super Porcelain - Ticp; e G4: Vita Titan Keramik-Ticp. Embora metade dos casos de cada combinação de metal e cerâmica foi testada aleatoriamente sem envelhecimento (armazenamento de água a $37^{\circ} \mathrm{C}$ por apenas 24 horas), a outra metade foi termociclada primeiro $\left(6.000\right.$ ciclos entre $5-55^{\circ} \mathrm{C}$, tempo de permanência: 13 seg e, em seguida, carregada mecanicamente (20.000 ciclos sob carga 50N, imersão em água destilada a $\left.37^{\circ} \mathrm{C}\right)$. As amostras foram carregadas sob cisalhamento em máquina de testes convencional com velocidade de $0,5 \mathrm{~mm} / \mathrm{min}$ até que a falha ocorresse. O tipo de falha foi anotado e as interfaces representativas das espécimes fraturadas de cada grupo foram examinadas com lupa e microscópio eletrônico de varredura (MEV). Tanto combinações de liga/ cerâmica quanto as condições de envelhecimento afetaram significativamente os valores de resistência à fratura. Os tipos de cerâmica e os fatores de fadiga não foram significantes. A ciclagem termomecânica diminuiu a resistência de união (MPa) para Gr3 e Gr4 quando comparados com os grupos não envelhecidos. $\mathrm{Na}$ análise em microscopia eletrônica de varredura, foram detectadas três regiões diferentes: (a) metal; (B) zona de interação de metal e cerâmica; (C) cerâmica. Verificou-se que todas as interfaces apresentaram-se intactas, com bom contato e molhabilidade entre cerâmica e liga, sem presença de falhas ou fendas, sugerindo adesão adequada entre os dois materiais. Termociclagem (6.000 ciclos) e ciclagem mecânica (20.000 ciclos) diminuiram a resistência de união significativamente. Triceram-Ticp pode ser recomendado como alternativa mais barata do que Au-Pd-cerâmica em restaurações extensas.

Shirakura et al. (2009) investigaram os efeitos de ciclos térmicos e cargas cíclicas na ocorrência de fissuras no revestimento de porcelana nos sistemas testados. Coroas de cerâmica pura e metalocerâmica $(n=20)$ foram fabricadas sobre um pilar de implante $(\mathrm{RN}$ Pilar sólido) para o estudo. Dois projetos de próteses com duas espessuras diferentes de 
revestimento de porcelana incisal $(2 \mathrm{~mm}$ e $4 \mathrm{~mm})$ foram usados para cada sistema de cerâmica pura e coroa metalocerâmica, resultando em quatro grupos experimentais $(n=10)$, com coroas de forma idêntica. A coroa de cerâmica pura consistiu de alumina All Ceram (Procera e revestimento de porcelana Cerabien), enquanto coroas metalocerâmicas eram feitas de metal nobre (LEO) e revestimento de porcelana (IPS Classic). Todas as coroas foram cimentadas sobre os pilares utilizando cimento resinoso (Panavia) e foram submetidas a 1.000 ciclos térmicos $\left(5-55^{\circ} \mathrm{C}\right)$. Cada espécime foi carregado por $1,2 \times 10^{6}$ ciclos ou até que falhasse. Os espécimes foram avaliados cuidadosamente quanto a rachaduras e/ou fraturas em microscópio óptico estereoscópico (10x). Os espécimes sem fratura foram carregados após o carregamento cíclico no longo eixo do dente, na borda incisal, em máquina universal de ensaios com velocidade de $1,5 \mathrm{~mm} / \mathrm{min}$, até que houvesse fratura. $\mathrm{O}$ grupo das coroas de cerâmica pura mostrou, significativamente, maior sucesso e taxas de sobrevivência do que os grupos metalocerâmicos após o carregamento cíclico; entretanto, demonstrou fratura da infraestrutura e da porcelana de recobrimento abaixo da carga de fratura requerida. Para o grupo metalocerâmica, coroas com $2 \mathrm{~mm}$ de porcelana tiveram, significativamente, maiores falhas no carregamento do que coroas com espessura de porcelana de $4 \mathrm{~mm}$. No entanto, o grupo de cerâmica pura não mostrou diferença significativa entre as duas espessuras de revestimento de porcelana. Dentro das limitações deste estudo, concluiram que coroas em cerâmica pura apresentaram maior sucesso e taxas de sobrevivência após o teste cíclico do que metalocerâmica; coroas metalocerâmicas apresentaram maior taxa de falha de fratura após carga cíclica e a espessura do revestimento na incisal influenciou no fracasso da porcelana nas coroas metalocerâmicas, mas não nas de cerâmica pura.

Andreiuolo et al. (2011) realizaram trabalho de revisão da literatura referente à zircônia. Restaurações metalocerâmicas têm sido, há décadas, a escolha ideal para a fabricação de próteses fixas sobre dentes e implantes. Recentemente, novos sistemas 
cerâmicos foram desenvolvidos para desempenhar este papel devido à inerente desvantagem estética da subestrutura metálica. Entretanto, a cerâmica é um material frágil por natureza, e sua baixa resistência à fratura, aliada à baixa resistência à flexão, vem à tona quando se discute a possibilidade de confecção de próteses parciais fixas e pilares para implantes. Isto se torna ainda mais crítico na região posterior da boca, onde as forças mastigatórias são maiores. A zircônia é um material comprovadamente indicado para uso restaurador sob aspectos biológicos, funcionais e estéticos, cabendo ao cirurgião-dentista estar informado quanto às suas propriedades, sistemas disponíveis e opções de processamento, assim como dos estudos laboratoriais e clínicos para indicar sua utilização de forma correta, extraindo o máximo proveito de suas características.

Triwatana et al. (2012) revisaram os trabalhos publicados entre 2000-2010 em relação ao desempenho clínico das próteses parciais fixas em zircônia e as causas de falha. Foi realizada busca eletrônica de artigos de revisão em inglês, por pares, através do PubMed, para obter todos os estudos clínicos focados no desempenho das próteses de zircônia. Ensaios clínicos longitudinais controlados e randomizados, de coorte prospectivo e retrospectivo, foram o foco desta revisão. As taxas de sobrevivência da zircônia em prótese parcial fixa anterior e posterior variou entre 73,9\% - 100\% depois de 2-5 anos. As causas de falha foram fratura da porcelana, fratura da infraestrutura de cerâmica, fratura do dente pilar, cáries secundárias e deslocamentos da restauração. De acordo com os resultados dos estudos clínicos revistos, próteses em zircônia podem fornecer forte suporte para a camada de revestimento, devido à alta resistência à fratura. Verificou-se que os sistemas CAD/CAM podem fornecer estruturas aceitáveis, em termos de desenho e adaptação marginal. Fratura do revestimento cerâmico foi observada em muitos estudos, mas não foi das principais causas para a substituição por nova restauração, uma vez que pode ser modificada e polida. As causas da fratura do recobrimento cerâmico poderiam ser diferenças térmicas incompatíveis, 
comportamentos elástico e viscoelástico da infraestrutura e do revestimento cerâmico. Devido à sua ocorrência repetida em muitos estudos, pesquisas futuras são essenciais para esclarecer este problema e reduzir a incidência de fratura.

Romeo e Storelli (2012) fizeram revisão sistemática com interesse em avaliar a taxa de sucesso e sobrevivência de implantes com prótese em cantilever, bem como a incidência de complicações técnicas e biológicas. Para isso foi realizada uma pesquisa no Medline até dezembro de 2011 de estudos com acompanhamento médio de 5 anos ou mais. Dois revisores independentes selecionaram os artigos encontrados e os dados foram extraídos. Dos 160 artigos selecionados, apenas 18 foram submetidos à análise de texto completo e apenas seis foram incluídos no estudo. A taxa estimada de sobrevivência cumulativa das próteses sobre implantes com apoio em cantilever foi de 98,9\%. Complicações biológicas foram estimadas em 5,7\% ao nível do implante, após 5 anos. As complicações técnicas mais comuns foram fratura da porcelana de cobertura $(10,1 \%)$ e fratura do parafuso do pilar $(1,6 \%), 5,9 \%$ de decementação e $7,9 \%$ de afrouxamento do parafuso. Fratura do implante foi rara $(0,7 \%)$ e não houve nenhum relato da infraestrutura não houve nenhum relato. Alterações radiográficas do nível ósseo não foi significativa em 5 anos de acompanhamento. Nenhum resultado estético foi relatado. Embora a literatura disponível seja limitada, a presente revisão sistemática indicou que não há aumento na taxa de complicação técnica devido à presença de cantilever. Portanto, prótese com cantilever pode ser considerada um tratamento confiável para o paciente parcialmente desdentado.

Papaspyridakos e Lal. (2013) fizeram um estudo retrospectivo cujo objetivo foi relatar as complicações técnicas do $2^{\circ}$ ao $4^{\circ}$ ano de próteses parafusadas confeccionadas em zircônia pelo sistema CAD/CAM para pacientes desdentados e os fatores de risco associados a essas complicações técnicas. Quatorze pacientes desdentados totais foram incluídos neste estudo. Dez pacientes eram do sexo feminino e quatro homens, com idade média de 58 anos. Dez mandibulas e seis maxilas foram restauradas com próteses totais com infra estrutura em 
zircônia e recobrimento em porcelana. O período de acompanhamento clínico médio foi de 3 anos. Na última visita de acompanhamento parâmetros técnicos e biológicos do tratamento com implantes dentários foram avaliados. A taxa de sobrevivência do implante e da prótese após a inserção da prótese foi de $100 \%$ até o quarto ano de acompanhamento. As próteses em 11 dos 16 arcos que foram restaurados com estruturas sólidas exibiram resposta dos tecidos moles, estética e satisfação do paciente favoráveis. Cinco próteses $(31,25 \%)$ em quatro pacientes apresentaram lascamento da porcelana de cobertura. Lascamento foi mínimo em três próteses (três pacientes) e foi corrigido intraoralmente com polimento (uma prótese) ou resina composta (duas próteses). Um paciente com prótese maxilar e mandibular em zircônia exibiu grande fratura na porcelana as quais tiveram que ser reparadas em laboratório. Função, estética e satisfação do paciente não foram afetados em três dos quatro incidentes de fratura. A presença de atividade parafuncional, prótese antagonista à dentição e a ausência de placa noturna oclusal foram associados com todos os incidentes de lascamento da cerâmica.

Bakeman et al. (2015) em seu estudo avaliou a influência dos materiais cerâmicos e sua espessura em relação à resistência à fratura das restaurações parciais posteriores. A hipótese nula foi que a resistência à fratura de restaurações parciais posteriores não seria afetada pela escolha de materiais cerâmicos (cerâmica reforçada com dissilicato de lítio e/ou cerâmica reforçada com leucita) ou pela espessura de cerâmica (1 ou $2 \mathrm{~mm}$ ). As amostras foram carregadas até ocorrer a falha em máquina universal de ensaios, no modo de compressão, com velocidade $1,0 \mathrm{~mm} / \mathrm{min}$. Os materiais cerâmicos tiveram efeito significativo sobre os valores de resistência à fratura; no entanto, não houve relação significativa entre a espessura da cerâmica e a resistência à fratura. Dentro das limitações deste estudo in vitro, a cerâmica dissilicato de lítio para restaurações parciais teve melhores resultados de resistência à fratura em comparação com a cerâmica reforçada com leucita. A espessura da cerâmica não teve nenhum efeito significativo sobre resistência à fratura. 

3. Proposiç̃̃o 

Neste estudo foram montados conjuntos pilar protético/infraestrutura obtidos pelos sistemas CAD/CAM Neodent digital (Neodent) e LAVA (3M ESPE). Foram utilizados pilares protéticos e infraestrutura em zircônia, e pilares protéticos em titânio com infraestrutura em Co-Cr (Neodent digital) e pilares em zircônia com link metálico com infraestrutura em zircônia (Lava). Como controle foram utilizados pilares e infraestrutura em Ni-Cr. Todos os grupos receberam revestimento estético cerâmico padronizado, por prensagem.

As avaliações foram realizadas para:

1. Desadaptação marginal vertical entre pilares/implante;

2. Desadaptação marginal (vertical e horizontal) entre pilares/infraestrutura, antes e após prensagem da porcelana e ciclagem termomecânica;

3. Desadaptação interna (axial e oclusal) das infraestruturas, antes e após prensagem da porcelana e ciclagem termomecânica;

4. Tensões geradas na interface osso-implantes (geral, cervical e apical) sob carga cêntrica estática;

5. Resistência à fratura da prótese, após ciclagem termomecânica;

6. Microscopia eletrônica de varredura de cortes transversais do conjunto implantes/prótese após o teste de resistência à fratura.

As hipóteses nulas desse trabalho foram:

1. Os diferentes sistemas $\mathrm{CAD} / \mathrm{CAM}$, consideradas as variações de materiais possíveis, não causam diferenças na desadaptação vertical pilar/implante;

2. Os diferentes sistemas $\mathrm{CAD} / \mathrm{CAM}$ não têm diferença quanto à desadaptação marginal (vertical e horizontal) e espaços internos (axial e oclusal) antes e após a prensagem do revestimento estético e ciclagem termomecânica; 
3. Os diferentes sistemas $\mathrm{CAD} / \mathrm{CAM}$, consideradas as variações de materiais possíveis, bem como a ciclagem termomecânica, não causam diferenças na desadaptação marginal (vertical e horizontal) pilar/infraestrutura antes e após termociclagem mecânica;

4. Os diferentes sistemas $\mathrm{CAD} / \mathrm{CAM}$, consideradas as variações de materiais possíveis, bem como a ciclagem termomecânica, não causam diferenças na desadaptação interna (axial e oclusal) pilar/infraestrutura;

5. Os diferentes sistemas CAD/CAM, consideradas as variações de materiais possíveis, não causam diferenças nas tensões observadas na região dos implantes;

6. Os diferentes sistemas CAD/CAM, consideradas as variações de materiais possíveis, não causam diferenças quanto à resistência à fratura das próteses fixas implantossuportadas obtidas. 
4. Materiale Métodos 

Todos os procedimentos de confecção dos modelos foram realizados por um único operador e os procedimentos protéticos por um técnico em prótese experiente.

\subsection{Obtenção dos modelos}

Foi confeccionado um modelo mestre em alumínio no formato de bloco retangular $(50 \times 30 \times 15 \mathrm{~mm})$ contendo dois implantes de hexágono externo 3,75 x $11 \mathrm{~mm}$ (Neodent, Curitiba, PR, Brasil) sendo um na área de primeiro pré-molar (14) e outro na região de primeiro molar (16), ambos ao nível da plataforma (Figura 1). Com auxílio de um paralelômetro, os implantes foram posicionados de forma alinhada no sentido mésio-distal, paralelos entre si e fixados às perfurações com cola à base de cianoacrilato (Super Bonder ${ }^{\circledR}$, Loctite, São Paulo, SP, Brasil) (Figuras 2 e 3). Assim, o modelo mestre simulou situação de ausência na região posterior da maxila, reabilitada com dois implantes e uma prótese fixa cimentada sobre os pilares intermediários.

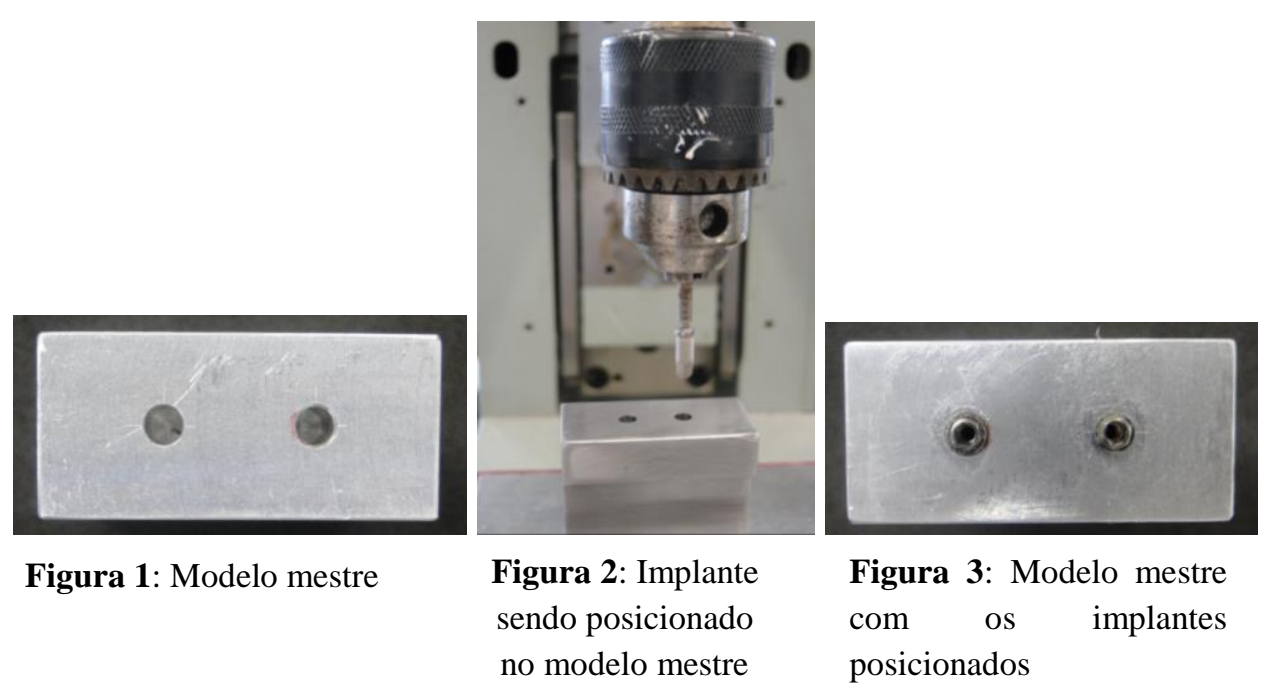

\section{Obtenção dos modelos em poliuretano}

Após o posicionamento dos implantes foram parafusados os transferentes sobre os implantes, dado o torque com torquímetro manual (Neodent) de $10 \mathrm{Ncm}$ com o modelo mestre perfeitamente apoiado sobre a mesa (Figura 4), realizada a união dos transferentes com 
hastes metálicas e resina Duralay (Reliance Dental Mfg. Co., Woth, IL, EUA) (Figura 5) e o encaixamento do modelo mestre com cera utilidade (Figura 6).

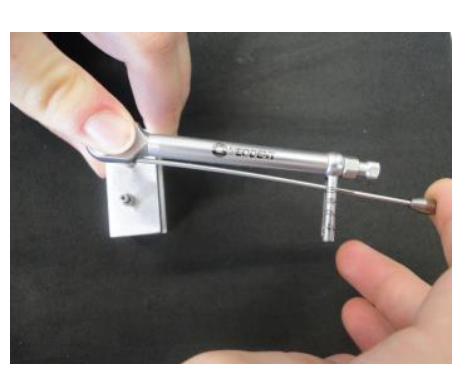

Figura 4: Torque de $10 \mathrm{Ncm}$

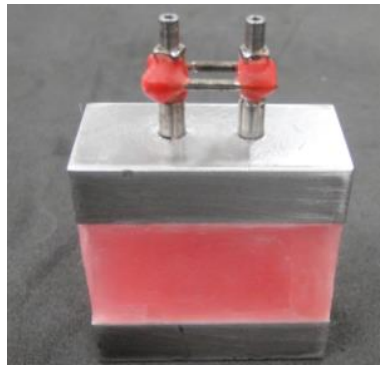

Figura 5: União dos transferentes

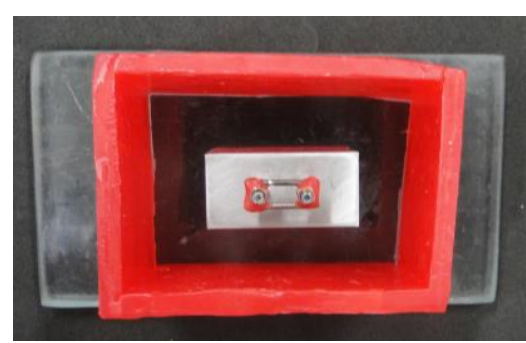

Figura 6: Encaixamento do modelo mestre

Em seguida foi realizada a moldagem, confeccionando, dessa forma, uma matriz de Silicone Master (Talmax, Curitiba, Paraná, Brasil) para que todos os modelos fossem obtidos de forma padronizada (Figura 7). Os modelos de trabalho foram confeccionados em poliuretano F16 Polyol (Axson Technologies, Saint-Ouen-l'Aumône, França), Moretti Neto et al, 2011.

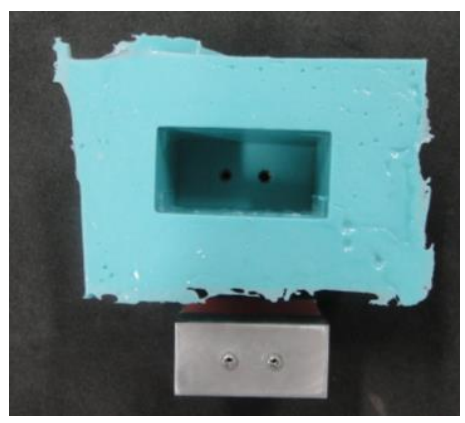

Figura 7: Molde de silicone para confecção dos modelos

Para a confecção dos modelos o poliuretano foi pesado - base e catalisador na proporção de 1:1 em balança analítica de precisão Mark (BEL Equipamentos Analíticos Ltda., Piracicaba, São Paulo, Brasil - resolução: 0,0001 g) (Figura 8). Após a pesagem, ambos os líquidos foram misturados por 60 segundos e a mistura vertida no molde (Figura 9). Após 30 minutos, o modelo de trabalho foi retirado do molde. Foram confeccionados 40 modelos, 10 deles ilustrados na Figura 10. 


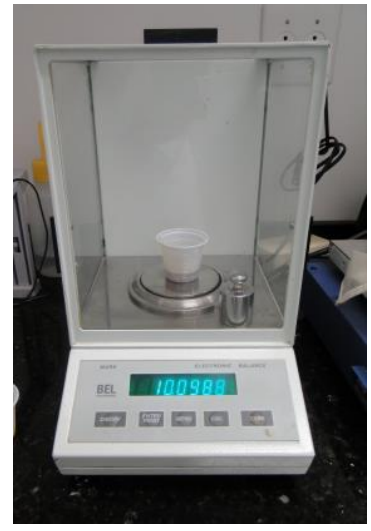

Figura 8: Pesagem do Poliuretano

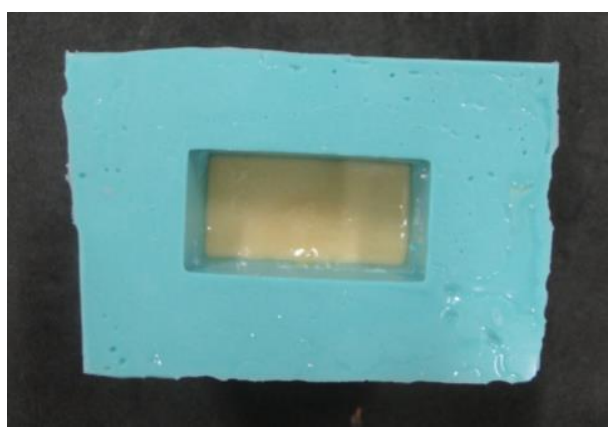

Figura 9: Poliuretano vazado na matriz

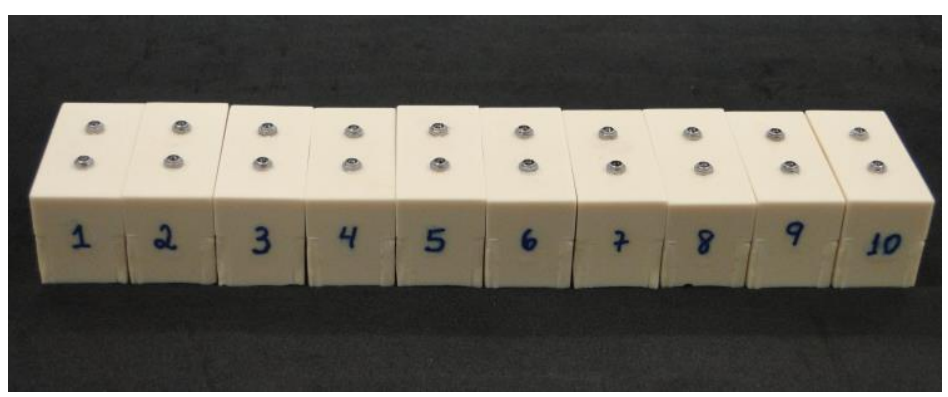

Figura 10: Modelos em Poliuretano

Para este estudo foram obtidas 40 próteses parciais fixas sobre implantes $(\mathrm{N}=10)$ com pilares e infraestruturas em zircônia pelo sistema Neodent digital (ZirNeo), com pilares em titânio e infraestruturas em CoCr pelo sistema Neodent digital (TiNeo), com pilares e infraestruturas em zircônia pelo sistema Lava (Lava) e com pilares e infraestrutura em $\mathrm{NiCr}$ para o grupo controle $(\mathbf{C o})$.

\subsection{Confecção dos pilares - TiNeo e ZirNeo (Neodent digital)}

Cilindros calcináveis (UCLA) com base pré-fabricada em $\mathrm{CoCr}$ antirotacional (Neodent, Curitiba, Brasil) foram parafusados aos implantes (Figura 11); em seguida foi realizado o enceramento dos pilares (Figura 12), posteriormente enviado a uma das empresas responsáveis pela usinagem - Neodent. 


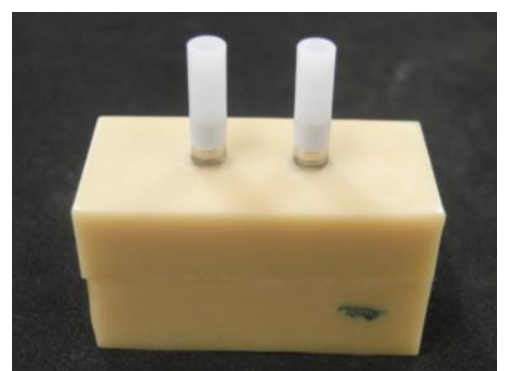

Figura 11: Cilindros calcináveis parafusados aos implantes

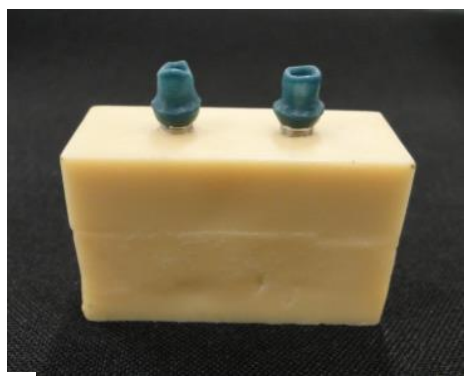

Figura 12: Pilares encerados

$\mathrm{Na}$ empresa, o enceramento original e cada modelo reproduzido foram escaneados, os pilares foram planejados e usinados pelo Sistema CAD/CAM Neodent digital. Os pilares foram fresados em zircônia - ZirNeo PM (pré-molar) e ZirNeo M (molar) (Figura 13) e em titânio - TiNeo PM (pré-molar) e TiNeo M (molar) (Figura 14).

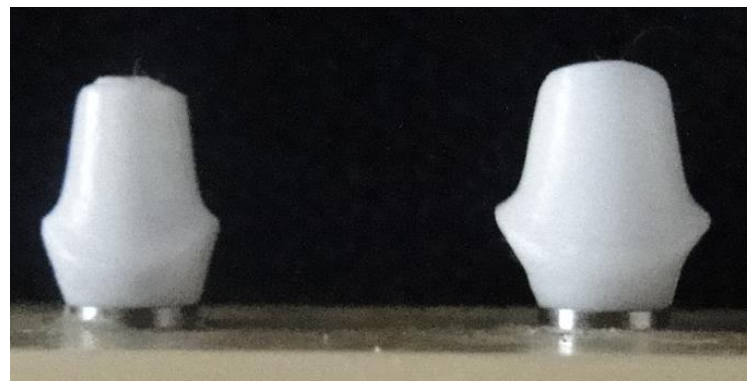

Figura 13: Pilares ZirNeo (Neodent digital)

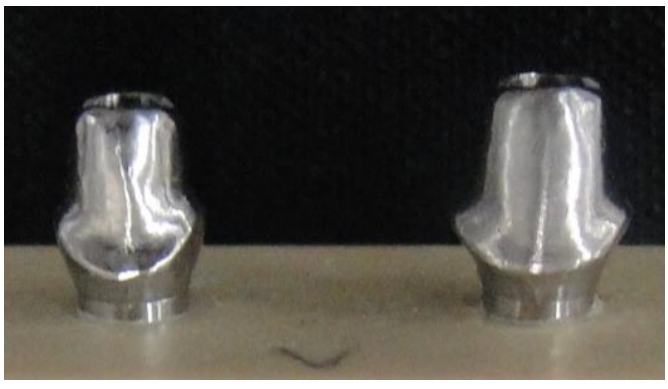

Figura 14: Pilares TiNeo (Neodent digital)

\subsection{Confecção dos pilares - Grupo Lava}

O mesmo enceramento dos pilares, reproduzido em resina acrílica Duralay (Figura 15), foi enviado ao laboratório credenciado do Sistema Lava (Protécnica Laboratório de Prótese S/S, Ribeirão Preto - SP). Foi realizado o escaneamento dos pilares e do link metálico (Figuras 16 e 17). Assim, forma, tamanho e contorno dos pilares dos grupos Neodent digital foram reproduzidos. Em seguida foi feito o projeto dos pilares no computador delimitando bordos, removendo áreas retentivas, corrigindo áreas com falhas e enviado para fresagem no laboratório Lava ${ }^{\mathrm{TM}}$, via internet. 


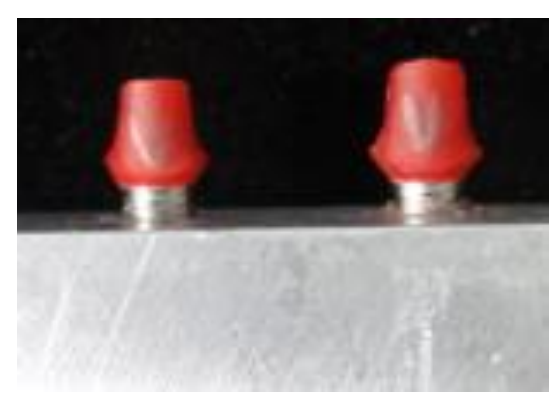

Figura 15: Pilares reproduzidos em resina acrílica

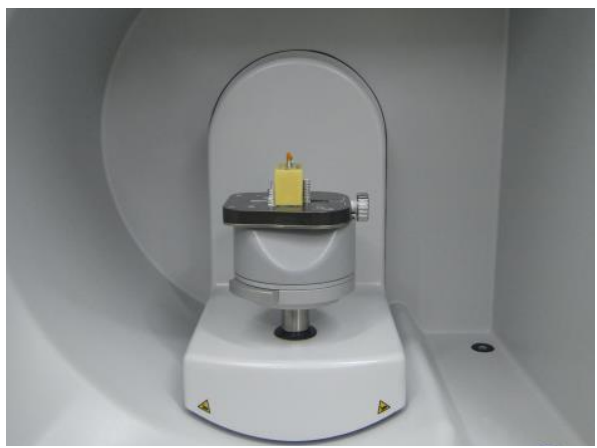

Figura 16: Enceramento sendo escaneado (Sistema Lava)

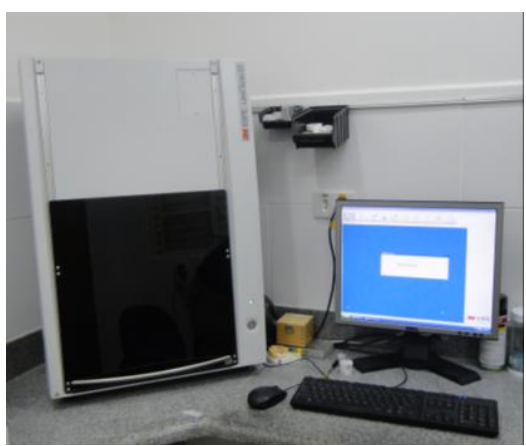

Figura 17: Planejamento dos pilares no computador (Sistema Lava)

Após os pilares serem fresados, foi aberto o orifício de acesso ao parafuso na oclusal de cada pilar (Figura 18) e realizado o jateamento com partículas de óxido de alumínio na superfície interna. Cada pilar foi cimentado sobre o respectivo link com cimento RelyX U200 (3M ESPE) (Figura 19).

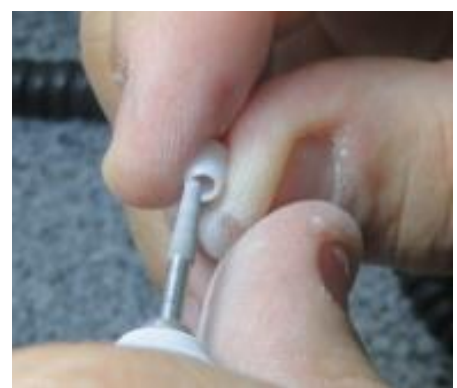

Figura 18: Abertura do orifício de acesso ao parafuso

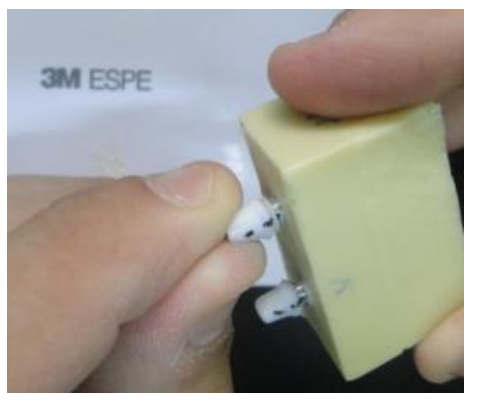

Figura 19: Cimentação dos pilares sobre os links 
Os pilares fresados em zircônia pelo laboratório responsável Lava 3M ESPE estão ilustrados na figura 20 .

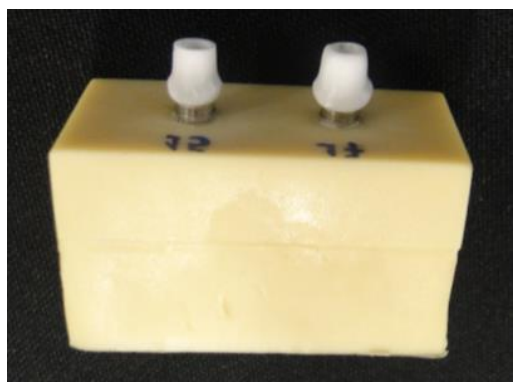

Figura 20: Pilares de zircônia (Lava 3M)

\subsection{Confecção dos pilares - Grupo Controle:}

Os pilares do grupo controle foram usinados em resina pelo sistema CAD/CAM Neodent digital/Neodent (Figura 21) para posterior fundição. A utilização da técnica de usinagem em resina foi para reproduzir a forma dos pilares dos outros grupos. Foi utilizada para isso a resina Stratasys Fullcure 720 (Objet - Billerica, Massachusetts, EUA) na impressora 3D Edent 260V (Object,-- Billerica).

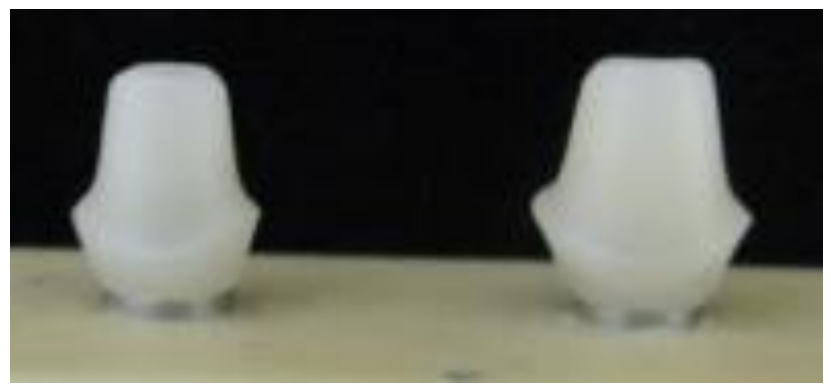

Figura 21: Pilares em resina - grupo controle

Sobre a superfície da resina foram posicionados sprues de cera de $2 \mathrm{~mm}$ de diâmetro (Ceras Babinete, Maringá, Paraná, Brasil), com angulação de aproximadamente $45^{\circ}$. Os padrões de cera assim preparados foram pulverizados com spray redutor de tensão de superfície (Kota, São Paulo, São Paulo, Brasil) e deixados secar em temperatura ambiente. 
Foi utilizado revestimento Microfine 1700 Talladium (Valencia, CA, EUA), proporcionado estritamente segundo recomendações do fabricante - proporção água/líquido de $7 \mathrm{~mL}$ de água para $15 \mathrm{~mL}$ de líquido para cada $60 \mathrm{~g}$ de revestimento, espatulado mecanicamente a vácuo por 60 segundos em espatulador elétrico (Turbomix, EDG Equipamentos e Controles Ltda, São Carlos - São Paulo, Brasil).

O revestimento foi inicialmente pincelado no interior do enceramento e depois o anel foi cuidadosamente completado sob vibração em vibrador de bancada (Vibrac VH Grupo Midas Dental Products Ltda., Araraquara, SP, Brasil) para melhor escoamento do revestimento e para evitar bolhas. $\mathrm{O}$ anel ficou sobre a bancada, em temperatura ambiente, até a cristalização do revestimento. Após 40 minutos o revestimento foi levado ao forno (Vulcan 3-130, Dentsply Ceramco, Petrópolis, Rio de Janeiro, Brasil) para volatização da cera e expansão do revestimento.

Os pilares foram fundidos por chama numa centrífuga (EDG, São Carlos, São Paulo, Brasil) em liga de NiCr - Fit Cast SB Plus (Talmax, Curitiba, Paraná, Brasil). Após o ciclo de aquecimento do revestimento por 20 minutos a $950^{\circ} \mathrm{C}$, abaixou-se a temperatura e retirou-se o anel em $850^{\circ} \mathrm{C}$. O metal foi aquecido até as pastilhas perderem sua definição, em seguida a centrífuga foi desarmada.

O revestimento foi deixado esfriar naturalmente para a desinclusão do trabalho, de forma convencional. Os condutos de alimentação foram seccionados com discos de carborundum. Foram removidos apenas pequenos nódulos e rebarbas que interferissem no assentamento dos pilares. Para isso foram utilizadas brocas de tungstênio em alta rotação sob refrigeração constante. Não foi realizado polimento em nenhuma peça para conservar a padronização da forma das amostras (Figura 22). 

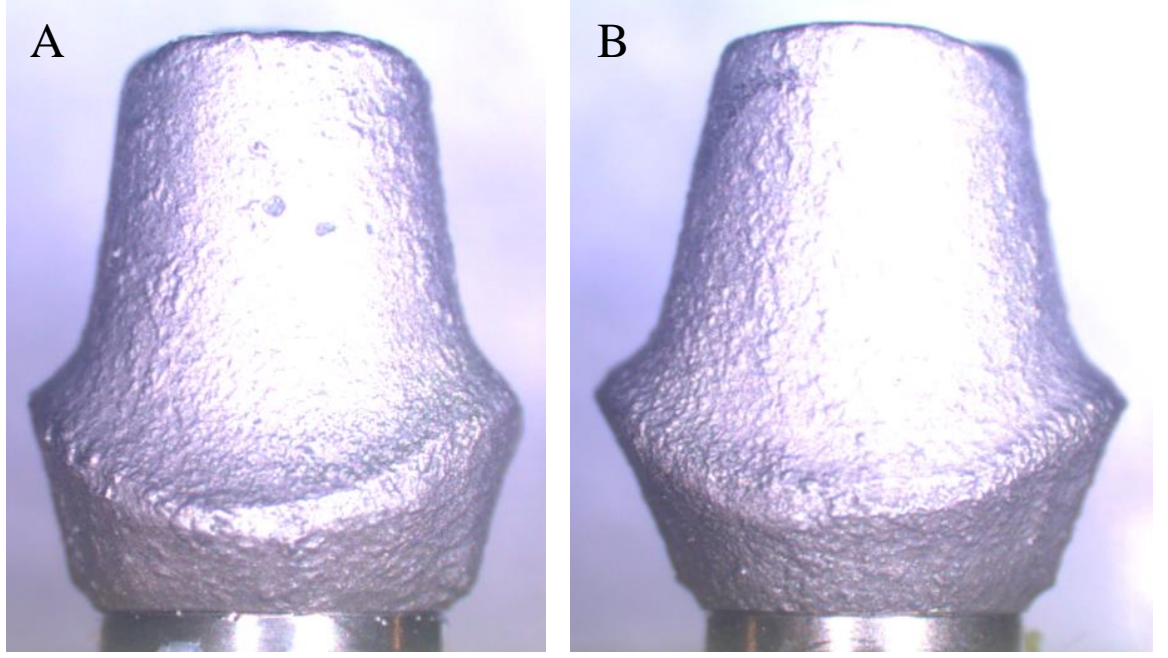

Figura 22: A) Pilar PM do grupo controle finalizado;

B) Pilar M do grupo controle finalizado

\subsection{Confecção das infraestruturas - ZirNeo e TiNeo (Neodent):}

Sobre os pilares foi encerada a infraestrutura da prótese parcial fixa de três elementos

(Figura 23).

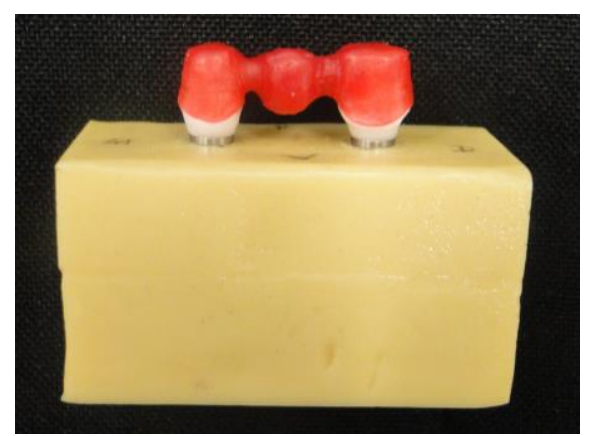

Figura 23: Enceramento da infraestrutura

$\mathrm{O}$ enceramento da infraestrutura e os modelos com os pilares foram enviados para empresa Neodent para confecção das infraestruturas.

O enceramento da infraestrutura da prótese parcial fixa e os pilares foram escaneados e a infraestrutura refinada no computador. Segue passo a passo (Figuras 24 a 33): 


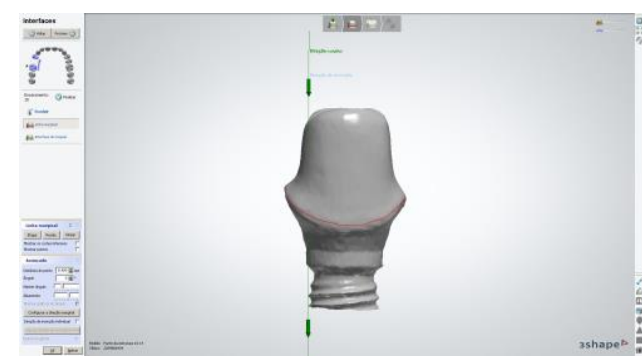

Figura 24: Delimitação dos bordos vestibular do 16 (Neodent digital)

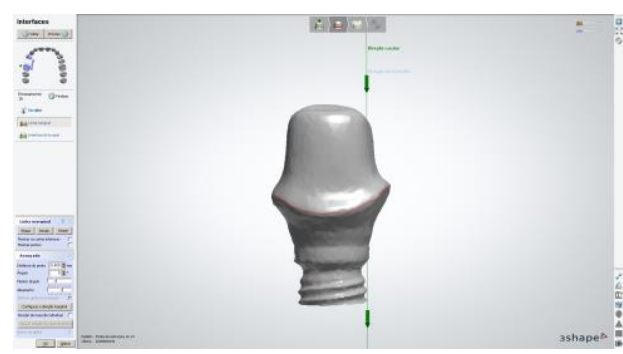

Figura 26: Delimitação dos bordos lingual do 16 (Neodent digital)

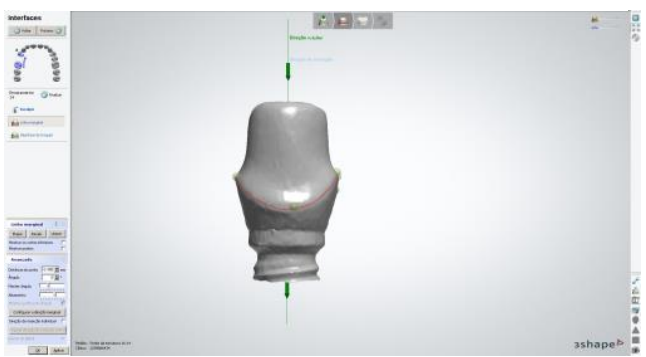

Figura 28: Delimitação dos bordos vestibular do 14 (Neodent digital)

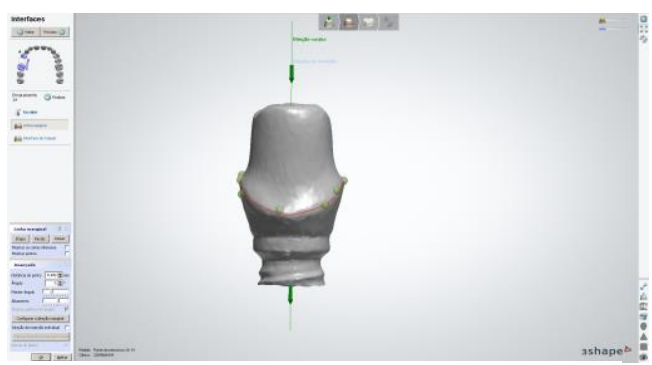

Figura 30: Delimitação dos bordos lingual do 14 (Neodent digital)

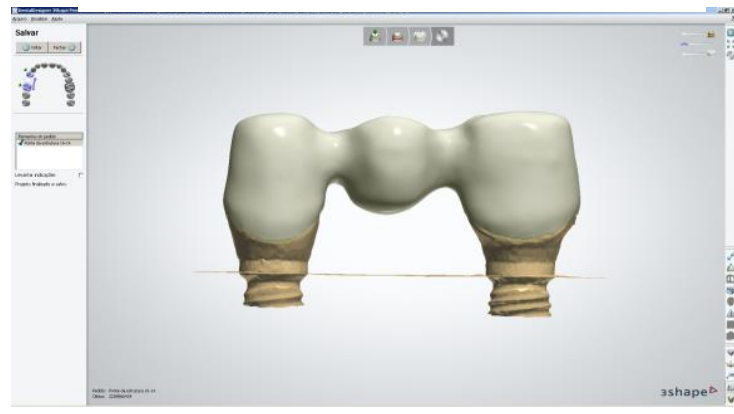

Figura 32: Infraestrutura por vestibular (Neodent digital)

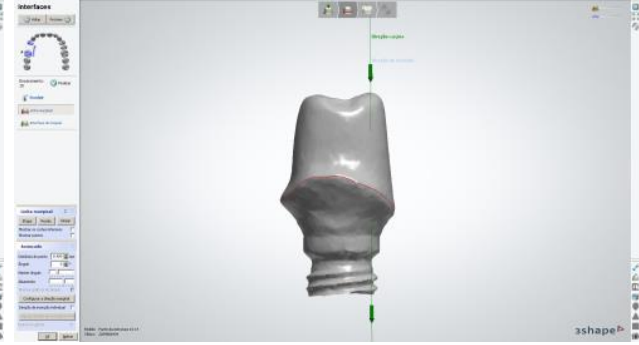

Figura 25: Delimitação dos bordos mesial do 16 (Neodent digital)

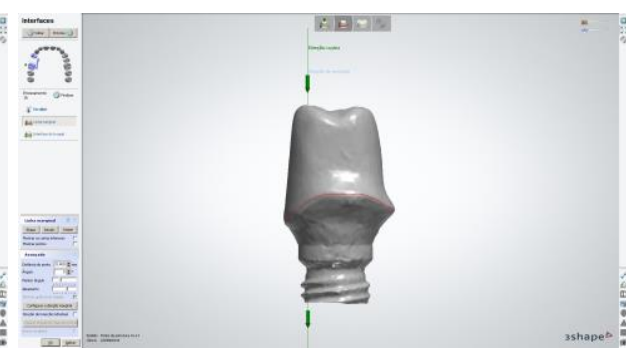

Figura 27: Delimitação dos bordos distal do 16 (Neodent digital)

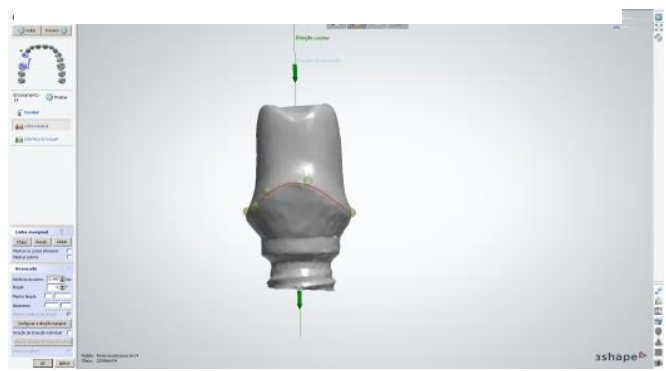

Figura 29: Delimitação dos bordos mesial do 14 (Neodent digital)

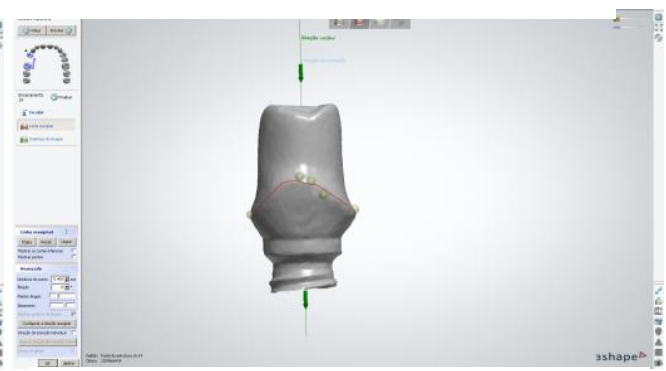

Figura 31: Delimitação dos bordos distal do 14 (Neodent digital)

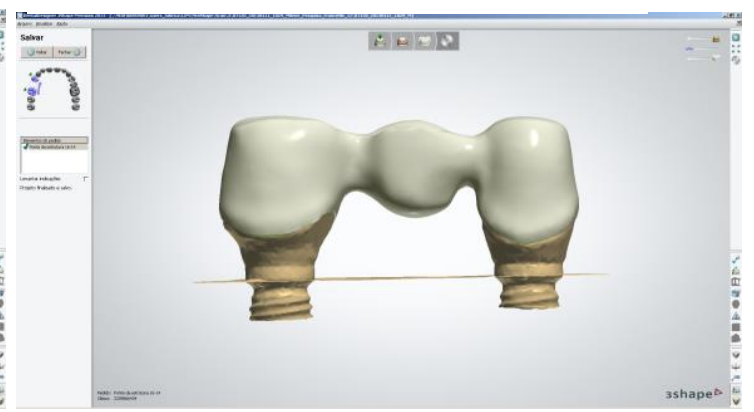

Figura 33: Infraestrutura por lingual (Neodent digital) 
Foram confeccionadas infraestruturas pelo sistema Neodent digital (Neodent) em CoCr (Figura 34) e em zircônia (Figura 35) pelo sistema Neodent digital

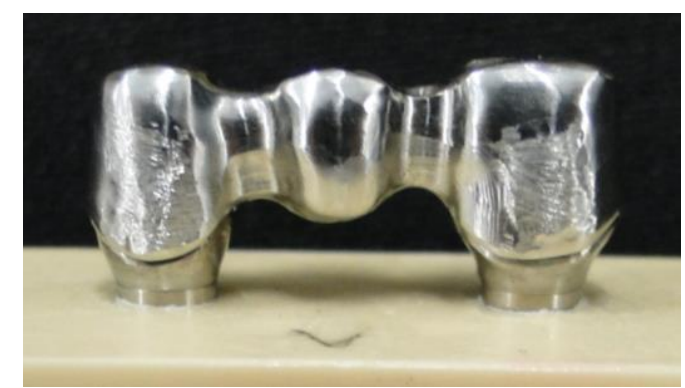

Figura 34: Infraestrutura em $\mathrm{CoCr}$ (TiNeo)

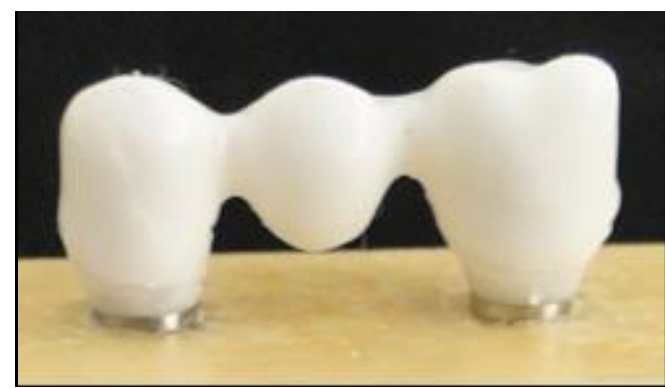

Figura 35: Infraestrutura em zircônia (ZirNeo)

\subsection{Confecção das infraestruturas - Lava:}

Sobre os pilares fresados em zircônia foi realizado o enceramento da infraestrutura utilizando a matriz de silicone feita sobre a infraestrutura da Neodent para com isso manter a reprodutibilidade entre os grupos (Figura 36).

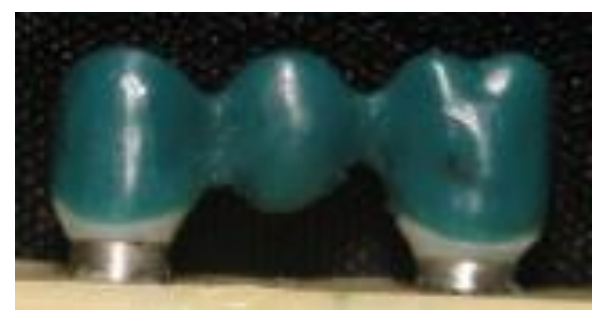

Figura 36: Enceramento da infraestrutura da prótese parcial fixa (Lava)

O enceramento da infraestrutura da prótese parcial fixa e os pilares foram escaneados e a infraestrutura refinada no computador. Segue passo a passo (Figuras 37 a 48): 


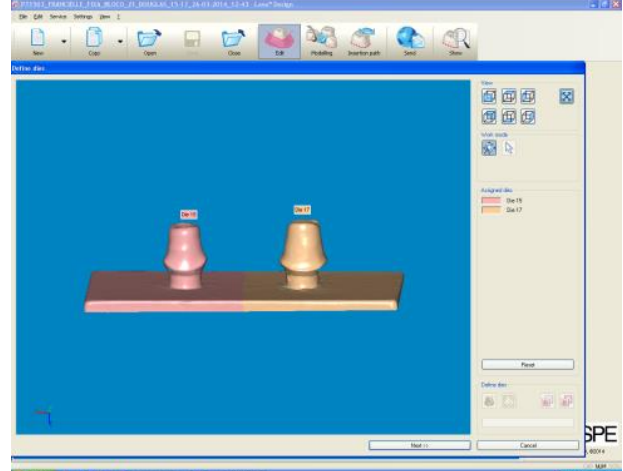

Figura 37: Preparos escaneados

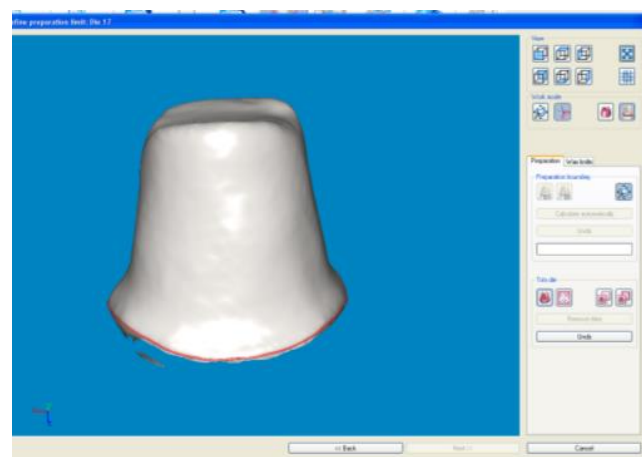

Figura 39: Delimitação bordos - dente16

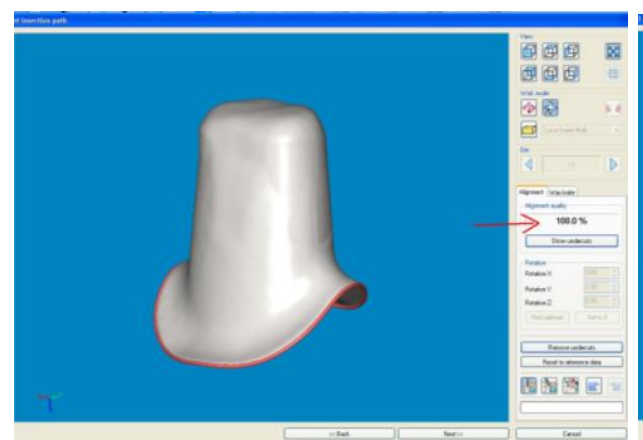

Figura 41: Eliminação das retenções do preparo - dente 14

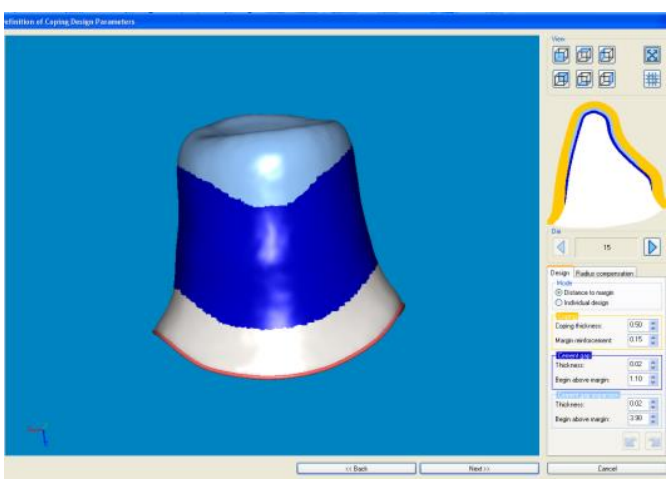

Figura 43: Definição do espaço de cimentação - dente 14

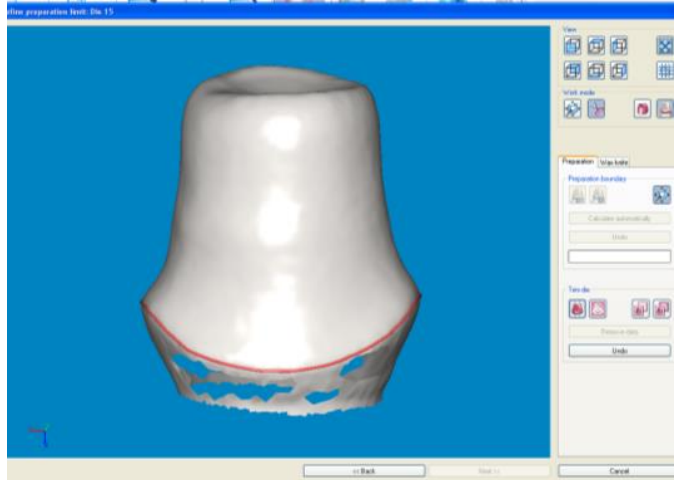

Figura 38: Delimitação bordos - dente14

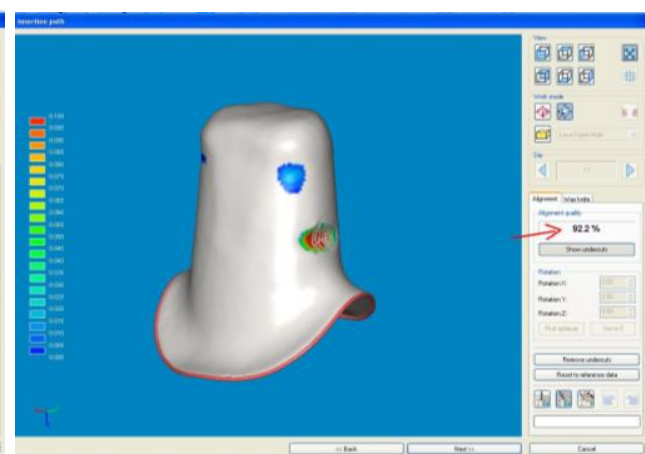

Figura 40: Detecção das retenções do preparo - dente 14

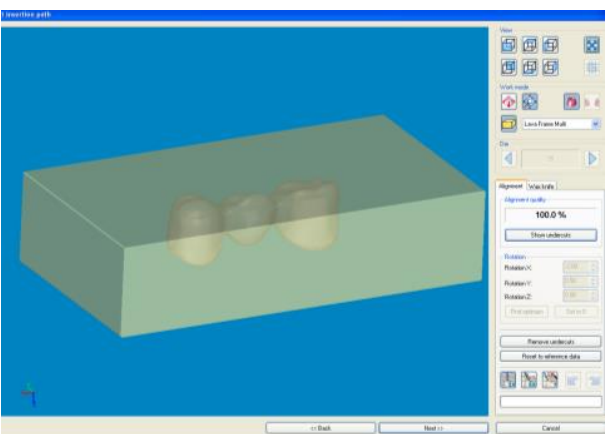

Figura 42: Simulação da estrutura com enceramento no bloco para usinagem

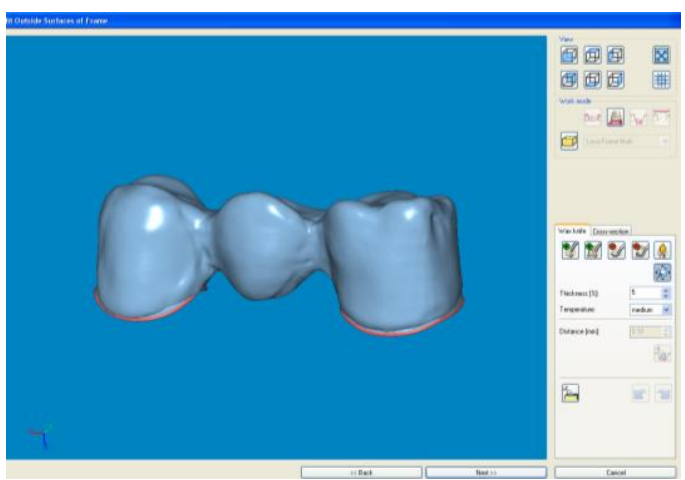

Figura 44: Visão 3D da infraestrutura não acabada 


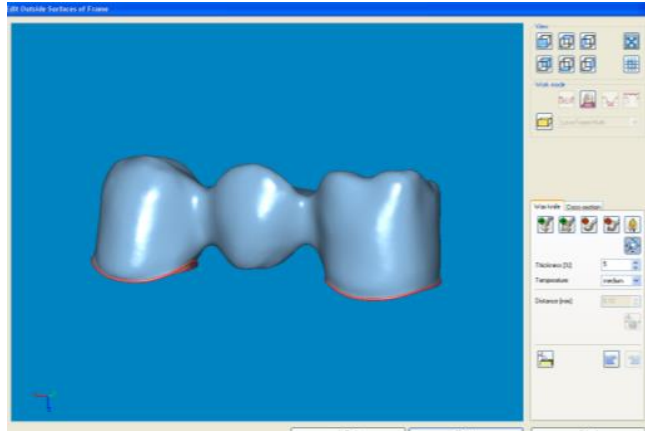

Figura45: Visão 3D da infraestrutura refinada

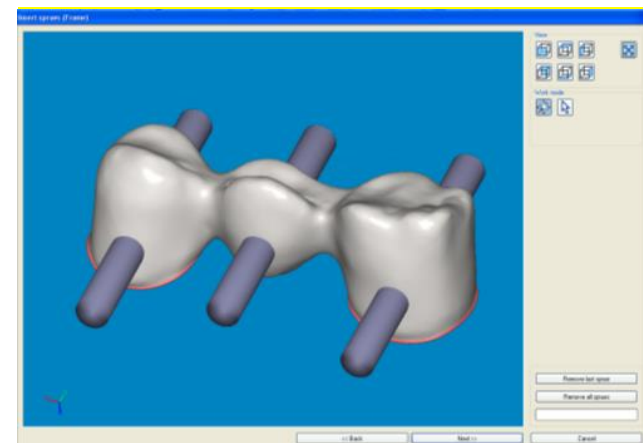

Figura 47: CAD finalizado

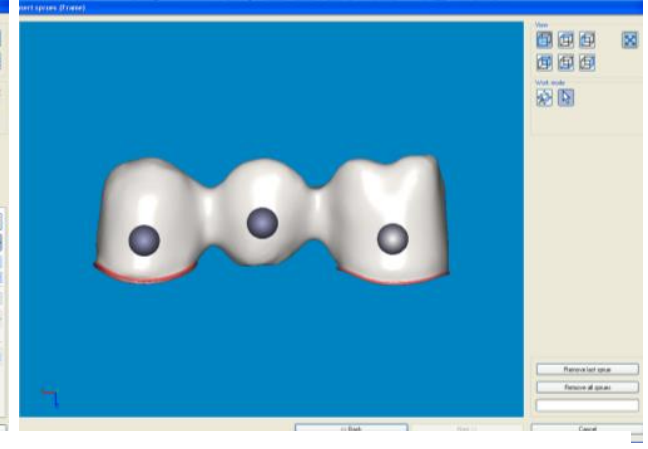

Figura 46: Inserção dos sprues

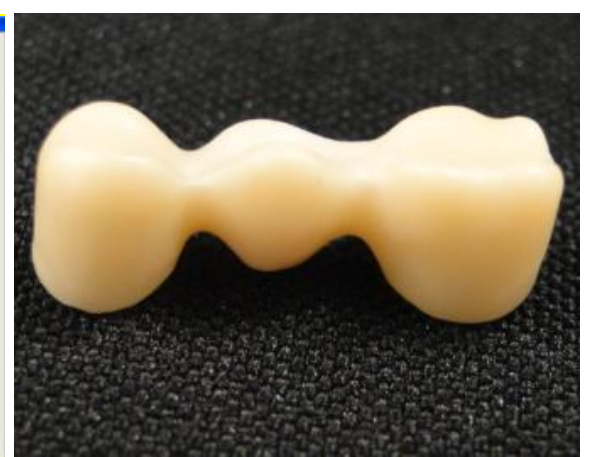

Figura 48: Infraestrutura Lava concluída

\subsection{Confecção das infraestruturas - Controle}

Sobre os pilares foi encerada a infraestrutura da prótese parcial fixa de três elementos por meio de uma matriz de silicone de adição Adsil (Coltene, Vigodent, Rio de Janeiro, Brasil) feita sobre uma infraestrutura de CoCr (Grupo TiNeo) (Figuras 49 e 50) com a finalidade de padronizar a forma da infraestrutura para todos os grupos.

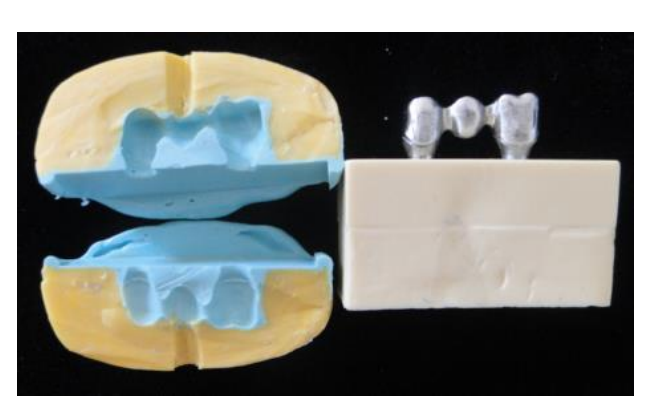

Figura 49: Matriz bipartida em silicone de adição

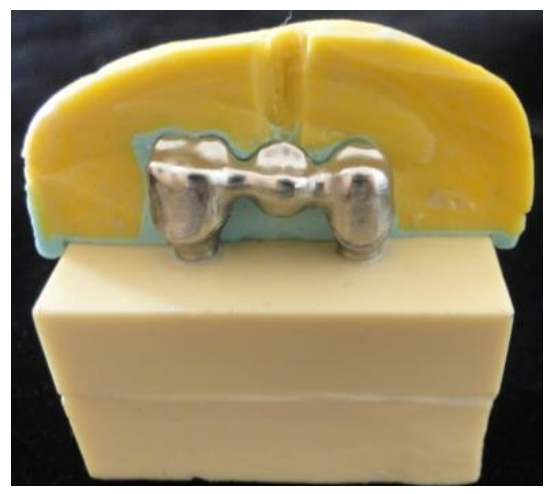

Figura 50: Hemi-matriz posicionada justaposta à infraestrutura 
Foi gotejada cera plastificada no interior da matriz de silicone e esta foi posicionada sobre os pilares, isolados com vaselina, reproduzindo assim a forma da infraestrutura TiNeo (Figura 51). Não foi utilizado espaçador para definir o espaço para cimentação. Sobre a superfície dos enceramentos foram posicionados sprues de cera de $2 \mathrm{~mm}$ de diâmetro (Ceras Babinete, Maringá, Paraná, Brasil), com angulação de aproximadamente $45^{\circ}$ (Figura 52).

Os padrões de cera assim preparados foram pulverizados com spray redutor de tensão de superfície (Kota, São Paulo, Brasil) e deixados secar em temperatura ambiente (Figura 53).

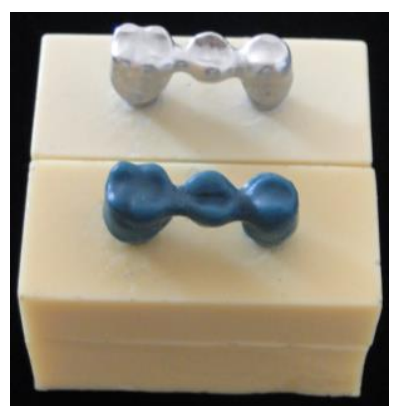

Figura 51: Duplicação da infraestrutura TiNeo em cera

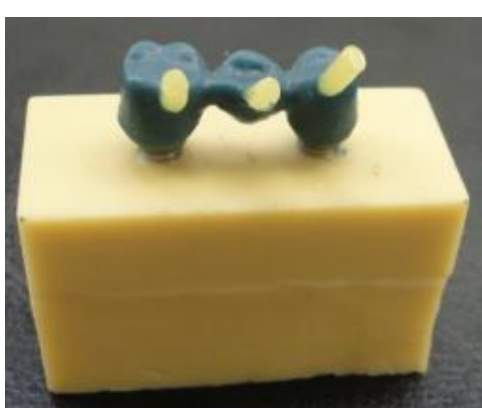

Figura 52: Posicionamento dos sprues

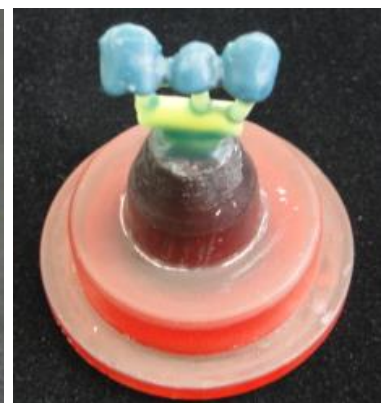

Figura 53: Enceramento após aplicação de spray redutor de tensão de superfície

As estruturas foram fundidas por chama em centrífuga (EDG, São Carlos, São Paulo, Brasil) em liga NiCr - Fit Cast SB (Talmax, Curitiba, Paraná, Brasil). Os procedimentos de fundição seguiram os mesmos passos da fundição dos pilares do grupo controle.

Após o processo de fundição e adequado resfriamento do revestimento, as estruturas foram desincluídas e assentadas sobre os pilares para avaliação da adaptação (Figura 54). 


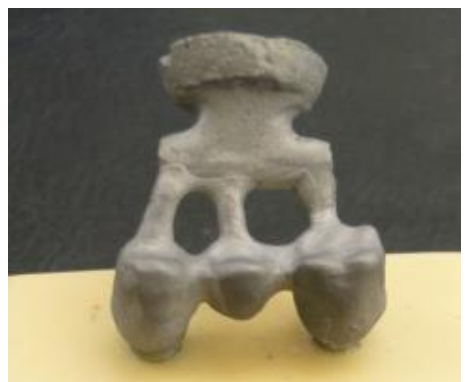

Figura 54: Infraestrutura assentada sobre os pilares após desinclusão

Para avaliação de possíveis áreas que impediriam o assentamento da infraestrutura foi pincelado carbono líquido sobre os pilares (Figuras 55 e 56).

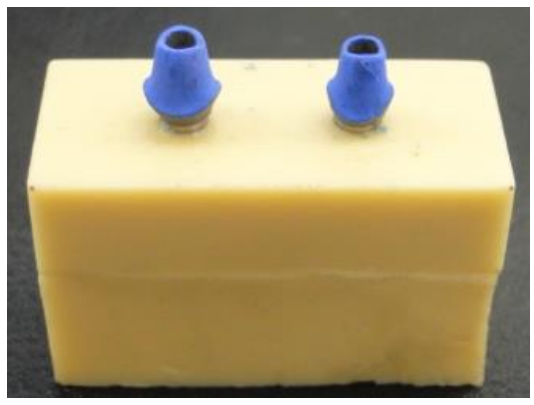

Figura 55: Carbono líquido pincelado sobre os pilares

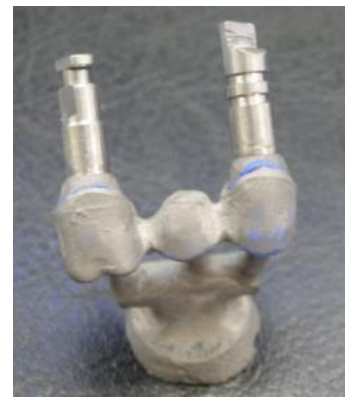

Figura 56: Marcação das áreas que impedem o assentamento da infraestrutura

Nas áreas onde houve exposição do metal após marcação com carbono líquido foi realizado cuidadoso desgaste com brocas de tungstênio em alta rotação sob refrigeração constante. Foi realizado o corte dos sprues com disco Ninja (Talmax, Curitiba, Paraná, Brasil) Em seguida foi realizado o seccionamento da infraestrutura com disco de carborundum para posterior soldagem (Figura 57 e 58).

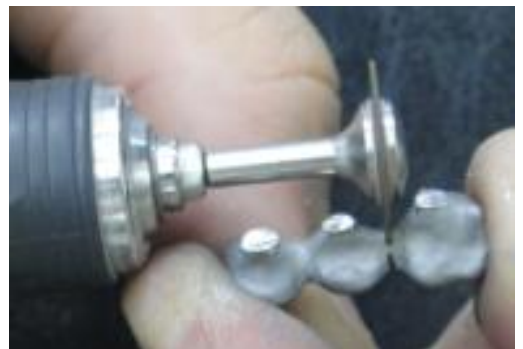

Figura 57: Seccionamento da infraestrutura

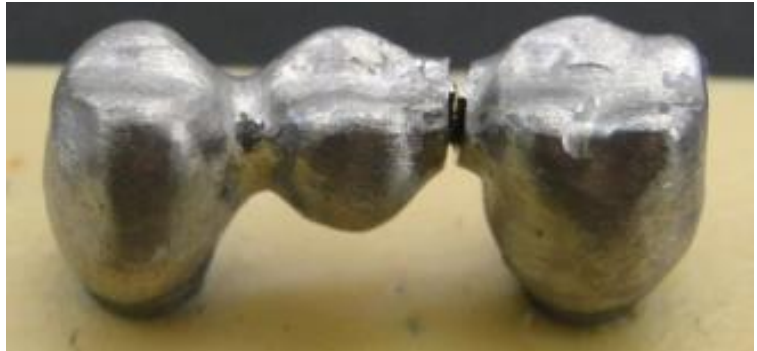

Figura 58: Infraestrutura seccionada 
Após o seccionamento da peça foi realizado o acabamento e polimento das infraestruturas com pedras de óxido de alumínio (Figura 59) para posteriormente realizar a solda a laser (Figura 60). Para este procedimento as infraestruturas foram colocadas sobre os pilares e as interfaces seccionadas justapostas para melhor resultado durante a soldagem.

As infraestruturas foram levadas ao interior da máquina de soldagem a laser Sisma LM-500 (YAG Laser Welder, Jundiaí, São Paulo, Brasil) e foi realizada a soldagem, com a máquina programada a $550 \mathrm{~V}$, pulso de $1,2 \mathrm{~m} / \mathrm{s}, 6,0$ Hertz e $0,3 \mathrm{~mm}$ de diâmetro do feixe de laser. Foi realizada solda por acréscimo, utilizando um fio de solda de $\mathrm{NiCr}$ de $0,4 \mathrm{~mm}-80 \%$ Ni e 20\% Cr (De Rogatis, São Paulo, São Paulo, Brasil).

Após a solda foi realizada usinagem no local da solda com ponta de óxido de alumínio de granulação média. Em seguida, foi realizado um jato de vapor para limpeza e retirada de gordura das peças.

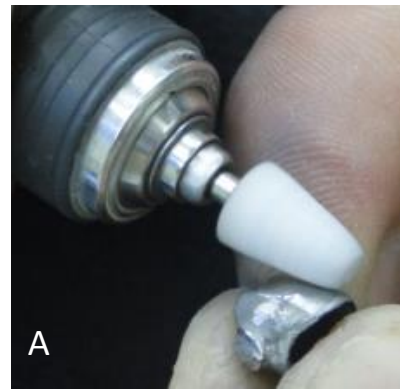

Figura 59: A e B) Usinagem da infraestrutura seccionada

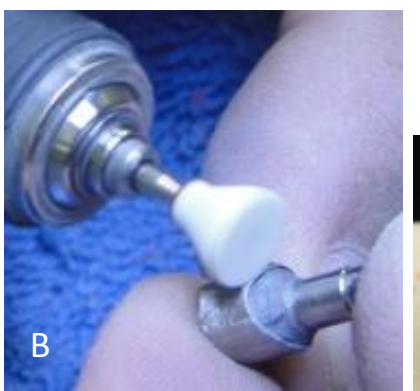

Figura 60: Infraestrutura após a solda a laser

\subsection{Cimentação provisória das infraestruturas sobre os pilares}

Cada infraestrutura da prótese fixa foi cimentada com cimento temporário (RelyX Temp NE - 3M ESPE, Sumaré, São Paulo, Brasil) sobre os pilares do seu respectivo modelo para avaliação da desadaptação prévia à prensagem da porcelana de cobertura (Figura 61). O

cimento foi colocado dentro das coroas, que foram posicionadas sobre os pilares no paralelômetro sob peso de 439 g, removido o excesso de cimento nas margens e aguardado o tempo de 2 minutos. 


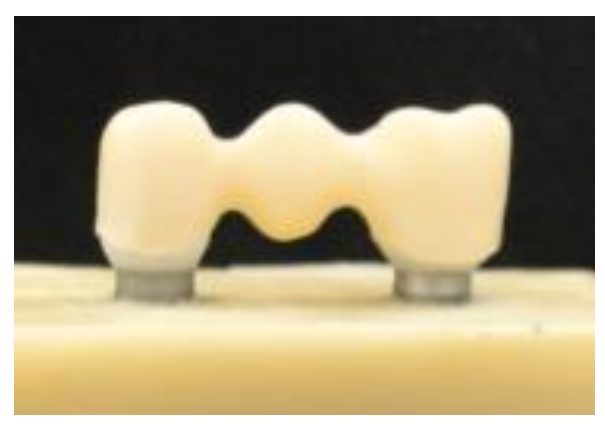

Figura 61: Infraestrutura cimentada sobre os pilares

\subsection{Prensagem da porcelana}

Após a confecção das infraestruturas foi prensada a porcelana. Para uniformizar a anatomia final de todos os corpos-de-prova, o revestimento estético foi infiltrado por meio da prensagem de pastilhas de porcelana (Ivoclar Vivadent, Barueri, São Paulo, Brasil), seguindo estritamente as recomendações do fabricante.

\subsubsection{Aplicação do Opaco (Grupos TiNeo e Controle)}

Foi realizado o tratamento prévio à aplicação do opaco. Inicialmente, foi realizada a degaseificação por 3 minutos a $600^{\circ} \mathrm{C}$ no Forno Ceramco (Dentsply Int., EUA) e o jateamento com partículas de óxido de alumínio - $320 \mu \mathrm{m}$ - pressão 60 lbs (Macro Cab Danville Engineering, Inc., EUA) até uniformizar a superfície externa das peças para com isso remover resíduos de sujeira e gordura, melhorar o imbricamento posterior da porcelana e eliminar a camada de óxido.

Em seguida foi aplicado vapor de água para remover o pó do jateamento e realizada a secagem das peças com jato de ar. Após a secagem o opaco foi misturado com líquido, formando uma pasta (Figura 62), que foi aplicada em camada uniforme e fina (Figura 63). Levou-se ao forno (Ivoclar, Programat EP 5000 - Barueri, São Paulo, Brasil) por aproximadamente 14 minutos com temperatura variando entre $450^{\circ} \mathrm{C}$ e $936^{\circ} \mathrm{C}$, sob vácuo. Foi aplicada uma segunda camada de opaco (Figura 64), usando o mesmo ciclo térmico. 


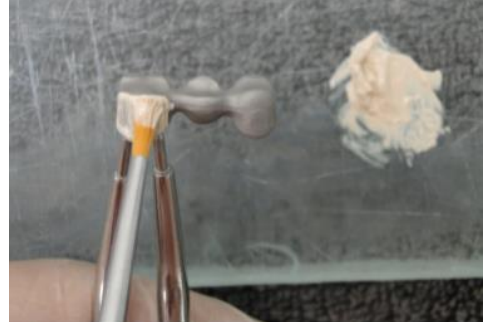

Figura 62: Aplicação do Opaco

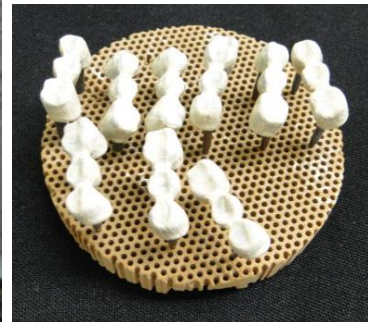

Figura 63: Infraestruturas com $1^{a}$ camada de opaco

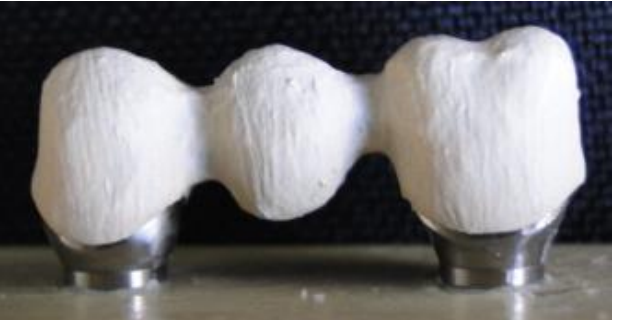

Figura 64: Infraestrutura após $2^{\mathrm{a}}$ camada de opaco

\subsubsection{Aplicação do ZirLiner (Grupos ZirNeo e Lava)}

Anteriormente à aplicação do ZirLiner, as infraestruturas em zircônia (Figura 65) foram devidamente tratadas. Inicialmente, foi realizado jateamento com partículas de óxido de alumíno $(320 \mu \mathrm{m})$ - (Asfer, São Caetano do Sul, São Paulo, Brasil) com o Macro Cab (Danville Engineering, Inc, EUA). O objetivo foi a remoção de resíduos e gordura, além de melhorar o imbricamento posterior da porcelana, semelhante ao que foi feito com os grupos metálicos. Em seguida foi aplicado vapor de água para remover o pó do jateamento e realizada a secagem das peças com jato de ar.

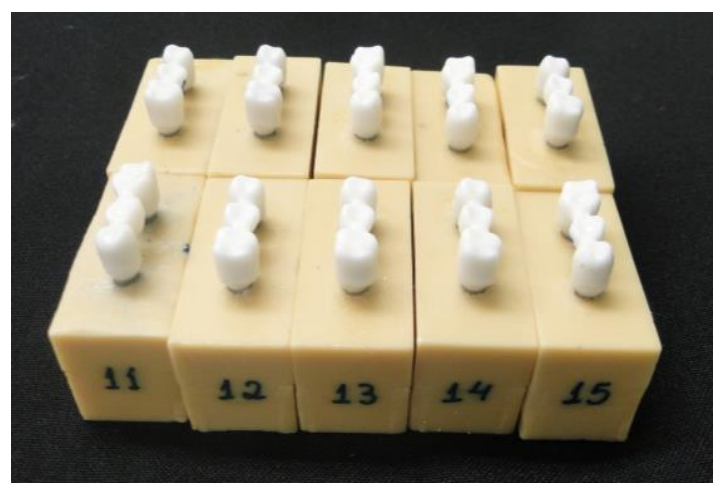

Figura 65: Modelos com as infraestruturas em zircônia em posição

Foi aplicada fina camada do ZirLiner com consistência pastosa (Figura 66). Em seguida, as estruturas foram levadas ao forno de cerâmica Ivoclar (Programat EP 5000 Barueri, São Paulo, Brasil) sobre um refratário à temperatura de $450-970^{\circ} \mathrm{C}$, por aproximadamente 15 minutos (Figura 67). 

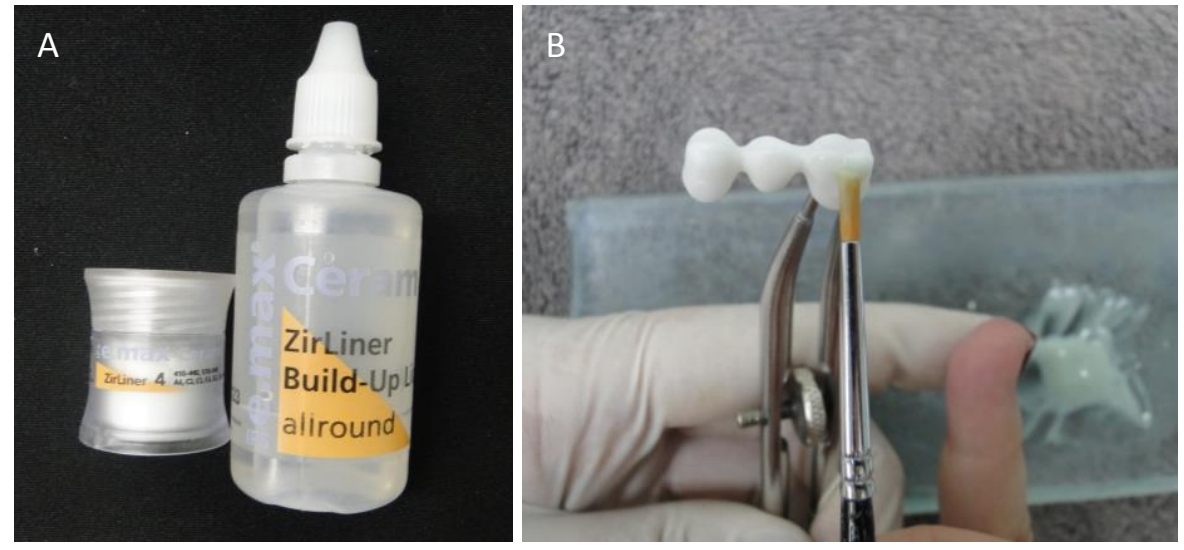

Figura 66: A) ZirLiner (pó e líquido);

B) Aplicação do ZirLiner
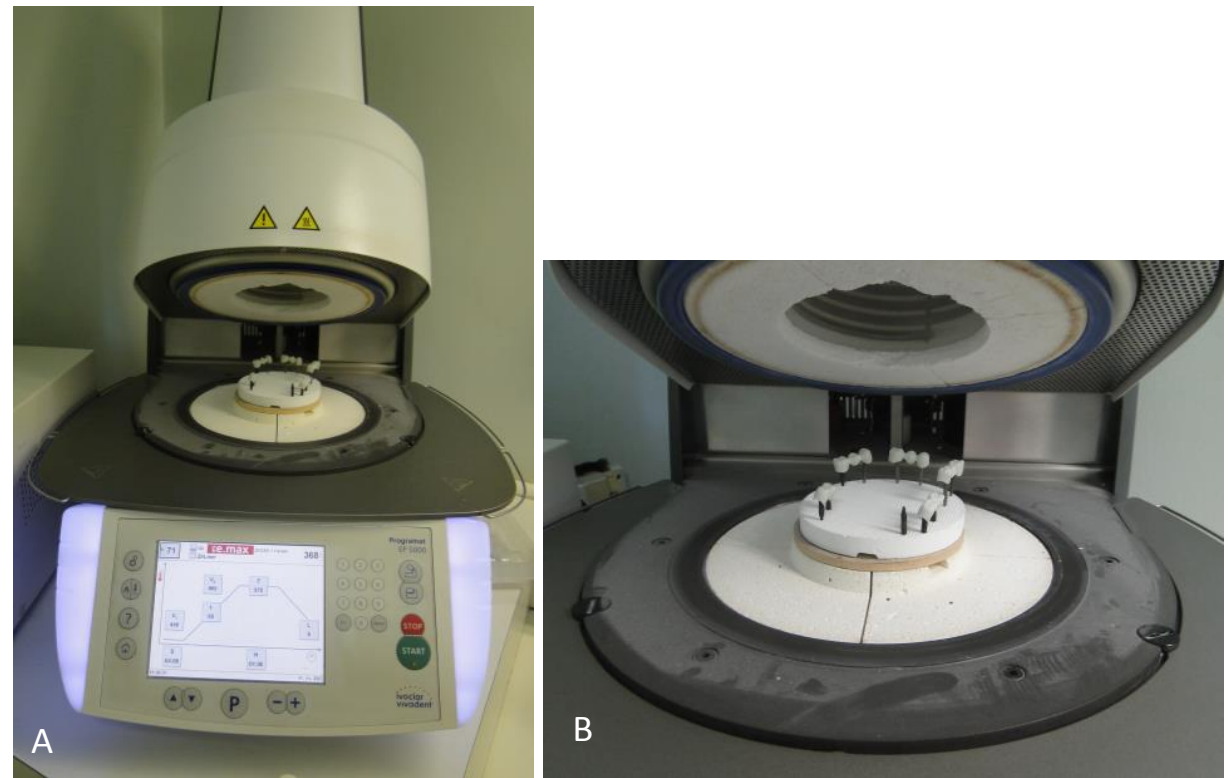

Figura 67: A e B) Estruturas no forno de cerâmica

\subsubsection{Recobrimento estético das infraestruturas}

Após a aplicação do opaco nas infraestruturas metálicas e do Zirliner nas infraestruturas em zircônia, foi realizado o enceramento do recobrimento estético das coroas (Figura 68) e em seguida confeccionada uma matriz de silicone (Figura 69) para reprodutibilidade da forma, contorno e tamanho para todos os grupos. 


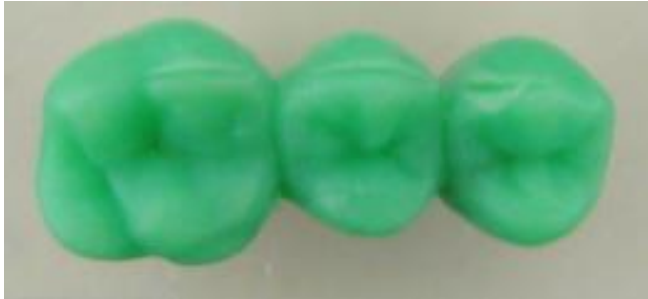

Figura 68: Enceramento das coroas

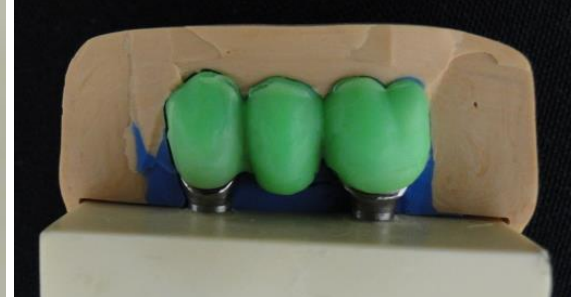

Figura 69: Matriz de silicone

A infraestrutura foi adaptada à base anel; o revestimento Gilvest HS (BK Giulini, Alemanha) foi manipulado a vácuo na proporção de $8 \mathrm{~mL}$ de água para $18 \mathrm{~mL}$ de líquido para cada 90 g de pó (Figura 70).
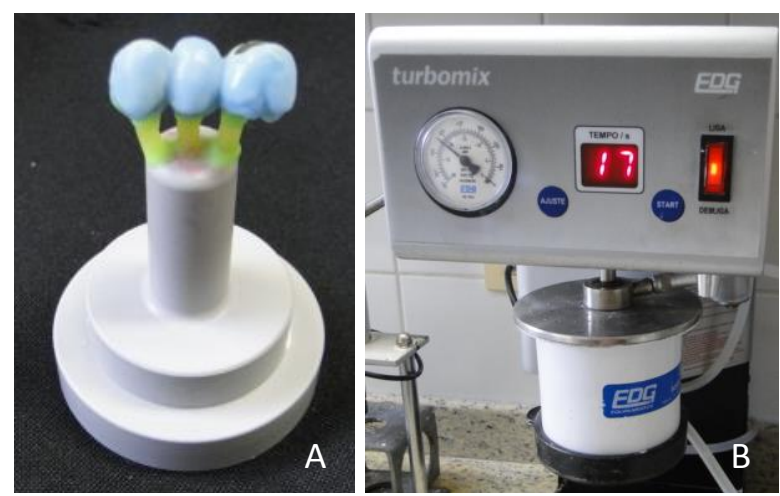

Figura 70: A): Infraestrutura posicionada na base do anel;

B) Espatulação do revestimento

O revestimento foi vertido sob vibração constante sobre o enceramento da infraestrutura (Figura 71); dado o tempo de presa inicial de 30 minutos, foi levado ao forno (Vulcan 3 -130, Dentsply Ceramco, Petrópolis, Rio de Janeiro, Brasil) numa temperatura de $850^{\circ} \mathrm{C}$ por 30 minutos, para queima da cera (Figura 72). 


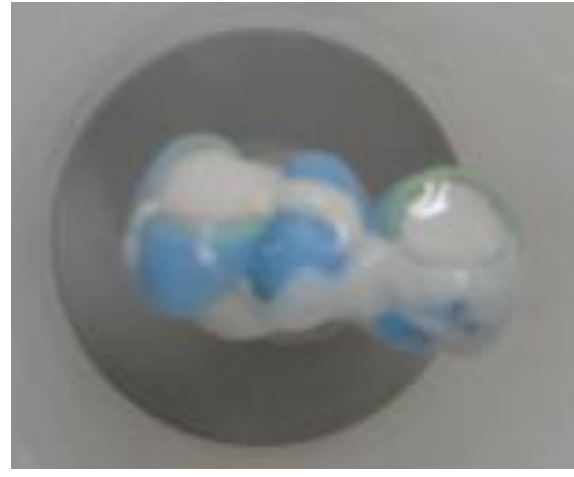

Figura 71: Revestimento vertido sobre o enceramento da infraestrutura

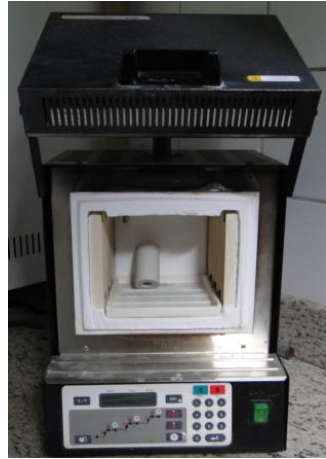

Figura 72: Anel no forno

Em seguida, pastilhas de porcelana InLine POM 1 S e 1 XS (Ivoclar Vivadent, Barueri, São Paulo, Brasil) foram colocadas no anel, o êmbolo foi posicionado, e o conjunto foi levado ao forno Ivoclar para prensagem da porcelana sobre o metal (Figura 73). Da mesma forma, pastilhas ZirPress, cerâmica vítrea de fluorapatita, para as infraestruturas em zircônia.
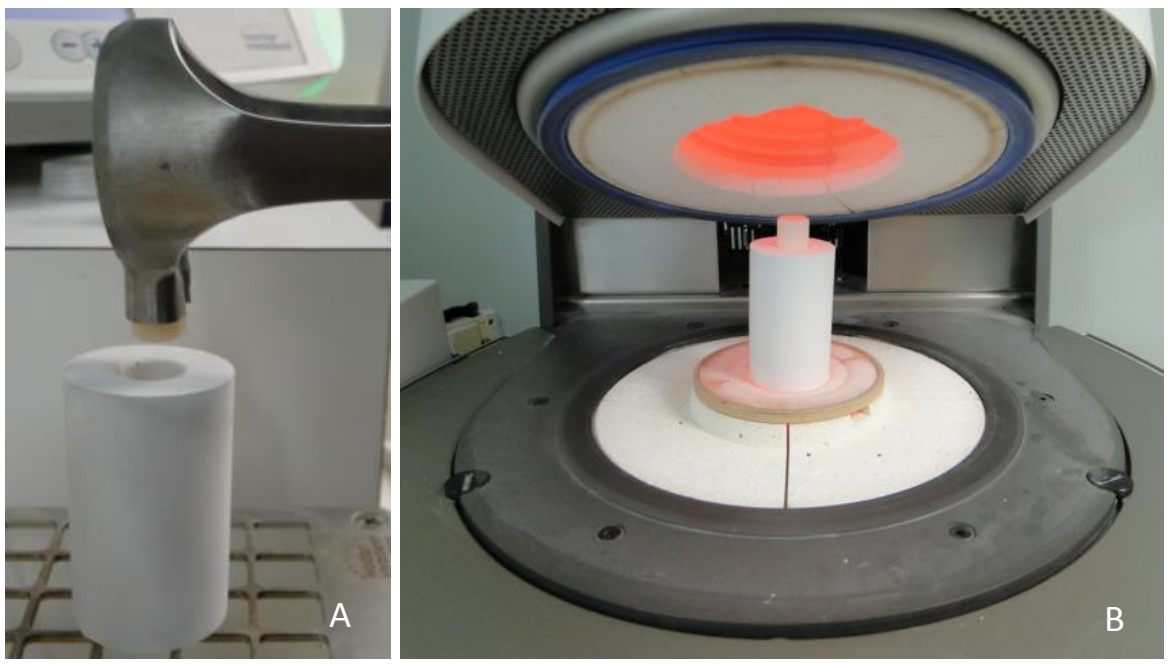

Figuras 73: A e B) Colocação das pastilhas de porcelana no anel e levado ao forno

O tempo para prensagem no forno foi de aproximadamente 30 minutos com temperatura inicial de $700^{\circ} \mathrm{C}$ até $927^{\circ} \mathrm{C}$, com vácuo total. Deixou-se esfriar por 40 minutos. Cortou-se o anel (Figura 74) e as peças foram desincluídas com jateamento de óxido de 
alumínio de $320 \mu \mathrm{m}^{1}$ (São Caetano do Sul, São Paulo, Brasil) - (Macro Cab - Danville Engineering, Inc, EUA) tomando cuidado com os bordos (Figura 75). A Figura 76 demonstra a prótese limpa após a desinclusão.
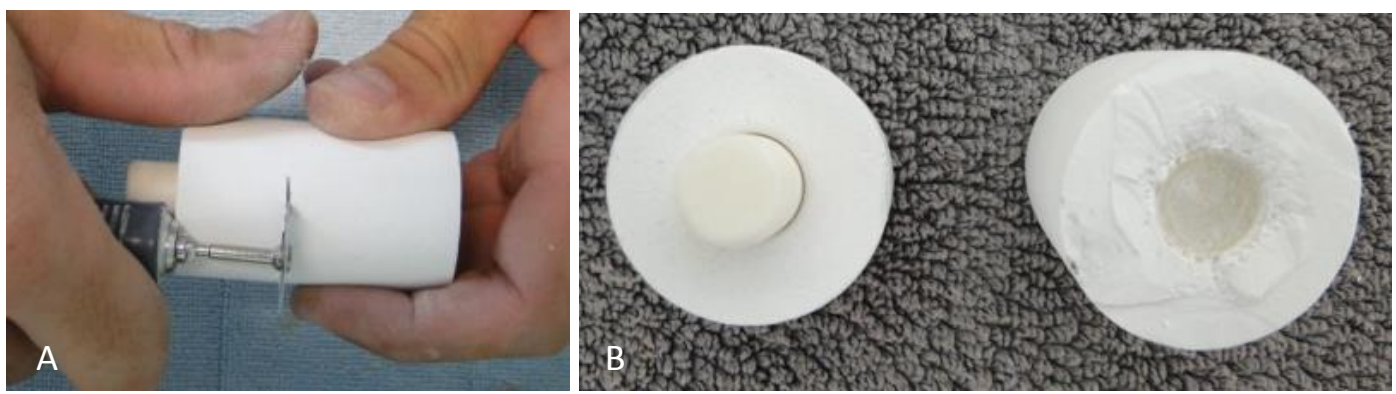

Figura 74: A) e B): Corte do anel

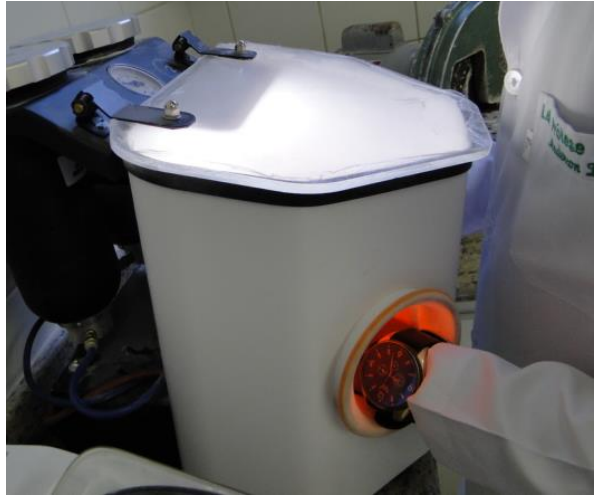

Figura 75: Desinclusão da prótese jateamento com óxido de alumínio

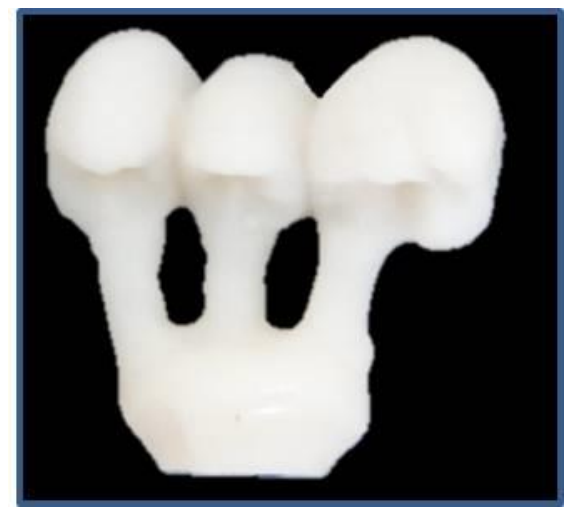

Figura 76: Prótese limpa após o jateamento

Após a desinclusão foram removidas as irregularidades com ponta de óxido de alumínio (Duracool) (Figura 77), realizado o refinamento das ameias interproximais com disco diamantado sinterizado (Vortex, São Paulo, São Paulo, Brasil) (Figura 78), realizado o acabamento e polimento das próteses parciais fixas (Figura 79).

\footnotetext{
${ }^{1}$ Procedimento seguido pelo laboratório que executou os procedimentos de prensagem da porcelana
} 


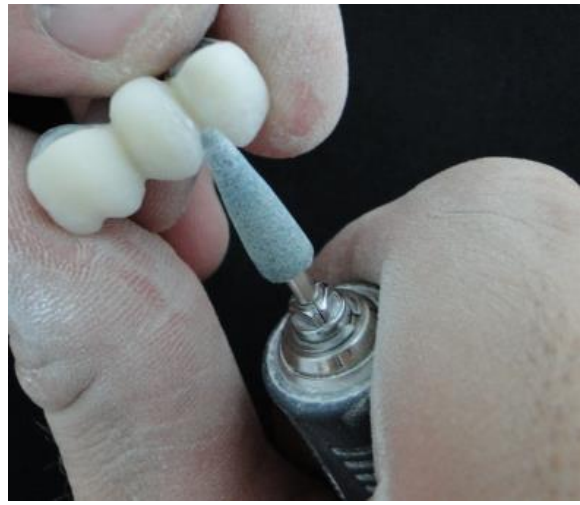

Figura 77: Remoção arestas e irregularidades

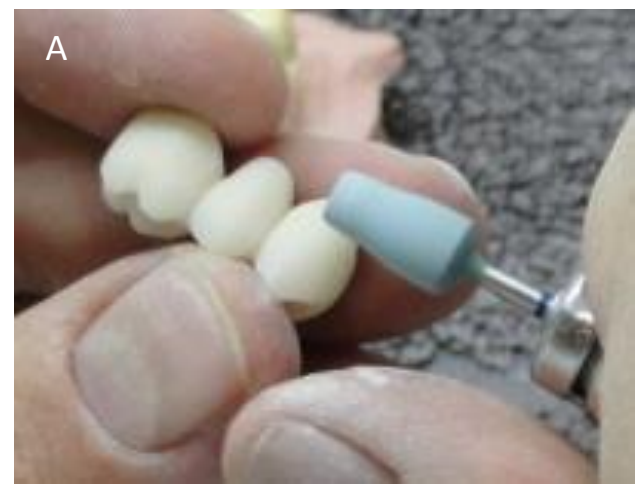

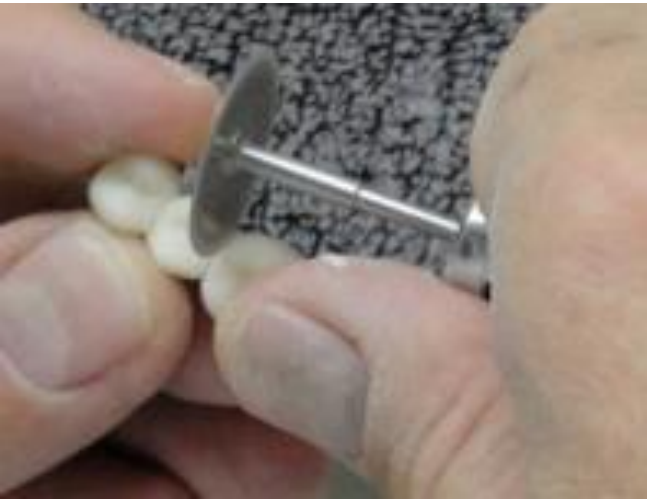

Figura 78: Refinamento das ameias interproximais

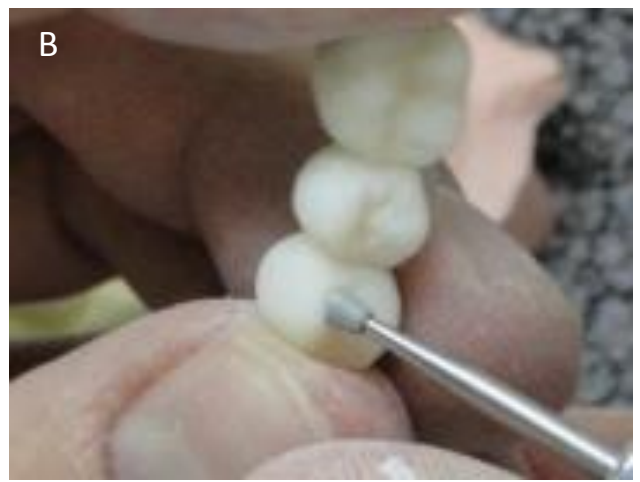

Figura 79: A) e B): Acabamento da prótese parcial fixa

Após o polimento foi aplicada camada fina e uniforme do glaze IPS InLine (Ivoclar Vivadent, Barueri, São Paulo, Brasil) (Figura 80), e as próteses foram levadas ao forno Ivoclar com ciclo pré-definido pelo fabricante por aproximadamente 15 minutos, iniciando com temperatura de $450^{\circ} \mathrm{C}$ até $800^{\circ} \mathrm{C}$. A Figura 81 ilustra a prótese concluída.

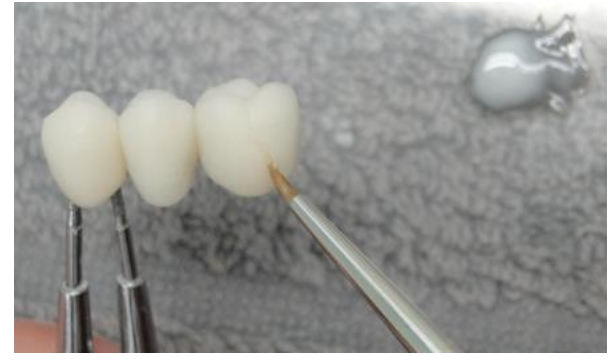

Figura 80: Aplicação do glaze

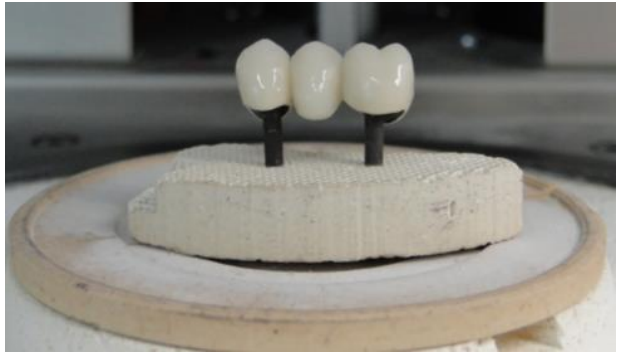

Figura 81: Prótese Parcial Fixa concluída 


\subsection{Tratamento interno da superfície, prévio à cimentação}

Antes da cimentação foi realizado o tratamento da superfície no interior da estrutura de zircônia com Rocatec (3M ESPE, St. Paul, MN, EUA) (pó de óxido de alumínio coberto por sílica) com partículas de $110 \mu \mathrm{m}$, seguindo as recomendações do fabricante para melhor união aos pilares. O jateamento com Rocatec (3M) ocorreu sob pressão de 2,8 bar para garantir nível suficientemente elevado de energia para criação do triboplasma. A superfície ficou à distância de $1 \mathrm{~cm}$ do jato e perpendicular a esse por 15 segundos.

Posteriormente as estruturas foram limpas com álcool isopropílico (PA-ACS Dinâmica Química Contemporânea LTDA), aplicado o Ceramic Primer RelyX (3M ESPE), jato de ar suave para remover o excesso do primer e aguardado cinco minutos. Em seguida foi manipulado o cimento RelyX U200 (3M ESPE) (Figura 82) em duas porções, colocado dentro das coroas as quais foram posicionadas sobre os pilares no paralelômetro sob peso de $439 \mathrm{~g}$ (Figura 83), removido o excesso de cimento nas margens e aguardado o tempo de 10 minutos.

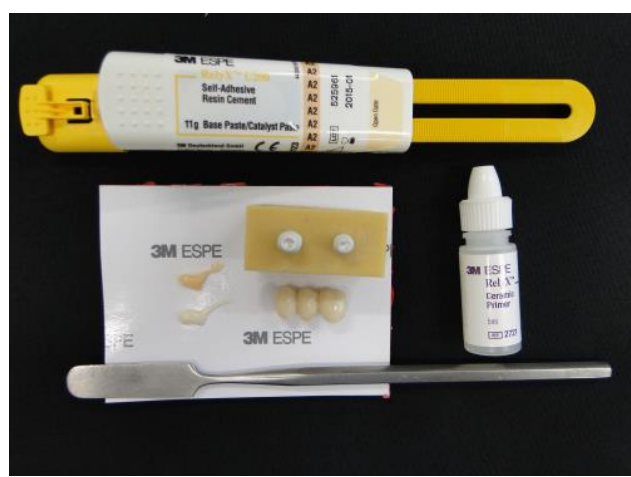

Figura 82: Cimentação com RelyX U200 (3M ESPE)
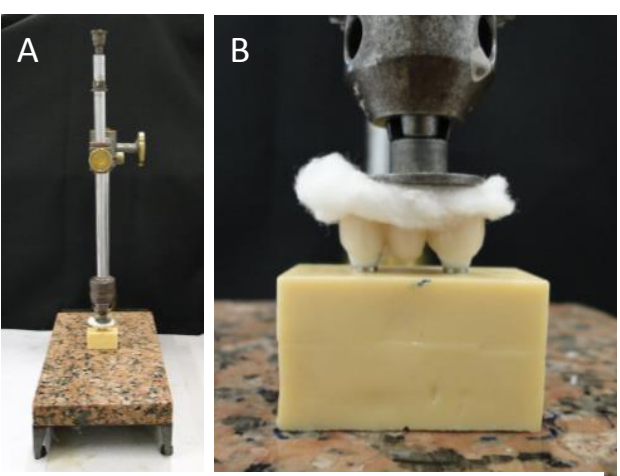

Figura 83: A) e B) Infraestrutura posicionada no paralelômetro

Após a cimentação, as próteses foram colocadas em estufa sob temperatura de $37^{\circ} \mathrm{C}$ e aguardou-se 24 horas. 


\subsection{Confecção dos antagonistas}

Foi realizado o enceramento e prensagem da porcelana dos dentes antagonistas seguindo os mesmos passos dos procedimentos realizados para o recobrimento estético da prótese parcial fixa. Subsequentemente, o ajuste oclusal das próteses fixas foi realizado de acordo com seu antagonista em porcelana (Figuras 84 e 85 ) até que a oclusão estivesse balanceada.

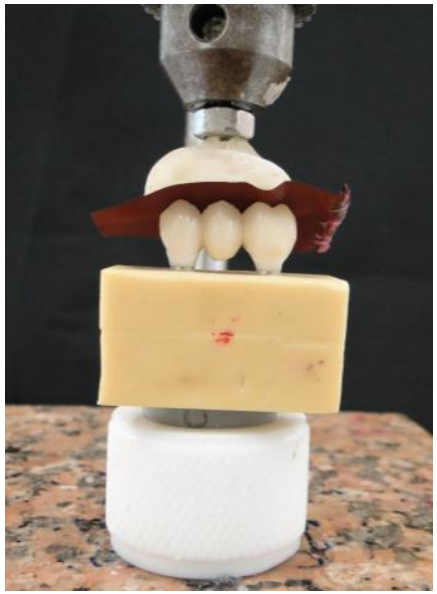

Figura 84: Ajuste oclusal

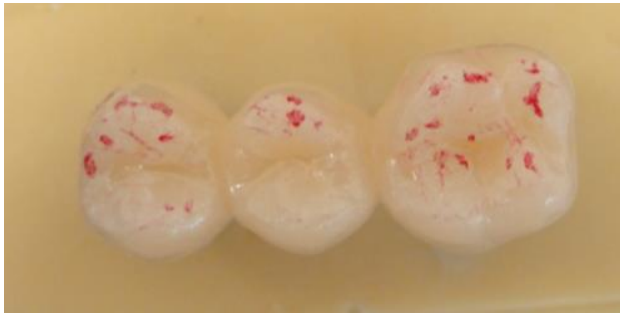

Figura 85: Oclusão balanceada

\subsection{Avaliação da desadaptação marginal pilares/implantes}

Os pilares foram parafusados utilizando torquímetro (TQ 680 Instrutherm Instrumentos de medição Ltda., São Paulo, Brasil), com precisão de 0,1 Ncm, fixado em dispositivo desenvolvido no Departamento de Materiais Dentários e Prótese da Faculdade de Odontologia de Ribeirão Preto - USP. Foram utilizados parafusos de pilar Neotorque (Neodent Curitiba, PR, Brasil).

A cada pilar foi aplicado o torque de fixação de $32 \mathrm{Ncm}$, conforme indicação do fabricante. Para utilização, o torquímetro ficou posicionado na haste superior, enquanto o conjunto ficou localizado na base, perfeitamente assentado, com o objetivo de padronizar a aplicação de torque em todas as amostras (Figura 86). Foi aguardado um tempo de 10 minutos e dado o torque de confirmação. Em seguida, as peças foram levadas à lupa estereoscópica S8APO (Leica, Leica Microsystems, Hurbrugg, Suíça) e foi avaliada a adaptação marginal 
dos pilares aos implantes - Figura 87. A captura das imagens foi realizada com câmera digital DFC 250 (Leica, Leica Microsystems, Hurbrugg, Suíça) com aumento de 80X e foi medido o espaço entre o pilar e o implante, no centro e um milímetro para cada lado das faces vestibular, lingual, mesial e distal das peças, totalizando 12 medidas por pilar; das três medidas obtidas, a média aritmética representou o desajuste observado em cada face do pilar.

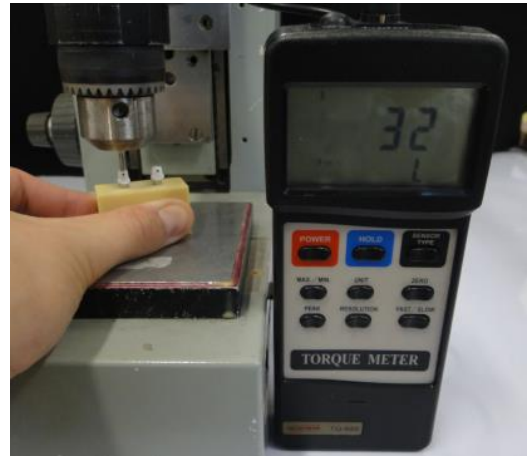

Figura 86: Aplicação do torque aos pilares

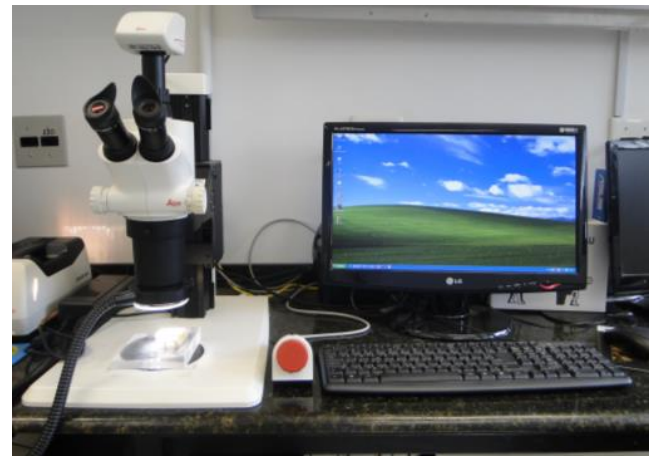

Figura 87: Lupa estereoscópica Leica

Importante salientar que no sistema Neodent o pilar foi fresado todo em zircônia, enquanto no sistema Lava o pilar de zircônia foi cimentado sobre um link metálico, correspondente à base metálica do UCLA (Neodent), como preconizado pelo sistema (Figura 88). Portanto, a zircônia no sistema Lava não se adapta diretamente ao implante. Nesse caso, a adaptação pilar/implante foi, na realidade, medida entre o pilar pré-fabricado e o implante.

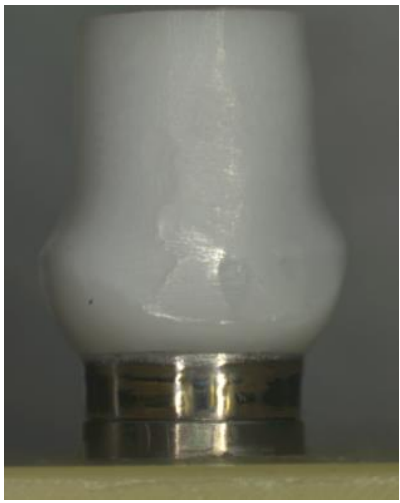

Figura 88: Pilar de zircônia (Sistema Lava 3M) 


\subsection{Avaliação da desadaptação marginal infraestruturas/pilares antes da ciclagem}

A desadaptação infraestrutura/pilar foi avaliada antes e após o recobrimento de porcelana e ciclagem pelo microtomógrafo computadorizado (MicroCT SKYSCAN 1176, Aartselaar, Bélgica) - Figura 89, com o qual foi possível avaliar tanto a desadaptação interna quanto externa.

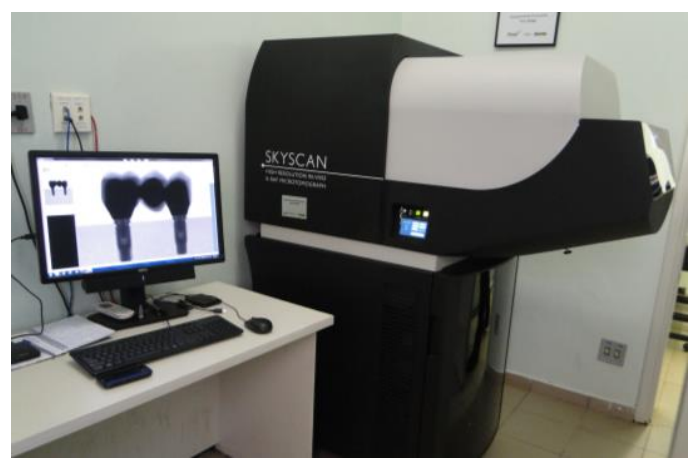

Figura 89: Microtomógrafo SKYSCAN 1176

As infraestruturas foram escaneadas individualmente pelo sistema microCT (Figura 90) acoplado a uma câmera de 8,59 mega pixels (Skyscan, Aartselaar, Bélgica). Os parâmetros do escaneamento foram: tensão de aceleração: $90 \mathrm{kV}$, corrente de $272 \mathrm{~mA}$, tempo de exposição de $81 \mathrm{~ms}$ por imagem, filtro $\mathrm{Al}+\mathrm{Cu}$, passo de rotação de $1^{\circ}$ ( $360^{\circ}$ de rotação), resolução de $18 \mu \mathrm{m}$ e frame 3 . O filtro utilizado durante o escaneamento foi de $0,1 \mathrm{~mm} \mathrm{Cu}$.

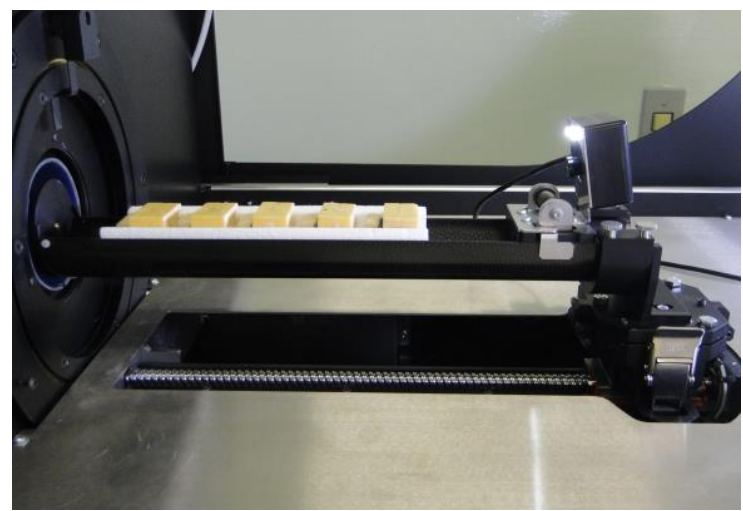

Figura 90: Próteses posicionadas para escaneamento 
As imagens adquiridas pelo MicroCT das infraestruturas antes da prensagem da porcelana e após recobrimento estético e ciclagem foram formadas e reconstruídas no software NRecon (SkyScan) com os seguintes ajustes da imagem: Smoothing = 5; Ring Artifact Correction $=20$; Beam hardening Correction $(\%)=78$. Após, as imagens foram transferidas para o DataViewer e reproduzidas nos cortes sagital e coronal, permitindo que a análise de possíveis falhas e a avaliação da adaptação marginal (horizontal e vertical) e interna (axial e oclusal) pudessem ser realizadas no CTAN (versão 1.14.4, Skyscan, Kontich, Bélgica), utilizando a ferramenta de medida linear disponibilizada no software.

Foram utilizados três cortes sagitais e três coronais para cada dente (PM e M) para mensuração das desadaptações. Para a seleção da primeira imagem, todos os cortes foram visualizados e foi selecionado o melhor corte sagital e coronal por meio do qual fosse possível mensurar a desadaptação das faces vestibular e palatina ou mesial e distal e a desadaptação interna. Após a seleção desse melhor corte (M) foram selecionados outros dois cortes, a um somando $0,5 \mathrm{~mm}(\mathrm{M}+0,5)$ e do outro subtraindo $0,5 \mathrm{~mm}(\mathrm{M}-0,5)$ da localização do primeiro corte selecionado. Resultou então em doze cortes tomográficos para cada prótese/infraestrutura em que foram possíveis duas mensurações verticais, duas mensurações horizontais e quatro internas dos dois dentes (PM e M) - Figura 91.

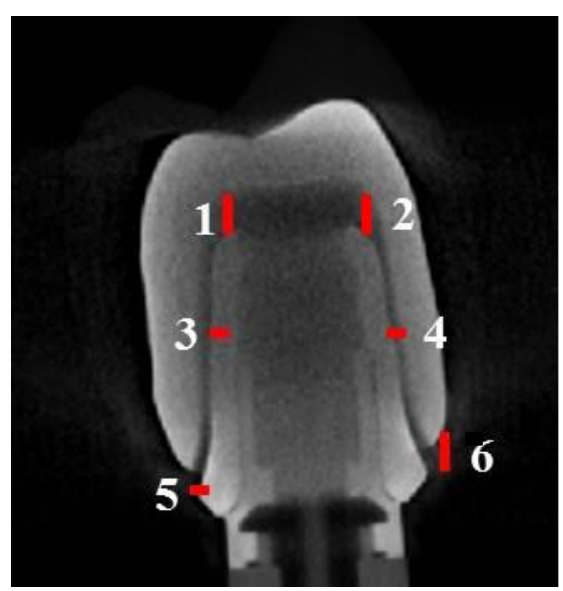

$$
\begin{aligned}
& 1 \text { e 2: Desadaptação interna oclusal } \\
& 3 \text { e 4: Desadaptação interna axial } \\
& \text { 5: Desadaptação horizontal } \\
& \text { 6: Desadaptação vertical }
\end{aligned}
$$

Figura 91: Representação dos locais de mensuração 
No desajuste vertical os pontos mais exteriores de cada dente foram marcados para medição. Para o desajuste horizontal, as medições foram efetuadas a partir do ponto mais externo da infraestrutura para o ponto mais externo do pilar. As medidas horizontais, verticais e internas, foram realizadas de cada lado da infraestrutura. Com isso, 32 medições foram realizadas para cada dente (PM e M). Portanto, considerando as 10 amostras de cada grupo, foram realizadas 320 medições para os PM e 320 para os M, sendo 120 mensurações verticais, 120 mensurações horizontais e 80 mensurações internas. As medições foram realizadas por um único examinador calibrado.

\subsection{Ensaio de ciclagem termomecânica}

Para a realização da ciclagem termomecânica foi utilizada a máquina simuladora de mastigação (BIOPDI, São Carlos, São Paulo, Brasil) - Figura 92. Para cada ciclagem seis próteses foram posicionadas simultaneamente, portanto foram necessários sete grupos de ciclagem. As próteses foram posicionadas na máquina de ensaios e foi aplicada carga de 120 N. Para a aplicação desta carga foi utilizada uma ponta que simula a oclusão antagonista em cerâmica pura.

Foram simulados $2 \times 10^{6}$ ciclos mecânicos que correspondem a dois anos de utilização da peça protética (Cibirka et al., 2001; Gratton Aquilino e Stanford, 2001; Khraisat et al., 2004), em frequência de $3 \mathrm{~Hz}$. Durante o ensaio, as próteses foram mantidas em água destilada e termocicladas com variação de temperatura entre $5^{\circ}-55^{\circ} \mathrm{C}$ (Vásquez, 2009), sendo realizados aproximadamente 4.000 ciclos térmicos. Ao final da ciclagem termomecânica foi reavaliada a adaptação marginal e interna das estruturas. 


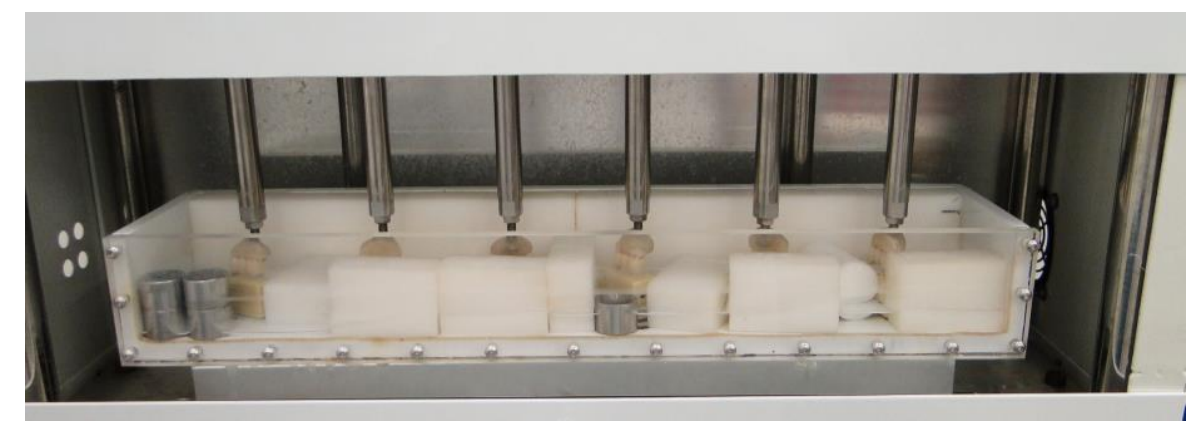

Figura 92: Máquina de ciclagem termomecânica

\subsection{Avaliação da adaptação das próteses sobre os pilares após ciclagem}

Foi realizado o escaneamento após a ciclagem das próteses com o mesmo microCT e seguindo os mesmos parâmetros inicialmente utilizados para avaliação da desadaptação infraestrutura-pilar (Figuras 93 e 94).
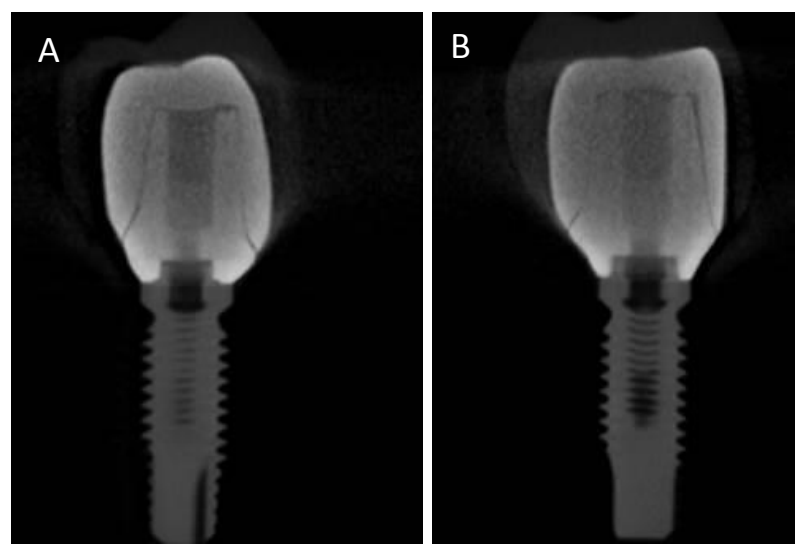

Figura 93: A) e B): Cortes tomográficos sagitais do PM e M (Grupo Ti Neo)
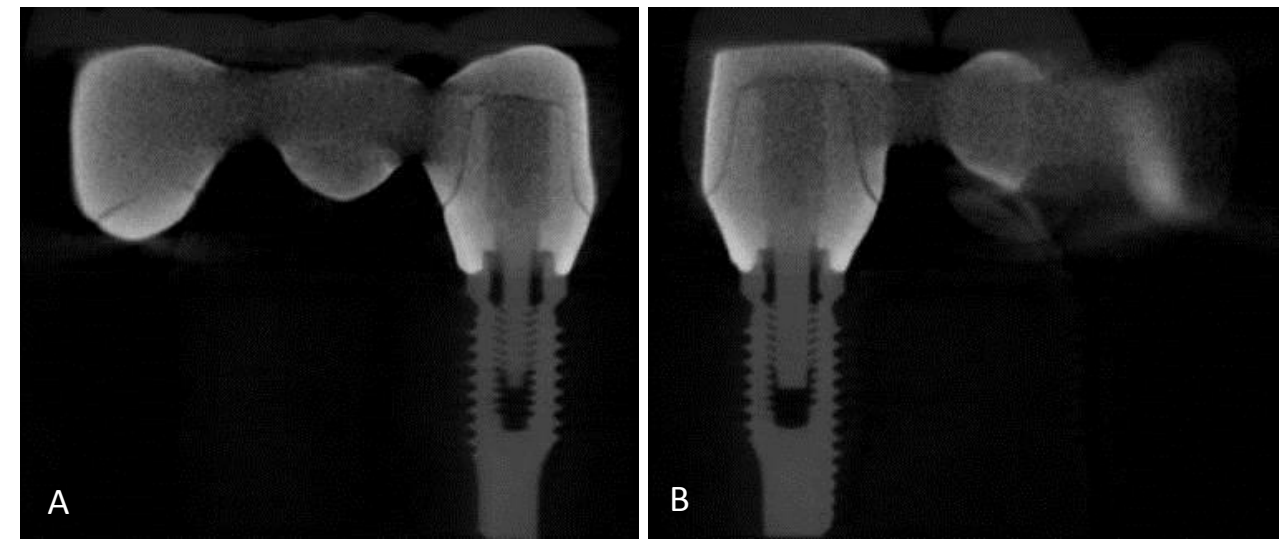

Figura 94: A) e B): Cortes tomográficos coronais do PM e M (Grupo Ti Neo) 


\subsection{Avaliação das tensões por correlação de imagens digitais (CID)}

Para a verificação das tensões geradas pelas próteses parciais fixas em torno dos implantes foi realizada a análise por correlação de imagens digitais. Foram selecionados cinco modelos de cada grupo estudado - TiNeo, ZirNeo, Lava e Controle - e um antagonista para a realização desta análise. Os modelos selecionados foram os que a porcelana de cobertura estava mais íntegra.

A técnica 3D de análise de tensões por correlação de imagens digitais foi realizada com o sistema de análise StrainMaster (LaVision Inc., Goettingen, Alemanha) formado por duas câmeras CCD (Charged-coupled device) (Imager Intense, LaVision Inc.), utilizadas para a captura das imagens do modelo em deformação, e por software específico (DaVis 8.1.2, LaVision Inc.) para análise das imagens capturadas e cálculo das tensões desenvolvidas. A resolução das câmeras é de 1039 X 1395 pixels e as imagens foram sempre calibradas por placa padrão fornecida pela empresa fabricante do sistema (LaVision Inc.)

Antes da captura das imagens, a superfície do modelo a ser analisado foi pintada por spray de tinta branca, ao fundo. Em seguida foi aplicado um spray de tinta preta, formando pequenos pontos irregulares sobre o fundo branco (Figura 95). Os pequenos pontos pretos foram então localizados pelo software durante a análise e a sua movimentação durante a aplicação da carga foi utilizada para calcular as tensões na superfície do modelo pelo sistema de correlação de imagens (Tiossi et al., 2011).

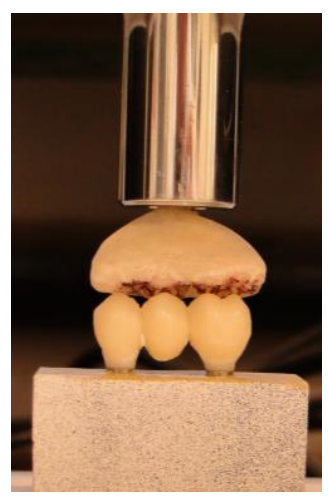

Figura 95: Modelo posicionado para CID 
Para medir as tensões geradas na superfície do modelo durante o carregamento, imagens da superfície pintada foram tiradas na frequência de $1 \mathrm{~Hz}$ (1 quadro/seg) até que a carga de $300 \mathrm{~N}$ fosse atingida. A primeira imagem foi tirada antes de qualquer carga aplicada e as imagens restantes foram comparadas à primeira para o cálculo dos deslocamentos dos pontos pretos na superfície do modelo (Figura 96).

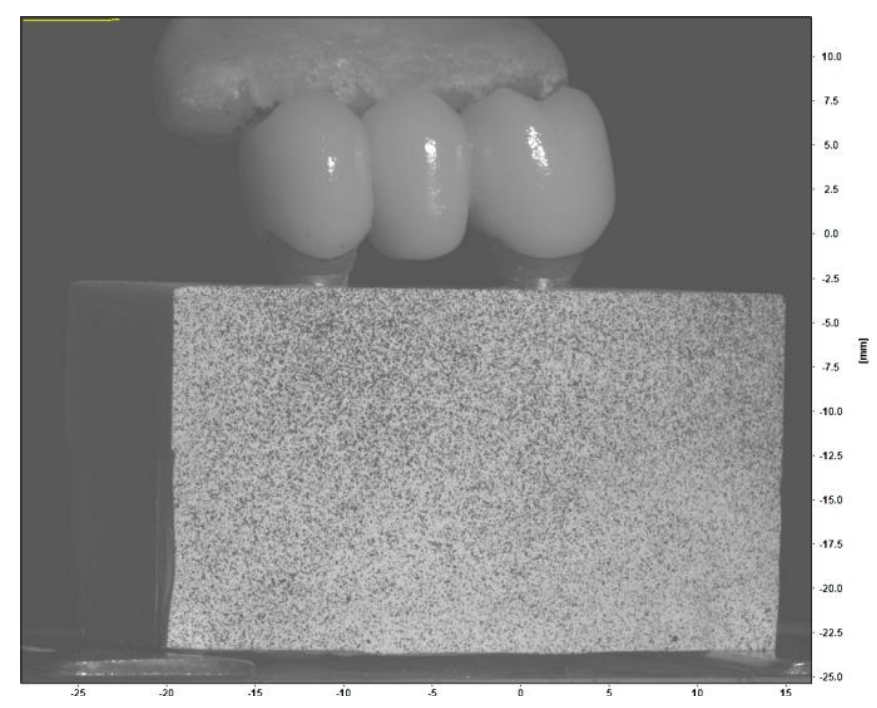

Figura 96: Imagem registrada durante a aplicação de força

As tensões superficiais foram calculadas a partir dos deslocamentos dos pontos pelo software de correlação de imagens (DaVis 8.1.2, LaVision Inc.). Para comparar as tensões geradas pelas diferentes situações clínicas, o ruído gerado em cada análise foi minimizado. Para isso, uma média dos valores de tensão em 5 pixels, com 0,5 milímetros de largura cada, foi calculada para cada situação ao longo da altura da região de interesse, totalizando uma largura do modelo de 2,5 mm. Para as tensões horizontais (Exx), a altura da região de interesse foi determinada pela linha neutra de tensões onde, até essa região, as tensões compressivas são capazes de mostrar as diferenças entre os grupos e, a partir da zona neutra de tensões, na parte inferior do modelo onde ocorrem tensões de tração. 


\subsection{Ensaio mecânico de resistência à fratura:}

Para a realização do ensaio mecânico de resistência à fratura, cada modelo foi posicionado na máquina universal de ensaios mecânicos (Instron 8872, Grove City, PA, EUA) (Figura 97), equipada com célula de carga de $5 \mathrm{KN}$ (500 kgf) com velocidade de 2 $\mathrm{mm} /$ minuto, com pré-carga de $50 \mathrm{~N}$. Foi utilizada ponta aplicadora com 2,5 mm de diâmetro, posicionada no centro da coroa do pôntico (Figura 98). A carga foi aplicada até que a falha catastrófica acontecesse na cerâmica de cobertura e/ou na infraestrutura metálica ou de zircônia.

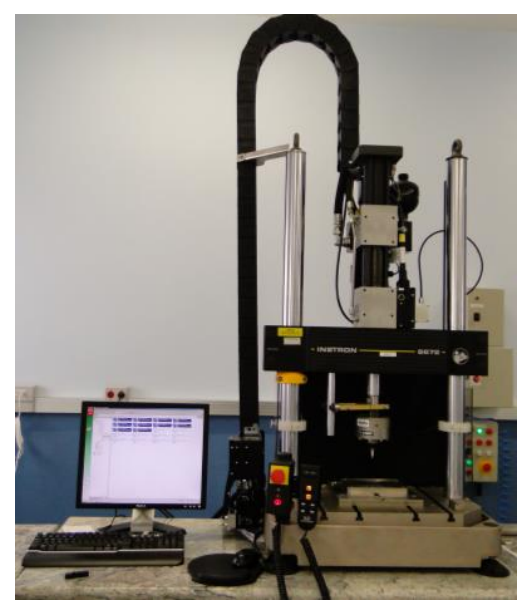

Figura 97: Máquina de ensaios universais

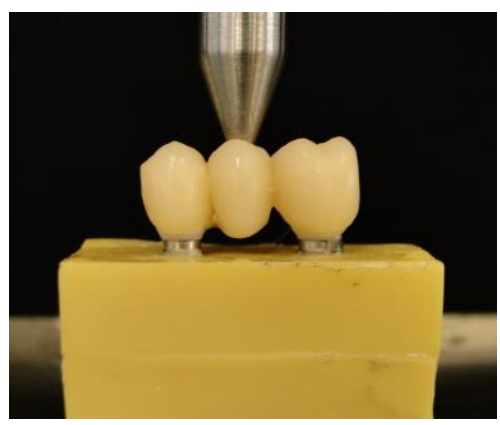

Figura 98: Modelo posicionado com ponta aplicadora de força

Após cada ensaio, as regulagens e o alinhamento da ponta aplicadora de carga foram conferidos, cada modelo posicionado e dada a pré-carga. A máquina foi regulada para aplicar e mensurar forças de compressão em ordem crescente, em Newton (N). O computador acoplado à célula de carga foi programado para registrar a resistência oferecida pelo material e a força máxima no momento da fratura, em Newton $(\mathrm{N})$. $\mathrm{O}$ desempenho mecânico de cada peça protética foi registrado no computador na forma de curvas para a posterior construção dos gráficos. As médias e desvios padrões foram calculados. 


\subsection{Avaliação pela microscopia eletrônica de varredura (MEV)}

Após o teste de resistência à fratura foi selecionada uma amostra de cada grupo, com o mesmo padrão de fratura, para análise das superfícies em MEV (EVO - MA 10, Zeiss, Suécia). Para isso, as amostras tiveram a parte coronária incluída em resina acrílica incolor e após a polimerização do material, cada amostra foi levada à cortadeira de precisão (Isomet 100, Buehler, Illinois, EUA) para secção longitudinal coincidente com o centro dos implantes. A superfície selecionada, correspondente ao centro da amostra, foi polida com lixas de carbeto de silício de granulações 400, 600, 1200, 1500 e 2000 (T223 Agua - Advance, Norton Abrasivos - Saint Gobain, Guarulhos, São Paulo, Brasil) sob irrigação abundante de água destilada. Debris foram removidos com ultrassom (Ultrasonic Cleaner 1440D, Odontobrás, São Paulo, Brasil) durante 5 minutos após o polimento. Em seguida essas amostras foram recobertas com ouro através do processo de pulverização catódica pelo período de 120 segundos a 0,1 mbar em equipamento Leica EM SCD050 - Sputter Coater (Leica Microsystems GmbH, Viena, Áustria). Em seguida, as amostras foram examinadas no MEV para realização de imagens e posterior análise.

\section{Forma de análise dos resultados}

Após realização das avaliações propostas os resultados foram submetidos à análise estatística específica, descrita nos resultados, com auxílio dos softwares SAS $^{\circledR}$ 9.1 (SAS, EUA) para avaliação das adaptações: infraestrutura/pilar e prótese parcial fixa e pilar e do sofware SPSS (SPSS 17.0, IBM, EUA) para todas as outras avaliações. No programa SPSS foram utilizados os testes estatísticos: Anova Oneway e Tukey b. 

5. Resultados 



\subsection{Adaptação marginal vertical entre pilares/implante (Lupa estereoscópica)}

Os dados observados da adaptação marginal entre pilar-implante utilizando a lupa estereoscópica Leica, para cada pilar, pré-molar (PM) ou molar (M), para cada sistema CAD/CAM: Neodent digital: em zircônia (ZirNeo PM e ZirNeo M), em titânio TiNeo PM e TiNeo M), Lava em zircônia (Lava PM e Lava M), e do grupo controle (Co PM e Co M), foram tabulados (Tabela 1 - Anexo 1) e submetidos à análise estatística.

As figuras 99 a 106 ilustram a adaptação pilar-implante de cada um dos grupos analisados.

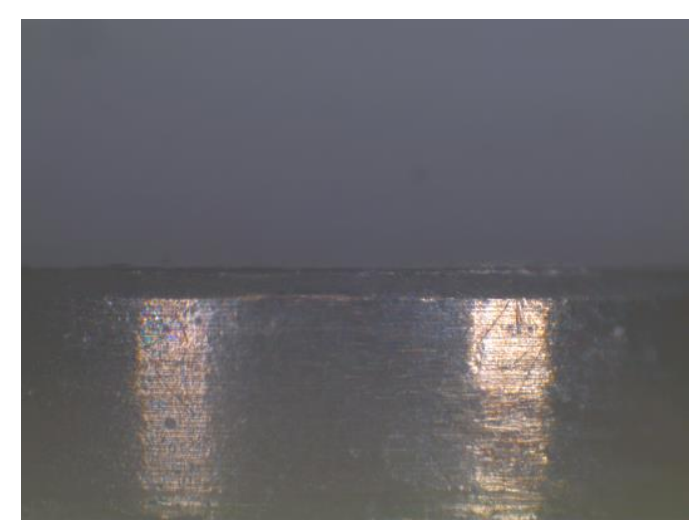

Figura 99: Adaptação pilar ZirNeo PM/implante

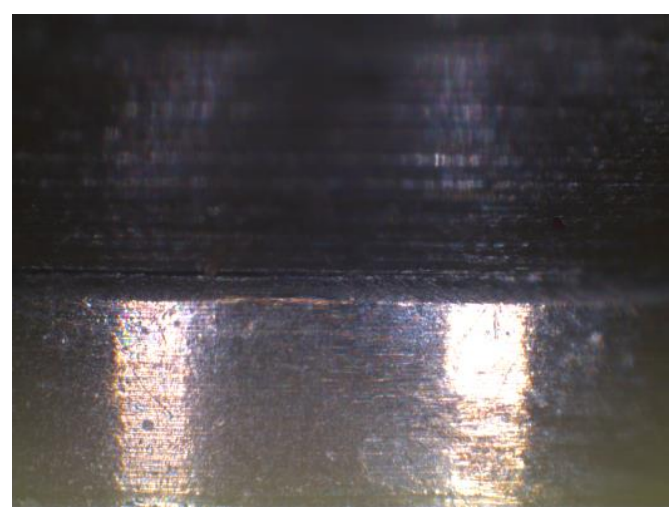

Figura 101: Adaptação pilar TiNeo PM/implante

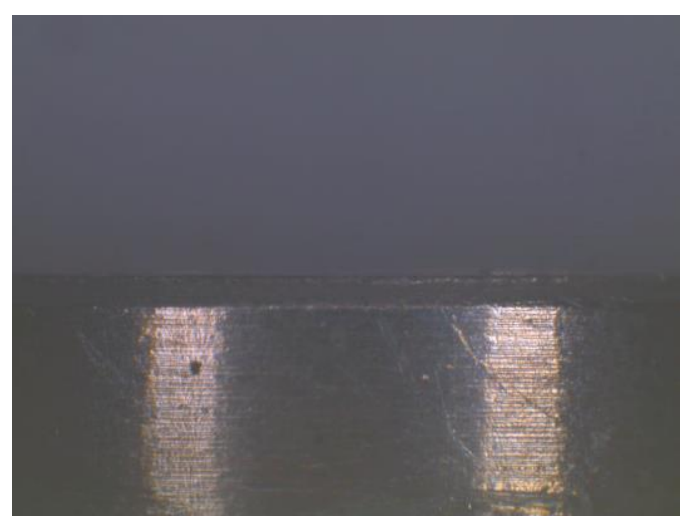

Figura 100: Adaptação pilar ZirNeo M/imnlante

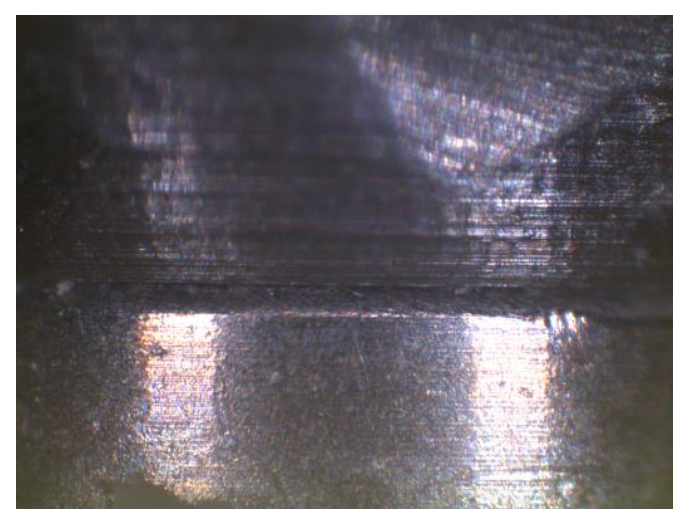

Figura 102: Adaptação pilar TiNeo M/implante 


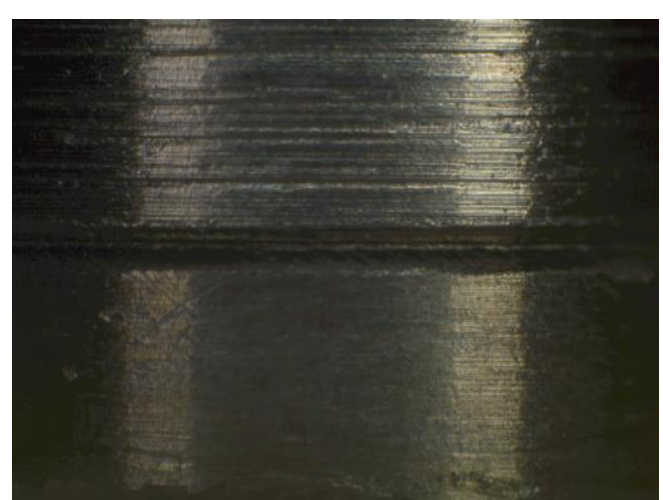

Figura 103: Adaptação pilar Lava PM/implante

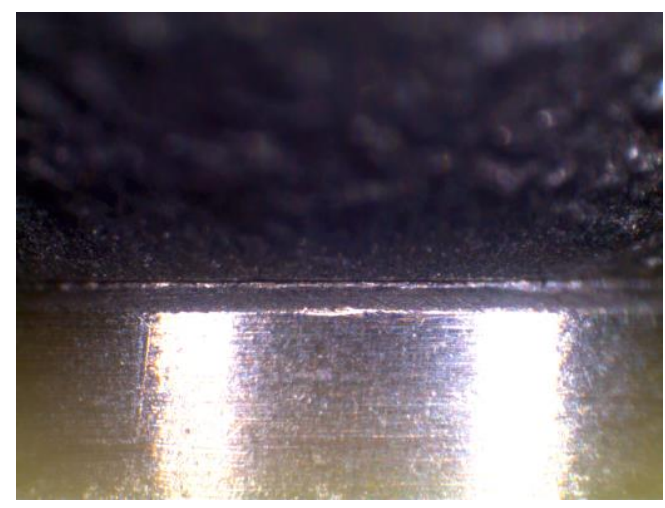

Figura 105: Adaptação pilar $\mathrm{Co}$ PM/implante

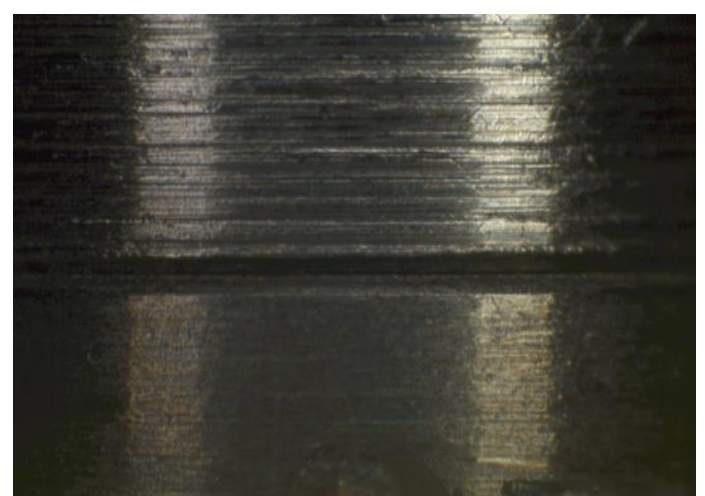

Figura 104: Adaptação pilar Lava M/implante

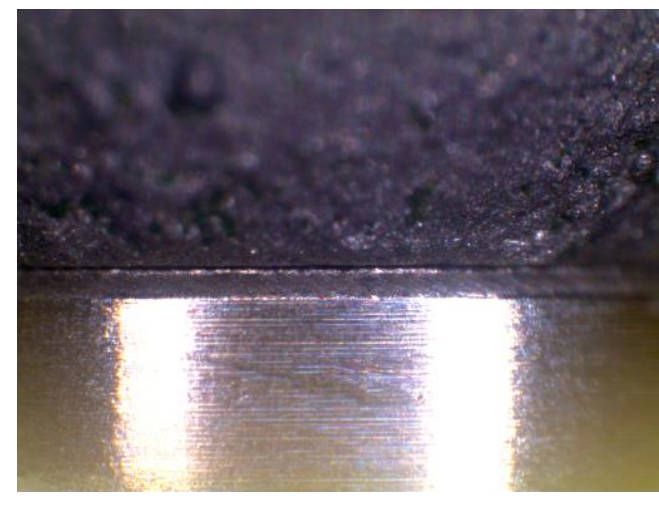

Figura 106: Adaptação pilar Co $\mathrm{M} /$ implante

Tabela 1: Média, desvio padrão, intervalo de confiança e valor de $p$ da adaptação marginal $(\mu \mathrm{m})$ entre pilares pré-molares/implante (TiNeo, ZirNeo, Lava e Controle)

\begin{tabular}{cccccc}
\hline Grupos & Média & Desvio & \multicolumn{2}{c}{$95 \%$ Intervalo de } & \\
& & padrão & Confiança para Médias & $p$ \\
& & & Inferior & Superior & \\
\hline TiNeo PM & 5,80 & 1,07 & 5,03 & 6,57 & \\
ZirNeo PM & 8,08 & 0,54 & 7,68 & 8,47 & \multirow{2}{*}{0,057} \\
Lava PM & 5,84 & 3,44 & 3,38 & 8,31 & \\
Co PM & 6,75 & 1,80 & 5,46 & 8,04 & \\
\hline
\end{tabular}

Teste Anova Oneway $(p<0,05)$ 
Tabela 2: Média, desvio padrão, intervalo de confiança, categoria estatística e valor de $p$ da adaptação marginal $(\mu \mathrm{m})$ entre pilares molares/implante (TiNeo, ZirNeo, Lava e Controle)

\begin{tabular}{ccccccc}
\hline Grupos & Média & $\begin{array}{c}\text { Desvio } \\
\text { padrão }\end{array}$ & \multicolumn{2}{c}{$95 \%$ Intervalo de } \\
Confiança para Médias & Categoria & estatística & $p$ \\
Inferior & Superior & & \\
\hline TiNeo M & 6,24 & 1,09 & 5,46 & 7,02 & AB & \\
ZirNeo M & 7,14 & 0,74 & 6,60 & 7,67 & A & 0,008 \\
Lava M & 4,98 & 1,93 & 3,59 & 6,36 & B & \\
Co M & 7,40 & 2,21 & 5,82 & 8,98 & A & \\
\hline
\end{tabular}

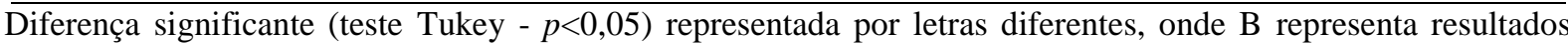
piores do que $\mathrm{A}$

Observou-se que não houve diferença significante dentro do grupo dos pré-molares $(p=0,057)$ para desadaptação entre pilar/implante (Tabela 1). Já para o grupo dos molares houve diferença significante $(p=0,008)$ entre os grupos ZirNeo e Lava, Lava e Co, sendo os menores valores para o grupo Lava (Tabela 2).

Entretanto, observa-se que, mesmo para os pilares molares de cada grupo, os valores das médias estão abaixo do que a literatura estabelece como aceitável para prótese fixa Figura 107.

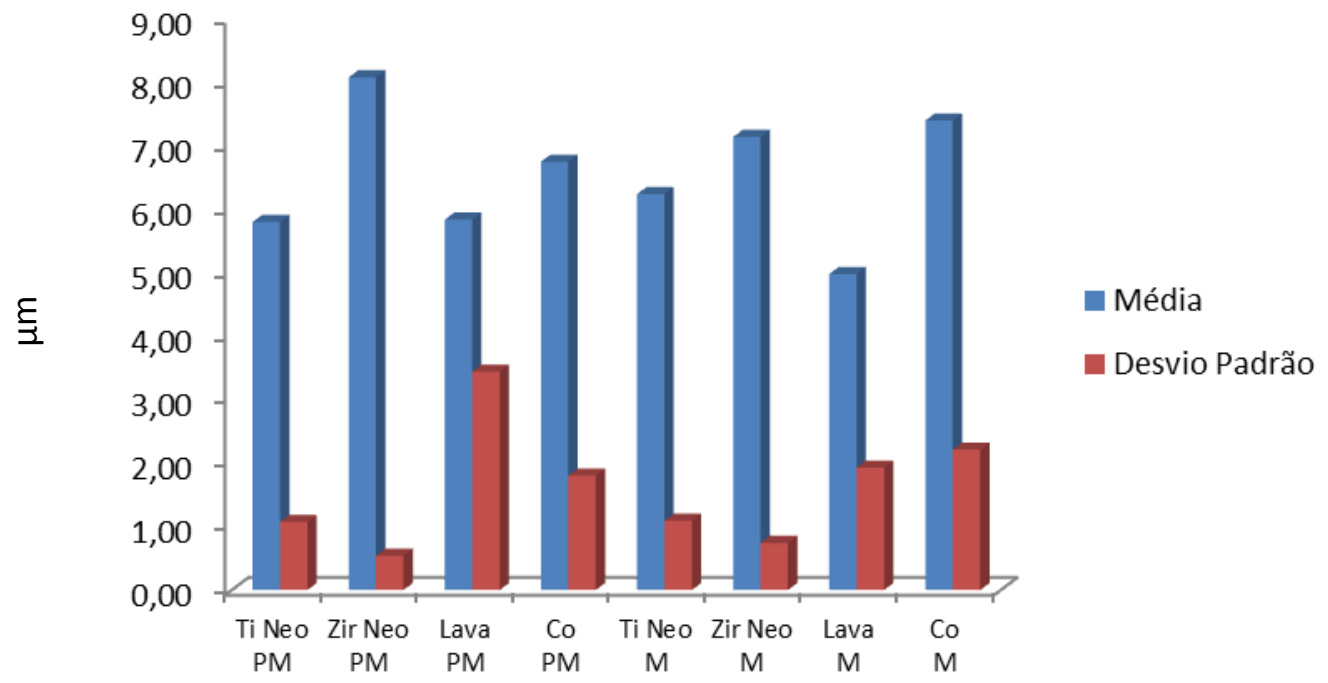

Figura 107: Adaptação marginal pilar/implante $(\mu \mathrm{m})$ - média e desvio padrão 
5.2 Adaptação marginal (vertical e horizontal) e interna (axial e oclusal) entre

\section{infraestrutura/pilares (MicroCT)}

As Figuras 108 a 115 ilustram a adaptação infraestrutura/pilar de cada um dos grupos analisados antes da prensagem da porcelana e ciclagem.
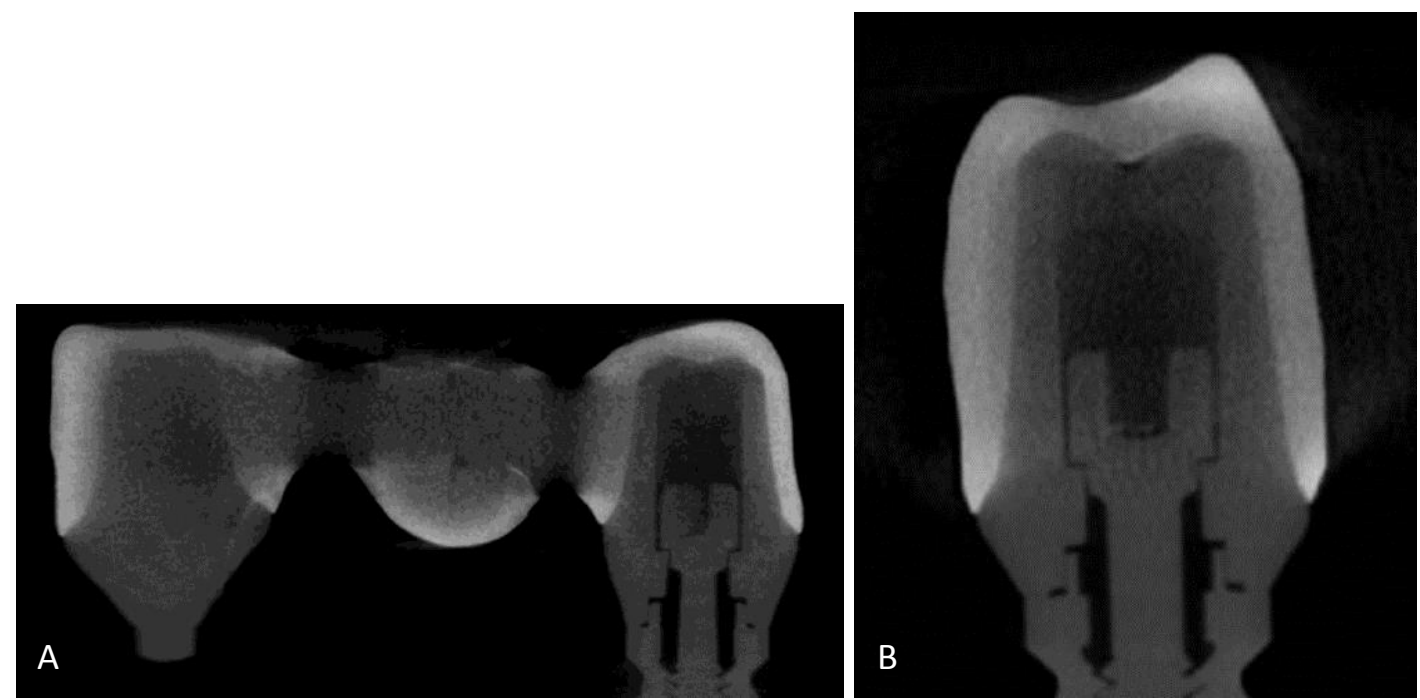

Figura 108: Adaptação TiNeo PM cortes coronal (A) e sagital (B), respectivamente, antes da prensagem da porcelana e ciclagem
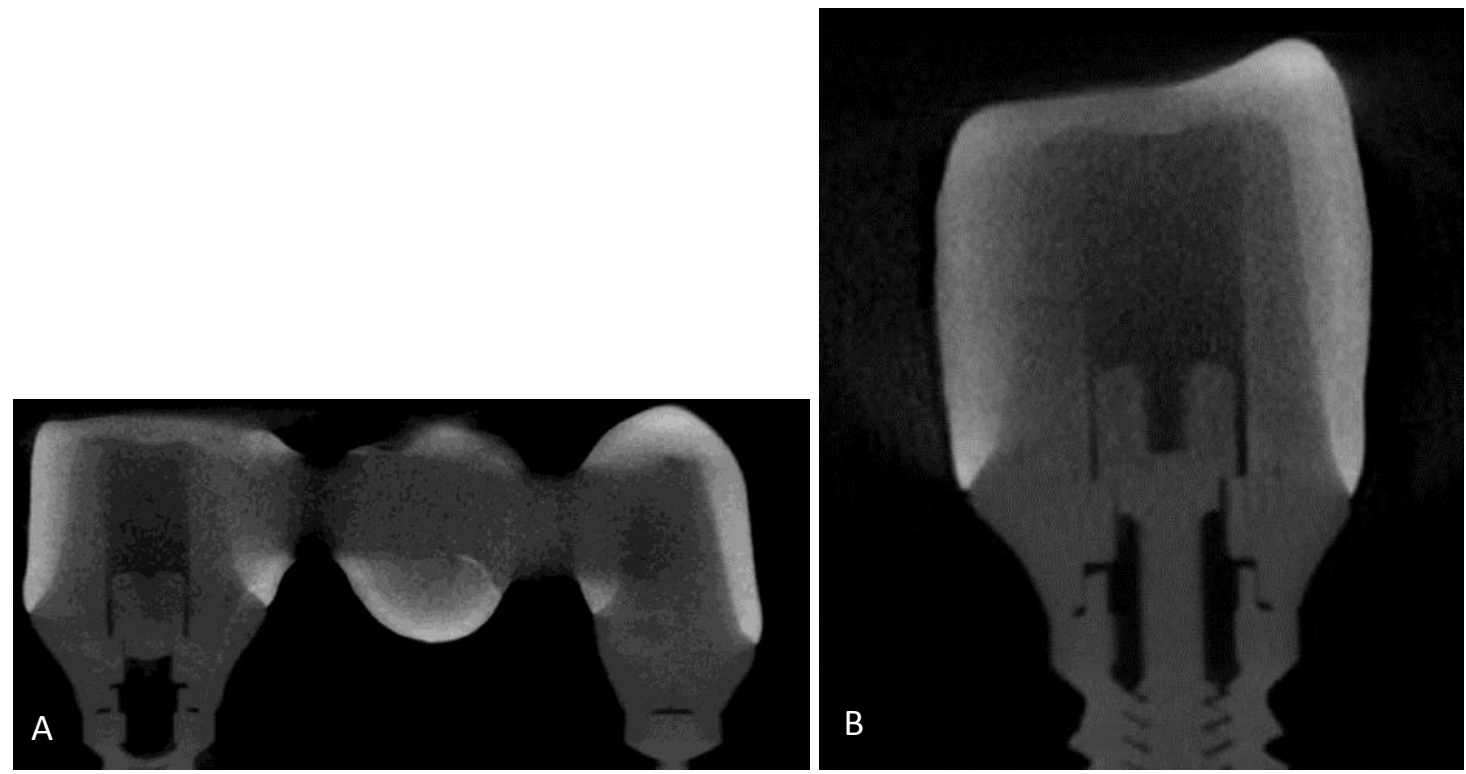

Figura 109: Adaptação TiNeo M cortes coronal (A) e sagital (B), respectivamente, Antes da prensagem da porcelana e ciclagem 

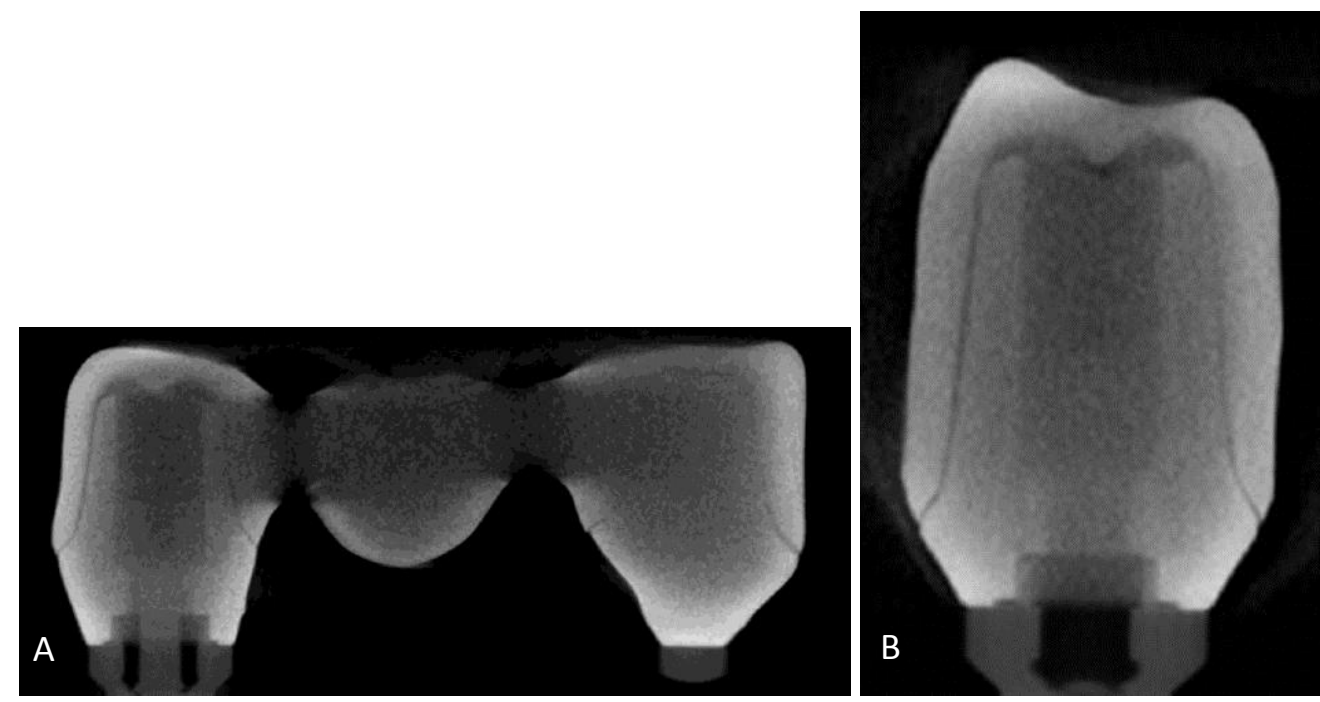

Figura 110: Adaptação ZirNeo PM cortes coronal (A) e sagital (B), respectivamente, antes da prensagem da porcelana e ciclagem
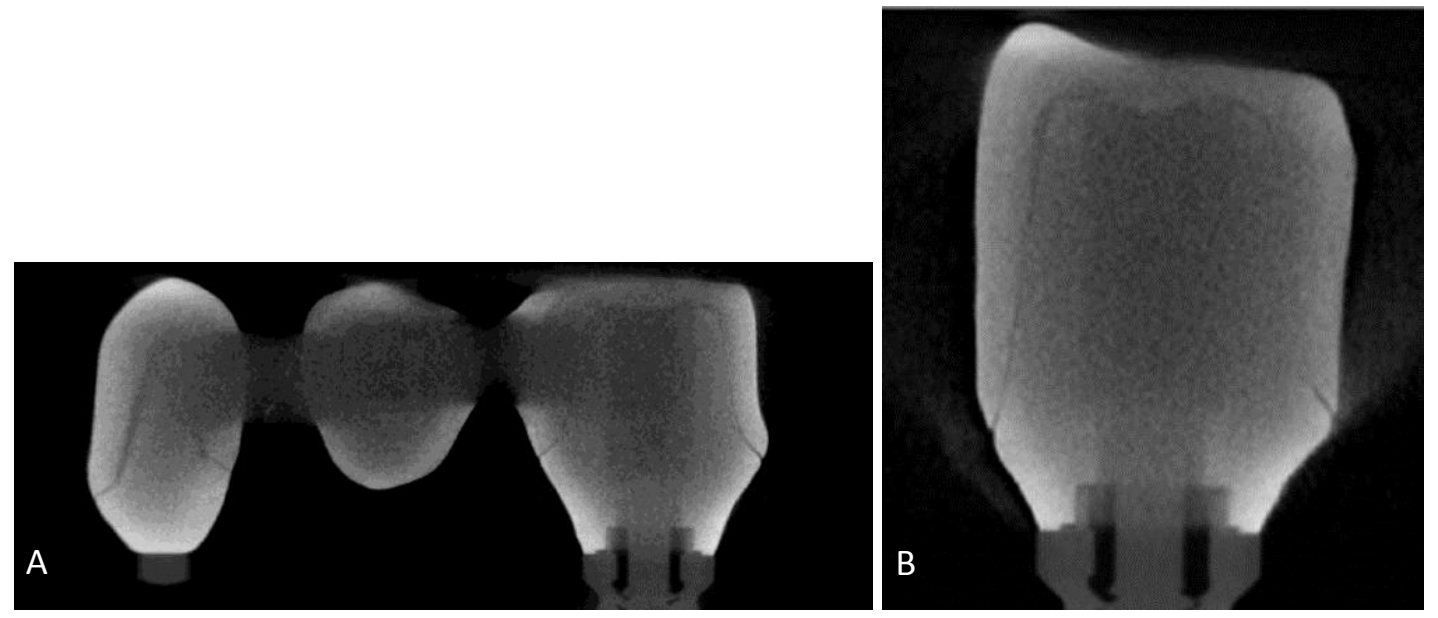

Figura 111: Adaptação ZirNeo M cortes coronal (A) e sagital (B), respectivamente, antes da prensagem da porcelana e ciclagem
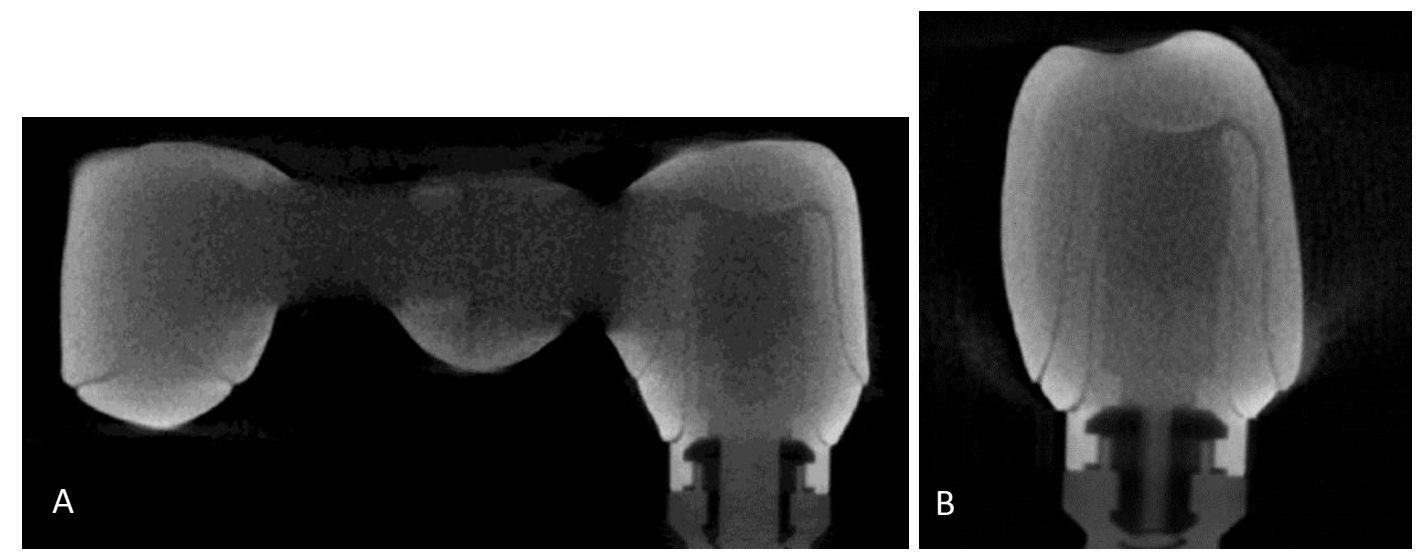

Figura 112: Adaptação Lava PM cortes coronal (A) e sagital (B), respectivamente, antes da prensagem da porcelana e ciclagem 

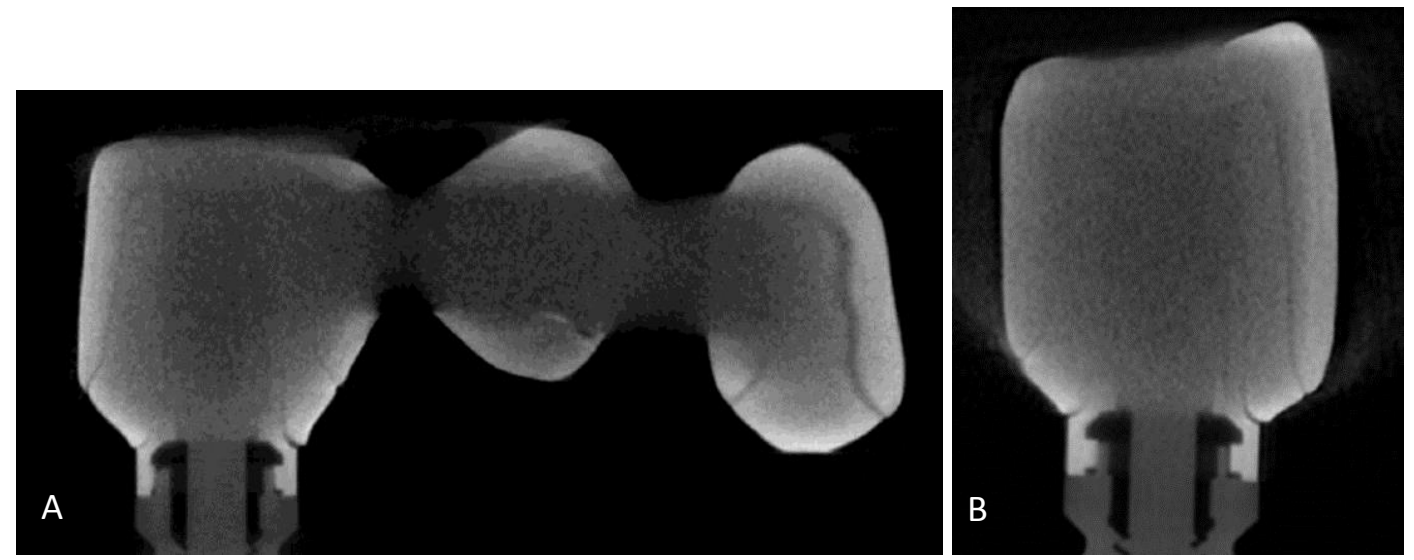

Figura 113: Adaptação Lava $M$ cortes coronal (A) e sagital (B), respectivamente, antes da prensagem da porcelana e ciclagem
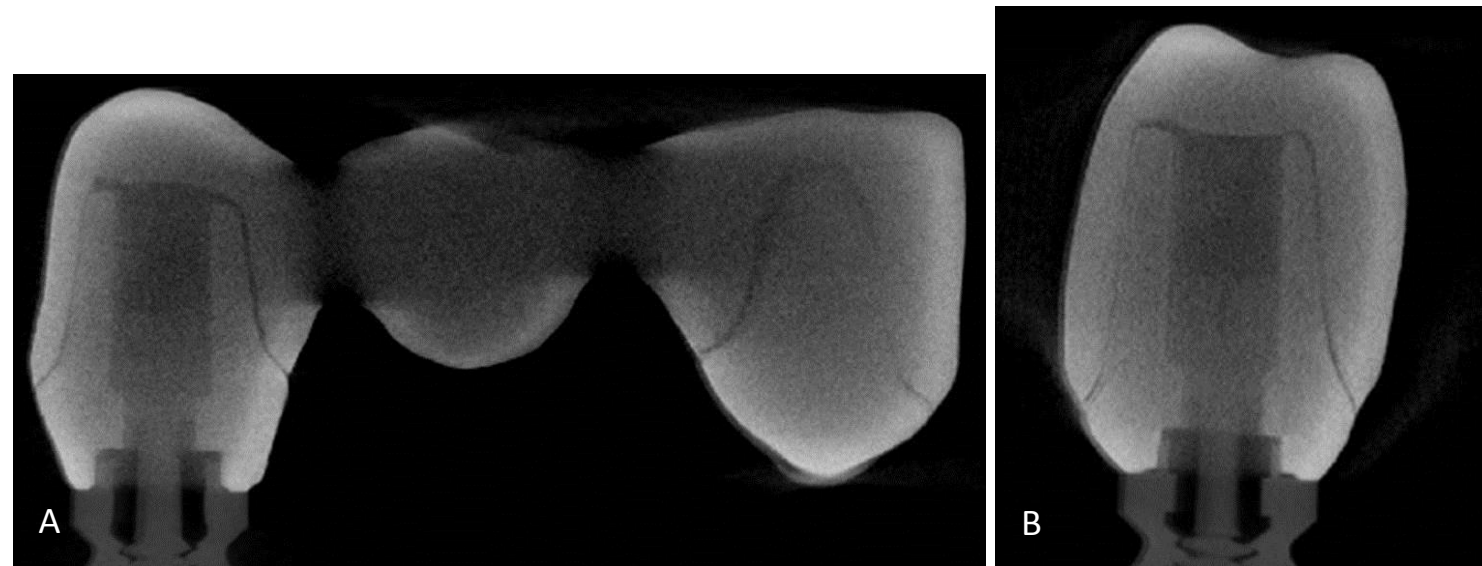

Figura 114: Adaptação Co PM cortes coronal (A) e sagital (B), respectivamente, antes da prensagem da porcelana e ciclagem
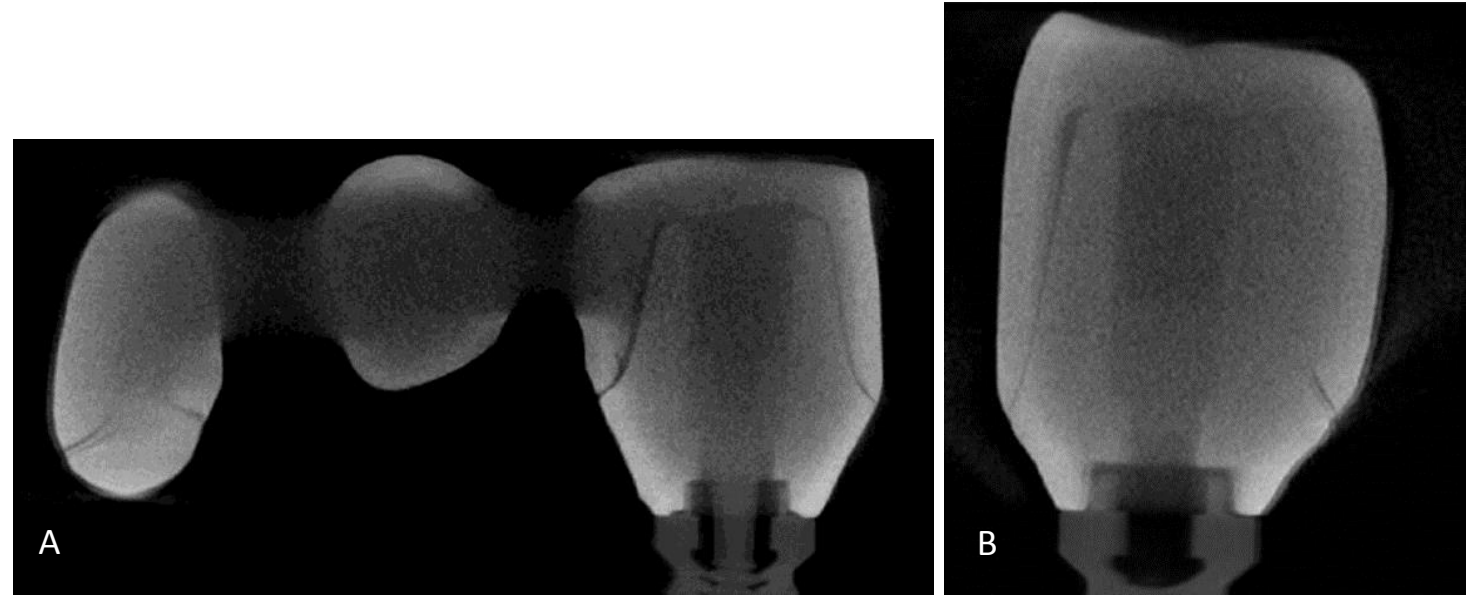

Figura 115: Adaptação Co $M$ cortes coronal (A) e sagital (B), respectivamente, antes da prensagem da porcelana e ciclagem 
As comparações entre os tempos (antes e após prensagem da porcelana e ciclagem) e entre os grupos (TiNeo, ZirNeo, Lava e Co) foram realizadas através de contrastes ortogonais, considerando o modelo linear de efeitos mistos (paramétrico) com efeitos aleatórios e fixos. Este tipo de análise é utilizado quando as respostas de um mesmo corpo de prova estão agrupadas e a suposição de independência entre as observações num mesmo grupo não é adequada (SCHALL, 1991). Foram realizados quatro modelos para as seguintes variáveis respostas: desadaptação vertical, horizontal, interna axial e interna oclusal. As variáveis independentes foram dentes (PM ou M), tempos (antes e após) e grupos (TiNeo, ZirNeo, Lava e Co). Para a utilização deste modelo, é preciso que seus resíduos tenham distribuição normal com média zero e variância constante. Quando este pressuposto não foi atendido, foi realizada uma transformação na variável resposta. $\mathrm{O}$ ajuste do modelo foi feito através do procedimento PROC MIXED do software $\operatorname{SAS}^{\circledR}$ 9.1. Foi considerado um nível de significância de $5 \%$.

Os dados referentes à desadaptação vertical - infraestrutura/pilares PM dos quatro grupos antes da prensagem da porcelana e ciclagem foram tabulados (Tabela 2 - anexo 2) e submetidos à análise estatística.

Tabela 3: Comparações, considerando a adaptação VERTICAL nos PM antes da ciclagem termomecânica:

\begin{tabular}{ccccc}
\hline \multirow{2}{*}{ Comparações } & Diferença entre as & \multicolumn{2}{c}{ IC 95\% } & \\
\cline { 3 - 4 } & médias & LI & LS & $\boldsymbol{p}$ \\
\hline (TiNeo -ZirNeo) PM & 0,081 & $-0,471$ & 0,634 & 0,771 \\
(TiNeo - Lava) PM & 0,284 & $-0,268$ & 0,836 & 0,310 \\
(TiNeo - Co) PM & $-0,258$ & $-0,810$ & 0,294 & 0,356 \\
(ZirNeo - Lava) PM & 0,365 & $-0,187$ & 0,917 & 0,192 \\
(ZirNeo - Co) PM & $-0,177$ & $-0,729$ & 0,375 & 0,527 \\
(Lava - Co) PM & $-0,542$ & $-1,094$ & 0,010 & 0,054 \\
\hline
\end{tabular}

*Diferença significante $(p<0,05)$ 
O intervalo de confiança nos fornece a magnitude da diferença entre os grupos e também testa a hipótese de que não existe diferença entre os grupos (se o intervalo contempla o valor zero, então não rejeita a hipótese de que não existe diferença entre os grupos).

Nesse caso, não houve diferença estatisticamente significante na adaptação vertical entre nenhum dos grupos pré-molares analisados (Tabela 3). Abaixo o gráfico da adaptação vertical dos pré-molares antes da prensagem da porcelana e ciclagem - Figura 116.

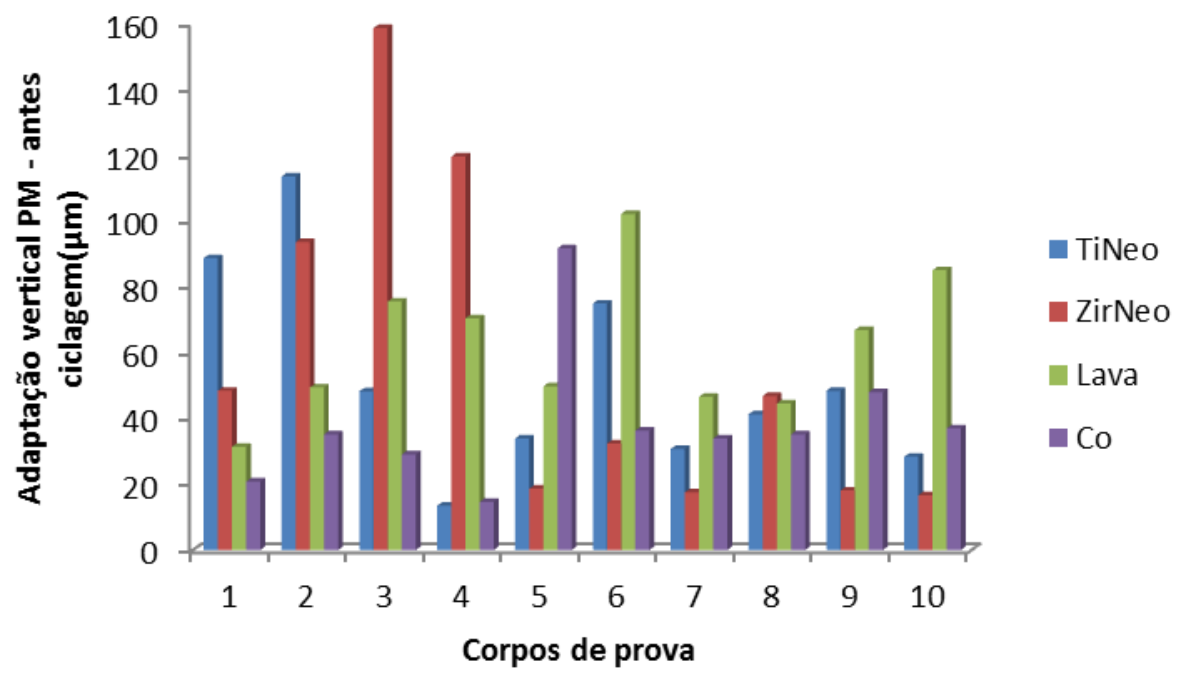

Figura 116: Adaptação vertical entre Infraestrutura/pilares PM $(\mu \mathrm{m})$ - antes da ciclagem

Os dados referentes à desadaptação vertical - infraestrutura/pilares $\mathrm{M}$ dos quatro grupos antes da prensagem da porcelana e ciclagem foram tabulados (Tabela 3 - anexo 2) e submetidos à análise estatística. 
Tabela 4: Comparações, considerando a adaptação VERTICAL nos $M$ antes da ciclagem termomecânica:

\begin{tabular}{ccccc}
\hline \multirow{2}{*}{ Comparações } & Diferença entre as & \multicolumn{2}{c}{ IC 95\% } & \\
& médias & LI & LS & $\boldsymbol{p}$ \\
\hline (TiNeo - ZirNeo) M & $-0,180$ & $-0,732$ & 0,372 & 0,520 \\
(TiNeo - Lava) M & 0,388 & $-0,164$ & 0,940 & 0,166 \\
(TiNeo - Co) M & $-0,834$ & $-1,386$ & $-0,282$ & $0,003^{*}$ \\
(ZirNeo - Lava) M & 0,208 & $-0,344$ & 0,760 & 0,456 \\
(ZirNeo - Co) M & $-1,014$ & $-1,566$ & $-0,462$ & $0,000^{*}$ \\
(Lava - Co) M & $-1,222$ & $-1,774$ & $-0,670$ & $<, 0001^{*}$ \\
\hline
\end{tabular}

*Diferença significante $(p<0,05)$

Houve diferença significante na adaptação vertical entre o grupo controle e todos os outros grupos molares analisados: TiNeo e Co, ZirNeo e Co e Lava e Co (Tabela 4). Abaixo o gráfico da adaptação vertical dos molares antes da prensagem da porcelana e ciclagem Figura 117. Em média os valores da desadaptação do grupo controle foi menor que a dos outros grupos.

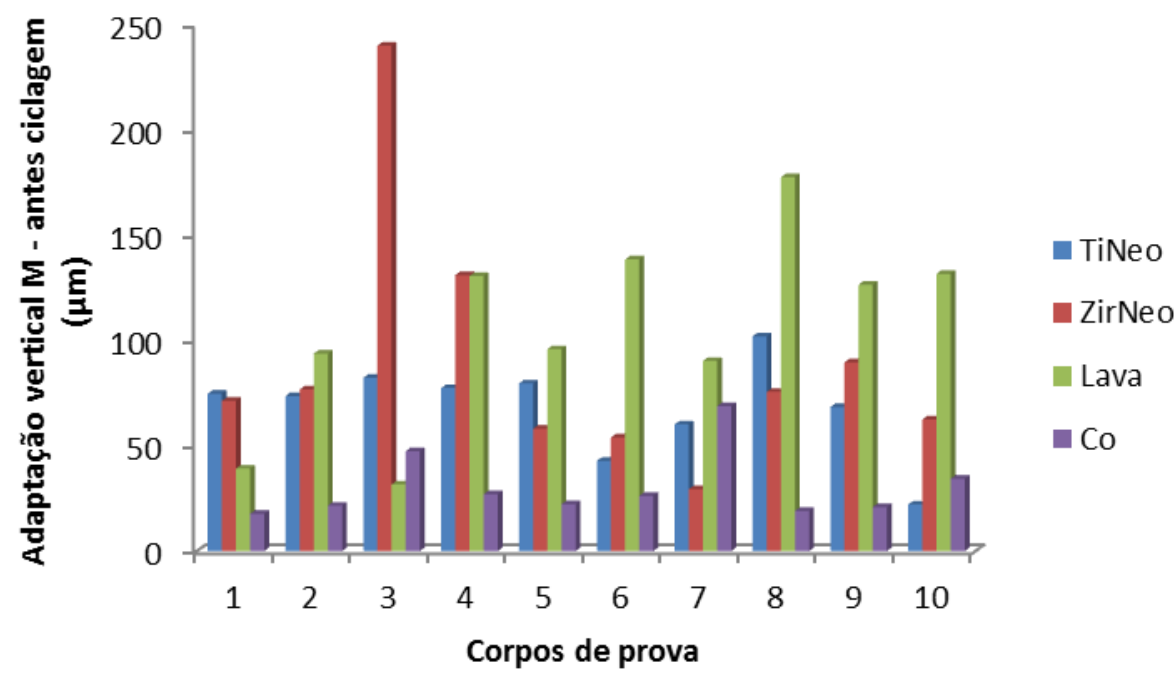

Figura 117: Adaptação vertical entre Infraestrutura/pilares $M(\mu \mathrm{m})$ - antes da ciclagem 
Os dados referentes à desadaptação horizontal - infraestrutura/pilares PM dos quatro grupos antes da prensagem da porcelana e ciclagem foram tabulados (Tabela 4 - anexo 3) e submetidos à análise estatística.

Tabela 5: Comparações, considerando a adaptação HORIZONTAL nos PM antes da ciclagem:

\begin{tabular}{ccccc}
\hline Comparações & Diferença entre as & & \multicolumn{2}{c}{ IC 95\% } \\
\cline { 5 - 6 } & médias & $\boldsymbol{p}$ & LI & LS \\
\hline (TiNeo -ZirNeo) PM & 0,746 & 0,393 & $-1,009$ & 2,500 \\
(Ti Neo - Lava) PM & 0,417 & 0,558 & $-1,016$ & 1,849 \\
(Ti Neo - Co) PM & $-0,773$ & 0,416 & $-2,684$ & 1,138 \\
(ZirNeo - Lava) PM & 1,162 & 0,137 & $-0,388$ & 2,712 \\
(ZirNeo - Co) PM & $-0,027$ & 0,978 & $-2,028$ & 1,973 \\
(Lava - Co) PM & $-1,189$ & 0,170 & $-2,914$ & 0,536 \\
\hline
\end{tabular}

*Diferença significante $(p<0,05)$

Não houve diferença significante na desadaptação horizontal dos pré-molares entre os grupos avaliados (Tabela 9). Abaixo o gráfico da adaptação horizontal dos pré-molares antes da prensagem da porcelana e ciclagem - Figura 118.

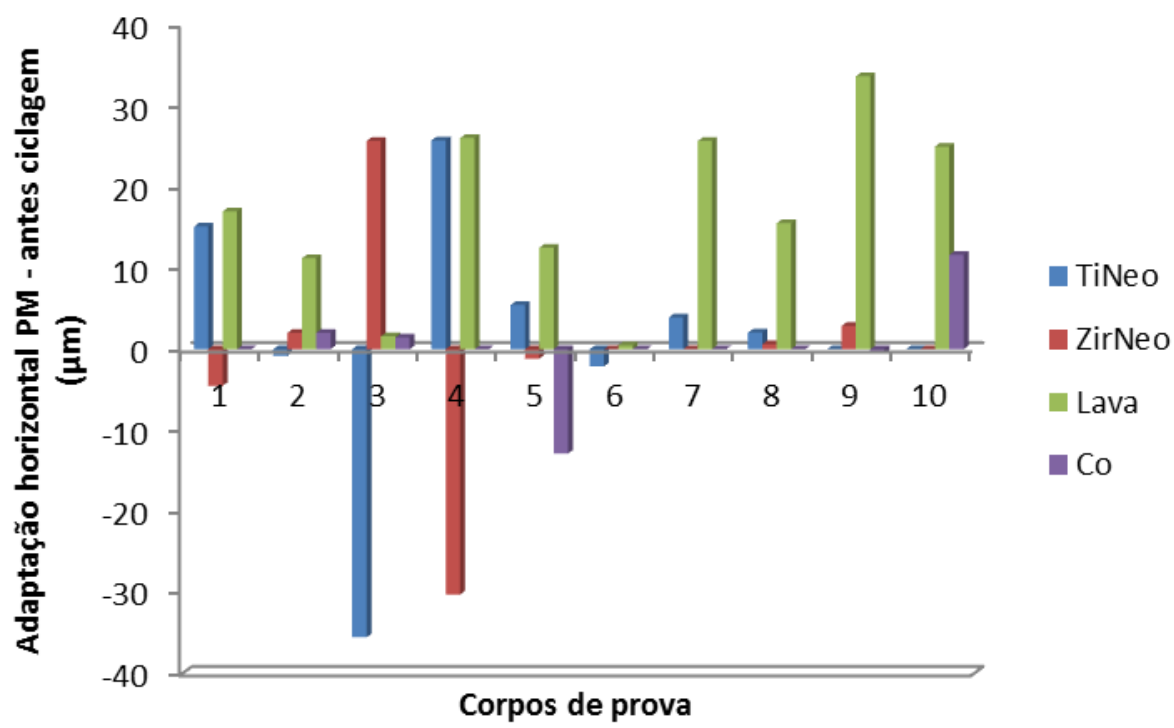

Figura 118: Adaptação horizontal entre infraestrutura/pilares PM $(\mu \mathrm{m})$ - antes da ciclagem 
Os dados referentes à desadaptação horizontal - infraestrutura/pilares M dos quatro grupos antes da prensagem da porcelana e ciclagem foram tabulados (Tabela 5 - anexo 3) e submetidos à análise estatística.

Tabela 6: Comparações, considerando a adaptação HORIZONTAL nos $M$ antes da ciclagem termomecânica:

\begin{tabular}{ccccc}
\hline Comparações & Diferença entre as & & \multicolumn{2}{c}{ IC 95\% } \\
\cline { 4 - 5 } & médias & $\boldsymbol{p}$ & $\mathbf{L I}$ & $\mathbf{L S}$ \\
\hline (TiNeo - ZirNeo) M & $-0,310$ & 0,705 & $-1,964$ & 1,345 \\
(TiNeo - Lava) M & 1,878 & $0,015^{*}$ & 0,389 & 3,368 \\
(TiNeo - Co) M & 0,408 & 0,667 & $-1,503$ & 2,319 \\
(ZirNeo - Lava) M & 1,569 & $0,040^{*}$ & 0,076 & 3,062 \\
(Zir Neo - Co) M & 0,098 & 0,918 & $-1,816$ & 2,011 \\
(Lava - Co) M & $-1,471$ & 0,101 & $-3,244$ & 0,302 \\
\hline
\end{tabular}

*Diferença significante $(p<0,05)$

Houve diferença estatisticamente significante na desadaptação horizontal dos molares entre os grupos ZirNeo e Lava e Lava e TiNeo (Tabela 6) sendo o grupo Lava com maiores valores de desadaptação. Abaixo o gráfico da adaptação horizontal dos molares antes da prensagem da porcelana e ciclagem - Figura 119.

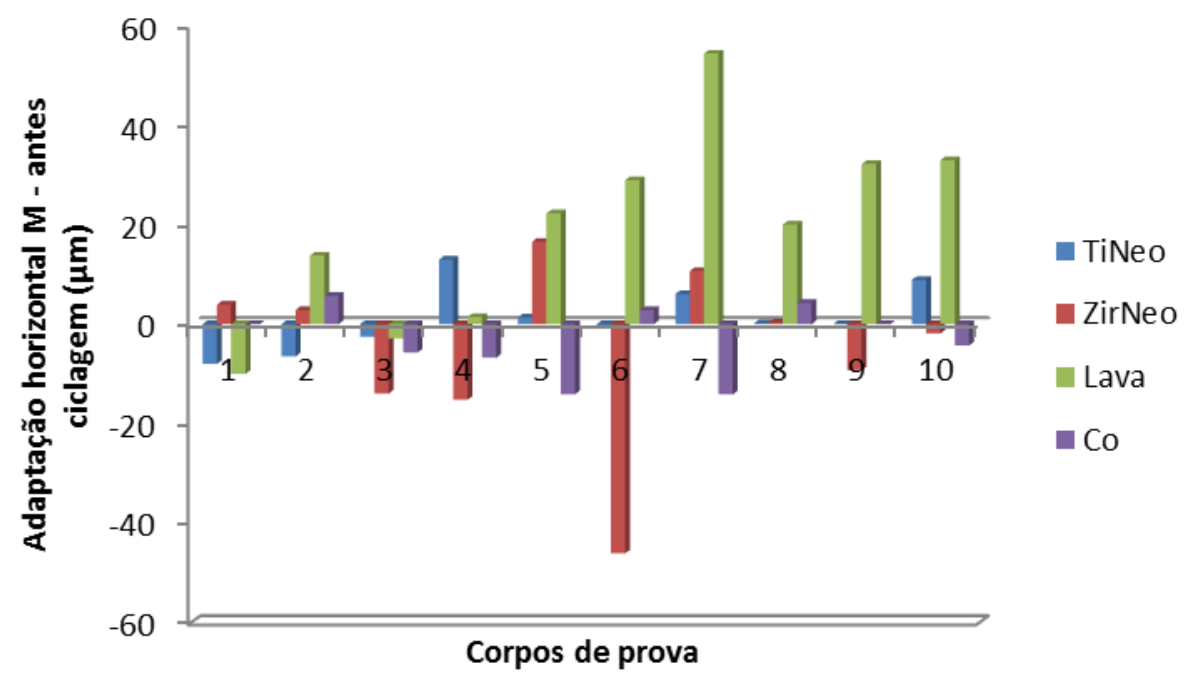

Figura 119: Adaptação horizontal entre infraestrutura/pilares $M(\mu \mathrm{m})$-antes da ciclagem 
Os dados referentes à desadaptação interna axial - infraestrutura/pilares PM dos quatro grupos antes da prensagem da porcelana e ciclagem foram tabulados (Tabela 6 - anexo 4) e submetidos à análise estatística.

Tabela 7: Comparações, considerando a adaptação INTERNA AXIAL nos PM antes da ciclagem termomecânica:

\begin{tabular}{ccccc}
\hline \multirow{2}{*}{ Comparações } & $\begin{array}{c}\text { Diferença entre as } \\
\text { médias }\end{array}$ & $\boldsymbol{p}$ & \multicolumn{2}{c}{ IC 95\% } \\
\cline { 4 - 6 } & 0,022 & 0,935 & $-0,507$ & 0,551 \\
\hline (ZirNeo - Lava) PM & $-0,230$ & 0,389 & $-0,759$ & 0,299 \\
(ZirNeo) PM & $-0,252$ & 0,346 & $-0,781$ & 0,277 \\
(Lava - Co) PM & & & & \\
\hline
\end{tabular}

*Diferença significante $(p<0,05)$

Não houve diferença significante na desadaptação interna axial dos pré-molares entre nenhum dos grupos avaliados (Tabela 7). Abaixo o gráfico da adaptação interna axial dos prémolares antes da prensagem da porcelana e ciclagem - Figura 120.

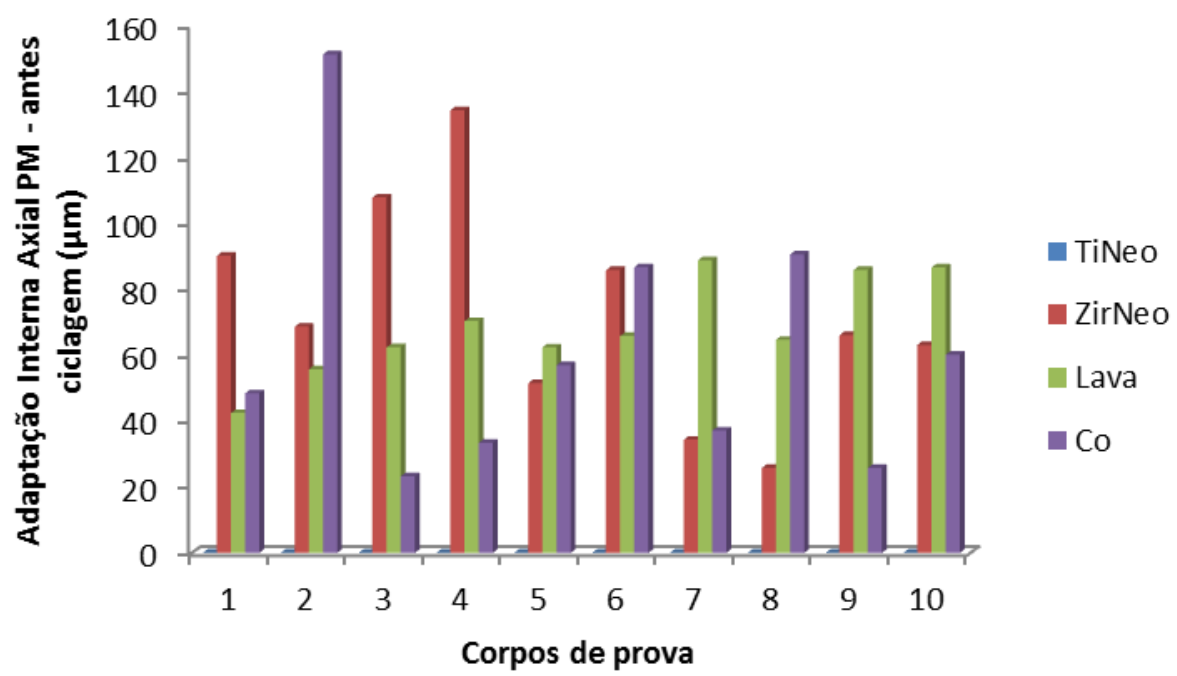

Figura 120: Adaptação Interna Axial entre infraestrutura/pilares PM $(\mu \mathrm{m})$ - antes da ciclagem 
Os dados referentes à desadaptação interna axial - infraestrutura/pilares $\mathrm{M}$ dos quatro grupos antes da prensagem da porcelana e ciclagem foram tabulados (Tabela 7 - anexo 4) e submetidos à análise estatística.

Tabela 8: Comparações, considerando a adaptação INTERNA AXIAL nos $M$ antes da ciclagem termomecânica:

\begin{tabular}{ccccc}
\hline \multirow{2}{*}{ Comparações } & Diferença entre as & & \multicolumn{2}{c}{ IC 95\% } \\
\cline { 3 - 5 } & médias & $\boldsymbol{p}$ & LI & LS \\
\hline (ZirNeo - Lava) M & 0,500 & 0,064 & $-0,029$ & 1,029 \\
(ZirNeo - Co) M & 0,203 & 0,447 & $-0,326$ & 0,732 \\
(Lava - Co) M & $-0,297$ & 0,267 & $-0,826$ & 0,232 \\
\hline
\end{tabular}

*Diferença significante $(p<0,05)$

Não houve diferença significante na desadaptação interna axial dos molares entre os grupos avaliados (Tabela 8). Abaixo o gráfico da adaptação interna axial dos Molares antes da prensagem da porcelana e ciclagem - Figura 121.

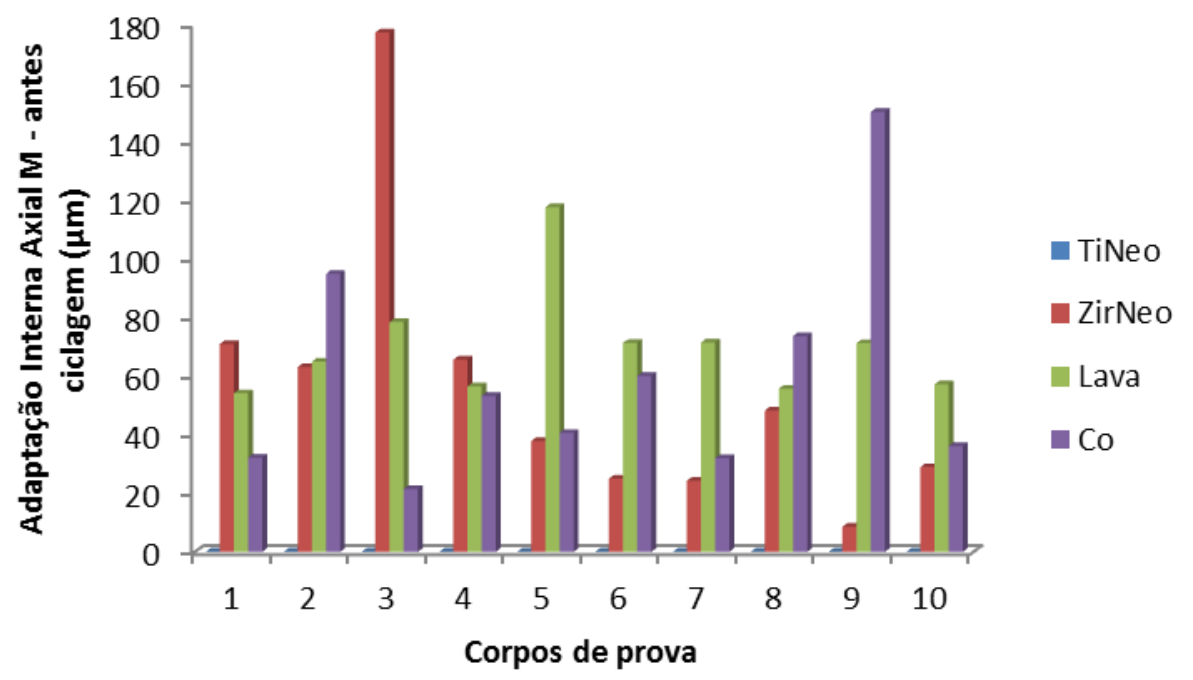

Figura 121: Adaptação Interna Axial entre infraestrutura/pilares $M$ - antes ciclagem $(\mu \mathrm{m})$ 
Para o grupo TiNeo - avaliação interna axial, como todos os valores são zero (0) não existe variabilidade, portanto, se não tem variabilidade não tem variância, logo não foi possível aplicar nenhum teste estatístico para realizar a comparação desse grupo.

Os dados referentes à desadaptação interna oclusal - infraestrutura/pilares PM dos quatro grupos antes da prensagem da porcelana e ciclagem foram tabulados (Tabela 8 - anexo 4) e submetidos à análise estatística.

Tabela 9: Comparações, considerando a adaptação INTERNA OCLUSAL nos PM antes da ciclagem termomecânica:

\begin{tabular}{ccccc}
\hline Comparações & Diferença entre as & \multicolumn{2}{c}{ IC 95\% } \\
\cline { 5 - 6 } & médias & $\boldsymbol{p}$ & LI & LS \\
\hline (TiNeo -ZirNeo) PM & $-0,077$ & 0,796 & $-0,669$ & 0,514 \\
(TiNeo - Lava) PM & $-0,235$ & 0,433 & $-0,827$ & 0,357 \\
(TiNeo - Co) PM & $-0,403$ & 0,180 & $-0,994$ & 0,189 \\
(ZirNeo- Lava) PM & $-0,312$ & 0,298 & $-0,904$ & 0,279 \\
(ZirNeo - Co) PM & $-0,480$ & 0,111 & $-1,072$ & 0,112 \\
(Lava - Co) PM & $-0,168$ & 0,575 & $-0,759$ & 0,424 \\
\hline
\end{tabular}

*Diferença significante $(p<0,05)$

Não houve diferença estatisticamente significante na desadaptação interna oclusal dos pré-molares entre nenhum dos grupos avaliados (Tabela 9). Abaixo o gráfico da adaptação interna oclusal dos pré-molares antes da prensagem da porcelana e ciclagem Figura 122 


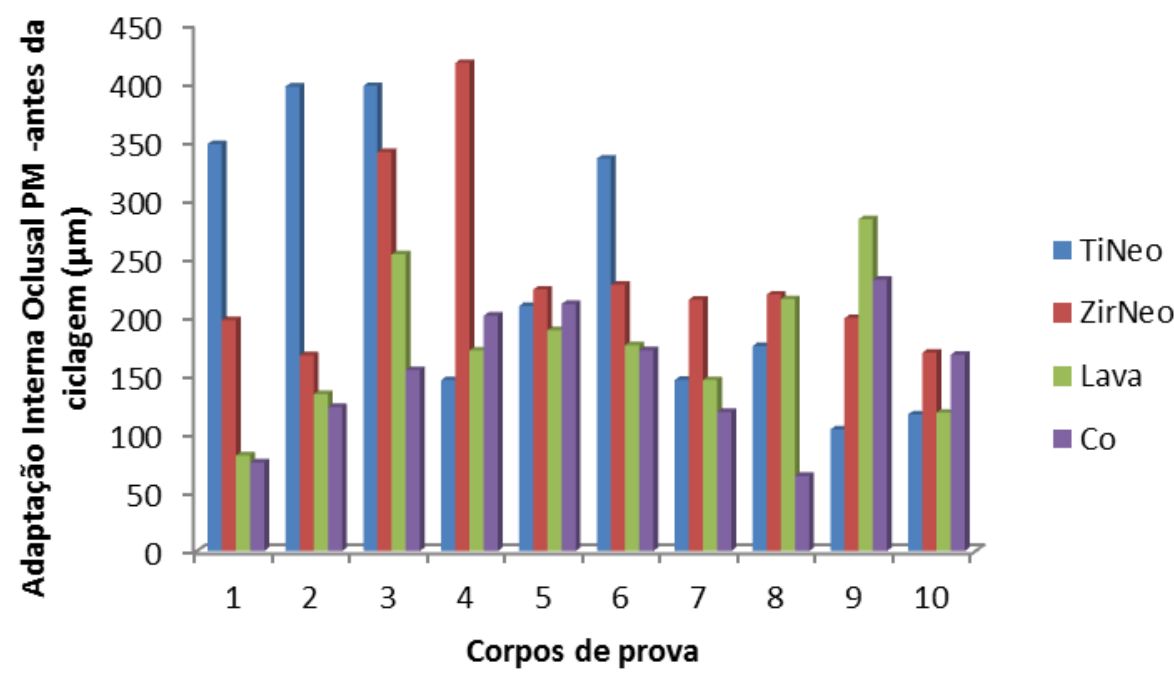

Figura 122: Adaptação Interna Oclusal entre infraestrutura/pilares PM - antes da ciclagem ( $\mu \mathrm{m})$

Os dados referentes à desadaptação interna oclusal infraestrutura/pilares $\mathrm{M}$ dos quatro grupos antes da prensagem da porcelana e ciclagem foram tabulados (Tabela 9 - anexo 4) e submetidos à análise estatística.

Tabela 10: Comparações, considerando a adaptação INTERNA OCLUSAL nos $M$ antes da ciclagem termomecânica:

\begin{tabular}{ccccc}
\hline Comparações & Diferença entre as & \multicolumn{2}{c}{ IC 95\% } \\
\cline { 4 - 5 } & médias & $\boldsymbol{p}$ & LI & LS \\
\hline (TiNeo - ZirNeo) M & $-1,037$ & $0,001^{*}$ & $-1,641$ & $-0,432$ \\
(TiNeo - Lava) M & 0,624 & $0,043^{*}$ & 0,019 & 1,228 \\
(TiNeo - Co) M & 0,318 & 0,299 & $-0,286$ & 0,922 \\
(ZirNeo - Lava) M & $-0,413$ & 0,169 & $-1,005$ & 0,179 \\
(ZirNeo - Co) M & $-0,719$ & $0,018^{*}$ & $-1,310$ & $-0,127$ \\
(Lava - Co) M & $-0,306$ & 0,308 & $-0,897$ & 0,286 \\
\hline
\end{tabular}

*Diferença significante $(p<0,05)$

Houve diferença significante na desadaptação interna oclusal dos molares entre os grupos TiNeo e Zir Neo, Ti Neo e Lava e Zir Neo e Co (Tabela 19) sendo os grupos ZirNeo e Lava com maiores valores de desadaptação. Abaixo o gráfico da adaptação interna oclusal dos molares antes da prensagem da porcelana e ciclagem - Figura 123. 


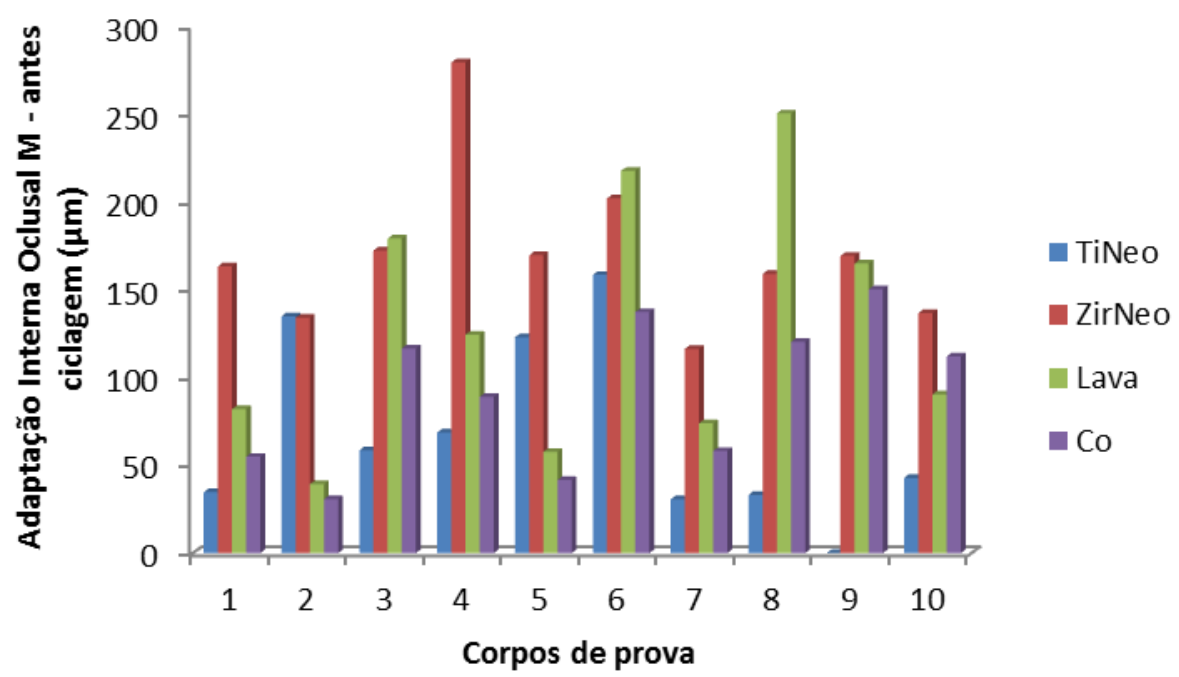

Figura 123: Adaptação Interna Oclusal entre infraestrutura/pilares $M$ - antes ciclagem $(\mu \mathrm{m})$

\subsection{Adaptação marginal (vertical e horizontal) e interna (oclusal e axial) entre a prótese}

fixa e pilares após prensagem da porcelana e ciclagem (MicroCT)

As Figuras 124 a 131 ilustram a adaptação infraestrutura/pilar de cada um dos grupos analisados após a prensagem da porcelana e ciclagem:
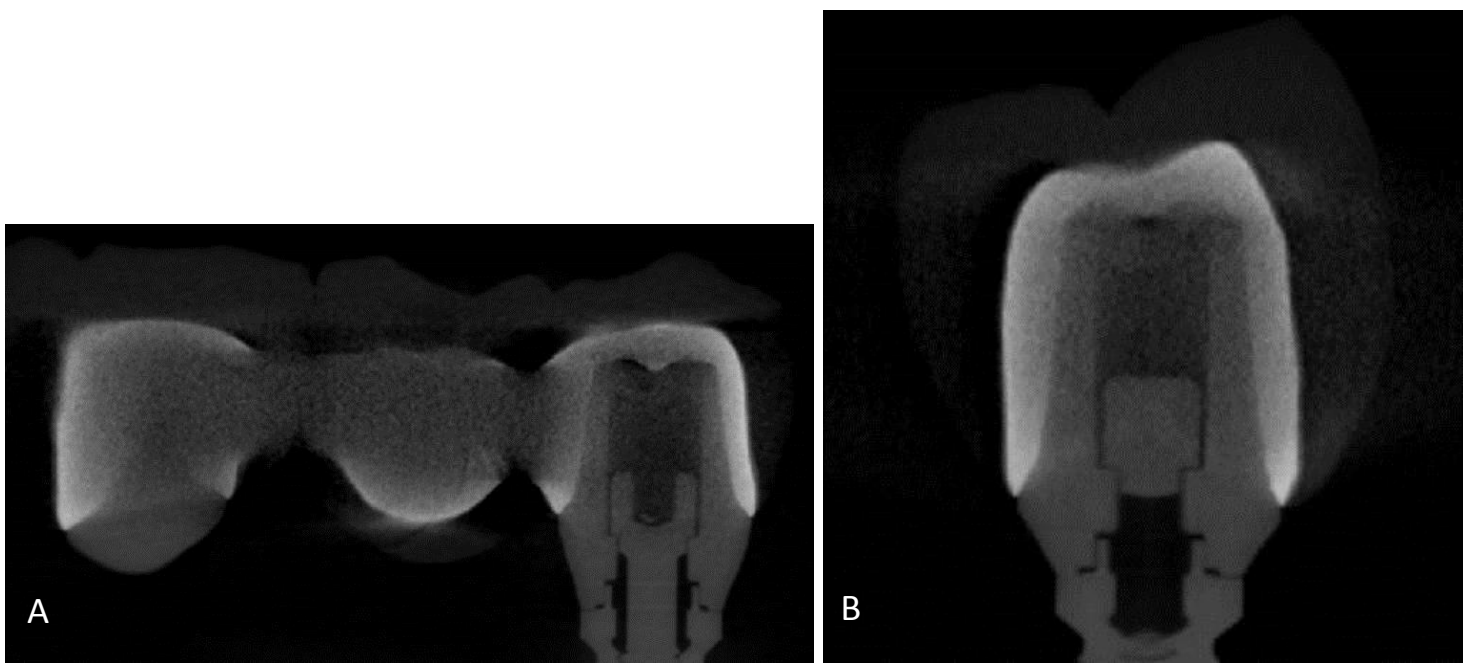

Figura 124: Adaptação TiNeo PM cortes coronal (A) e sagital (B), respectivamente, após prensagem da porcelana e ciclagem 

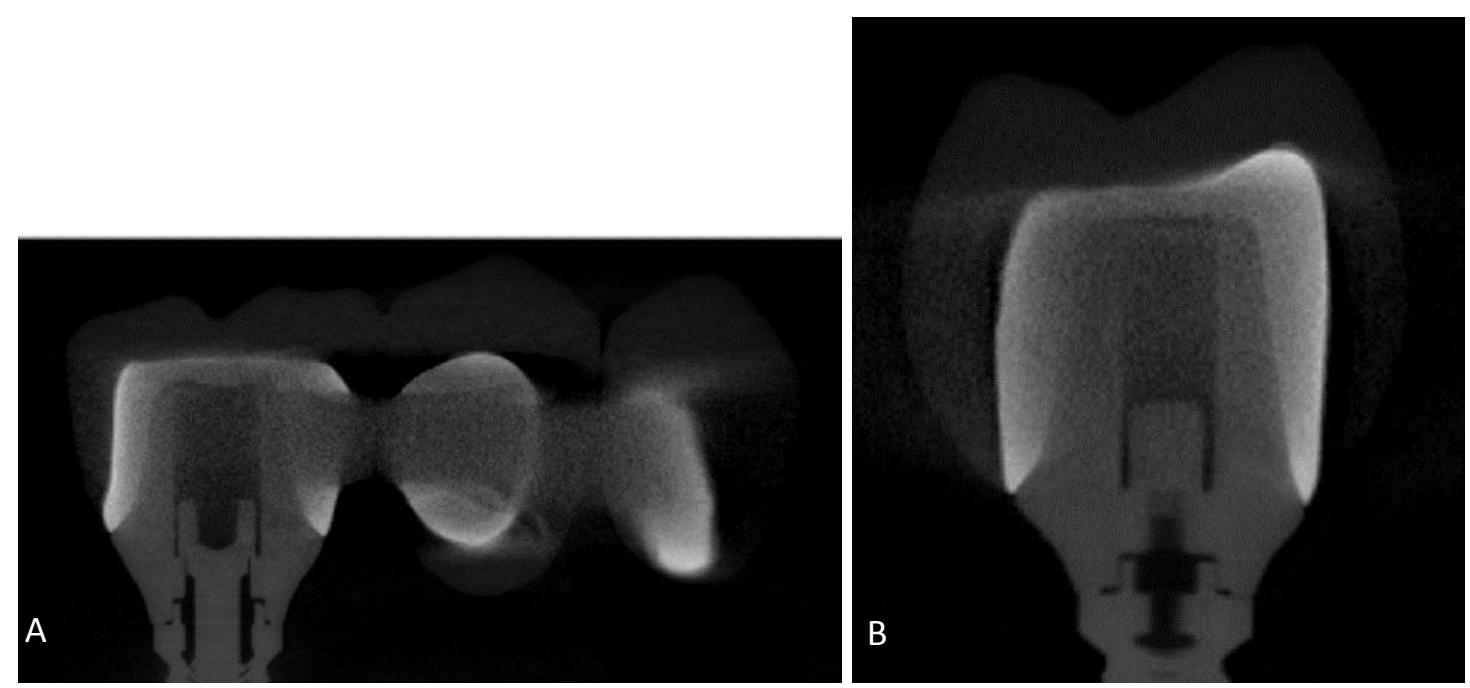

Figura 125: Adaptação TiNeo M cortes coronal (A) e sagital (B), respectivamente, após prensagem da porcelana e ciclagem
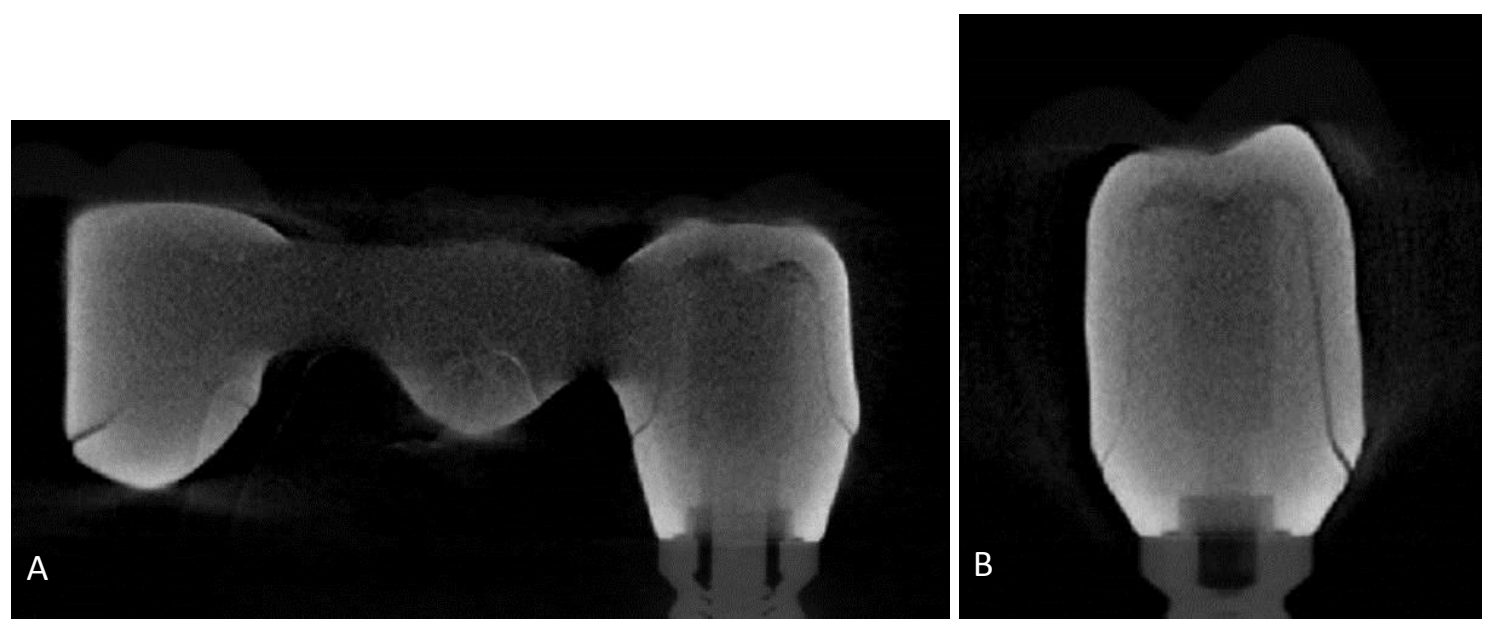

Figura 126: Adaptação ZirNeo PM cortes coronal (A) e sagital (B), respectivamente, após prensagem da porcelana e ciclagem
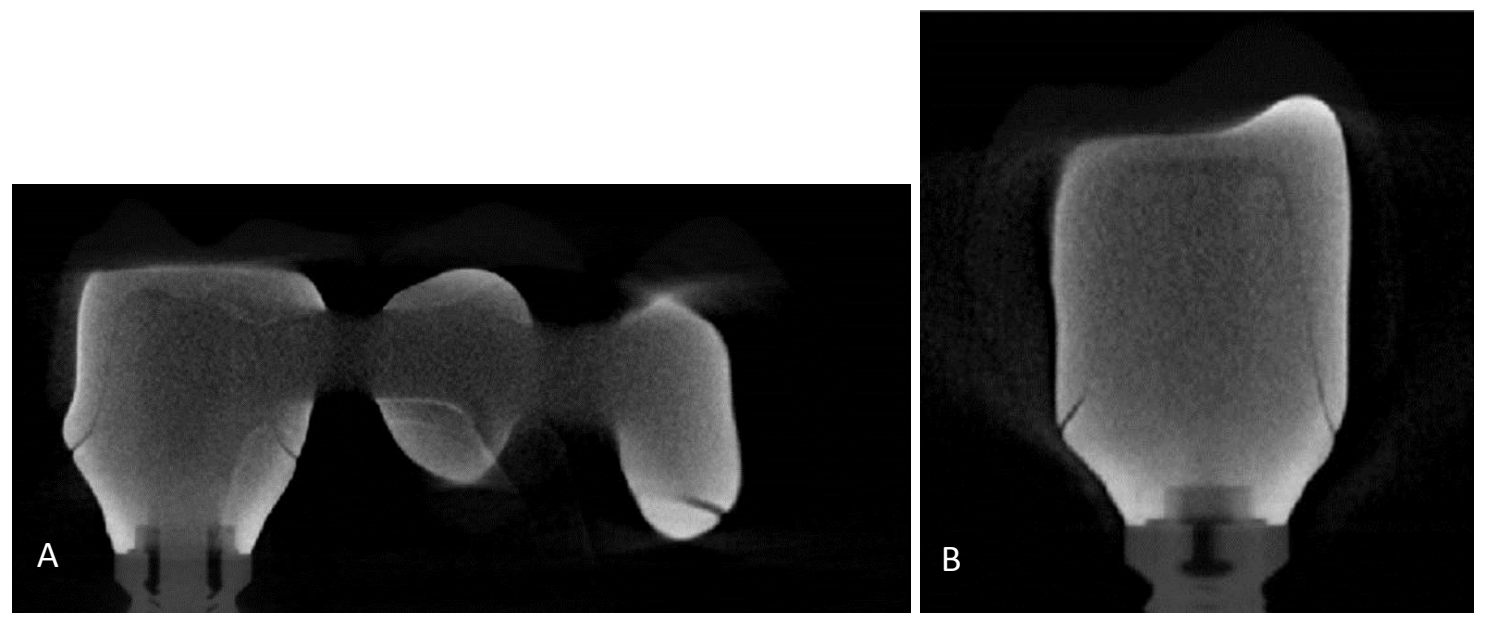

Figura 127:Adaptação ZirNeo M cortes coronal (A) e sagital (B), respectivamente, após prensagem da porcelana e ciclagem 

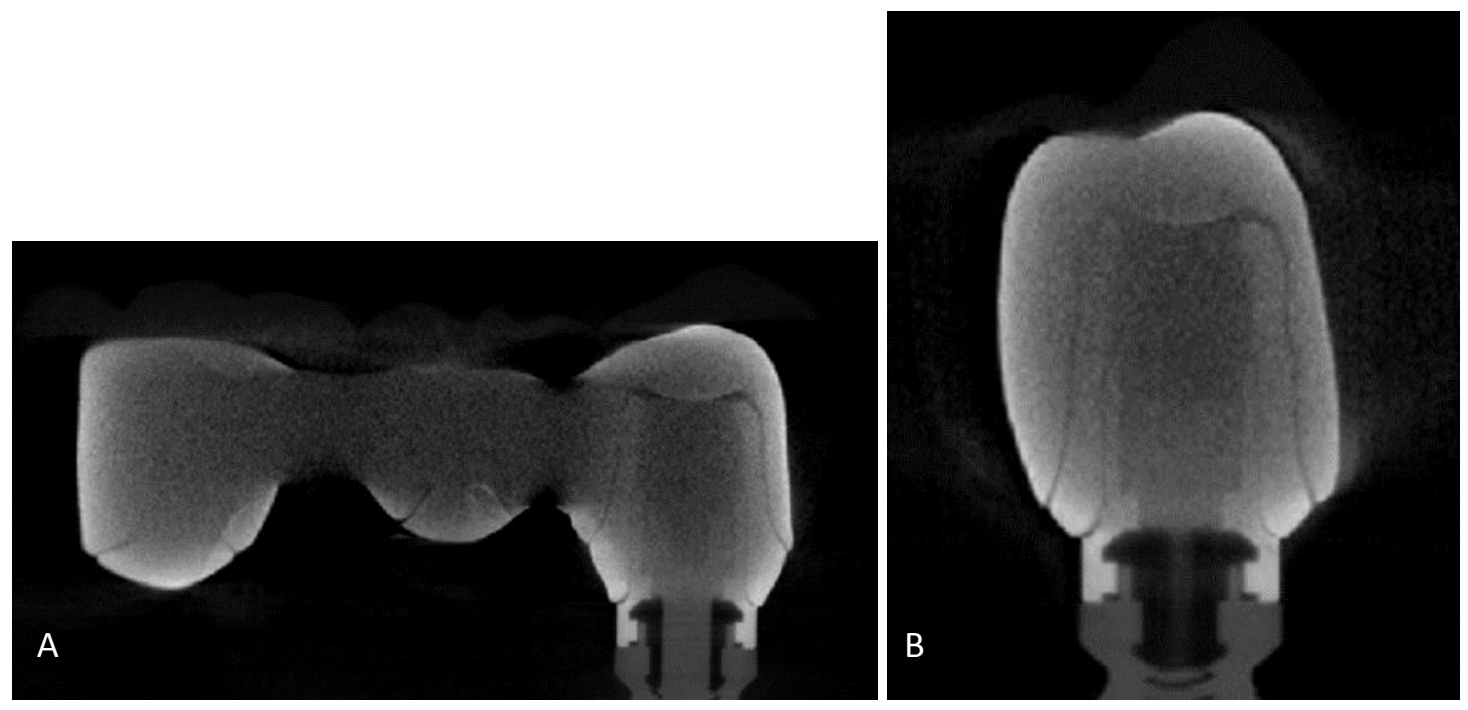

Figura 128: Adaptação Lava PM cortes coronal (A) e sagital (B), respectivamente, após prensagem da porcelana e ciclagem
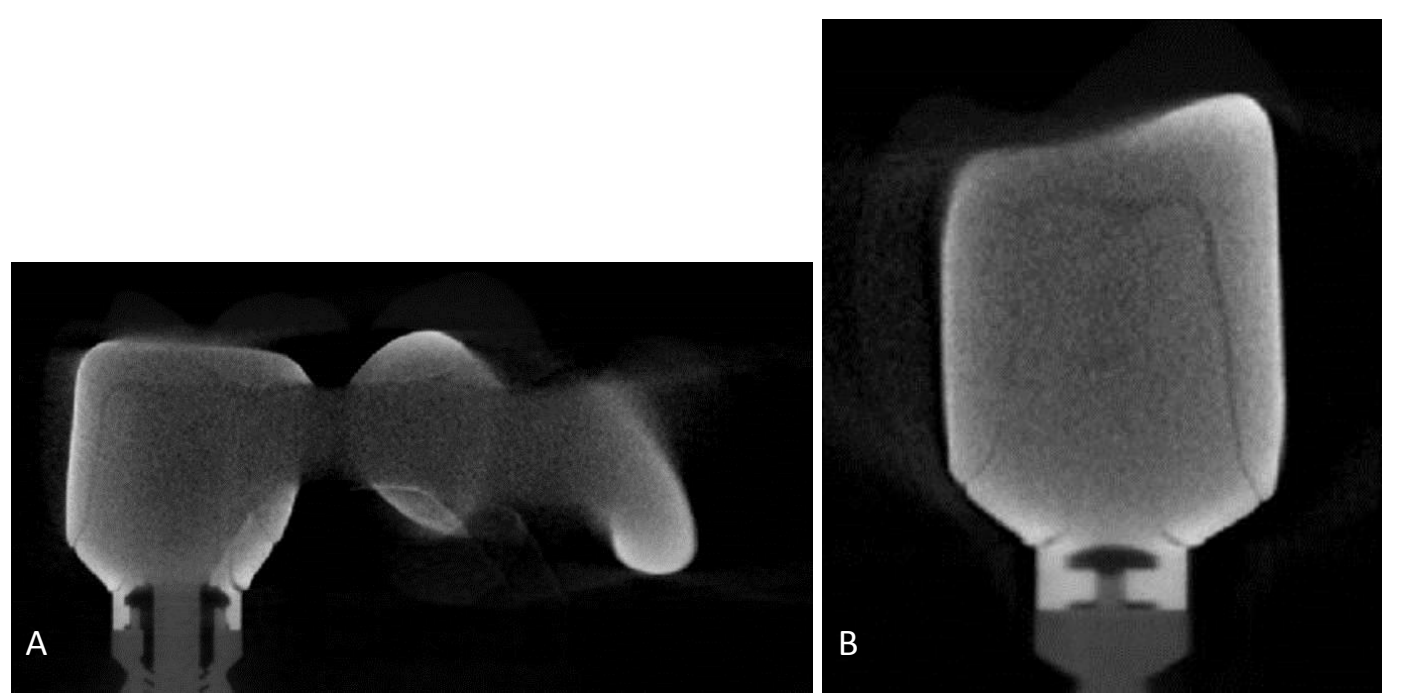

Figura 129: Adaptação Lava $M$ cortes coronal (A) e sagital (B), respectivamente, após prensagem da porcelana e ciclagem 

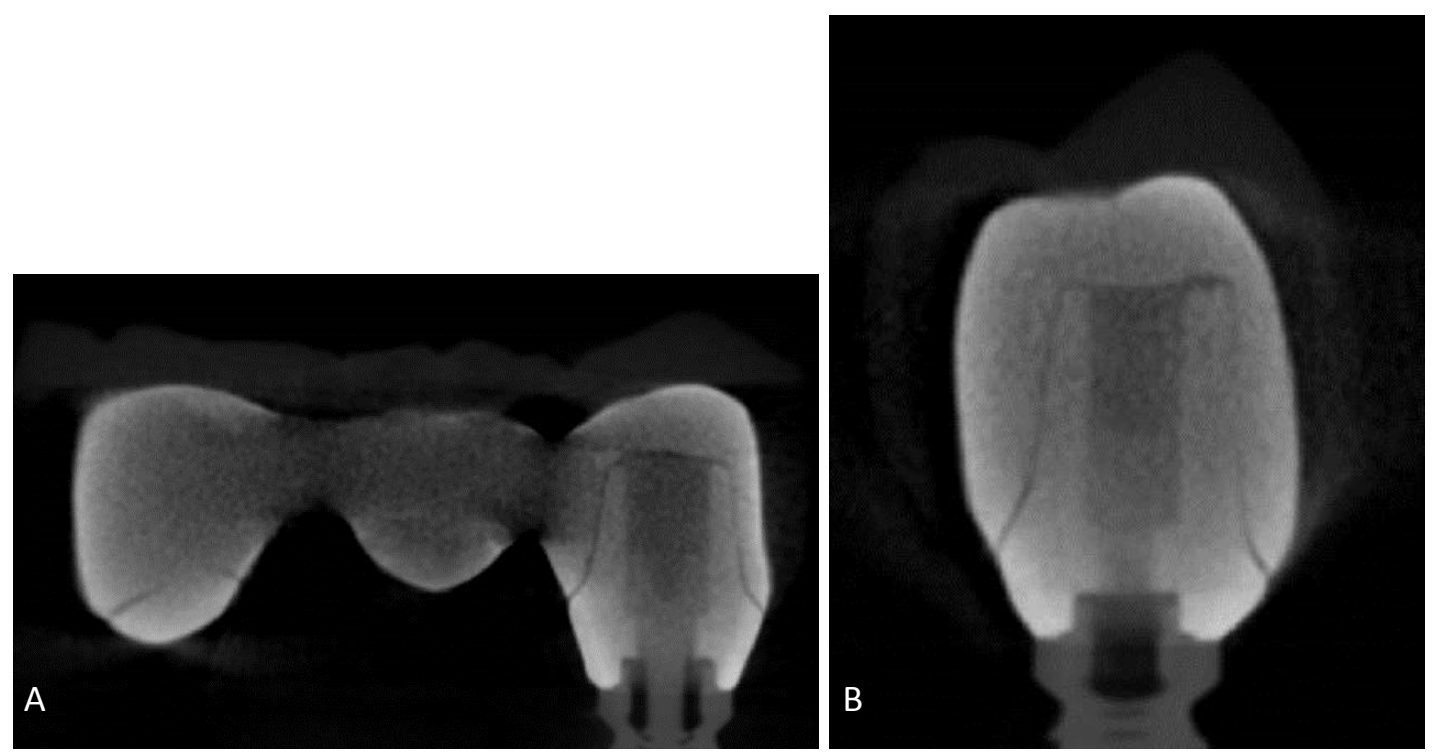

Figura 130: Adaptação Co PM cortes coronal (A) e sagital (B), respectivamente, após prensagem da porcelana e ciclagem
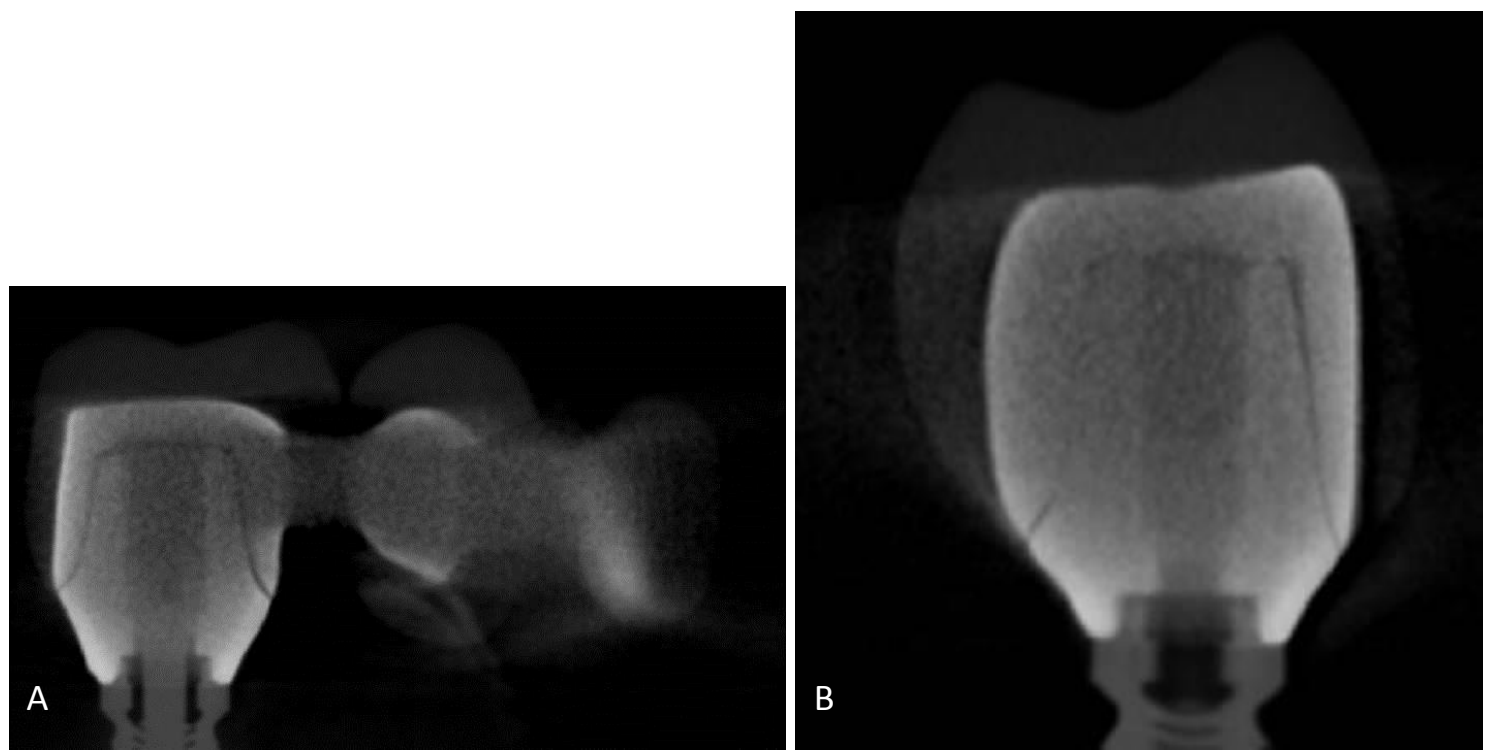

Figura 131: Adaptação Co M cortes coronal (A) e sagital (B), respectivamente, após prensagem da porcelana e ciclagem

Os dados referentes à desadaptação vertical - prótese fixa/pilares PM dos quatro grupos após a prensagem da porcelana e ciclagem foram tabulados (Tabela 10 - anexo 5) e submetidos à análise estatística. 
Tabela 11: Comparações, considerando a adaptação VERTICAL nos PM após a ciclagem termomecânica:

\begin{tabular}{ccccc}
\hline \multirow{2}{*}{ Comparações } & Diferença entre as & \multicolumn{2}{c}{ IC 95\% } & \\
\cline { 3 - 4 } & médias & LI & LS & $\boldsymbol{p}$ \\
\hline (TiNeo - ZirNeo) PM & $-0,005$ & $-0,557$ & 0,547 & 0,985 \\
(TiNeo - Lava) PM & 0,368 & $-0,185$ & 0,920 & 0,190 \\
(TiNeo - Co) PM & $-0,312$ & $-0,857$ & 0,233 & 0,259 \\
(ZirNeo - Lava) PM & 0,362 & $-0,190$ & 0,914 & 0,196 \\
(ZirNeo - Co) PM & $-0,317$ & $-0,862$ & 0,228 & 0,251 \\
(Lava - Co) PM & $-0,680$ & $-1,225$ & $-0,135$ & $0,015^{*}$ \\
\hline
\end{tabular}

*Diferença significante $(p<0,05)$

Houve diferença significante na desadaptação vertical dos pré-molares entre os grupos Lava e Controle (Tabela 11) sendo o grupo Lava com maiores valores de desadaptação. Abaixo o gráfico da adaptação vertical dos pré-molares após a prensagem da porcelana e ciclagem - Figura 132.

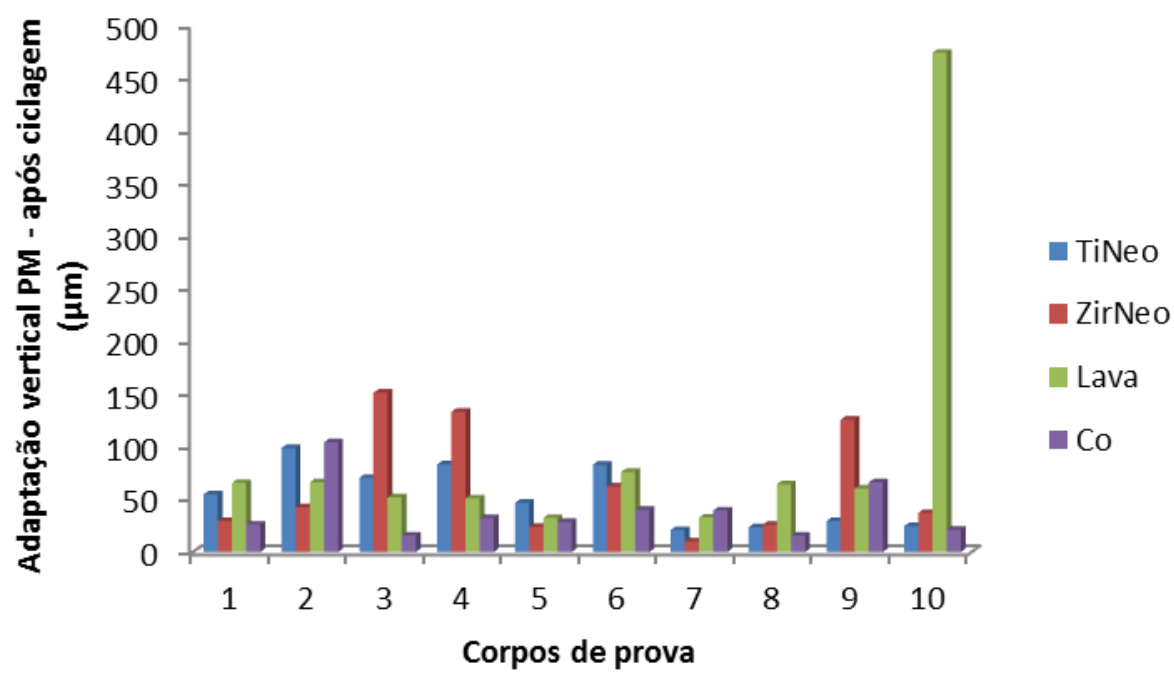

Figura 132: Adaptação Vertical entre prótese/pilares PM após ciclagem $(\mu \mathrm{m})$

Os dados referentes à desadaptação vertical - prótese fixa/pilares M dos quatro grupos após a prensagem da porcelana e ciclagem foram tabulados (Tabela 11 - anexo 5) e submetidos à análise estatística. 
Tabela 12: Comparações, considerando a adaptação VERTICAL nos $M$ após a ciclagem termomecânica:

\begin{tabular}{ccccc}
\hline \multirow{2}{*}{ Comparações } & Diferença entre as & \multicolumn{2}{c}{ IC 95\% } & \\
\cline { 3 - 4 } & médias & LI & LS & $\boldsymbol{p}$ \\
\hline (TiNeo - ZirNeo) M & $-0,323$ & $-0,875$ & 0,229 & 0,249 \\
(TiNeo - Lava) M & 0,614 & 0,062 & 1,166 & $0,030^{*}$ \\
(TiNeo - Co) M & $-0,190$ & $-0,754$ & 0,374 & 0,505 \\
(ZirNeo - Lava) M & 0,292 & $-0,260$ & 0,844 & 0,297 \\
(ZirNeo - Co) M & $-0,513$ & $-1,076$ & 0,051 & 0,074 \\
(Lava - Co) M & $-0,804$ & $-1,368$ & $-0,241$ & $0,006^{*}$ \\
\hline
\end{tabular}

*Diferença significante $(p<0,05)$

Houve diferença significante na desadaptação vertical dos molares entre os grupos TiNeo e Lava e Lava e Controle (Tabela 12) sendo os maiores valores para o grupo Lava. Abaixo o gráfico da adaptação vertical dos molares após a prensagem da porcelana e ciclagem - Figura 133.

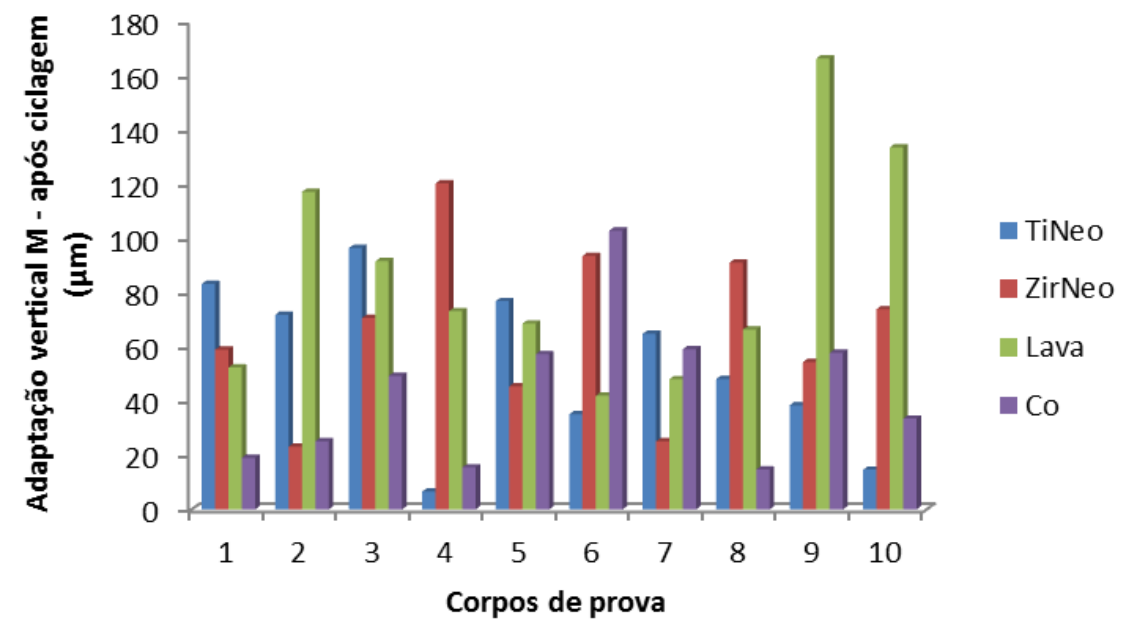

Figura 133: Adaptação Vertical entre Prótese/pilares M após ciclagem $(\mu \mathrm{m})$

Os dados referentes à desadaptação horizontal - prótese fixa/pilares PM dos quatro grupos após a prensagem da porcelana e ciclagem foram tabulados (Tabela 12 - anexo 6) e submetidos à análise estatística 
Tabela 13: Comparações, considerando a adaptação HORIZONTAL nos PM após a ciclagem termomecânica:

\begin{tabular}{ccccc}
\hline Comparações & $\begin{array}{c}\text { Diferença entre as } \\
\text { médias }\end{array}$ & $\boldsymbol{p}$ & \multicolumn{2}{c}{ IC 95\% } \\
\cline { 4 - 6 } & 1,063 & 0,295 & $-0,969$ & 3,095 \\
\hline (TiNeo - ZirNeo) PM & $-0,612$ & 0,308 & $-1,816$ & 0,592 \\
(TiNeo - Lava) PM & $-0,654$ & 0,517 & $-2,686$ & 1,378 \\
(TiNeo - Co) PM & 0,451 & 0,657 & $-1,599$ & 2,501 \\
(ZirNeo - Lava) PM & 0,409 & 0,753 & $-2,214$ & 3,033 \\
(ZirNeo - Co) PM & $-0,042$ & 0,967 & $-2,092$ & 2,008 \\
(Lava - Co) PM & & & & \\
\hline
\end{tabular}

*Diferença significante $(p<0,05)$

Não houve diferença significante na desadaptação horizontal dos pré-molares para nenhum dos grupos avaliados (Tabela 13). Abaixo o gráfico da adaptação horizontal dos prémolares após a prensagem da porcelana e ciclagem - Figura 134.

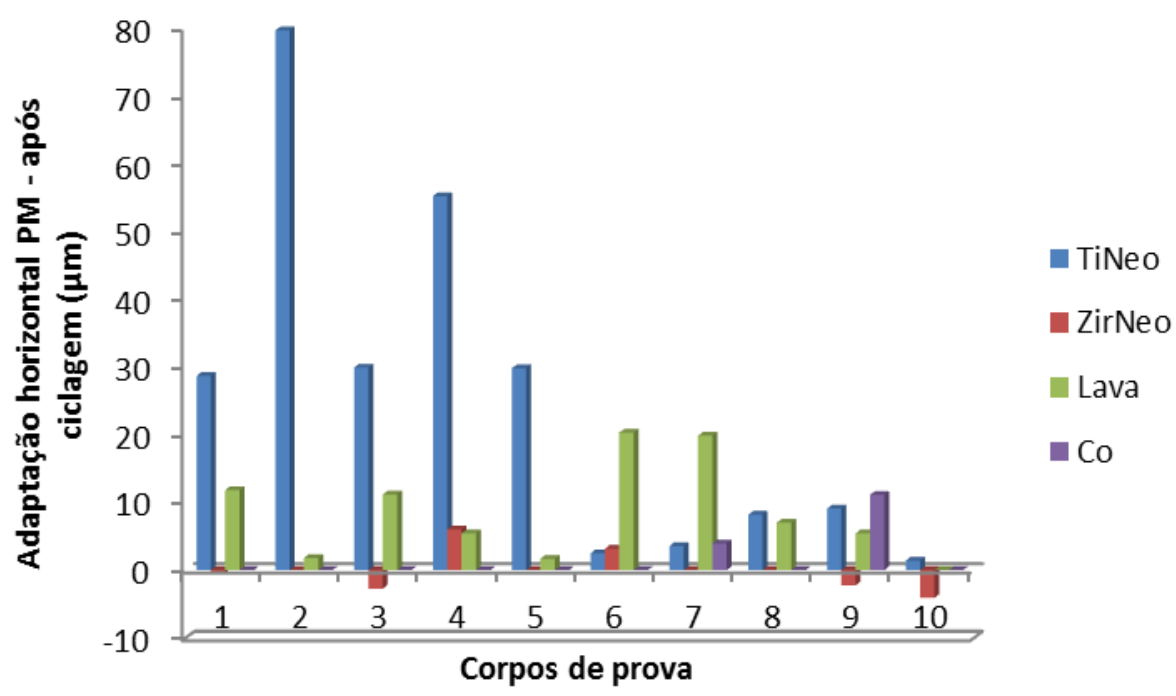

Figura 134: Adaptação Horizontal entre prótese/pilares PM após ciclagem $(\mu \mathrm{m})$

Os dados referentes à desadaptação horizontal - prótese fixa/pilares $\mathrm{M}$ dos quatro grupos após a prensagem da porcelana e ciclagem foram tabulados (Tabela 13 - anexo 6) e submetidos à análise estatística. 
Tabela 14: Comparações, considerando a adaptação HORIZONTAL nos $M$ após a ciclagem termomecânica:

\begin{tabular}{ccccc}
\hline Comparações & Diferença entre as & & \multicolumn{2}{c}{ IC 95\% } \\
\cline { 4 - 5 } & médias & $\boldsymbol{p}$ & LI & LS \\
\hline (TiNeo - ZirNeo) M & $-0,032$ & 0,982 & $-2,892$ & 2,829 \\
(TiNeo - Lava) M & $-0,299$ & 0,715 & $-1,949$ & 1,351 \\
(TiNeo - Co) M & $-0,886$ & 0,533 & $-3,751$ & 1,979 \\
(ZirNeo - Lava) M & $-0,331$ & 0,815 & $-3,191$ & 2,529 \\
(ZirNeo - Co) M & $-0,918$ & 0,616 & $-4,614$ & 2,778 \\
(Lava - Co) M & $-0,587$ & 0,679 & $-3,451$ & 2,277 \\
\hline
\end{tabular}

*Diferença significante $(p<0,05)$

Não houve diferença estatisticamente significante na desadaptação horizontal dos molares para nenhum dos grupos avaliados (Tabela 14). Abaixo o gráfico da adaptação horizontal dos molares após a prensagem da porcelana e ciclagem - Figura 135.

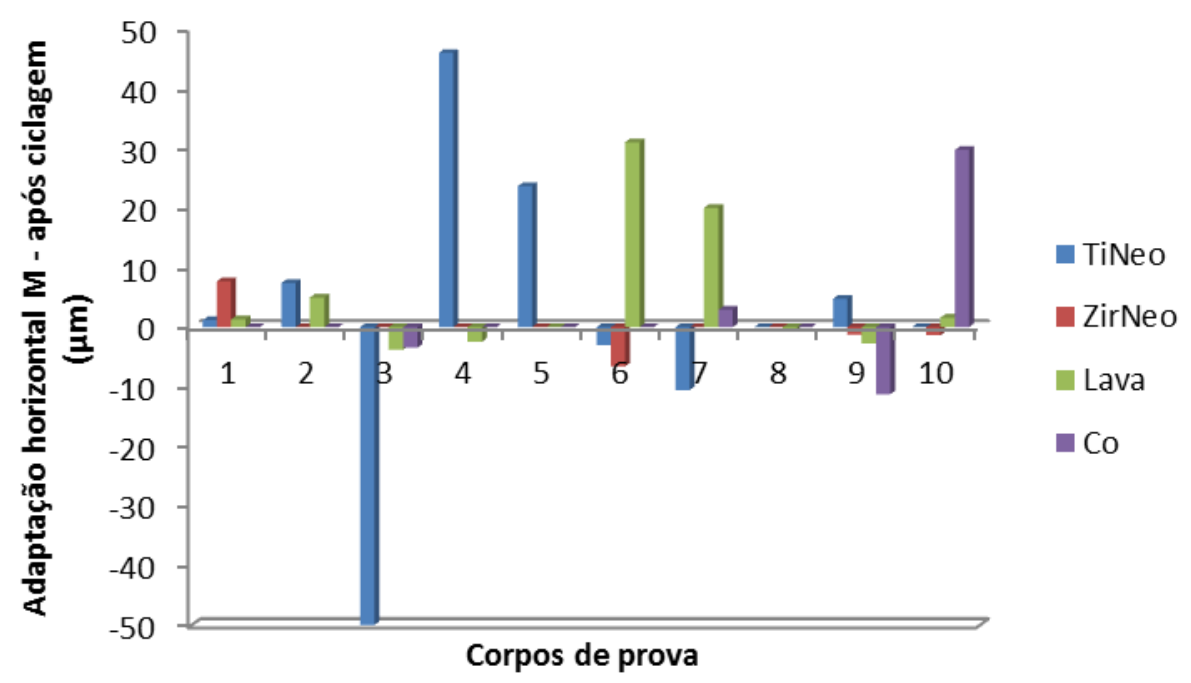

Figura 135: Adaptação Horizontal entre prótese/pilares M após ciclagem $(\mu \mathrm{m})$

Os dados referentes à desadaptação interna axial - prótese fixa/pilares PM dos quatro grupos após a prensagem da porcelana e ciclagem foram tabulados (Tabela 14 - anexo 7) e submetidos à análise estatística. 
Tabela 15: Comparações, considerando a adaptação INTERNA AXIAL nos PM após da ciclagem termomecânica:

\begin{tabular}{ccccc}
\hline & Diferença entre as & & \multicolumn{2}{c}{ IC 95\% } \\
\cline { 3 - 5 } Comparações & médias & $\boldsymbol{p}$ & LI & LS \\
\hline (ZirNeo - Lava) PM & $-0,034$ & 0,900 & $-0,576$ & 0,507 \\
(ZirNeo - Co) PM & $-0,367$ & 0,175 & $-0,901$ & 0,166 \\
(Lava - Co) PM & $-0,333$ & 0,207 & $-0,854$ & 0,188 \\
\hline
\end{tabular}

*Diferença significante $(p<0,05)$

Não houve diferença significante na desadaptação interna axial nos pré-molares.

(Tabela 15). Abaixo o gráfico da adaptação interna axial nos pré-molares após a prensagem da porcelana e ciclagem - Figura 136.

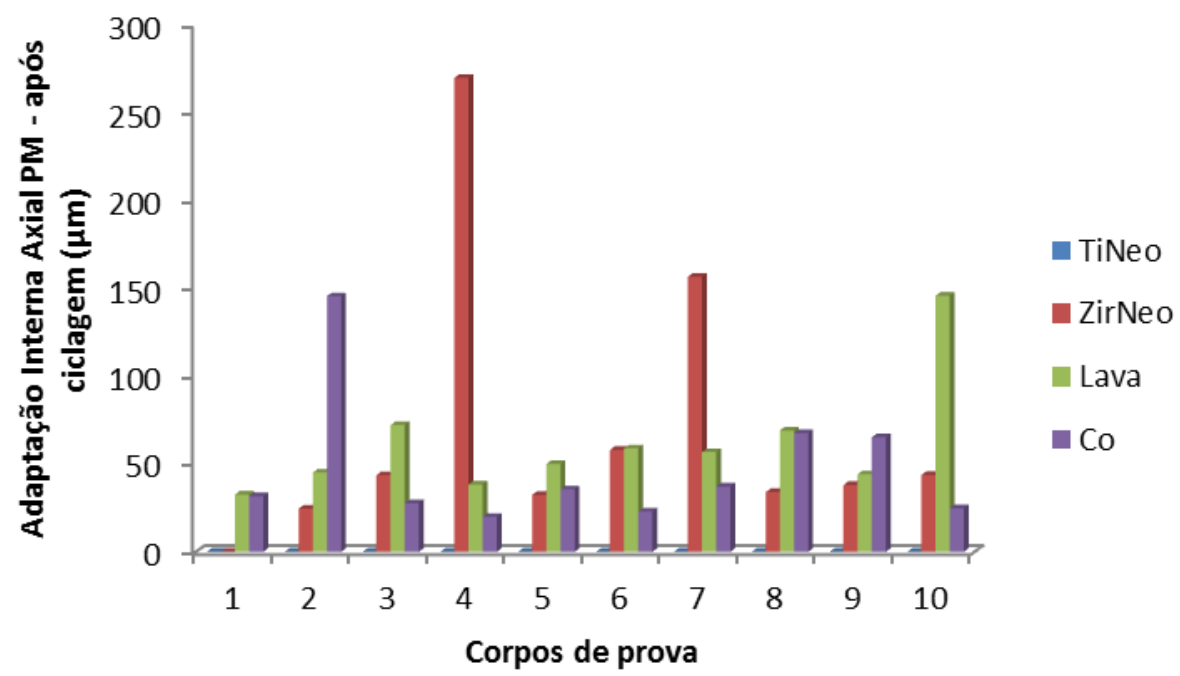

Figura 136: Adaptação Interna Axial entre prótese/pilares PM após ciclagem $(\mu \mathrm{m})$

Os dados referentes à desadaptação interna axial - prótese fixa/pilares $\mathrm{M}$ dos quatro grupos após a prensagem da porcelana e ciclagem foram tabulados (Tabela 15 - anexo 7) e submetidos à análise estatística. 
Tabela 16: Comparações, considerando a adaptação INTERNA AXIAL nos $M$ após da ciclagem termomecânica:

\begin{tabular}{ccccc}
\hline Comparações & Diferença entre as & & \multicolumn{2}{c}{ IC 95\% } \\
\cline { 4 - 5 } & médias & $\boldsymbol{p}$ & LI & LS \\
\hline (ZirNeo - Lava) M & 0,603 & $0,026^{*}$ & 0,074 & 1,132 \\
(ZirNeo - Co) M & 1,003 & $0,000^{*}$ & 0,462 & 1,544 \\
(Lava - Co) M & $-0,454$ & 0,099 & $-0,995$ & 0,087 \\
\hline
\end{tabular}

*Diferença significante $(p<0,05)$

Houve diferença significante na desadaptação interna axial nos molares para os grupos ZirNeo e Lava e ZirNeo e Controle (Tabela 16). Abaixo o gráfico da adaptação Interna Axial nos Molares após a prensagem da porcelana e ciclagem - Figura 137 demonstrando que a desadaptação do grupo ZirNeo em geral foram menores que os grupos Lava e Controle.

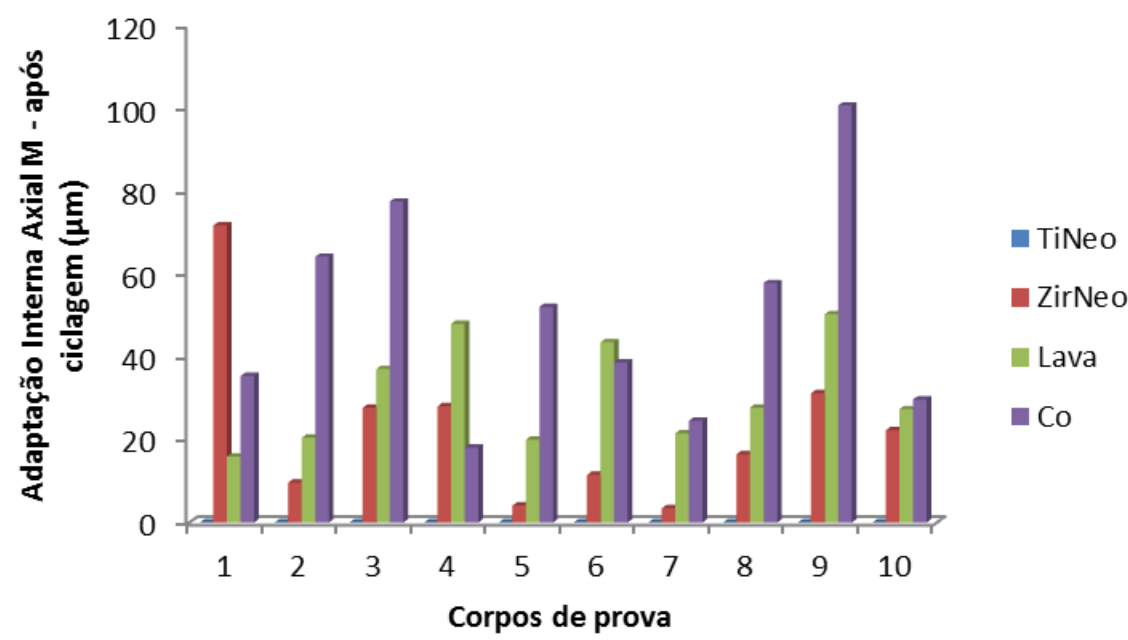

Figura 137: Adaptação Interna Axial entre prótese/pilares M após ciclagem $(\mu \mathrm{m})$

Os dados referentes à desadaptação interna oclusal - prótese fixa/pilares PM dos quatro grupos após a prensagem da porcelana e ciclagem foram tabulados (Tabela 16 - anexo 7 e submetidos à análise estatística. 
Tabela 17: Comparações, considerando a adaptação INTERNA OCLUSAL nos PM após a ciclagem termomecânica:

\begin{tabular}{ccccc}
\hline Comparações & $\begin{array}{c}\text { Diferença entre as } \\
\text { médias }\end{array}$ & $\boldsymbol{p}$ & \multicolumn{2}{c}{ IC 95\% } \\
\cline { 4 - 5 } & $-0,387$ & 0,198 & $\mathbf{L S}$ \\
\hline (TiNeo - ZirNeo) PM & 0,539 & 0,074 & $-0,053$ & 1,131 \\
(TiNeo - Lava) PM & $-0,132$ & 0,655 & $-0,716$ & 0,452 \\
(TiNeo - Co) PM & 0,152 & 0,611 & $-0,440$ & 0,744 \\
(ZirNeo - Lava) PM & $-0,519$ & 0,081 & $-1,103$ & 0,065 \\
(ZirNeo - Co) PM & $-0,671$ & $0,025^{*}$ & $-1,255$ & $-0,087$ \\
(Lava - Co) PM & & & &
\end{tabular}

*Diferença significante $(p<0,05)$

Houve diferença significante na desadaptação interna oclusal nos pré-molares entre os grupos Lava e Controle (Tabela 17) sendo os maiores valores de desadaptação para o grupo Lava. Abaixo o gráfico da adaptação interna oclusal nos pré-molares após a prensagem da porcelana e ciclagem - Figura 138.

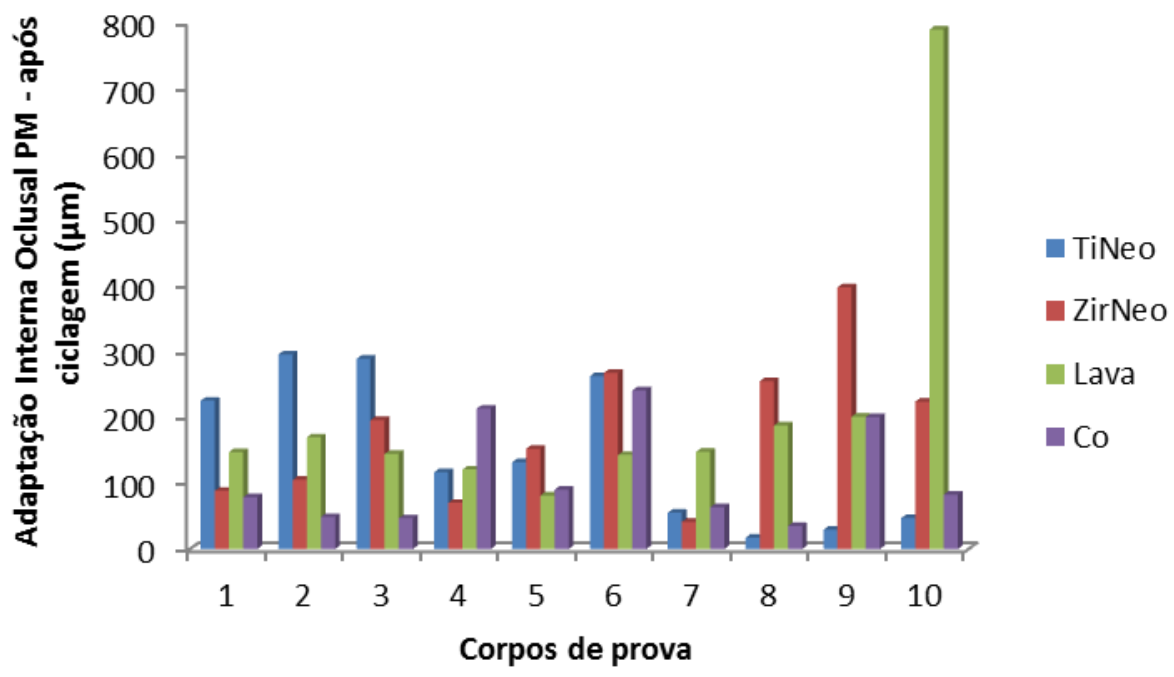

Figura 138: Adaptação Interna Oclusal entre prótese/pilares PM após ciclagem $(\mu \mathrm{m})$ 
Os dados referentes à desadaptação interna oclusal - prótese fixa/pilares $\mathrm{M}$ dos quatro grupos após a prensagem da porcelana e ciclagem foram tabulados (Tabela 17 - anexo 7) e submetidos à análise estatística.

Tabela 18: Comparações, considerando a adaptação INTERNA OCLUSAL nos M após a ciclagem termomecânica:

\begin{tabular}{ccccc}
\hline Comparações & Diferença entre as & & \multicolumn{2}{c}{ IC 95\% } \\
\cline { 3 - 5 } & médias & $\boldsymbol{p}$ & LI & LS \\
\hline (TiNeo - ZirNeo) M & 0,252 & 0,419 & $-0,365$ & 0,869 \\
(TiNeo - Lava) M & 0,010 & 0,974 & $-0,607$ & 0,627 \\
(TiNeo - Co) M & 0,084 & 0,792 & $-0,547$ & 0,716 \\
(ZirNeo - Lava) M & 0,262 & 0,401 & $-0,355$ & 0,879 \\
(ZirNeo - Co) M & 0,336 & 0,294 & $-0,295$ & 0,968 \\
(Lava - Co) M & 0,074 & 0,817 & $-0,557$ & 0,706 \\
\hline
\end{tabular}

*Diferença significante $(p<0,05)$

Não houve diferença significante na desadaptação interna oclusal nos molares entre nenhum dos grupos avaliados (Tabela 18). Abaixo o gráfico da adaptação interna oclusal nos Molares após a prensagem da porcelana e ciclagem - Figura 139.

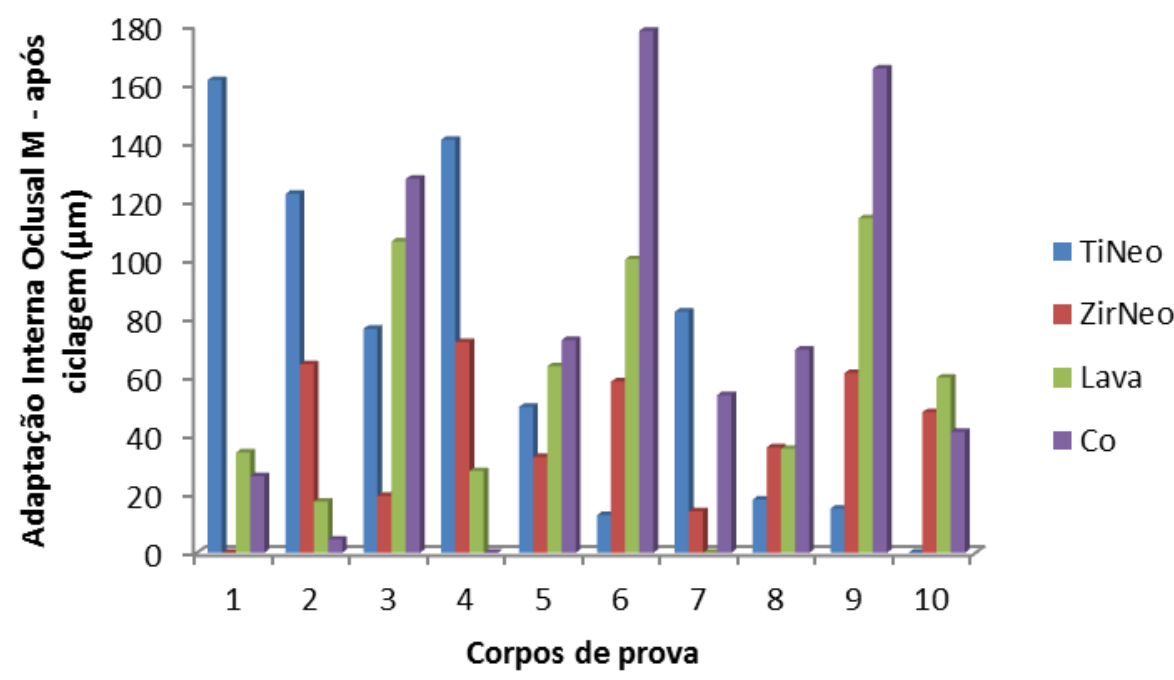

Figura 139: Adaptação Interna Oclusal entre prótese/pilares $M$ após ciclagem $(\mu \mathrm{m})$ 
5.4 Adaptação marginal (vertical e horizontal) e interna (oclusal e axial) antes e após prensagem da porcelana e ciclagem (MicroCT)

Tabela 19: Comparações, considerando a adaptação VERTICAL, antes e após ciclagem termomecânica:

\begin{tabular}{ccccc}
\hline \multirow{2}{*}{ Comparações } & Diferença entre as & \multicolumn{2}{c}{ IC 95\% } & \\
\cline { 3 - 4 } & médias & LI & LS & p \\
\hline TiNeo PM & $-0,041$ & $-0,487$ & 0,405 & 0,857 \\
TiNeo M & 0,412 & $-0,034$ & 0,858 & 0,070 \\
ZirNeo PM & $-0,127$ & $-0,573$ & 0,319 & 0,573 \\
ZirNeo M & 0,269 & $-0,177$ & 0,715 & 0,234 \\
Lava PM & $-0,124$ & $-0,570$ & 0,322 & 0,582 \\
Lava M & 0,186 & $-0,260$ & 0,632 & 0,411 \\
Co PM & 0,013 & $-0,424$ & 0,450 & 0,953 \\
Co M & $-0,232$ & $-0,692$ & 0,229 & 0,321 \\
\hline
\end{tabular}

*Diferença significante $(p<0,05)$

Não houve diferença significante na desadaptação vertical dos pré-molares e molares, antes e após a ciclagem, entre nenhum dos grupos avaliados (Tabela 19). Abaixo segue o gráfico ilustrando a mediana e o desvio padrão da desadaptação vertical de cada grupo (Figura 140). 


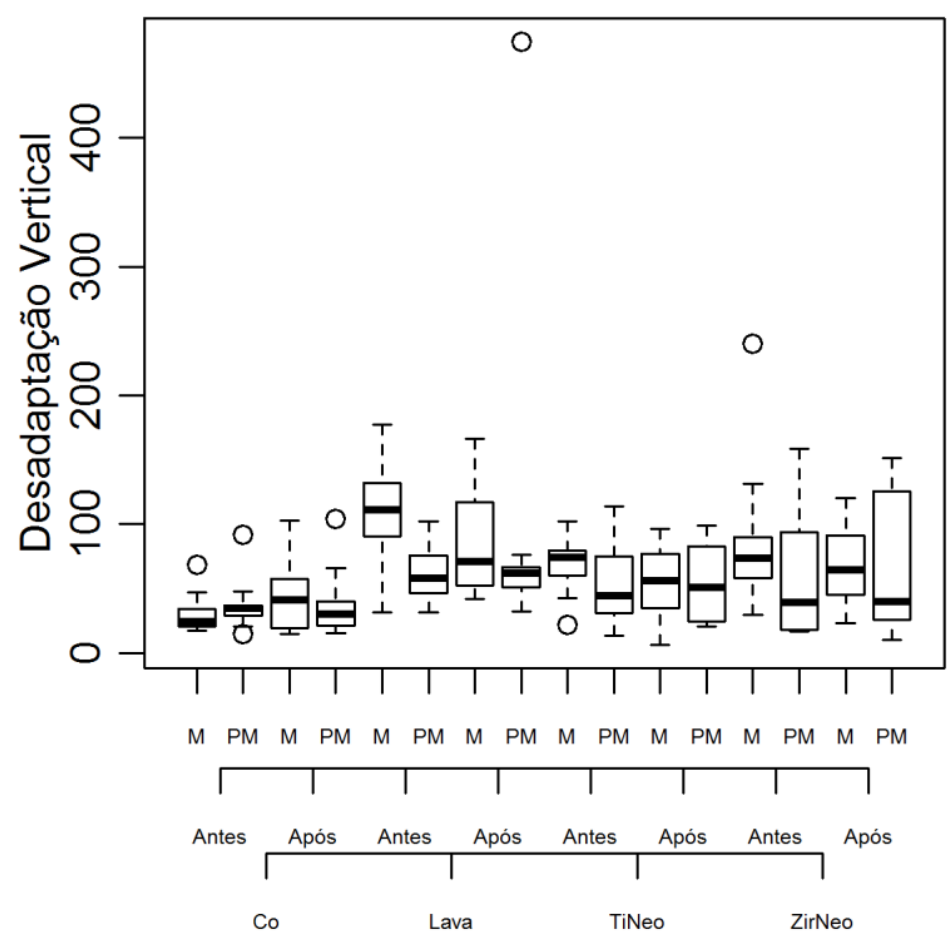

Figura 140: Desadaptação vertical $(\mu \mathrm{m})$ antes e após ciclagem dos quatro grupos

Tabela 20: Comparações, considerando a adaptação HORIZONTAL antes e após a ciclagem termomecânica:

\begin{tabular}{ccccc}
\hline Comparações & Diferença entre as & & \multicolumn{2}{c}{ IC 95\% } \\
\cline { 4 - 6 } & médias & $\boldsymbol{p}$ & LI & LS \\
\hline TiNeo PM & $-0,607$ & 0,378 & $-1,987$ & 0,774 \\
TiNeo M & $-0,981$ & 0,225 & $-2,595$ & 0,633 \\
ZirNeo PM & $-0,289$ & 0,797 & $-2,560$ & 1,981 \\
ZirNeo M & $-0,704$ & 0,614 & $-3,515$ & 2,108 \\
Lava PM & 0,422 & 0,457 & $-0,721$ & 1,564 \\
Lava M & 1,196 & 0,100 & $-0,243$ & 2,634 \\
Co PM & $-0,726$ & 0,541 & $-3,119$ & 1,668 \\
Co M & 0,312 & 0,835 & $-2,709$ & 3,334 \\
\hline
\end{tabular}

*Diferença significante $(p<0,05)$

Não houve diferença significante na desadaptação horizontal dos pré-molares e molares, antes e após a ciclagem, para nenhum dos grupos avaliados (Tabela 20). Abaixo segue o gráfico ilustrando a mediana e o desvio padrão da desadaptação horizontal de cada grupo (Figura 141). 


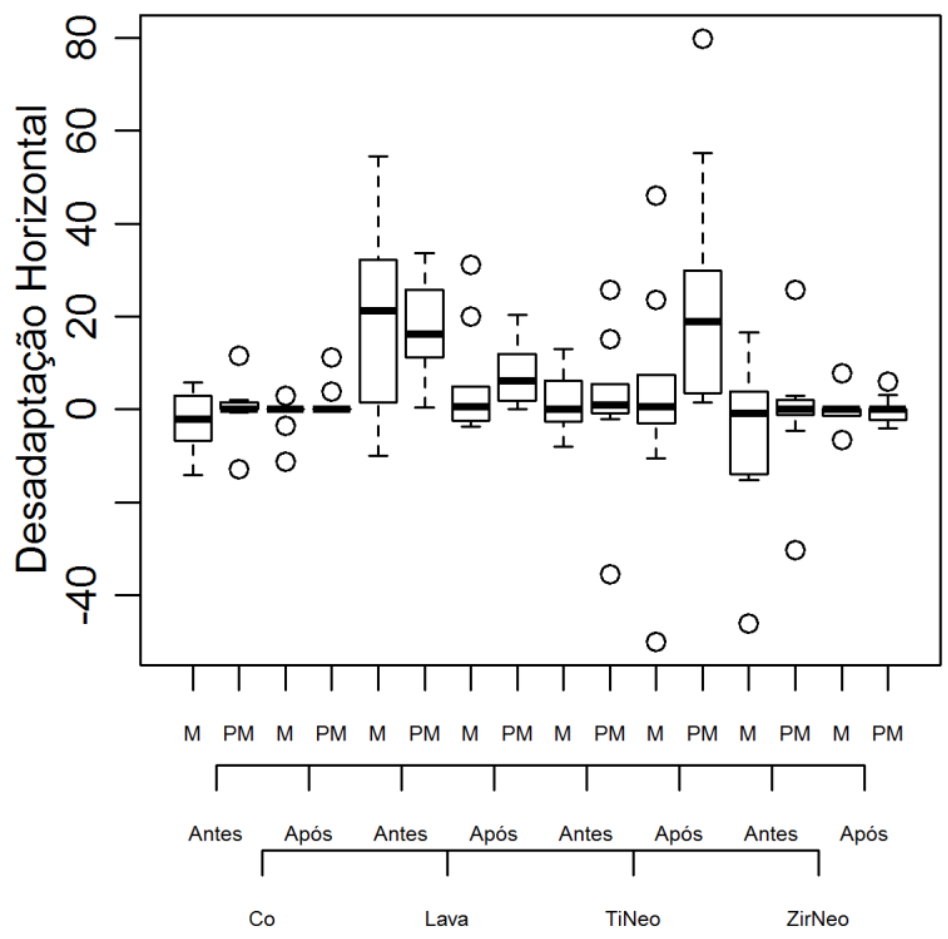

Figura 141: Desadaptação Horizontal $(\mu \mathrm{m})$ antes e após ciclagem dos quatro grupos

Tabela 21: Comparações, considerando a adaptação INTERNA AXIAL antes e após a ciclagem termomecânica:

\begin{tabular}{rcccc}
\hline Comparações & $\begin{array}{c}\text { Diferença entre as } \\
\text { médias }\end{array}$ & $\boldsymbol{p}$ & \multicolumn{2}{c}{ IC 95\% } \\
\cline { 4 - 6 } & 0,123 & 0,599 & $-0,341$ & 0,587 \\
ZirNeo PM & 0,957 & $<, 0001^{*}$ & 0,508 & 1,407 \\
ZirNeo M & 0,179 & 0,430 & $-0,271$ & 0,629 \\
Lava PM & 0,855 & $0,000^{*}$ & 0,405 & 1,304 \\
Lava M & 0,260 & 0,244 & $-0,181$ & 0,701 \\
Co PM & 0,157 & 0,502 & $-0,307$ & 0,621 \\
Co M & & & & \\
\hline
\end{tabular}

*Diferença significante $(p<0,05)$

Houve diferença significante na desadaptação interna axial para os molares, antes e após a ciclagem, para os grupos ZirNeo e Lava (Tabela 21) sendo que os valores diminuíram após a ciclagem. Abaixo segue o gráfico ilustrando a mediana e o desvio padrão da desadaptação interna axial de cada grupo (Figura 142). 


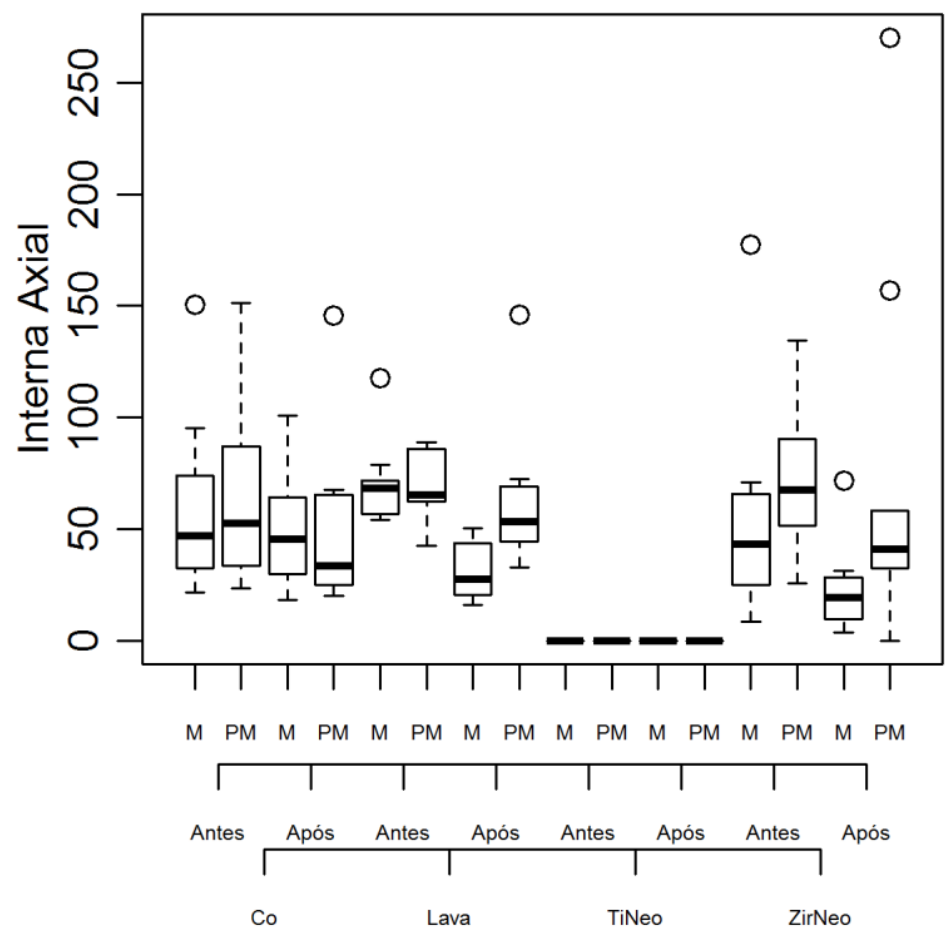

Figura 142: Desadaptação Interna Axial antes e após ciclagem dos quatro grupos $(\mu \mathrm{m})$

Tabela 22: Comparações, considerando a adaptação INTERNA OCLUSAL antes e após a ciclagem termomecânica:

\begin{tabular}{ccccc}
\hline Comparações & Diferença entre as & \multicolumn{2}{c}{ IC 95\% } \\
\cline { 4 - 5 } médias & 0,745 & $\boldsymbol{p}$ & LI & LS \\
\hline TiNeo PM & 0,149 & $0,002^{*}$ & 0,271 & 1,218 \\
TiNeo M & 0,560 & $-0,356$ & 0,654 \\
ZirNeo PM & 0,435 & 0,072 & $-0,039$ & 0,909 \\
ZirNeo M & 1,438 & $<, 0001^{*}$ & 0,948 & 1,927 \\
Lava PM & $-0,029$ & 0,902 & $-0,503$ & 0,444 \\
Lava M & 0,763 & $0,003^{*}$ & 0,273 & 1,252 \\
Co PM & 0,474 & $0,046^{*}$ & 0,009 & 0,938 \\
Co M & 0,383 & 0,138 & $-0,125$ & 0,891 \\
\hline
\end{tabular}

*Diferença significante $(p<0,05)$

Houve diferença significante na desadaptação interna oclusal, antes e após a ciclagem, para os grupos: TiNeo Pré Molar, Controle Pré Molar, ZirNeo Molar e Lava Molar (Tabela 22) sendo que todos os valores de desadaptação diminuíram após a ciclagem. Abaixo 
segue o gráfico ilustrando a mediana e o desvio padrão da desadaptação interna oclusal de cada grupo (Figura 143).

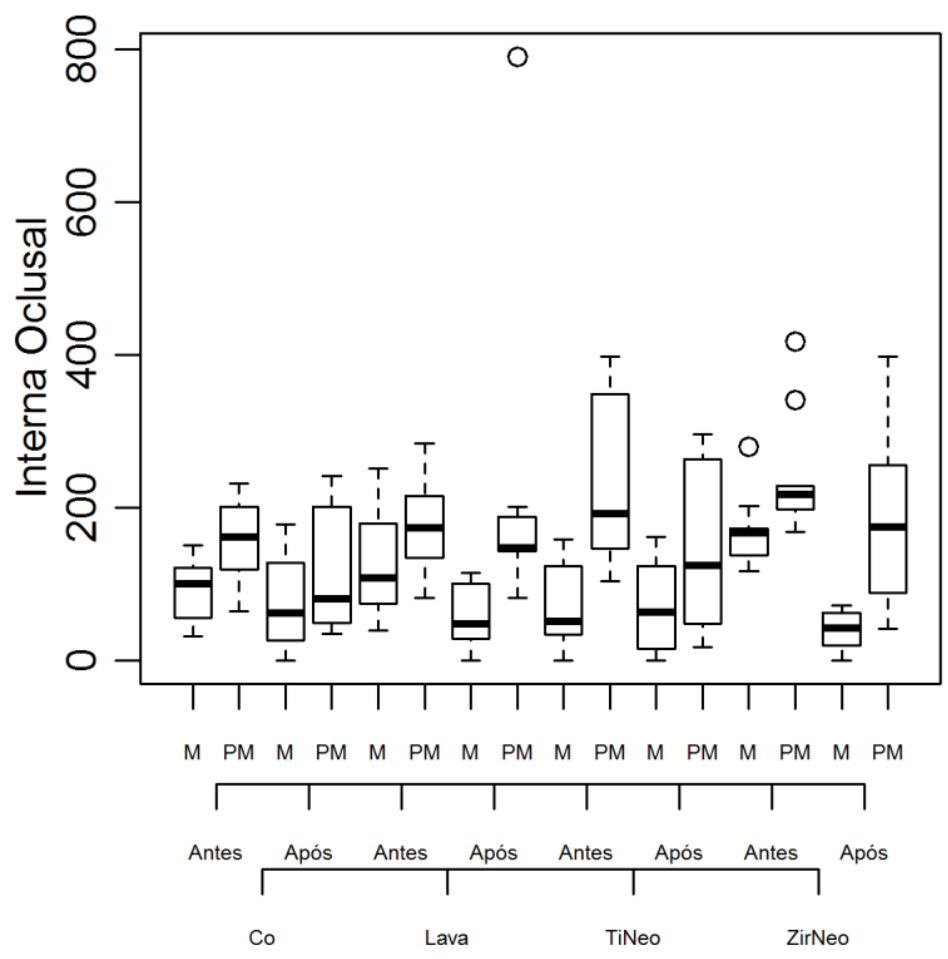

Figura 143: Desadaptação Interna Oclusal antes e após ciclagem dos quatro grupos $(\mu \mathrm{m})$

\subsection{Correlação de Imagens Digitais}

As imagens abaixo ilustram a tensão no eixo horizontal de cada grupo (Figuras 144147).

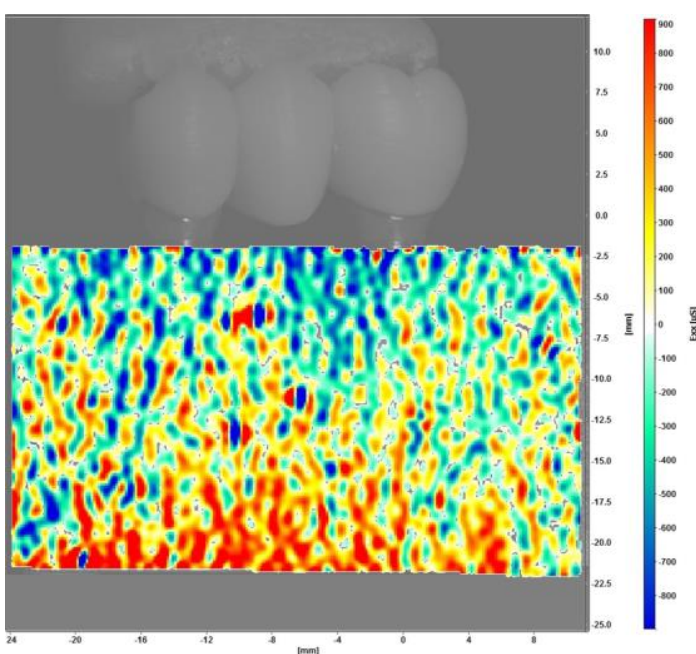

Figura 144: Grupo Ti Neo

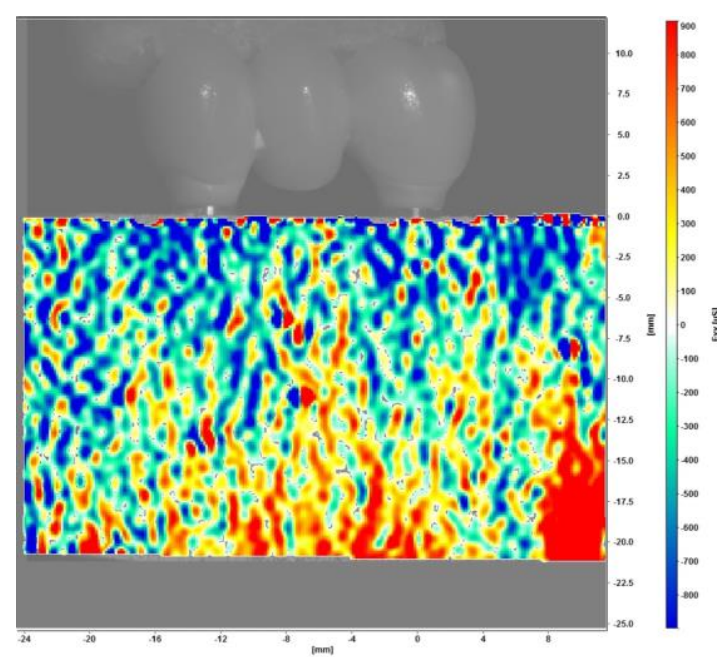

Figura 145: Grupo Zir Neo 


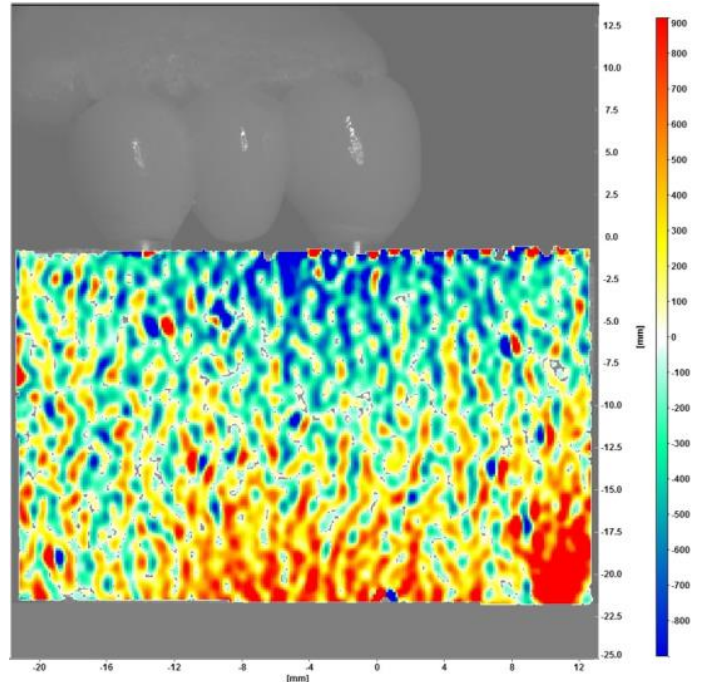

Figura 146: Grupo Lava

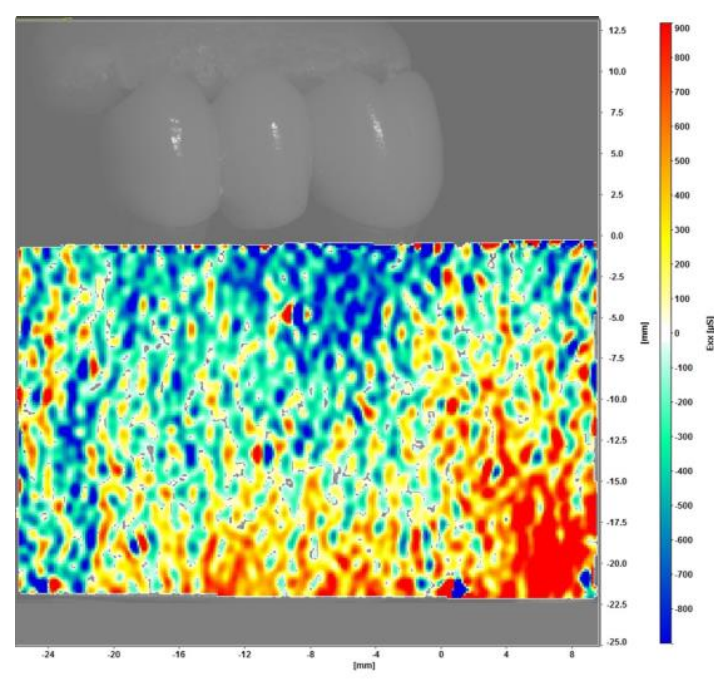

Figura 147: Grupo Controle

Na Tabela 18 (anexo 8) constam os valores de tensão em toda região de cada implante (PM e M).

Tabela 23: Médias, desvio padrão e categoria estatística $(p<0,05)$ da distribuição de tensões aos implantes - PM - nos 4 grupos TiNeo, ZirNeo, Lava e Controle

\begin{tabular}{ccccccc}
\hline Grupos & Média & Desvio & \multicolumn{2}{c}{$95 \%$ Intervalo de } & Categoria & \\
& & padrão & Confiança para Médias & estatística & $p$ \\
& & & Inferior & Superior & & \\
\hline Ti Neo & $-150,76$ & 35,54 & $-194,89$ & $-106,62$ & A & \\
Zir Neo & $-237,21$ & 138,78 & $-409,54$ & $-64,89$ & A & 0,155 \\
Lava & $-84,65$ & 88,28 & $-194,27$ & 24,96 & A & \\
Co & $-140,84$ & 106,79 & $-273,44$ & $-8,24$ & A &
\end{tabular}

*Diferença significante pelo teste Anova Oneway $(p<0,05)$

Não houve diferença significante na distribuição de tensões nos PM de todos os grupos. 
Tabela 24: Médias, desvio padrão e categoria estatística $(p<0,05)$ da distribuição de tensões aos implantes - M - nos 4 grupos TiNeo, ZirNeo, Lava e Controle

\begin{tabular}{ccccccc}
\hline \multirow{2}{*}{ Grupos } & Média & Desvio & \multicolumn{2}{c}{$95 \%$ Intervalo de } & \multirow{2}{*}{ Categoria } & \multirow{2}{*}{ Confiança para Médias } \\
& & padrão & Inferior & Superior & estatística & $p$ \\
\hline Ti Neo & 32,56 & 88,83 & $-77,73$ & 142,86 & A & \\
Zir Neo & $-73,17$ & 55,91 & $-142,60$ & $-3,75$ & B & \multirow{2}{*}{0,015} \\
Lava & 49,81 & 138,93 & $-122,70$ & 222,32 & A & \\
Co & 3,59 & 70,45 & $-83,87$ & 91,07 & AB & \\
\hline
\end{tabular}

*Diferença significante pelo teste Anova Oneway $(p<0,05)$

**Diferença significante (teste Tukey $-p<0,05$ ) representada por letras diferentes, onde B representa resultados piores do que $\mathrm{A}$

Houve diferença significante na distribuição de tensões nos $M$ entre os grupos:

TiNeo e ZirNeo, ZirNeo e Lava (sendo que os maiores valores de tensão ocorreram no grupo ZirNeo). Observa-se que nos molares do grupo Controle a média de tensão foi menor. Abaixo o gráfico das tensões em no PM e M de cada corpo de prova analisado (Figura 148).

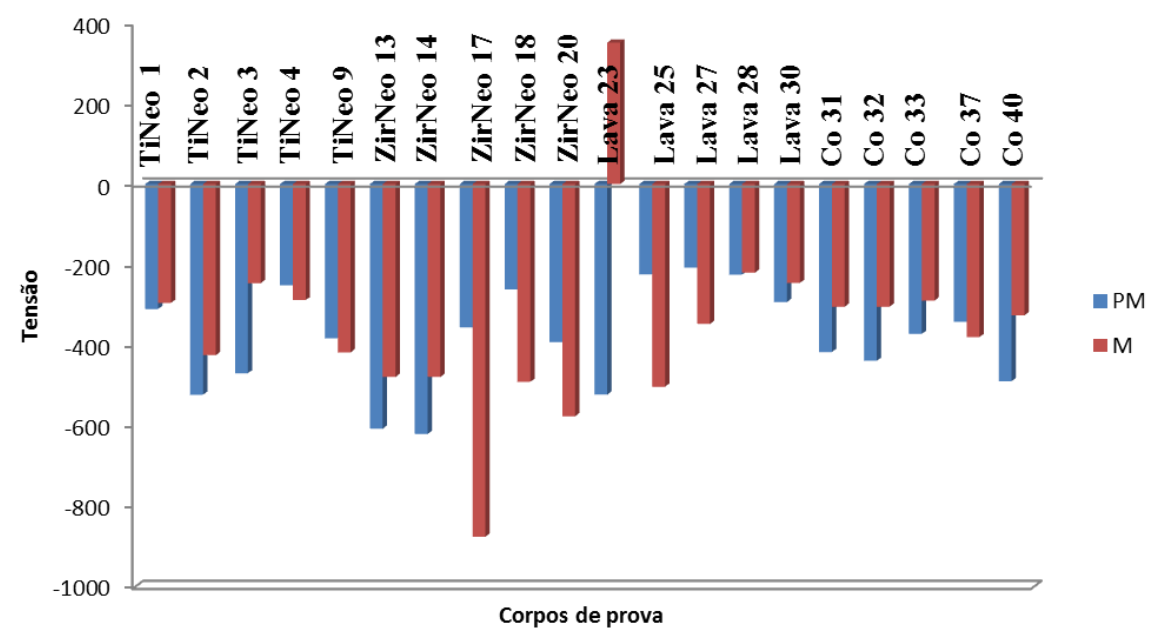

Figura 148: Tensões nos PM e M de cada corpo de prova

Na Tabela 19 (anexo 8) consta os valores de tensão na região cervical de cada implante (PM e M). 
Tabela 25: Médias, desvio padrão e categoria estatística $(p<0,05)$ da distribuição de tensões aos implantes nos 4 grupos TiNeo, ZirNeo, Lava e Controle - região cervical dos PM

\begin{tabular}{|c|c|c|c|c|c|c|}
\hline \multirow[t]{2}{*}{ Grupos } & \multirow[t]{2}{*}{ Média } & \multirow{2}{*}{$\begin{array}{l}\text { Desvio } \\
\text { padrão }\end{array}$} & \multicolumn{2}{|c|}{$\begin{array}{c}\text { 95\% Intervalo de } \\
\text { Confiança para Médias }\end{array}$} & \multirow{2}{*}{$\begin{array}{l}\text { Categoria } \\
\text { estatística }\end{array}$} & \multirow[t]{2}{*}{$p$} \\
\hline & & & Inferior & Superior & & \\
\hline Ti Neo & $-387,68$ & $-111,50$ & $-526,13$ & $-249,22$ & A & \multirow{4}{*}{0,262} \\
\hline Zir Neo & $-447,78$ & 159,58 & $-645,93$ & $-249,63$ & A & \\
\hline Lava & $-294,57$ & 131,95 & $-458,41$ & $-130,72$ & A & \\
\hline Co & $-412,13$ & 57,45 & $-483,48$ & $-340,79$ & A & \\
\hline
\end{tabular}

*Diferença significante pelo teste Anova Oneway $(p<0,05)$

Não houve diferença significante na distribuição de tensões nos implantes PM na região cervical.

Tabela 26: Médias, desvio padrão e categoria estatística $(p<0,05)$ da distribuição de tensões aos implantes nos 4 grupos TiNeo, ZirNeo, Lava e Controle - região cervical dos M

\begin{tabular}{ccccccc}
\hline \multirow{2}{*}{ Grupos } & Média & Desvio & \multicolumn{2}{c}{$95 \%$ Intervalo de } & Categoria & \multirow{2}{*}{ Confiança para Médias } \\
& & padrão & estatística & $p$ \\
& & & Inferior & Superior & & \\
\hline Ti Neo & $-334,55$ & 81,72 & $-436,02$ & $-233,08$ & AB & \\
Zir Neo & $-580,52$ & 170,26 & $-791,94$ & $-369,11$ & A & \multirow{2}{*}{0,034} \\
Lava & $-193,05$ & 324,18 & $-595,58$ & 209,47 & B & \\
Co & $-320,95$ & 35,66 & $-365,23$ & $-276,67$ & AB & \\
\hline
\end{tabular}

* Diferença significante pelo teste Anova Oneway $(p<0,05)$

**Diferença significante (teste Tukey - $p<0,05)$ representada por letras diferentes, onde B representa resultados piores do que $\mathrm{A}$

Houve diferença significante na distribuição de tensões na região cervical dos implantes $\mathrm{M}$ entre os grupos: ZirNeo e Lava, sendo que os maiores valores de tensão foram no grupo ZirNeo. Observa-se que nos molares do grupo Lava a média de tensão foi menor e no grupo ZirNeo a média de tensões foi maior. Abaixo o gráfico das tensões na cervical no PM e M de cada corpo de prova analisado (Figura 149). 


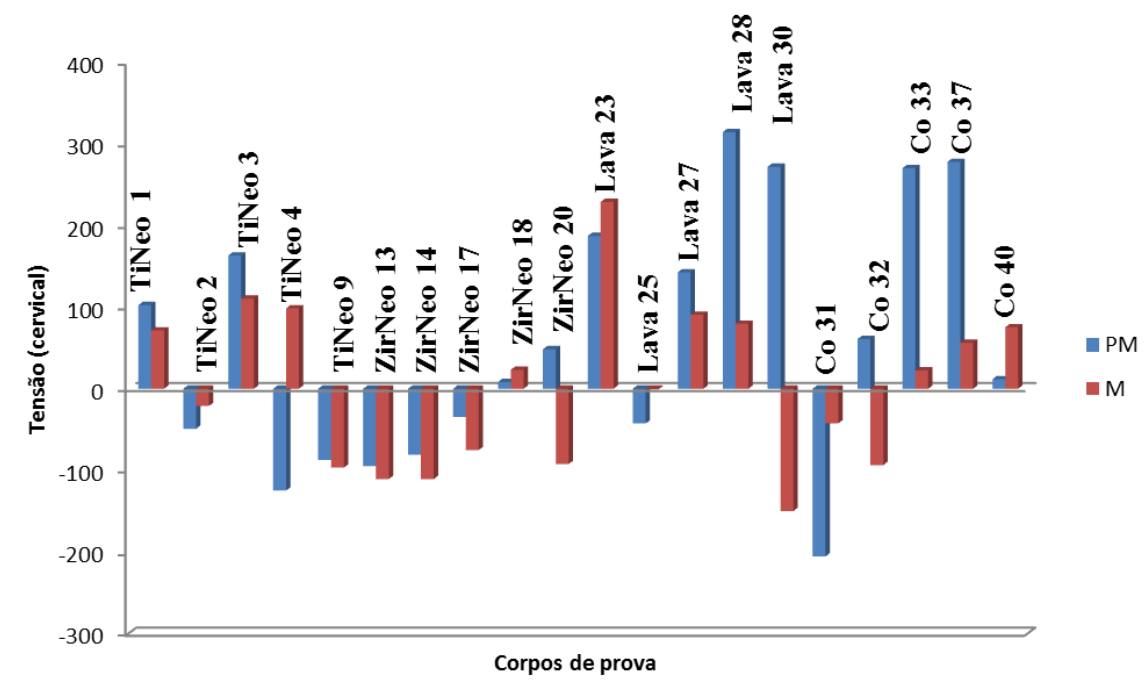

Figura 149: Tensão (cervical) nos PM e M de cada corpo de prova

Na Tabela 20 (anexo 8) consta os valores de tensão na região apical de cada implante (PM e M).

Tabela 27: Médias, desvio padrão e categoria estatística $(p<0,05)$ da distribuição de tensões aos implantes nos 4 grupos TiNeo, ZirNeo, Lava e Controle - região apical dos Pré-molares

\begin{tabular}{|c|c|c|c|c|c|c|}
\hline \multirow[t]{2}{*}{ Grupos } & \multirow[t]{2}{*}{ Média } & \multirow{2}{*}{$\begin{array}{l}\text { Desvio } \\
\text { padrão }\end{array}$} & \multicolumn{2}{|c|}{$\begin{array}{c}95 \% \text { Intervalo de } \\
\text { Confiança para Médias }\end{array}$} & \multirow{2}{*}{$\begin{array}{l}\text { Categoria } \\
\text { estatística }\end{array}$} & \multirow[t]{2}{*}{$p$} \\
\hline & & & Inferior & Superior & & \\
\hline Ti Neo & 0,95 & 125,32 & $-154,65$ & 156,57 & A & \multirow{4}{*}{0,135} \\
\hline Zir Neo & $-30,68$ & 60,02 & $-105,20$ & 43,84 & A & \\
\hline Lava & 174,92 & 139,20 & 2,08 & 139,20 & A & \\
\hline Co & 83,14 & 201,30 & $-166,80$ & 333,09 & A & \\
\hline
\end{tabular}

* Diferença estatisticamente significante pelo teste Anova Oneway $(p<0,05)$

Não houve diferença na distribuição de tensões na região apical dos implantes PM. 
Tabela 28: Médias, desvio padrão e categoria estatística $(p<0,05)$ da distribuição de tensões aos implantes nos 4 grupos TiNeo, ZirNeo, Lava e Controle - região apical dos Molares

\begin{tabular}{|c|c|c|c|c|c|c|}
\hline \multirow[t]{2}{*}{ Grupos } & \multirow[t]{2}{*}{ Média } & \multirow{2}{*}{$\begin{array}{l}\text { Desvio } \\
\text { padrão }\end{array}$} & \multicolumn{2}{|c|}{$\begin{array}{c}\text { 95\% Intervalo de } \\
\text { Confiança para Médias }\end{array}$} & \multirow{2}{*}{$\begin{array}{l}\text { Categoria } \\
\text { estatística }\end{array}$} & \multirow[t]{2}{*}{$p$} \\
\hline & & & Inferior & Superior & & \\
\hline Ti Neo & 32,56 & 88,83 & $-77,73$ & 142,86 & A & \multirow{4}{*}{0,212} \\
\hline Zir Neo & $-73,17$ & 55,91 & $-142,60$ & $-3,75$ & A & \\
\hline Lava & 49,81 & 138,93 & $-122,70$ & 222,32 & A & \\
\hline Co & 3,59 & 70,45 & $-83,87$ & 91,07 & A & \\
\hline
\end{tabular}

*Diferença significante pelo teste Anova Oneway $(p<0,05)$

Não houve diferença significante na região apical dos implantes Molares. Abaixo o gráfico das tensões na apical no PM e M de cada corpo de prova analisado (Figura 150).

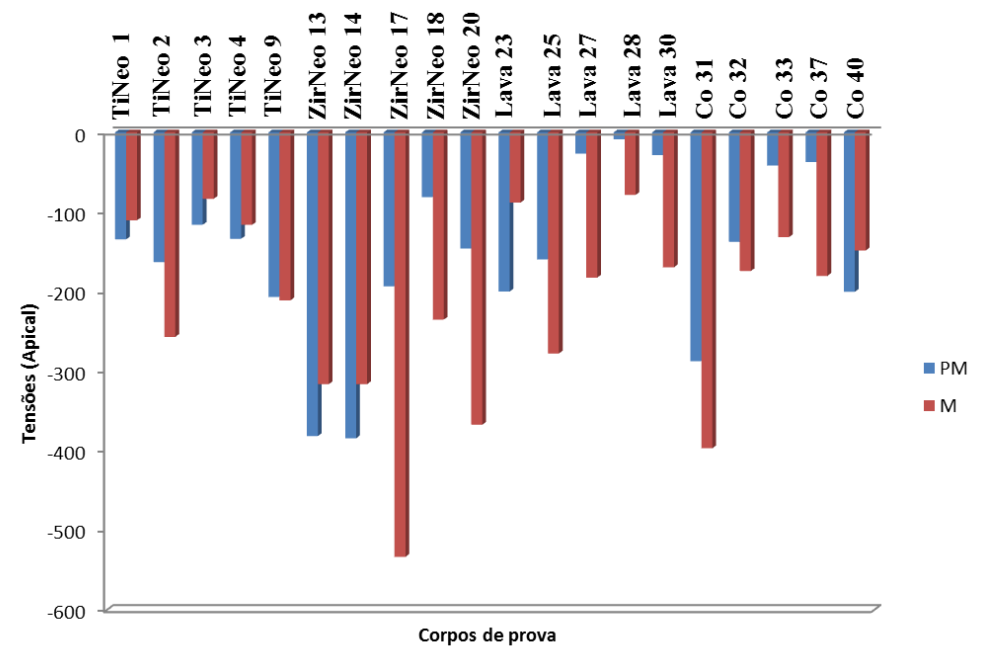

Figura 150: Tensão (apical) nos PM e M de cada corpo de prova

Tabela 29: Médias, desvio padrão e categoria estatística $(p<0,05)$ comparando a distribuição de tensões aos implantes nos 4 grupos TiNeo, ZirNeo, Lava e Controle entre PM e M

\begin{tabular}{ccccccc}
\hline Grupos & Média & Desvio & \multicolumn{2}{c}{$95 \%$ Intervalo de } & & Categoria \\
& & padrão & Confiança para Médias & $p$ & estatística \\
& & & Inferior & Superior & & \\
\hline Ti Neo & 4,80 & 51,66 & $-59,34$ & 68,95 & 0,845 & A \\
Zir Neo & 74,53 & 179,86 & $-106,87$ & 339,77 & 0,221 & A \\
Lava & 116,45 & 109,17 & $-61,02$ & 210,09 & 0,202 & A \\
Co & 65,36 & 76,10 & $-29,13$ & 159,84 & 0,127 & A \\
\hline
\end{tabular}

*Diferença significante pelo teste Anova Oneway $(p<0,05)$ 
Tabela 30: Médias e desvio padrão das tensões nos implantes PM e M de cada grupo:

\begin{tabular}{ccc}
\hline Grupos & Médias & Desvio Padrão \\
\hline TiNeo PM & $-150,76$ & 35,54 \\
TiNeo M & $-155,57$ & 74,39 \\
ZirNeo PM & $-237,22$ & 138,79 \\
ZirNeo M & $-353,67$ & 111,01 \\
Lava PM & $-84,65$ & 88,28 \\
Lava M & $-159,19$ & 81,04 \\
Co PM & $-140,84$ & 106,79 \\
Co M & $-206,20$ & 108,36 \\
\hline
\end{tabular}

Não houve diferença significante entre PM e M nos quatro grupos avaliados (Tabela 29). Porém, observando os valores das médias na Tabela 30, nota-se que os maiores valores de tensão foram observados nos molares.

\subsection{Resistência à fratura}

Abaixo fotos das fraturas nos corpos de prova (Figuras 151 a 154).
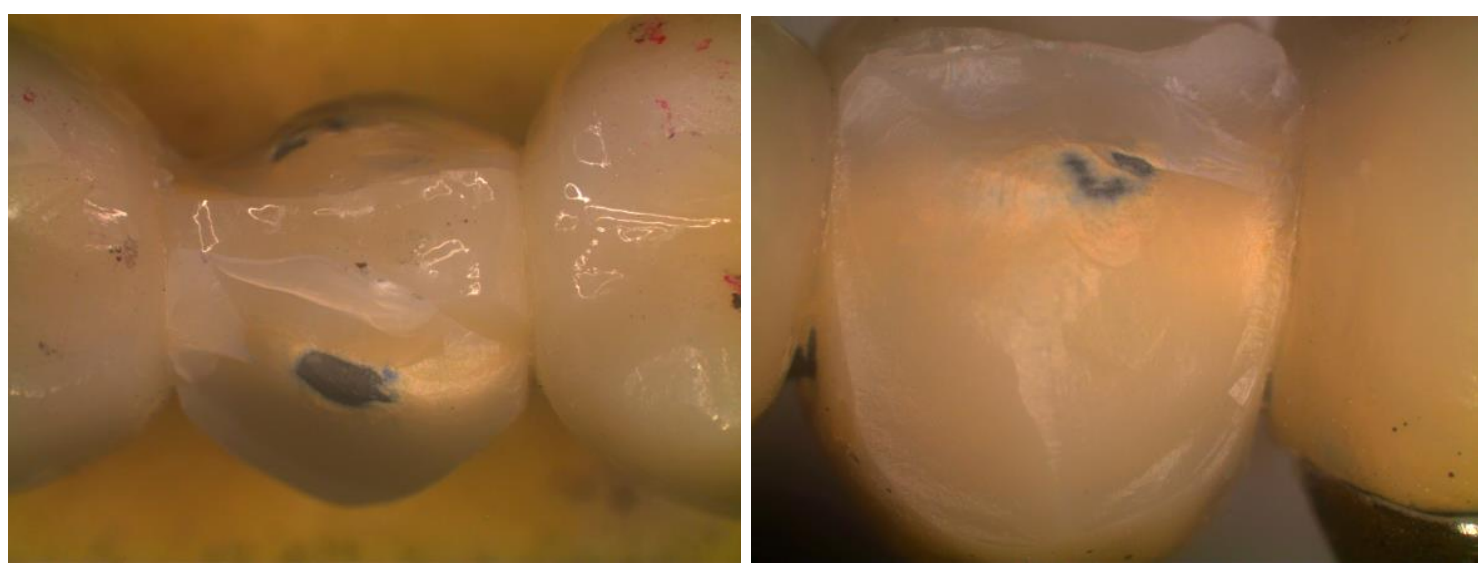

Figura 151: Fratura - TiNeo 


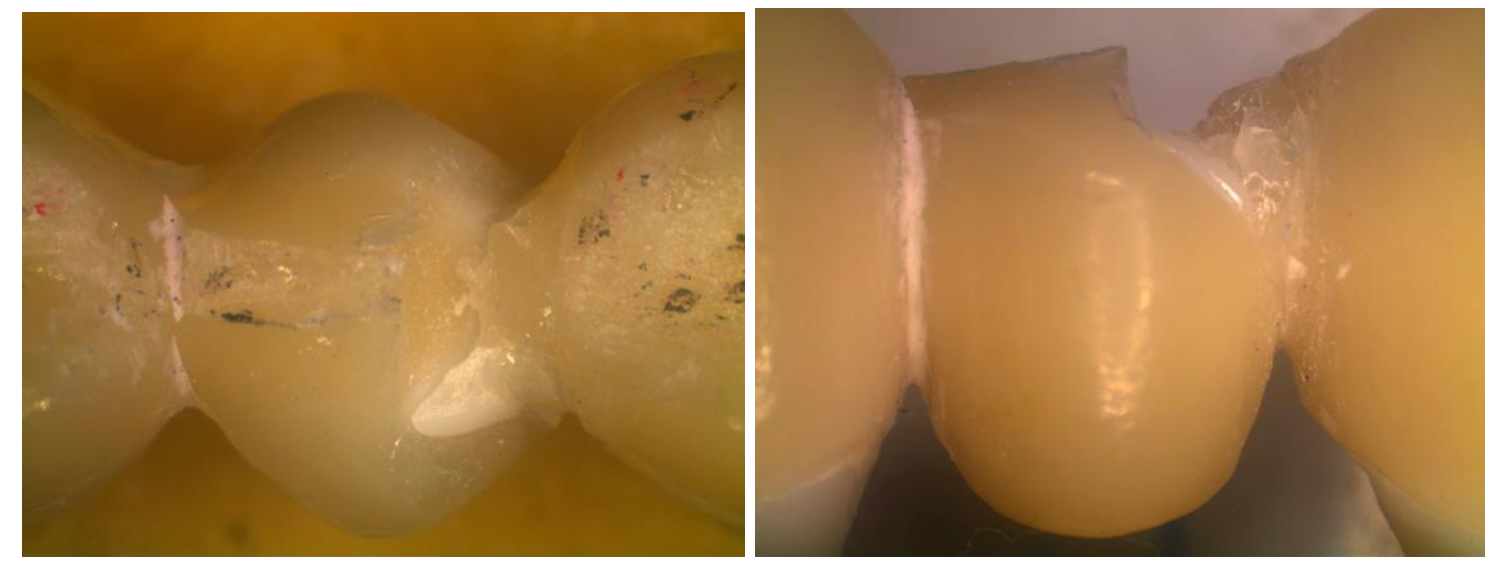

Figura 152: Fratura - ZirNeo

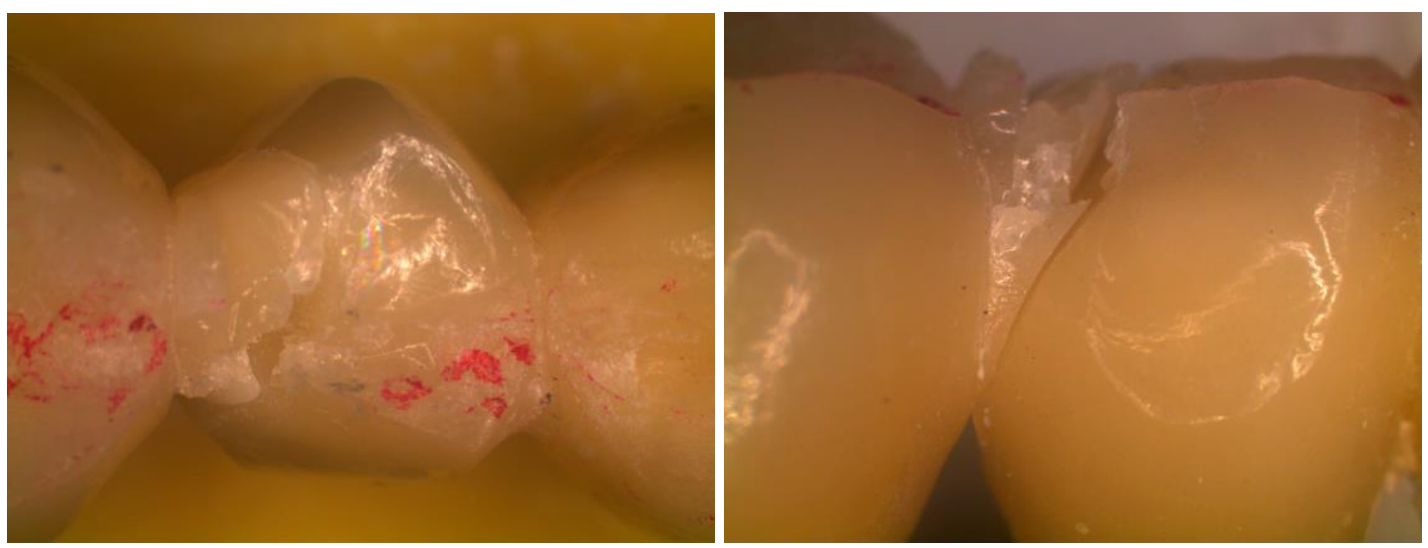

Figura 153: Fratura - Lava

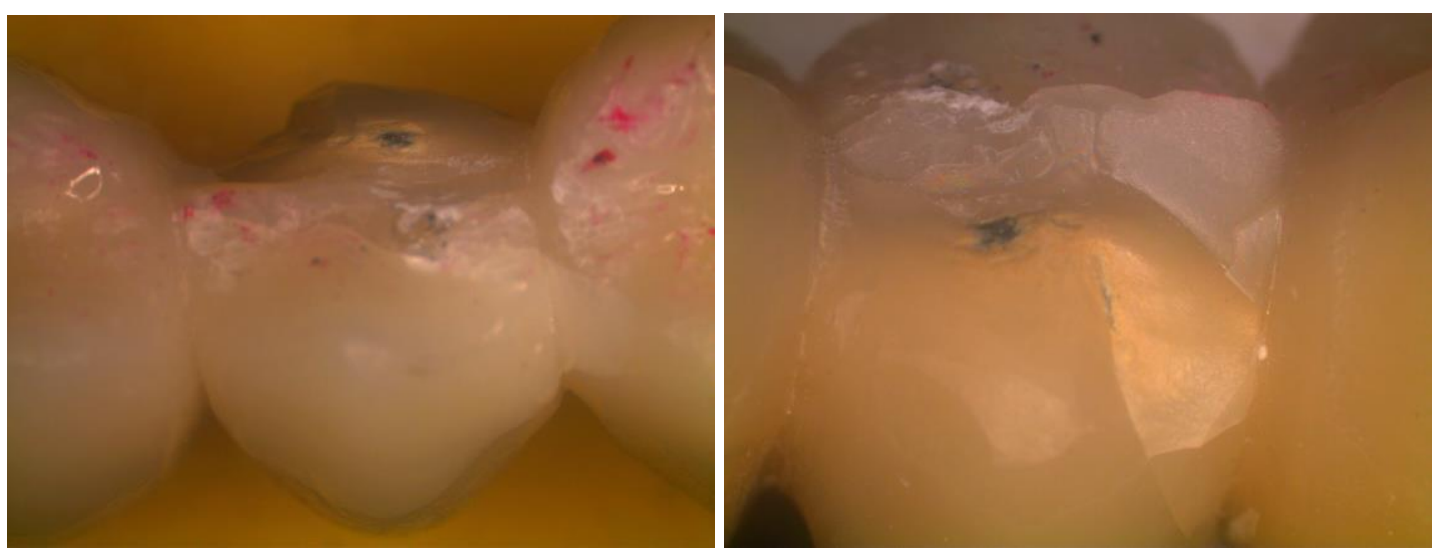

Figura 154: Fratura - Co 
Os gráficos abaixo (Figuras 155 a 158) ilustram a resistência à fratura de cada grupo (TiNeo, ZirNeo, Lava e Co). Na Tabela 21 (anexo 9) estão todos os valores de resistência à fratura de cada modelo dos quatro grupos.

\section{TiNeo}

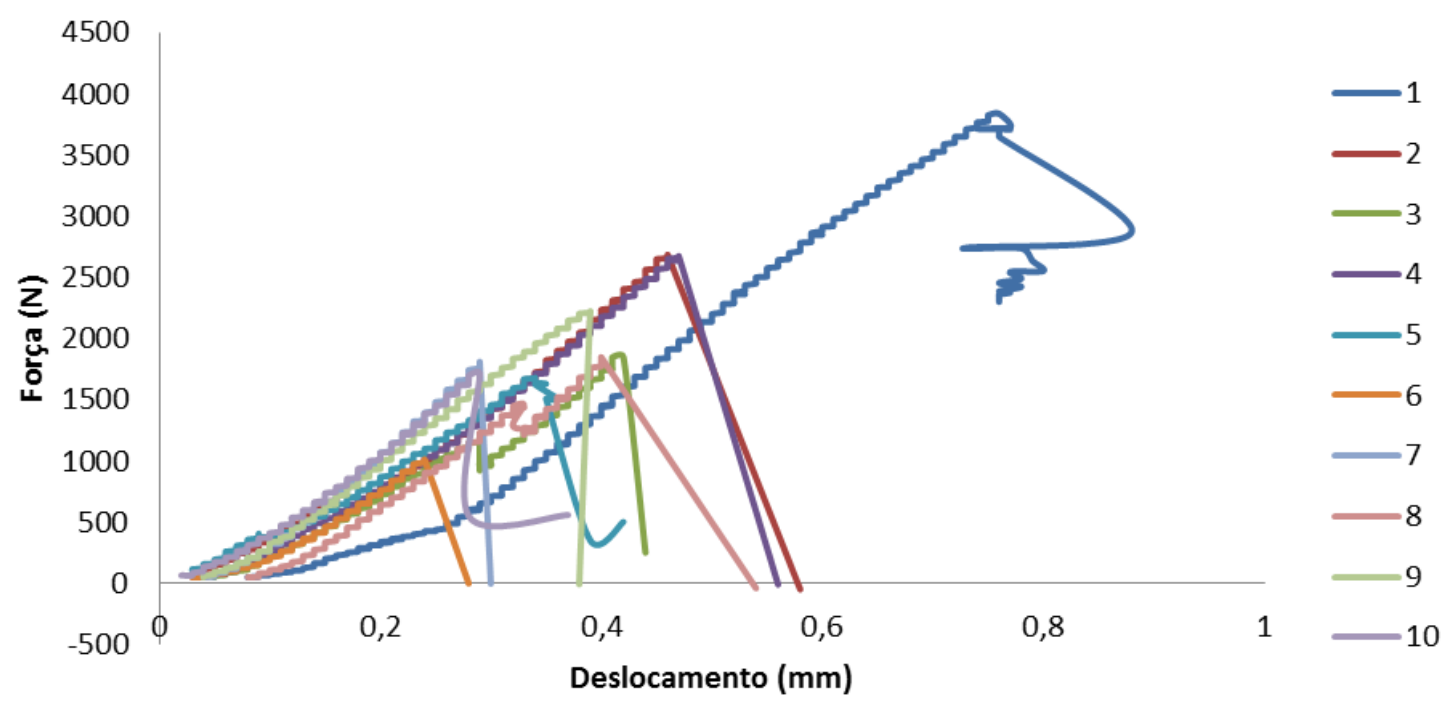

Figura 155: Gráfico tensão X deformação do grupo TiNeo

\section{ZirNeo}

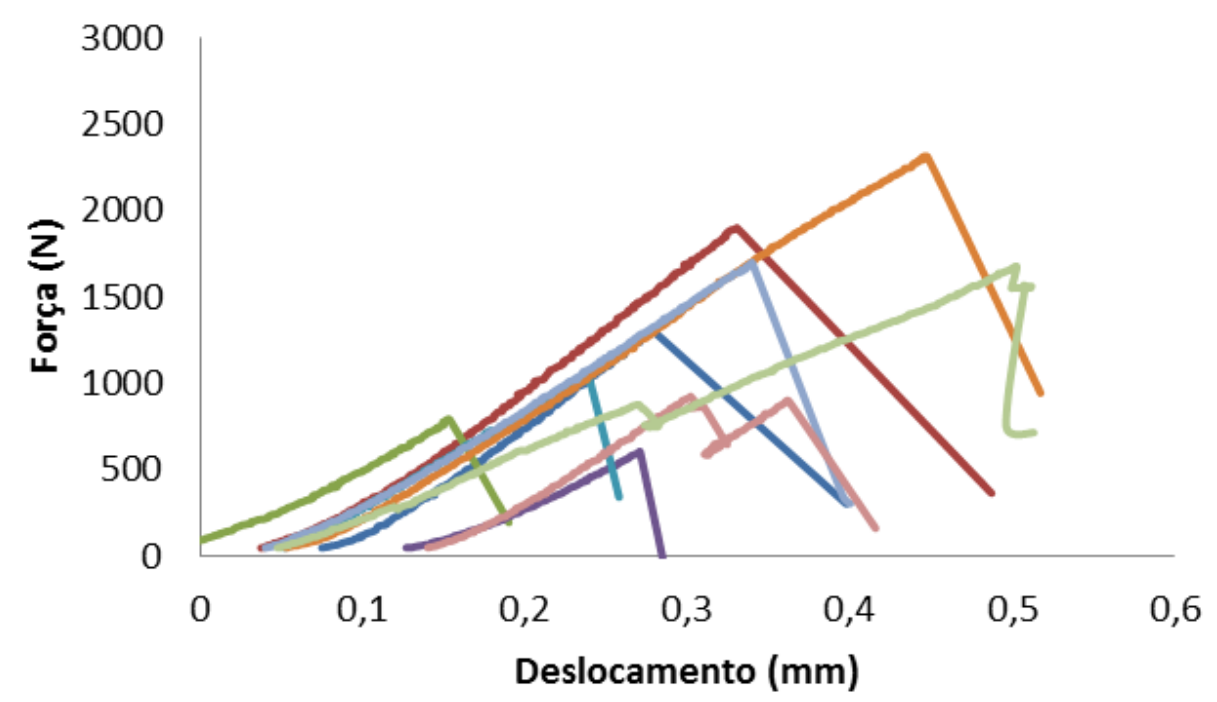

Figura 156: Gráfico tensão $X$ deformação do grupo ZirNeo 


\section{Lava}

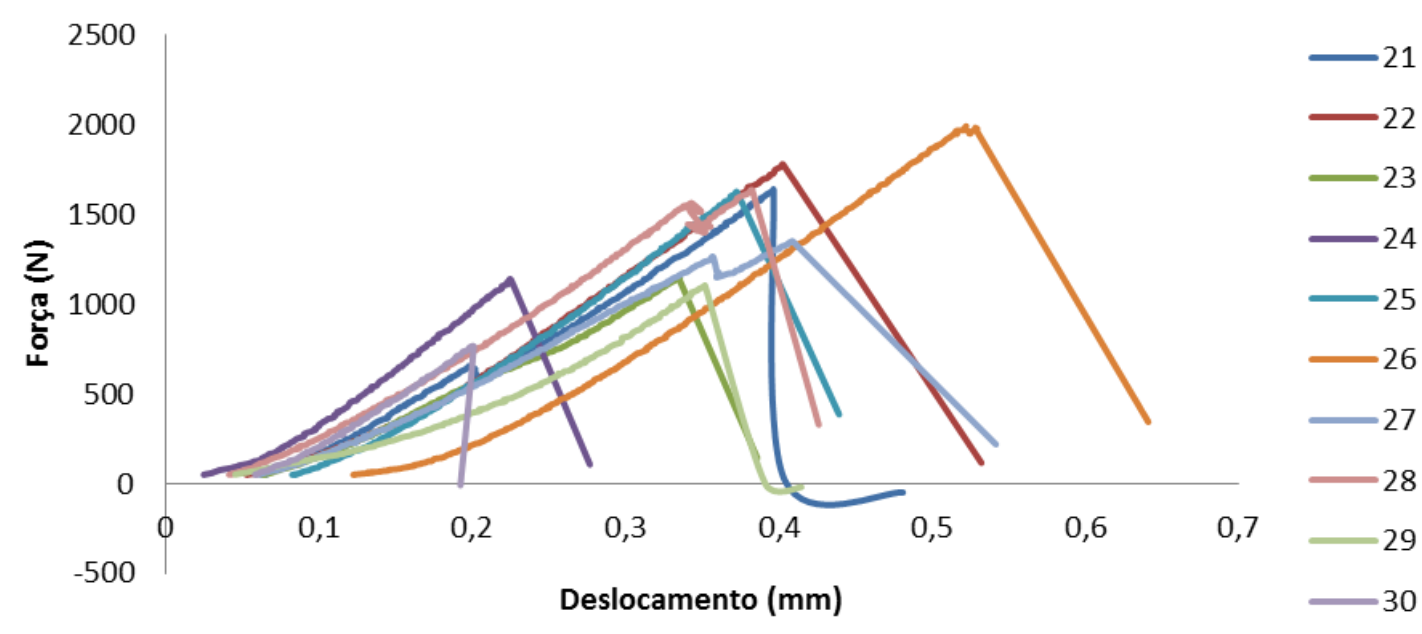

Figura 157: Gráfico tensão X deformação do grupo Lava

\section{Controle}

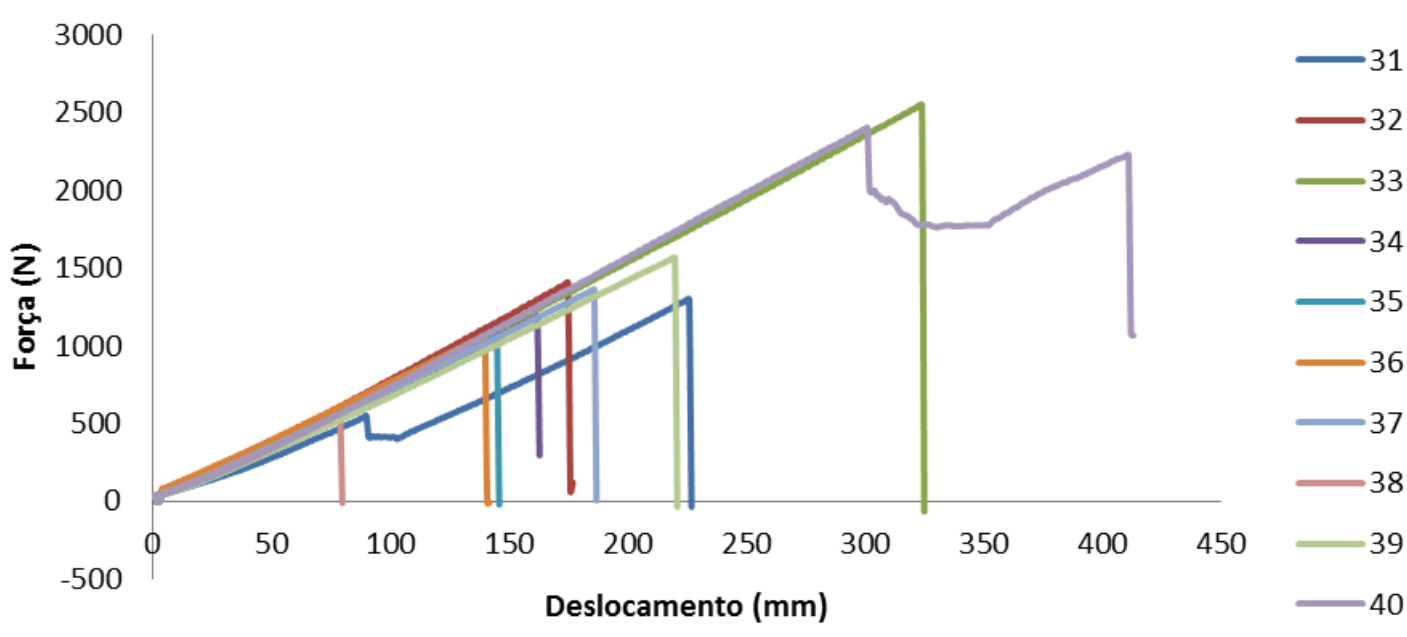

Figura 158: Gráfico tensão X deformação do grupo Controle

Observa-se que todos os gráficos seguiram o mesmo padrão. Na figura 159 estão as médias e desvio padrão de cada grupo. 


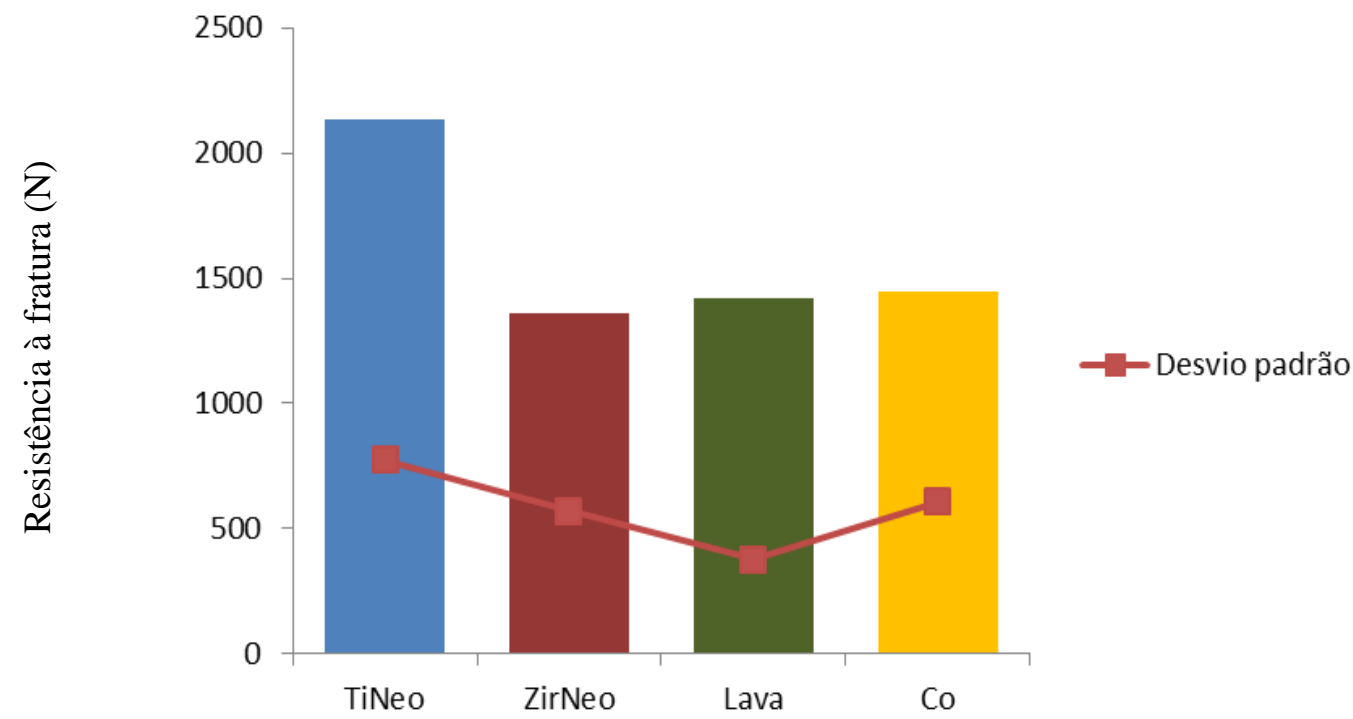

Figura 159: Médias e desvio padrão da resistência à fratura dos quatro grupos

A média dos valores de resistência à fratura do grupo TiNeo foi maior que a dos outros grupos as quais permaneceram com um mesmo padrão.

Tabela 31: Médias, desvio padrão e categoria estatística $(p<0,05)$ da resistência à fratura $(\mathrm{N})$ entre os grupos TiNeo, ZirNeo, Lava e Controle

\begin{tabular}{|c|c|c|c|c|c|c|}
\hline \multirow[t]{2}{*}{ Grupos } & \multirow[t]{2}{*}{ Média } & \multirow{2}{*}{$\begin{array}{l}\text { Desvio } \\
\text { padrão }\end{array}$} & \multicolumn{2}{|c|}{$\begin{array}{c}\text { 95\% Intervalo de } \\
\text { Confiança para Médias }\end{array}$} & \multirow{2}{*}{$\begin{array}{l}\text { Categoria } \\
\text { estatística }\end{array}$} & \multirow[t]{2}{*}{$p$} \\
\hline & & & Inferior & Superior & & \\
\hline Ti Neo & 2134,78 & 775,54 & 1579,99 & 2689,58 & A & \multirow{4}{*}{0,022} \\
\hline Zir Neo & 1390,09 & 544,88 & 1000,31 & 1779,88 & B & \\
\hline Lava & 1393,72 & 391,57 & 1092,73 & 1694,71 & B & \\
\hline Co & 1447,06 & 608,21 & 1011,97 & 1882,15 & B & \\
\hline
\end{tabular}

*Diferença significante pelo teste Anova Oneway $(p<0,05)$

**Diferença significante (teste Tukey $-p<0,05$ ) representada por letras diferentes, onde B representa resultados piores do que A

Dos quatro grupos analisados apenas o grupo TiNeo apresentou diferença significante com os demais com $p=0,022$ em relação à resistencia à fratura, (TiNeo[2134,78 $\pm 775,54 \mathrm{~N}]$, ZirNeo $[1390,09 \pm 544,88 \mathrm{~N}]$, Lava $[1393,72 \pm 391,57 \mathrm{~N}]$, Co $[1447,06 \pm$ 608,21 N]). O grupo TiNeo apresentou resistência à fratura significativamente maior que os demais - Tabela 31 . 


\section{Correlação de Pearson (desadaptação e resistência)}

Foi aplicado o teste de correlação de Pearson entre as variáveis da desadaptação e da resistência à fratura para avaliar se houve correlação positiva ou negativa entre as varíaveis acima (Tabela 32). Considera-se a correlação positiva quando o valor da correlação for positivo e o negativo quando o valor for negativo. Nesse caso, uma correlação negativa significa que quanto maior a desadaptação menor a resistência à fratura.

Tabela 32: Valores da Correlação de Pearson e nível de significância correlacionando os quatro tipos de desadaptações com a resistência à fratura entre os grupos TiNeo, ZirNeo, Lava e Controle $(p<0,05)$

\begin{tabular}{|c|c|c|c|}
\hline Grupos & Adaptação & Correlação de Pearson & $p$ \\
\hline TiNeo PM & Vertical & 0,187 & 0,605 \\
\hline TiNeo PM & Horizontal & 0,524 & 0,120 \\
\hline TiNeo PM & Interna Axial & - & - \\
\hline TiNeo PM & Interna Oclusal & 0,173 & 0,634 \\
\hline ZirNeo PM & Vertical & $-0,175$ & 0,629 \\
\hline ZirNeo PM & Horizontal & $-0,208$ & 0,564 \\
\hline ZirNeo PM & Interna Axial & $-0,459$ & 0,182 \\
\hline ZirNeo PM & Interna Oclusal & $-0,171$ & 0,637 \\
\hline Lava PM & Vertical & $-0,175$ & 0,629 \\
\hline Lava PM & Horizontal & $-0,208$ & 0,564 \\
\hline Lava PM & Interna Axial & $-0,459$ & 0,182 \\
\hline Lava PM & Interna Oclusal & $-0,171$ & 0,637 \\
\hline Co PM & Vertical & 0,193 & 0,592 \\
\hline Co PM & Horizontal & $-0,010$ & 0,979 \\
\hline Co PM & Interna Axial & 0,223 & 0,535 \\
\hline TiNeo M & Vertical & 0,221 & 0,539 \\
\hline TiNeo M & Horizontal & 0,246 & 0,494 \\
\hline TiNeo M & Interna Axial & - & - \\
\hline TiNeo M & Interna Oclusal & 0,811 & $0,004 *$ \\
\hline ZirNeo M & Vertical & $-0,128$ & 0,725 \\
\hline ZirNeo M & Horizontal & 0,875 & $0,001 *$ \\
\hline ZirNeo M & Interna Axial & 0,773 & $0,009 *$ \\
\hline ZirNeo M & Interna Oclusal & $-0,243$ & 0,498 \\
\hline Lava M & Vertical & 0,047 & 0,897 \\
\hline Lava M & Horizontal & $-0,467$ & 0,173 \\
\hline Lava M & Interna Axial & $-0,294$ & 0,410 \\
\hline Lava M & Interna Oclusal & $-0,408$ & 0,242 \\
\hline Co M & Vertical & $-0,689$ & $0,028 *$ \\
\hline Co M & Horizontal & $-0,036$ & 0,921 \\
\hline Co M & Interna Axial & $-0,63$ & 0,863 \\
\hline Co M & Interna Oclusal & $-0,591$ & 0,072 \\
\hline
\end{tabular}


Os resultados demostraram que houve correlação significativa com valores positivos entre a resistência à fratura e a desadaptação interna oclusal no grupo TiNeo $\mathrm{M}$ e a resistência à fratura e a desadaptação horizontal e interna axial no grupo ZirNeo M. Portanto para esses grupos quanto maior a desadaptação maior a resistência à fratura. Já para o grupo Co $\mathrm{M}$ houve correlação porém negativa, quanto maior a desadaptação vertical menor a resistência à fratura.

$\mathrm{Na}$ correlação de Pearson considera-se uma correlação fraca quando o valor numérico for menor que 0,3 , moderada quando o valor for entre $0,3-0,7$ e forte quando o valor da correlação for maior que 0,7 . Portanto todas as correlações foram fortes com exceção da vertical do Co M que foi considerada moderada.

Após o teste de resistência a fratura dois corpos de prova apresentaram fratura da infraestrutura entre pôntico e conector molar - corpos de prova: 12 (ZirNeo) e 25 (Lava) Figuras 152 e 153. 


\subsection{Microscopia eletrônica de varredura (MEV)}

Abaixo seguem as imagens em microscopia eletrônica de varredura do corpo de prova 8 do grupo TiNeo (Figuras 160 a 165).

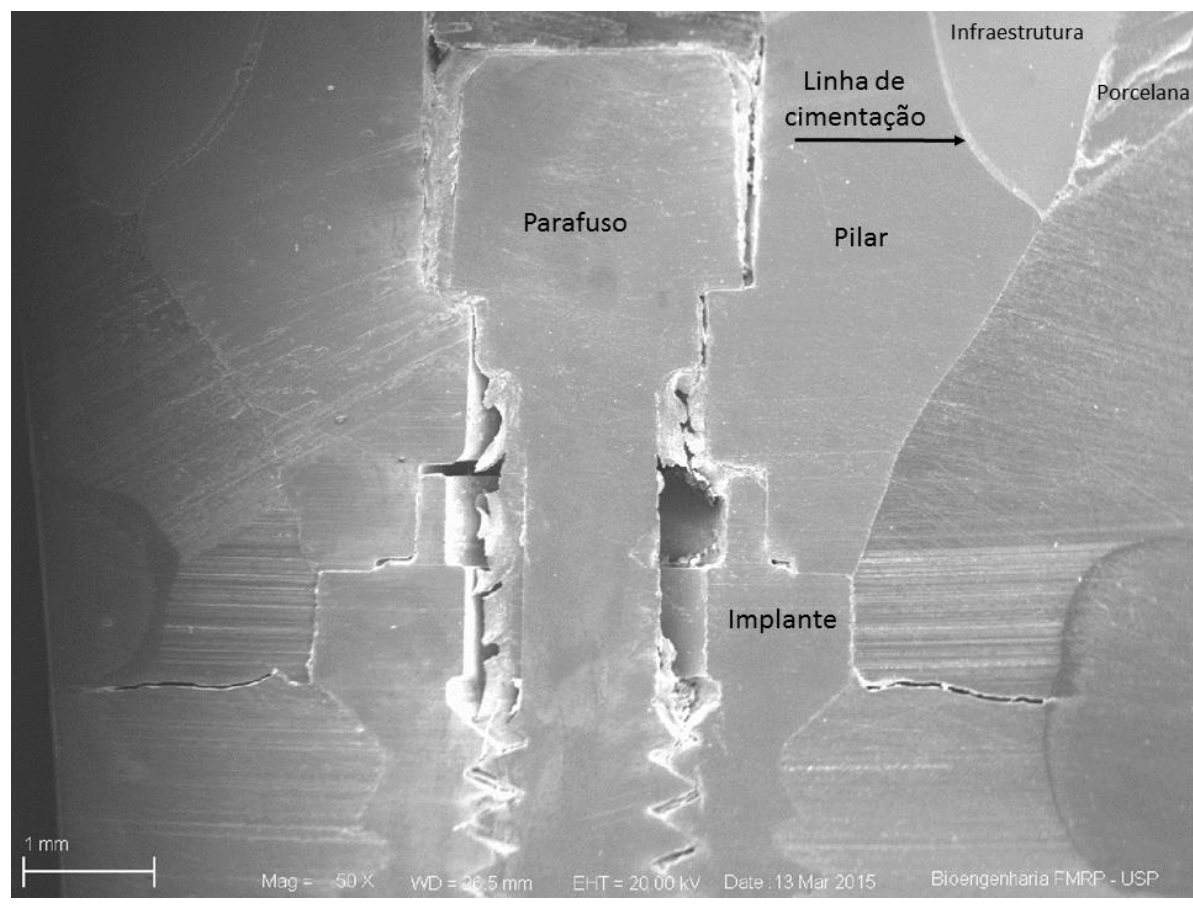

Figura 160: MEV - relacionamento coroa molar/pilar/implante - TiNeo

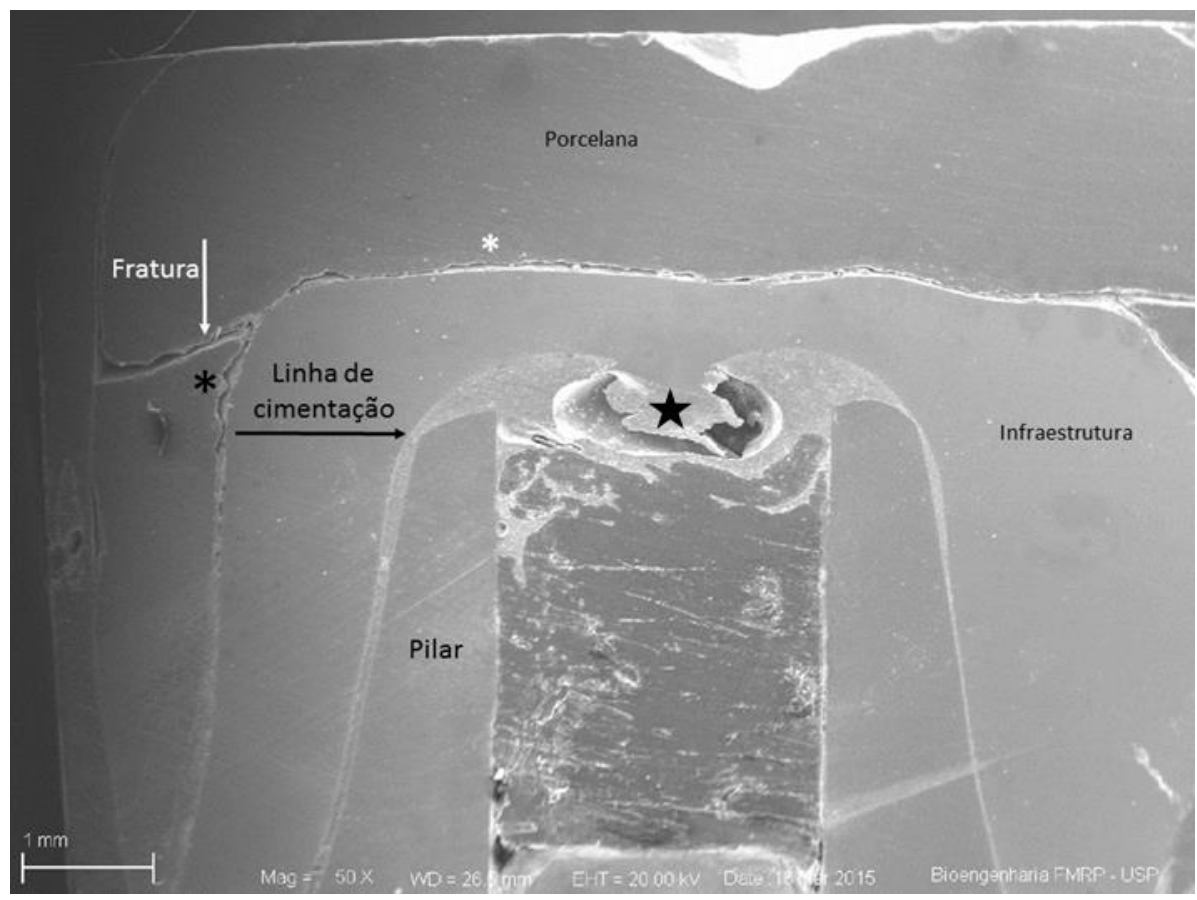

Figura 161: MEV: fratura da porcelana Molar - TiNeo 


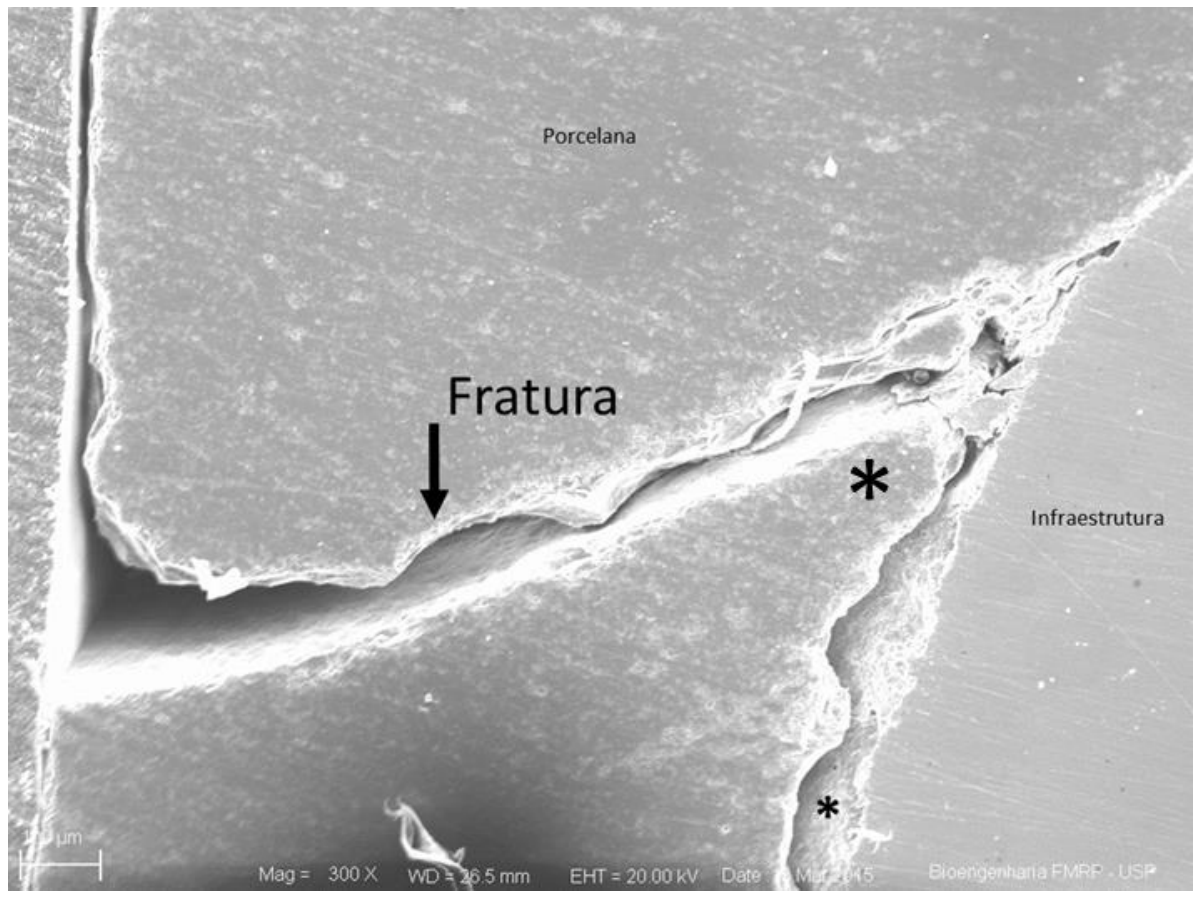

Figura 162: MEV - fratura da porcelana Molar - TiNeo

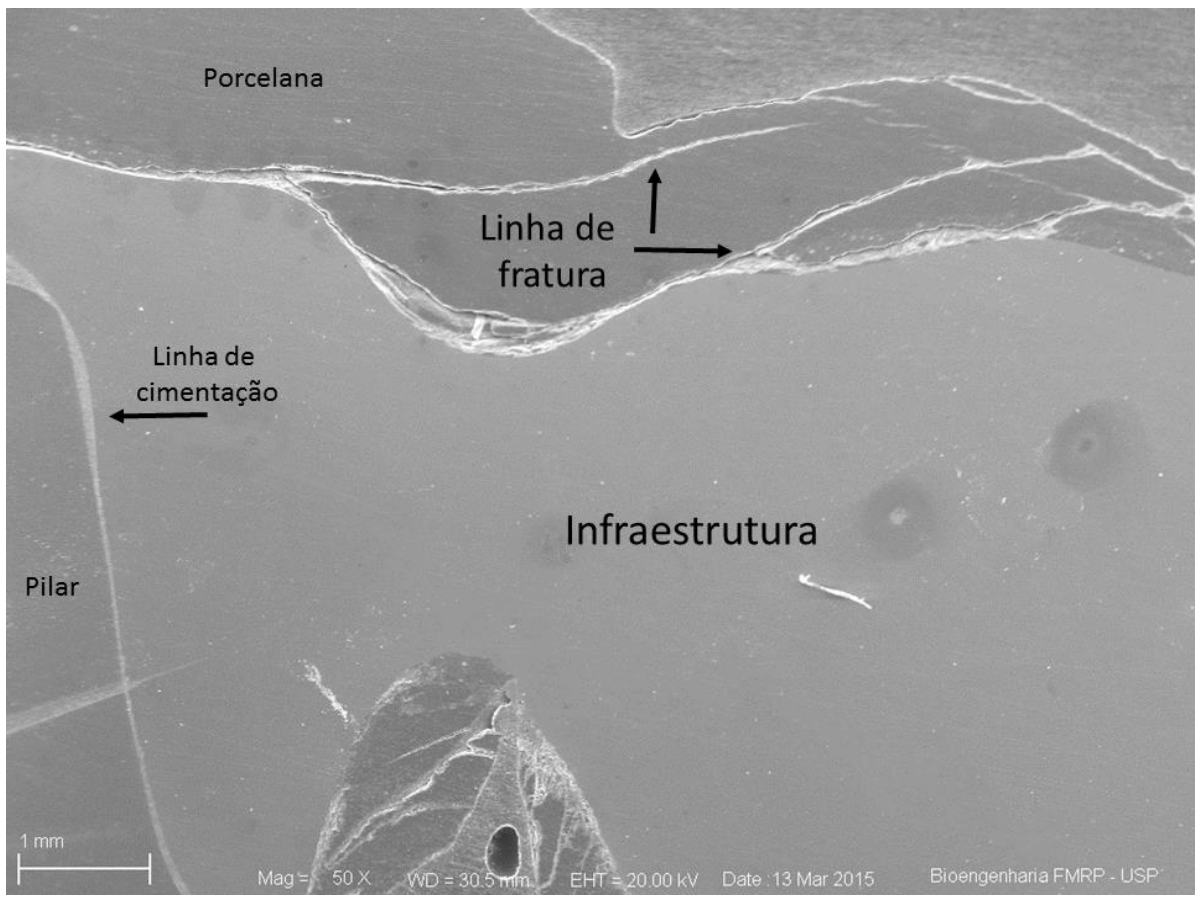

Figura 163: $M E V$ - região $M$ - pôntico - TiNeo 


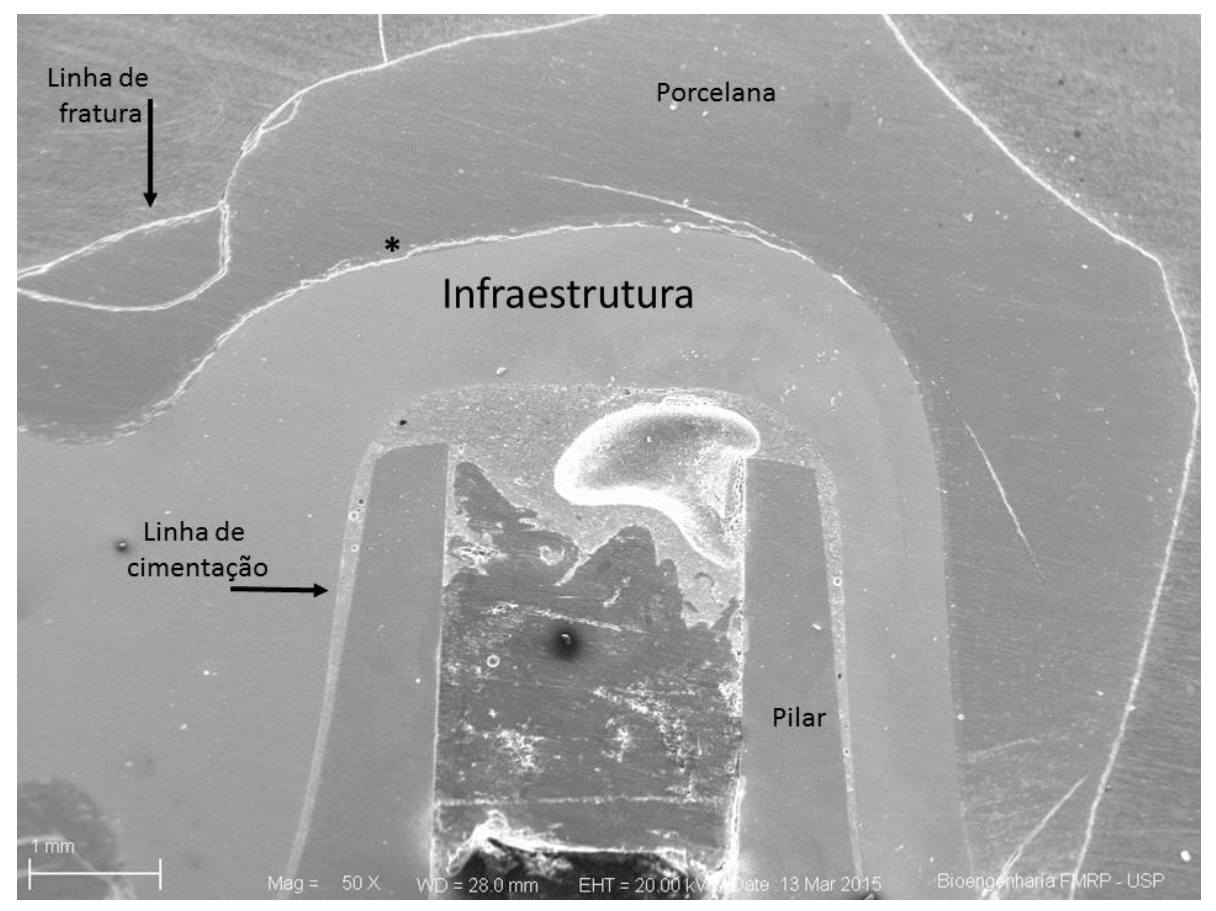

Figura 164: MEV - PM - TiNeo

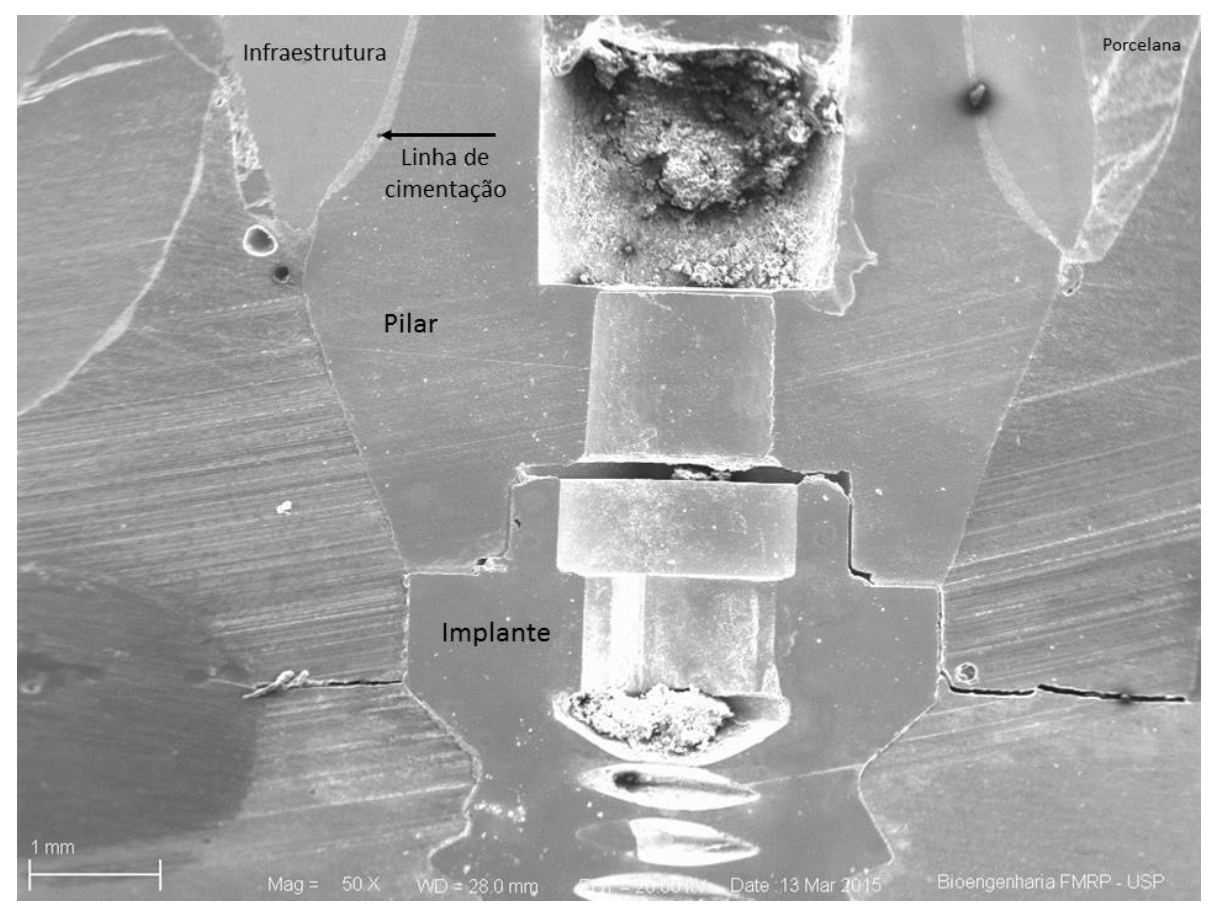

Figura 165: MEV - PM - TiNeo 
Para o grupo TiNeo, analisando as fotomicrografias acima, é possível verificar o relacionamento entre os diversos componentes (Figura 160 - pilar molar). Fica evidente que não houve uniformidade da linha de cimentação entre pilar e infraestrutura. Na Figura 161 nota-se maior espaçamento entre pilar/infraestrutura na oclusal, e a presença de uma bolha de ar $(\star)$ na massa de cimento resinoso. Ainda, nota-se que a falha $(*)$ se propaga por toda a interface porcelana/infraestrutura de zircônia. A Figura 162 mostra a mesma linha de fratura da porcelana, em maior aumento, com evidente propagação da falha (*) pela interface porcelana/infraestrutura de zircônia. Sugere-se que essa propagação de falha ocorreu a partir da região do pôntico, local de aplicação da carga, e as Figuras 163 e 164 evidenciam linhas de fratura da porcelana. Nas Figuras 164 e 165, observando o pilar pré-molar nota-se linha de cimentação mais uniforme sob a infraestrutura de cobalto cromo. Na Figura 165, também, o bom assentamento do pilar no implante.

Abaixo seguem as imagens em microscopia eletrônica de varredura do corpo de prova 12 do grupo ZirNeo (Figuras 166 a 171).

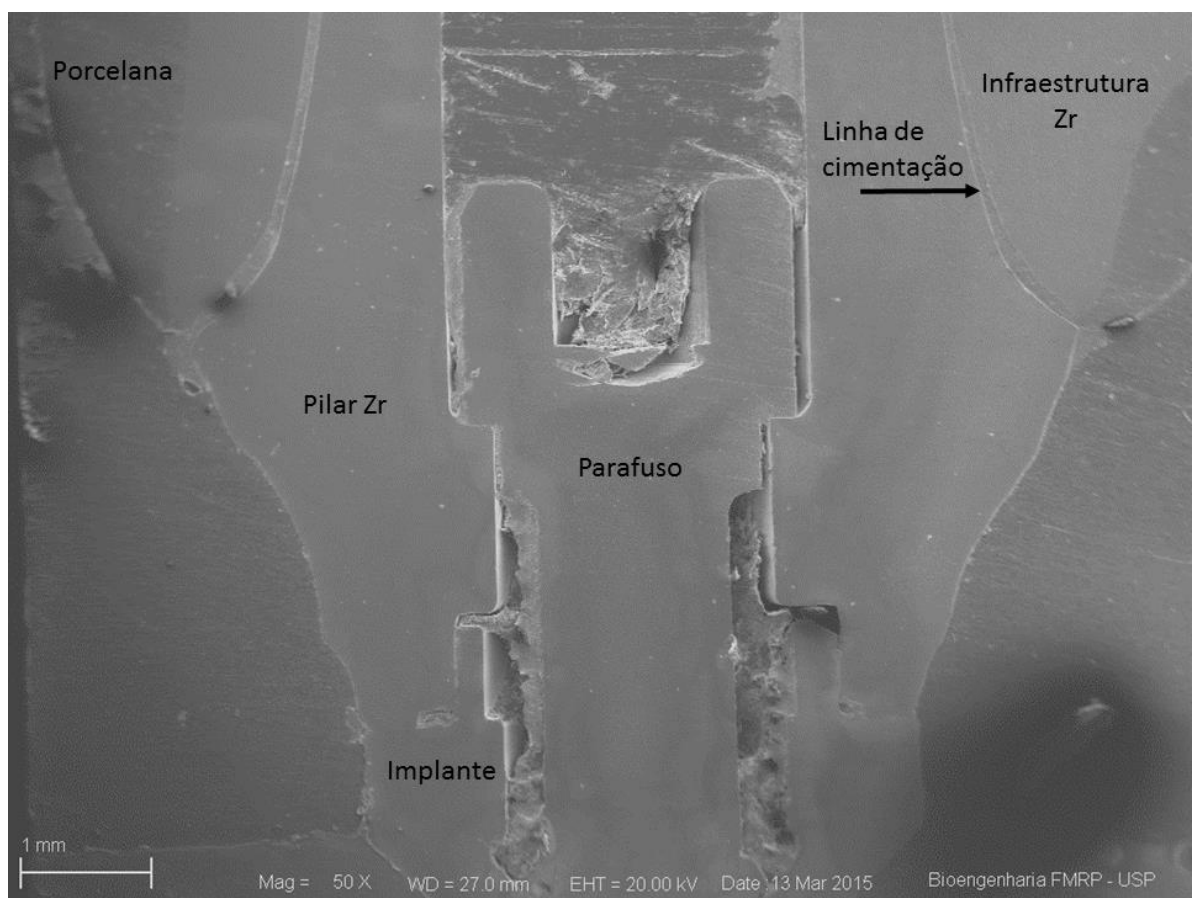

Figura 166: MEV - relacionamento coroa molar - pilar- implante - ZirNeo 


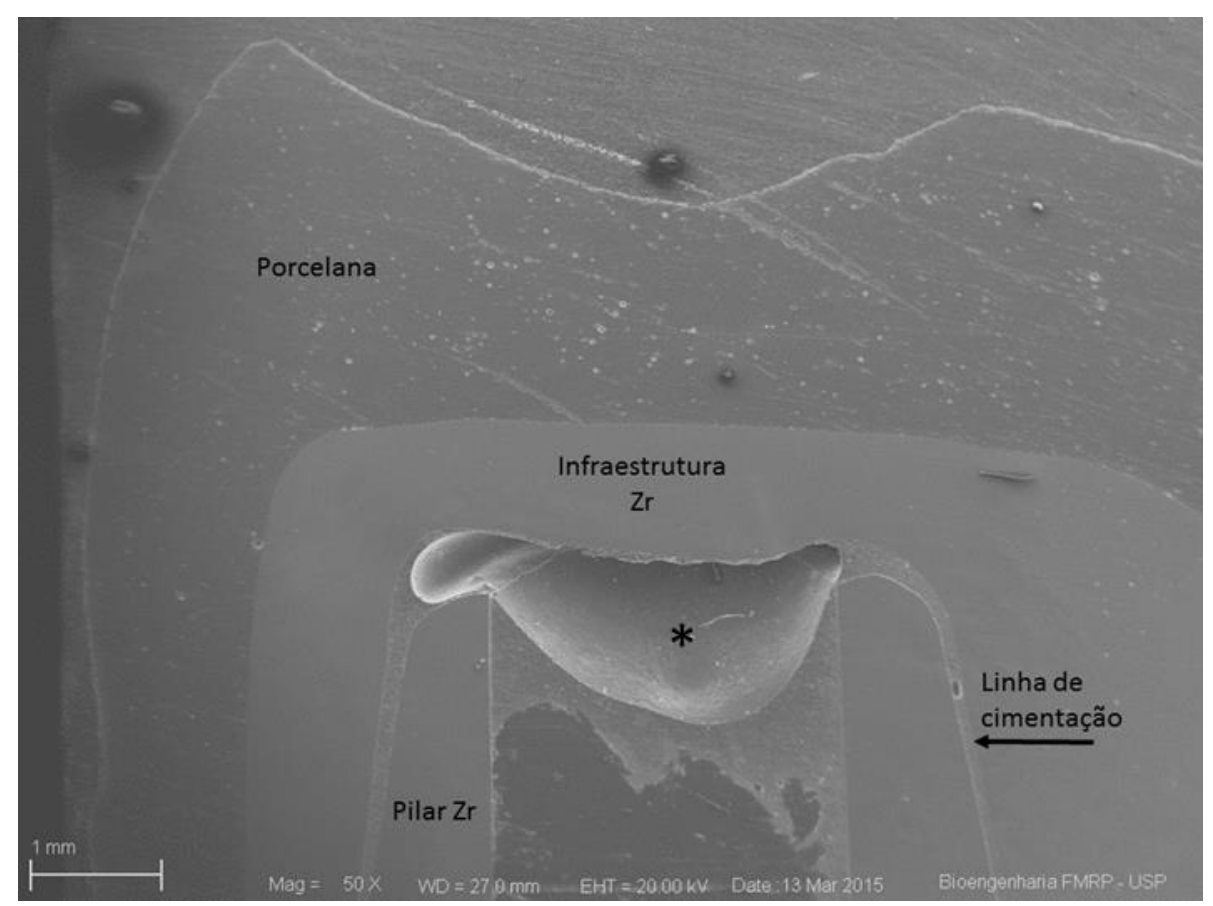

Figura 167: MEV: Molar (sem fratura) - ZirNeo

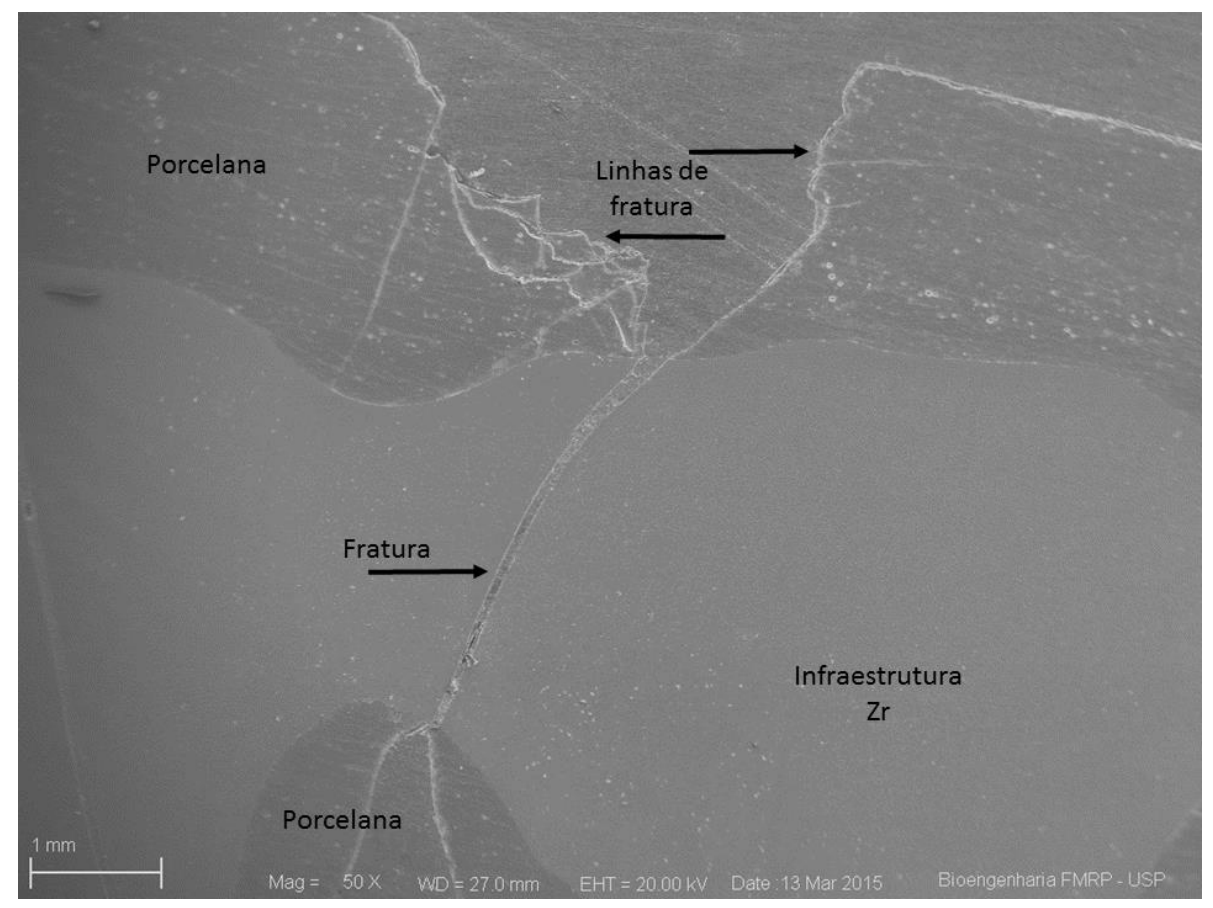

Figura 168: MEV - fratura região $M$ - pôntico - ZirNeo 


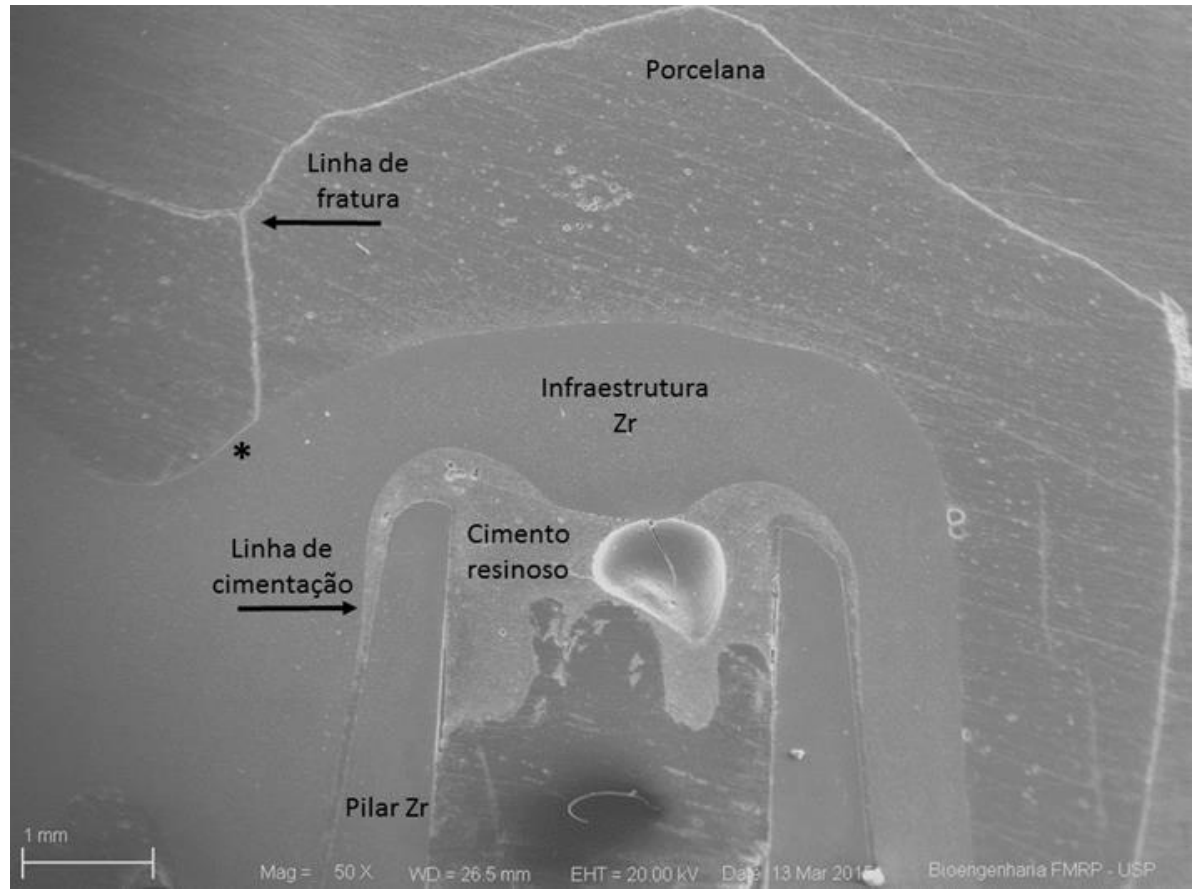

Figura 169: MEV - pôntico - região PM - ZirNeo

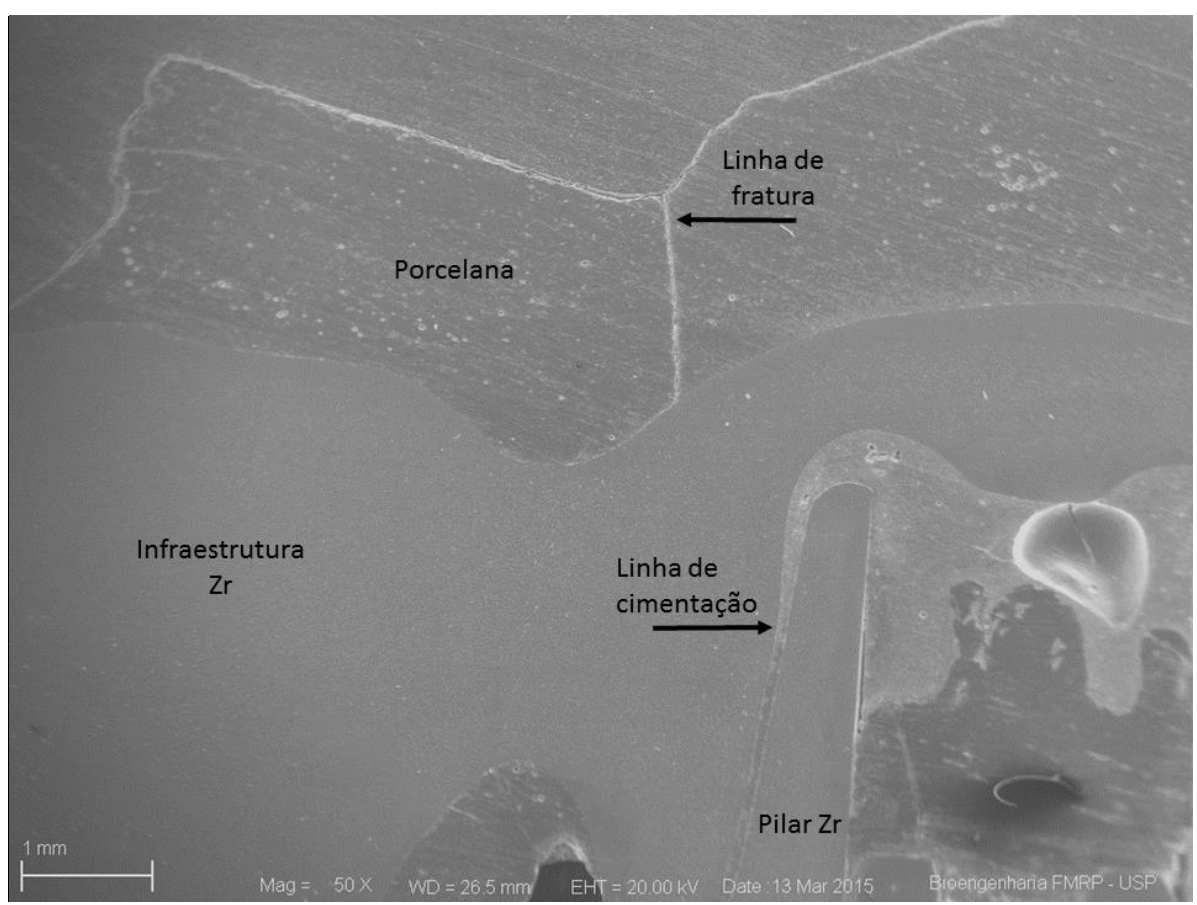

Figura 170: MEV - relacionamento coroa PM - pilar - implante - ZirNeo 


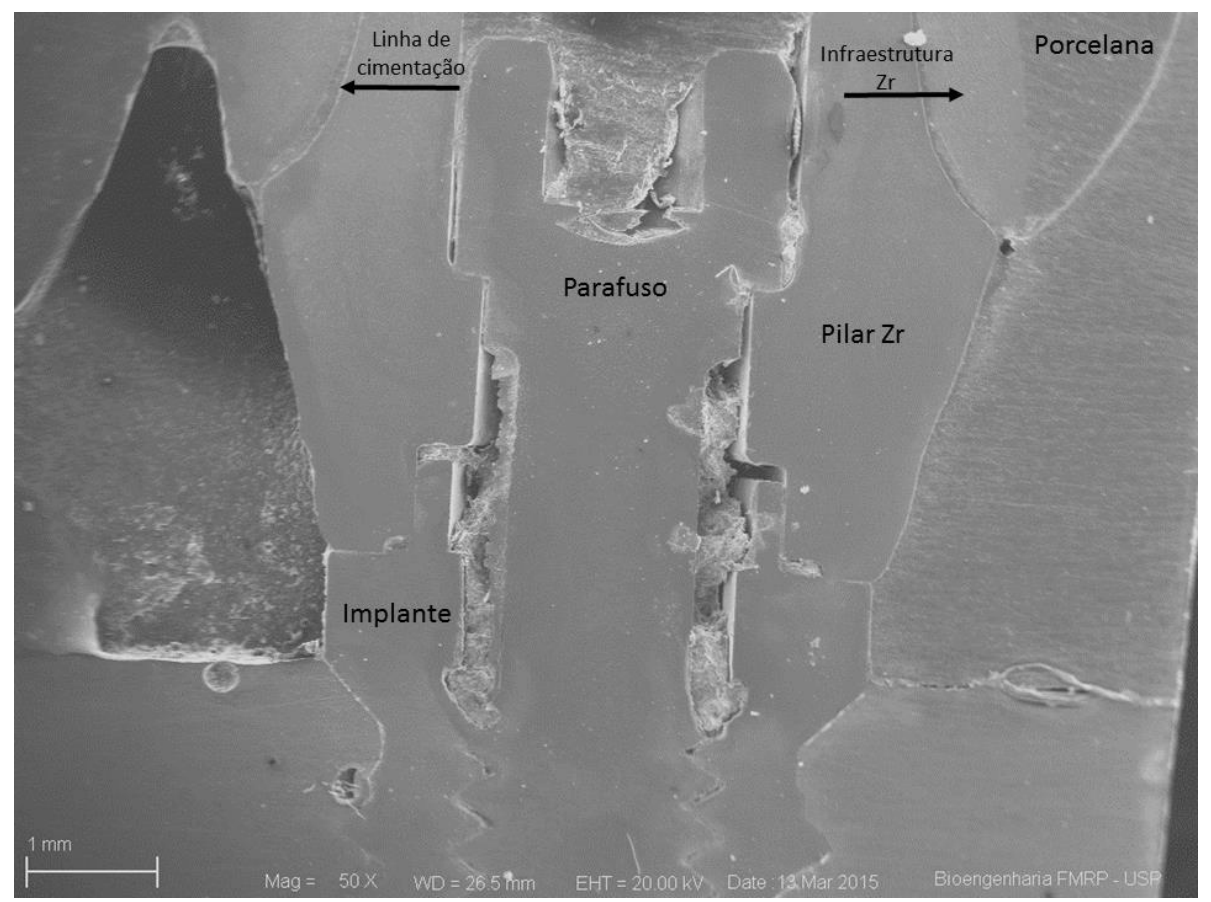

Figura 171: MEV - relacionamento coroa PM - pilar - implante - ZirNeo

As fotomicrografias do grupo ZirNeo permitem verificar o relacionamento entre os componentes do pilar molar (Figura 166), que mostra bom assentamento entre pilar/implante, e alguma variação na espessura da linha de cimentação entre pilar e infraestrutura de zircônia. A Figura 167 mostra estrutura íntegra, apenas com uma bolha de ar (*) presa na massa de cimento resinoso, associada ao orifício de acesso do parafuso do pilar. A Figura 168 evidencia linhas de fratura, tanto na porcelana quanto na infraestrutura de zircônia, na região de conexão do pôntico. A Figura 169 mostra linha de fratura na porcelana, que tem pequena extensão $(*)$ para a interface com a infraestrutura de zircônia. A Figura 170 mostra essa região em maior aumento, e evidencia o espaço interno na região oclusal do pilar. A Figura 171 mostra o pilar pré-molar, também evidenciando bom assentamento do pilar no implante e alguma variação na espessura da linha de cimentação.

Abaixo seguem as imagens em microscopia eletrônica de varredura do corpo de prova 25 do grupo Lava (Figuras 172 a 176). 


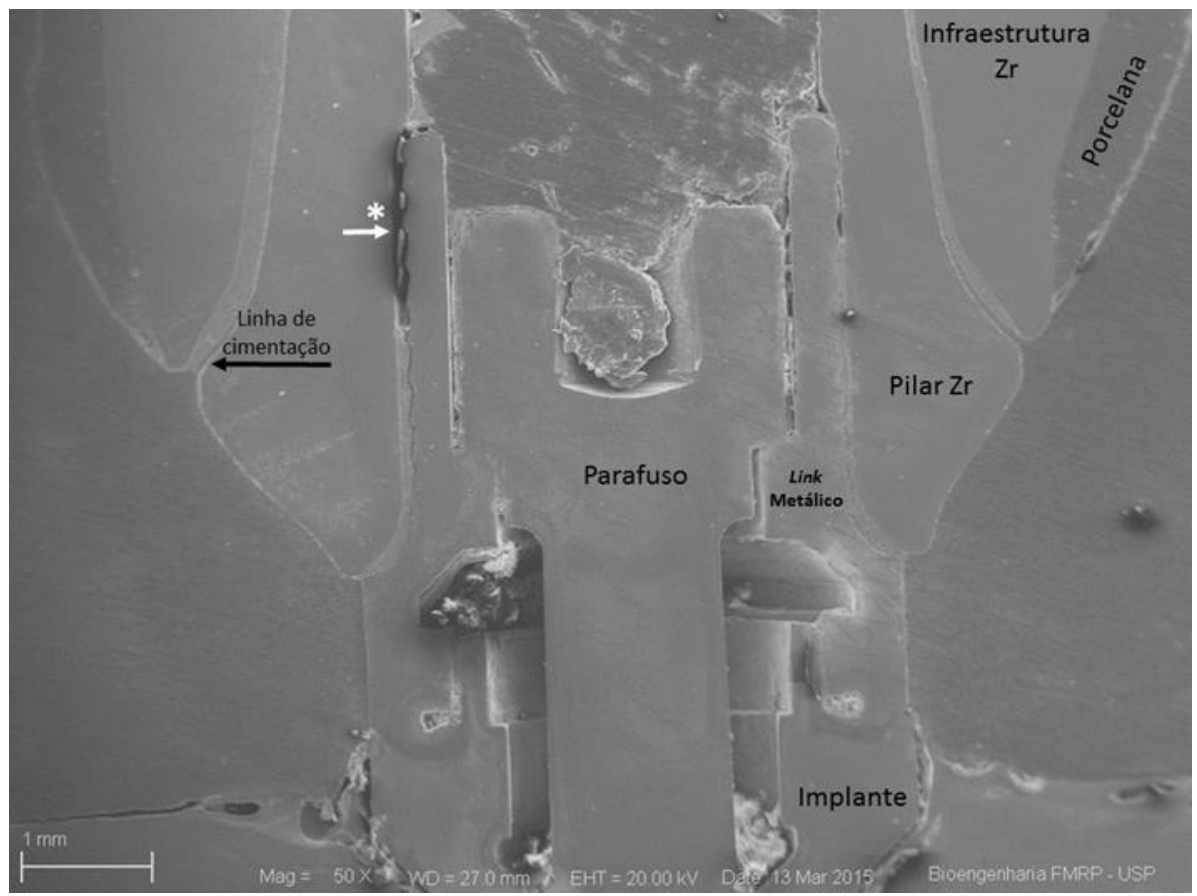

Figura 172: MEV - relacionamento coroa molar - pilar- implante - Lava

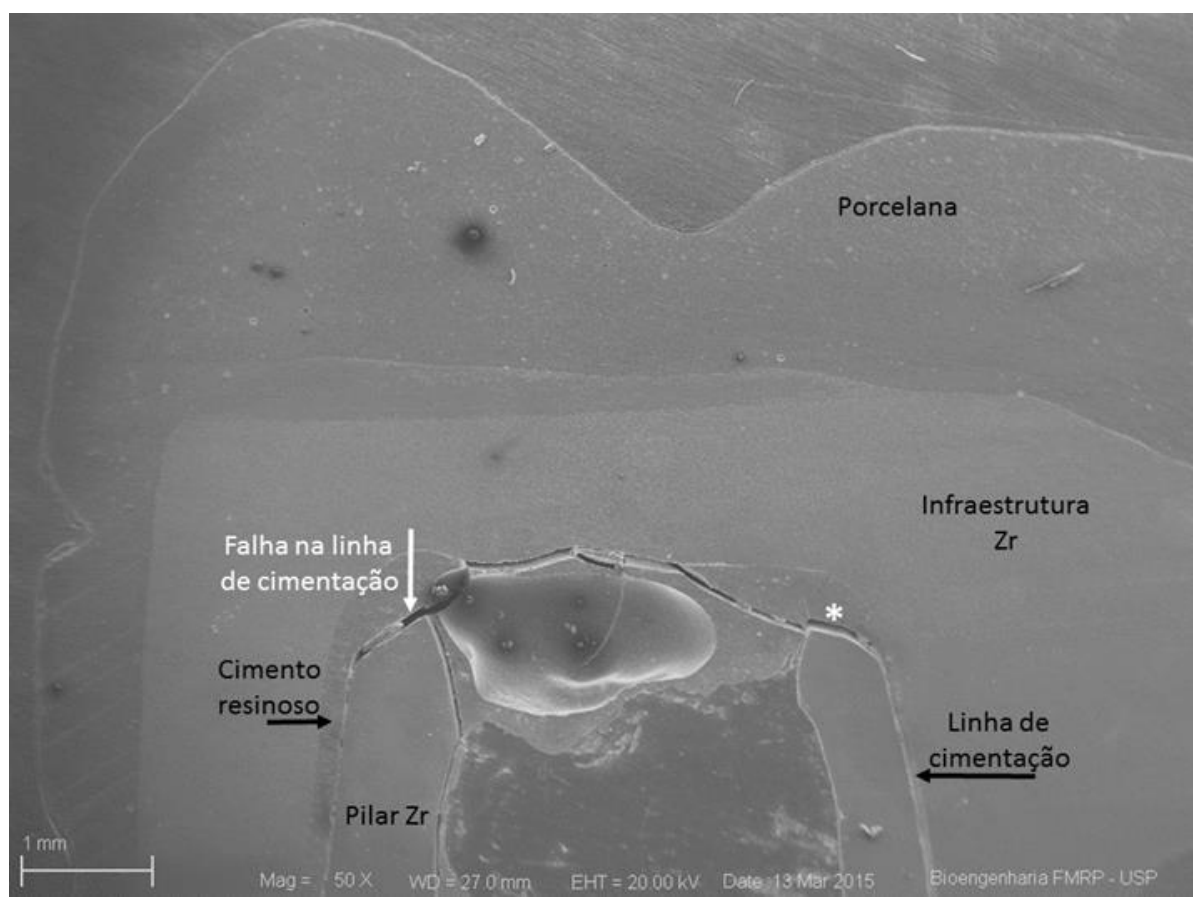

Figura 173: MEV - Molar (sem fratura) - Lava 


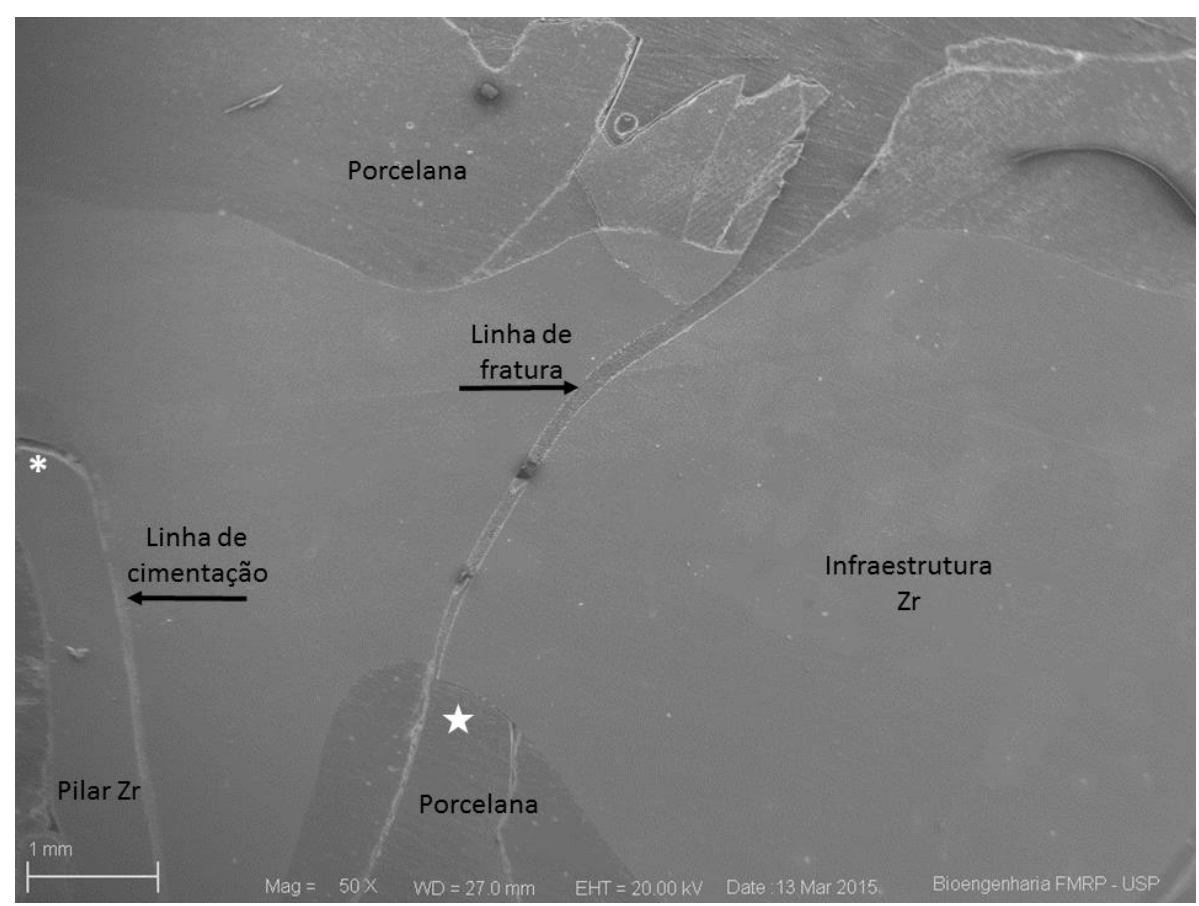

Figura 174: MEV - fratura região $M$ - pôntico - Lava

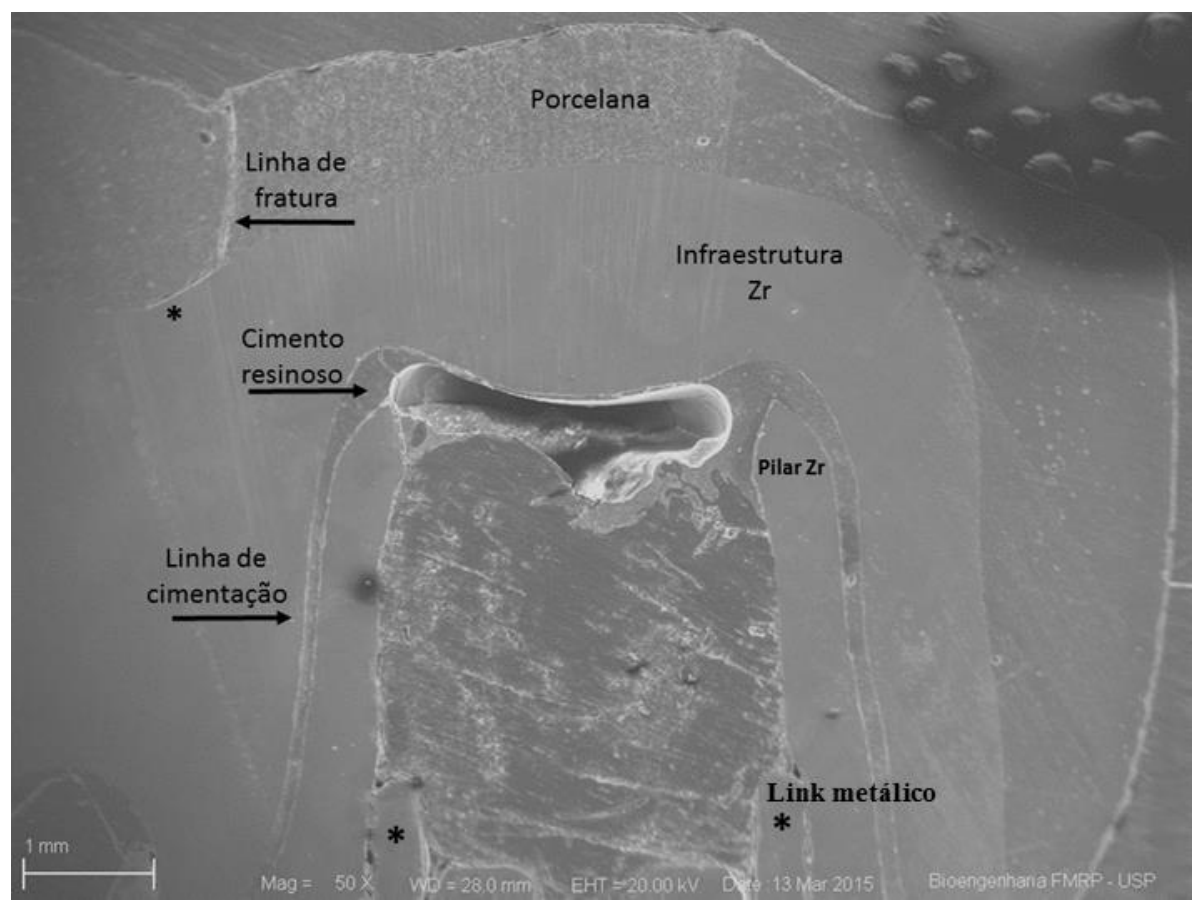

Figura 175: MEV - fratura região $M$ - pôntico - Lava 


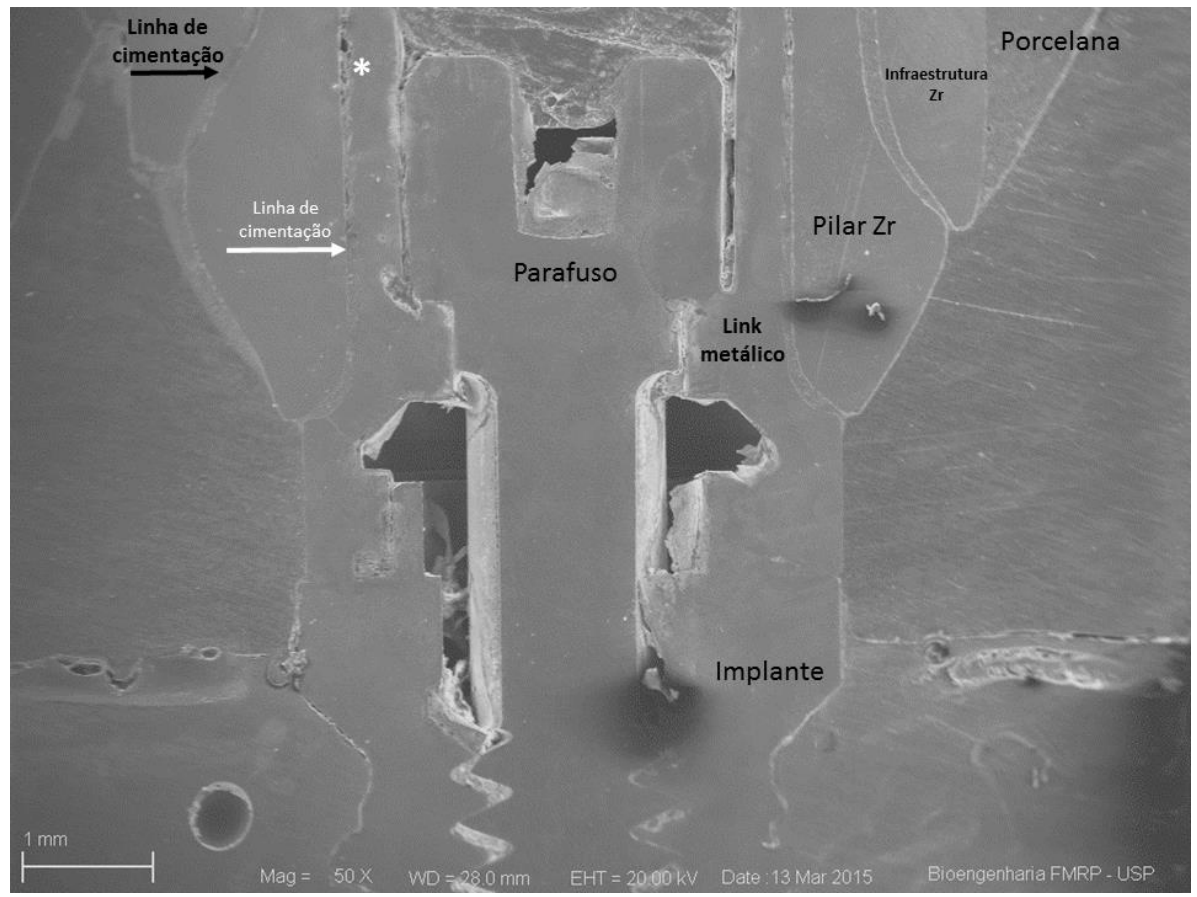

Figura 176: $M E V$ - relacionamento coroa $P M$ - pilar - implante - Lava

Analisando as fotomicrografias do grupo Lava, na Figura 172 é possível verificar todos os componentes do conjunto, com especial atenção à presença do link metálico sobre o qual é cimentada a porção de zircônia do pilar. Fica evidente a ocorrência de falha na cimentação entre link metálico/zircônia (*). Também chama atenção a não homogeneidade de espaço de cimentação entre infraestrutura/pilar de zircônia, com sugestão de falha de cimentação nas margens, na interface cimento/pilar. Na Figura 173 também se pode visualizar falha na linha de cimentação entre pilar/infraestrutura, com soltura do cimento do pilar de zircônia (*). A Figura 174 mostra linha de fratura que atravessa a porcelana e a infraestrutura de zircônia na região do pôntico, com propagação na interface infraestrutura/porcelana ( $\star$ ). Também fica evidente falha de cimentação ao pilar (*). Na Figura 175 também fica evidente linha de fratura da porcelana com propagação $\left(^{*}\right)$ na interface porcelana/infraestrutura de zircônia. Ainda, linha de cimentação com espessura aumentada entre o pilar molar e a infraestrutura. A Figura 176 também mostra todos os componentes, com ocorrência de falha 
(*) na interface link metálico/zircônia do pilar pré-molar. Ainda, variação da espessura da linha de cimentação entre pilar/infraestrutura de zircônia.

Abaixo seguem as imagens em microscopia eletrônica de varredura do corpo de prova 40 do grupo Controle (Figuras 177 a 181).

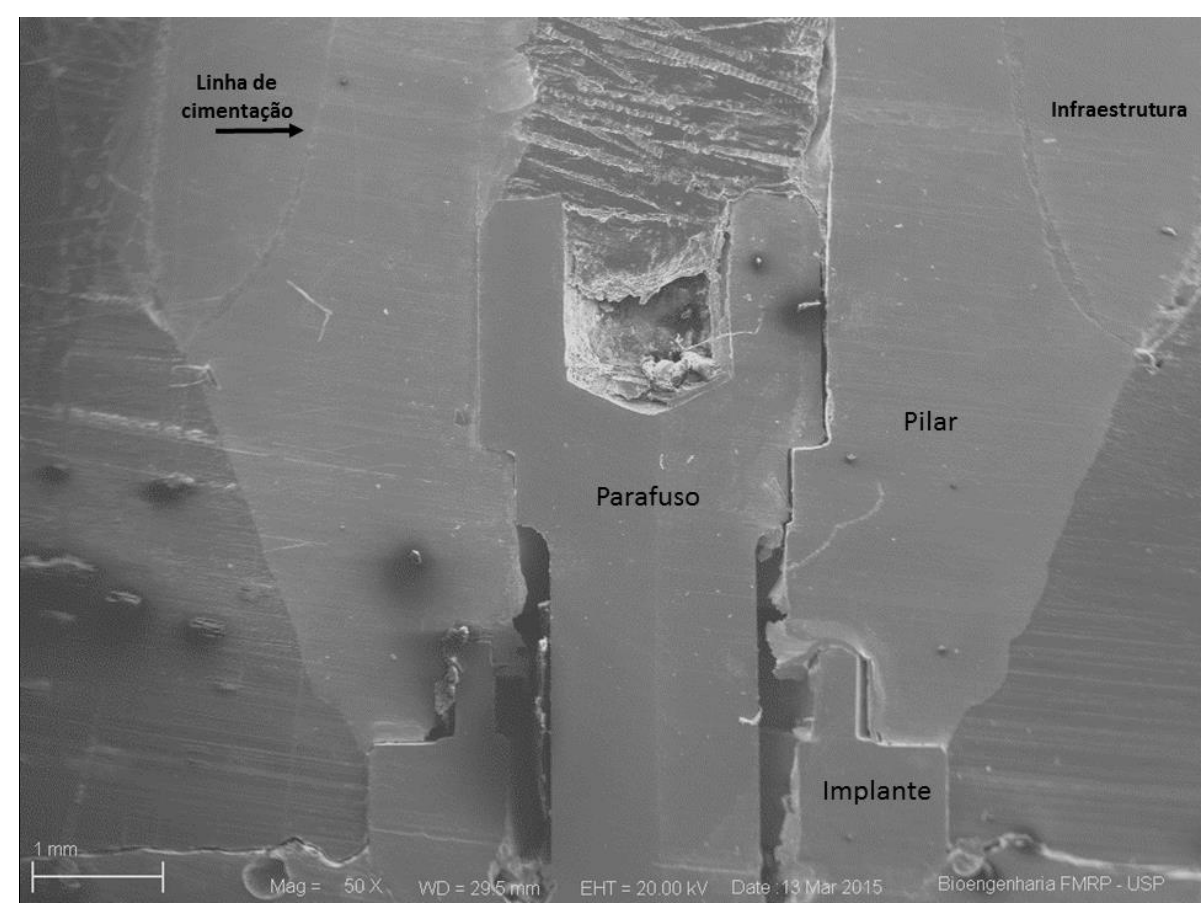

Figura 177: MEV - relacionamento coroa molar - pilar- implante - Co

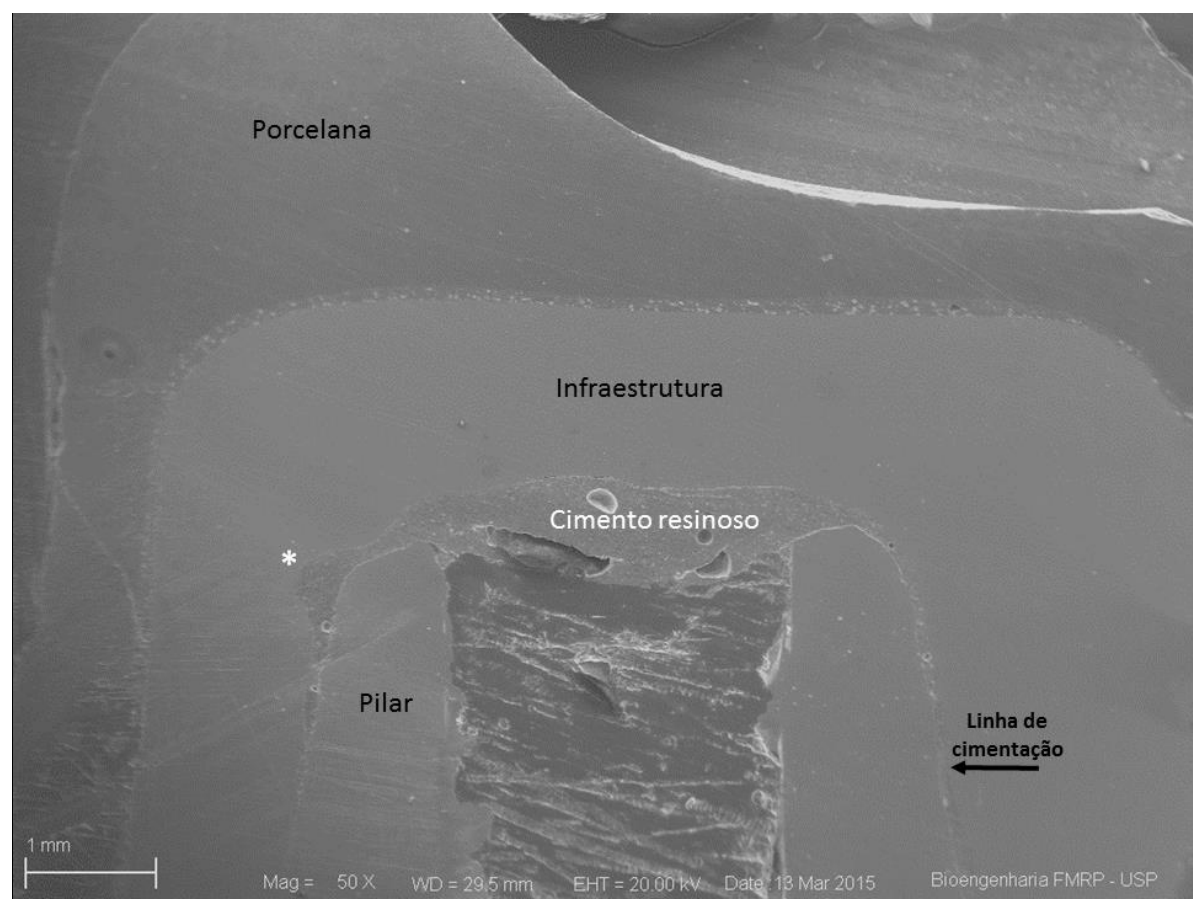

Figura 178: MEV - pôntico - região $M$ - Co 


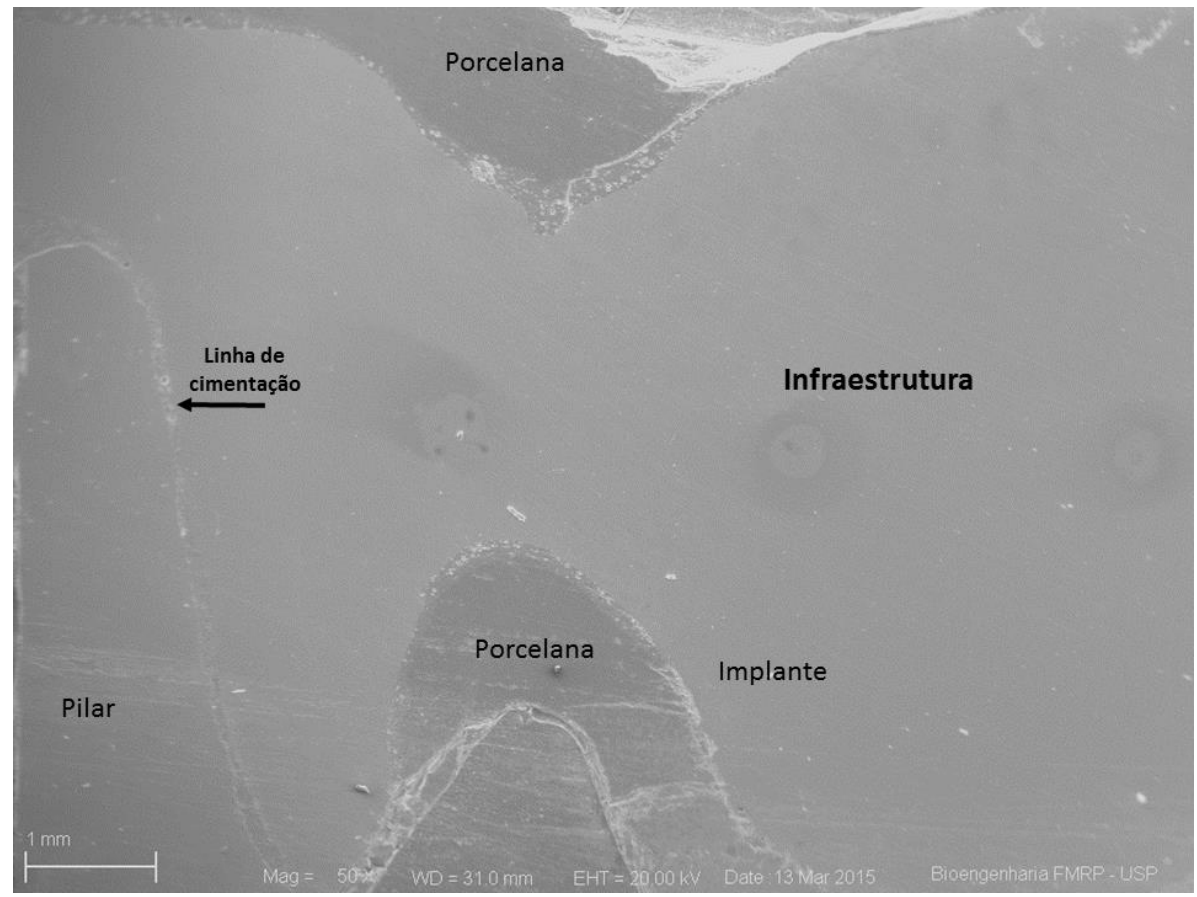

Figura 179: $M E V$ - pôntico - região $M$ - Co

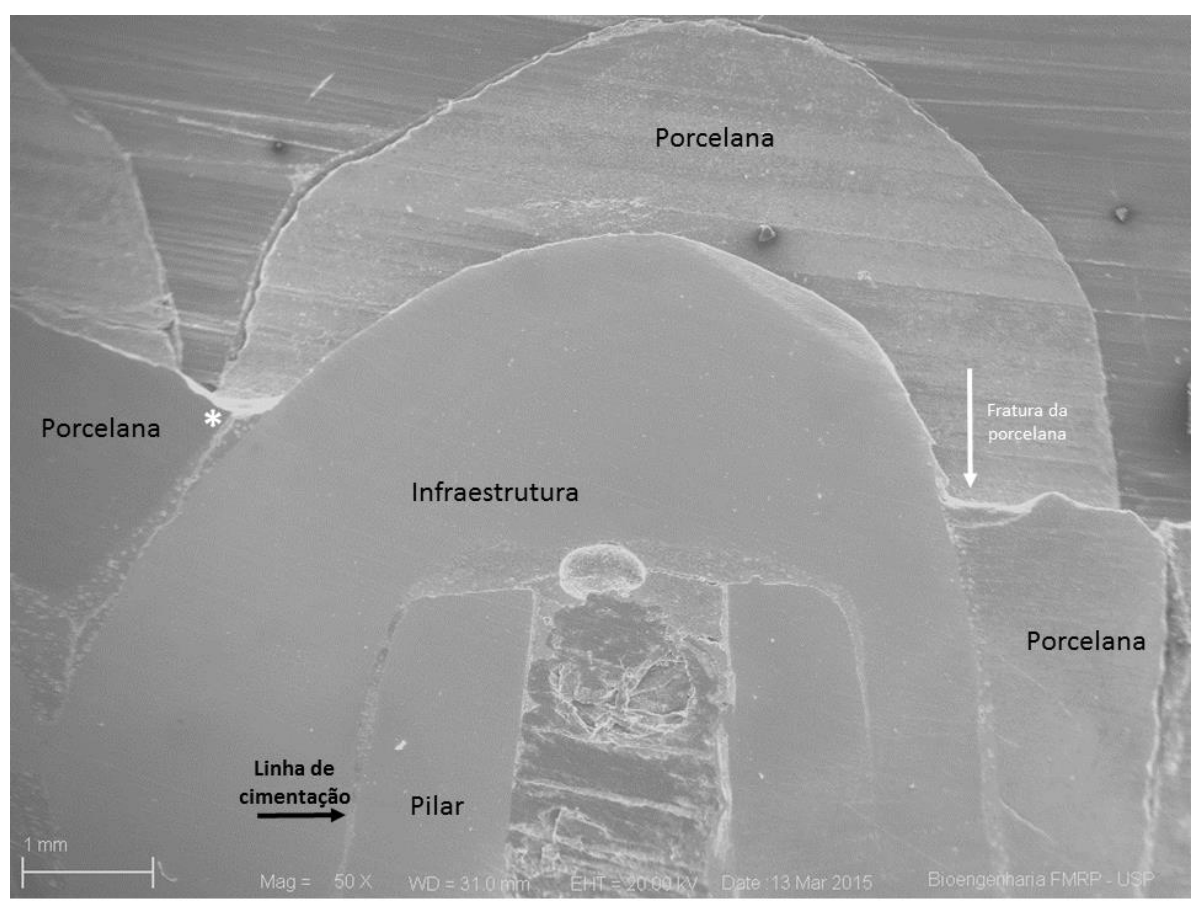

Figura 180: $M E V$ - PM - Co 


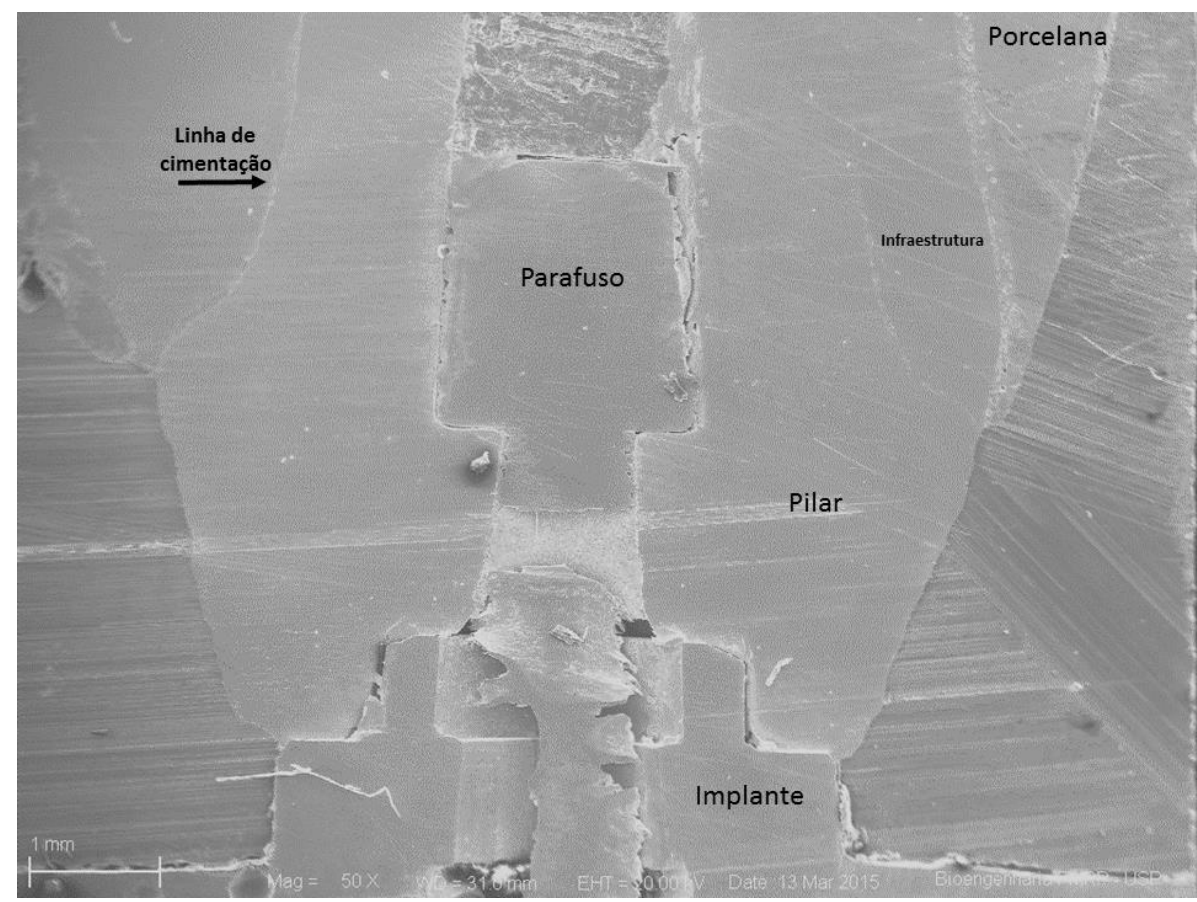

Figura 181: MEV - relacionamento coroa PM - pilar/implante - Co

Analisando as fotomicrografias do grupo Controle pode-se observar, na Figura 177 o bom assentamento do pilar fundido sobre a plataforma do implante. Há pequena variação na espessura da linha de cimentação entre pilar/infraestrutura metálica. A Figura 178 mostra corte na região mais oclusal do conjunto. A camada de cimento tem pequenas bolhas, mas, em geral, parece íntegra. Há um "defeito" (*) na parte interna da infraestrutura, que pode ter sido causado na fase de ajuste ao pilar. Na Figura 179 é mostrada a região de conexão do pôntico ao pilar pré-molar. A Figura 180 mostra nítida fratura do recobrimento estético de porcelana, com alguma propagação no lado mesial do pilar molar (*). A fratura permitiu deslocamento de maior volume de porcelana, com exposição na oclusal da infraestrutura. Na Figura 181 pode-se ver o bom assentamento do pilar molar ao implante. 

6. Discussão 

Pobre adaptação marginal predispõe ao acúmulo de placa e altera a composição da flora subgengival, predispondo à doença periodontal. A boa adaptação das peças protéticas é responsável pela diminuição da infiltração bacteriana, melhor distribuição de forças sobre os pilares, saúde dos tecidos periodontais/periimplantares, diminuição da perda óssea marginal e, com isso, melhor estética (Pak et al., 2010).

Diferentes métodos têm sido usados para avaliar a adaptação interna e marginal. A adaptação marginal clínica pode ser grosseiramente avaliada, diretamente com espelho e uma sonda, ou indiretamente, pela moldagem do dente e confecção de uma réplica que pode ser levada ao microscópio óptico ou de varredura. A desadaptação interna pode ser avaliada pela técnica da réplica, em que uma impressão de silicone do espaço de cimentação é utilizada. Em estudos laboratoriais, é possível a avaliação direta da amostra seccionada sob um microscópio.

Neste estudo foi utilizada a lupa estereoscópica para avaliação do desajuste pilar/implante porque o contraste entre os materiais (metal/metal e metal/zircônia) era suficiente para permitir visualização adequada.

Para avaliação da adaptação da infraestrutura de zircônia/pilar de zircônia houve dificuldade de visualização com o uso da lupa estereoscópica, devido à pouca diferenciação em função falta de contraste entre infraestrutura e pilares e/ou a inclinação do modelo sob a lupa. Por isso um novo método que utiliza microtomografia computadorizada (microCT) foi usado, permitindo maior confiabilidade para visualização de materiais com alta radiopacidade, como a zircônia. Além disso, este método possibilita a investigação 2D e 3D da desadaptação interna e marginal dentro do intervalo de alguns micrometros, em múltiplos lugares e direções (Seo et al., 2009) e é um método não destrutivo.

A hipótese de que não haveria diferença na adaptação vertical pilar/implante entre os grupos foi parcialmente aceita. Houve diferença nos pilares M entre ZirNeo e Lava, Lava e 
Co. Entretanto, maioria dos valores de desadaptação estavam abaixo de $10 \mu \mathrm{m}$, o que é considerado "clinicamente aceitável”, ainda que essa situação mereça cuidado na avaliação e discussão mais aprofundada. É imperativo destacar que os níveis de desajuste devem, sempre, serem os menores possíveis, e quanto maior a tecnologia empregada, espera-se que realmente sejam reduzidos. A menor desadaptação foi no grupo Lava no qual os pilares foram cimentados em um link metálico (base do pilar UCLA Neodent - pré-fabricado). Tanto o grupo controle quanto o ZirNeo tiveram maiores valores médios de desadaptação. O grupo ZirNeo pode ter tido a interferência da contração de sinterização da zircônia. Já o grupo controle, no qual os pilares foram fundidos em $\mathrm{Ni}-\mathrm{Cr}$, pode ter tido a interferência das características da liga, dos materiais de enceramento, inclusão e fundição, além do trabalho do técnico em prótese. Harish (2014) relata que há melhor adaptação entre pilar pré-fabricado e implante do que usinado, já que variáveis como fundição/usinagem podem interferir na adaptação dos pilares.

Há bastante controvérsia quanto ao desajuste marginal aceitável, especialmente em uma peça fundida com múltiplas unidades (Jemt et al., 1996; Tiossi et al., 2010). A maioria dos autores ainda concorda que aberturas marginais abaixo de $120 \mu \mathrm{m}$ são clinicamente aceitáveis (Beuer et al., 2009; Gonzalo et al., 2008). Nesse trabalho os valores médios de desadaptação marginal (vertical e horizontal) foram menores que $120 \mu \mathrm{m}$ para todos os grupos.

A hipótese que não há diferença na adaptação marginal (vertical e horizontal) entre pilares e infraestruturas antes da termociclagem foi parcialmente aceita. Para a adaptação vertical houve diferença significante apenas para os pilares M (Co e ZirNeo, Co e TiNeo, Co e Lava) e para adaptação horizontal (ZirNeo e Lava, Lava e TiNeo). Considerando que para desadaptação vertical nos pilares $\mathrm{M}$ o grupo controle apresentou valores menores do que os outros três grupos e levando-se em consideração que todos os grupos com exceção do 
controle foram usinados pela técnica CAD/CAM, em zircônia e titânio, a forma convencional de fundição de infraestruturas com a liga $\mathrm{NiCr}$ teve melhores resultados. A delimitação do término cervical em ombro arredondado com chanfro profundo nos pilares no momento do desenho no computador pode ter sido um momento falho. Tanto no sistema Neodent, quanto no Lava, os técnicos responsáveis pelo escaneamento, desenho e fresagem, apesar de entenderem muito sobre o programa e o sistema CAD/CAM em si, não são cirurgiõesdentistas e nem técnicos em prótese, o que pode ter contribuído de forma importante para essa falta de adaptação nas estruturas. Foi buscada, durante toda a execução dos trabalhos, a maior interação possível com o laboratório, na tentativa de explorar a máxima capacidade de todos os sistemas. No entanto, seja pela distância, seja pela rotina empregada em cada um, nem sempre se conseguiu atingir esse objetivo. Apesar de todo avanço tecnológico, o selamento de bordo tradicional, quando realizado de forma criteriosa e por técnico experiente, ainda pode ser a melhor escolha para obter próteses com adaptações satisfatórias. É fundamental, além de saber manusear o software CAD/CAM, entender dos princípios técnicos, biológicos e mecânicos dos preparos cavitários e de confecção das próteses.

A desadaptação horizontal da infraestrutura dos molares do grupo Lava antes da prensagem da porcelana e termociclagem foi significativamente maior que a dos grupos TiNeo e ZirNeo, fresados pelo sistema Neodent digital. Um dos possíveis motivos pode ter sido a possibilidade de alterar o espaço de cimentação para este sistema, a critério do responsável, na etapa CAD. No sistema Neodent digital o espaço para cimentação é fixo e o computador não permite alteração, mesmo quando o pilar não está com as características satisfatórias de angulação. Nesse caso, no sistema Lava adapta-se a infraestrutura, no sistema Neodent digital recomenda-se a repetição do pilar.

Considerando o desajuste horizontal, houve falha das próteses usinadas em zircônia, com subcontorno e sobrecontorno. O grupo Lava não apresentou subcontorno, mas muitas 
peças com sobrecontorno nítido. Já o grupo ZirNeo apresentou mais subcontorno que sobrecontorno. No sistema Lava o responsável pelo sistema pode estar exagerando no contorno cervical das peças, enquanto no Neodent digital o responsável pecou na delimitação do preparo, erro esse que foi comprovado, justificando a necessidade de repetição das infraestruturas iniciais. É importante considerar que, apesar da tecnologia empregada, a interferência humana ainda é decisiva.

A hipótese de que não há diferença na adaptação interna (axial e oclusal) antes da prensagem da porcelana e termociclagem foi parcialmente aceita. Houve diferença significativa para a interna oclusal dos pilares M (TiNeo e ZirNeo, TiNeo e Lava, ZirNeo e Co). O sistema Neodent digital inicialmente preconiza um alívio interno de $10 \mu \mathrm{m}$ na cervical e $50 \mu \mathrm{m}$ nas paredes axiais e oclusal, porém o próprio sistema alivia as regiões retentivas onde a broca não conseguiria penetrar, no momento da especificação do alívio. Da mesma forma que no sistema Lava, o espaço (gap) para o cimento pode ser ajustado para cada caso individualmente. Para certas partes da subestrutura no sistema Lava, por exemplo, na metade superior do coping, o espaço para o cimento pode ser maior. Esse espaço é ajustado pelo especialista CAD, no centro de escaneamento, de acordo com as necessidades particulares do dentista e de cada situação clínica, individualmente. $\mathrm{O}$ valor da adaptação interna axial do grupo TiNeo foi muito próximo de zero para todos os corpos de prova, o que sugere não ter havido alívio interno nas paredes axiais para esse grupo. $\mathrm{O}$ material da infraestrutura desse grupo foi Co-Cr, o que também pode ter influenciado, pela menor distorção do que a da zircônia parcialmente sinterizada. Em relação às desadaptações internas oclusais, os valores nas infraestruturas em zircônia (ZirNeo e Lava) foram maiores do que os valores das infraestruturas metálicas (TiNeo e Co). Os grupos metálicos, em geral, apresentaram melhor adaptação interna. A sinterização parcial da zircônia pode ser o fator principal para essa diferença em seguida a diferença no alivio interno entre os grupos. O que enfatiza a diferença de alivio interno até mesmo dentro do mesmo sistema para diferentes materiais, zircônia e CoCr. 
A hipótese de que não há diferença na discrepância marginal (vertical e horizontal) após a prensagem da porcelana e termociclagem foi parcialmente aceita. Houve diferença significativa na desadaptação vertical para os pilares PM (Lava e Co) e para os pilares M (Lava e TiNeo, Lava e Co) sendo os valores do grupo Lava maiores. Os grupos metálicos apresentaram melhor adaptação marginal do que os grupos fresados em zircônia. A utilização de blocos pré-sinterizados de zircônia pode ser o motivo da maior discrepância. Segundo Reich et al. (2005), algumas das vantagens da utilização da zircônia pré-sinterizada é a maior economia de tempo na usinagem e o menor desgaste das brocas de fresagem, por ser mais macia. Porém, tem a desvantagem da precisão de ajuste ser potencialmente mais baixa, devido à contração de sinterização, dependente do ciclo térmico utilizado.

A hipótese que não há diferença na adaptação interna (axial e oclusal) após prensagem da porcelana e termociclagem também foi parcialmente aceita. Houve diferença na adaptação interna axial nos pilares M (ZirNeo e Lava, ZirNeo e Co) e na adaptação interna oclusal nos pilares PM (Lava e Co). Tanto usinado quanto fundido, o metal apresentou menores valores de adaptação interna que os grupos em zircônia. A diferença entre os alívios internos de cada sistema justifica a diferença nas desadaptações internas dos grupos. Já o grupo controle foi fundido pela técnica da cera perdida, usando uma matriz de silicone para reprodução de todos os grupos diretamente sobre os pilares. Não foi utilizado espaçador para padronizar o espaço de cimentação, o que pode ter influenciado nos resultados desse grupo.

A hipótese de que não haveria diferença na adaptação marginal (vertical e horizontal) entre pilares e infraestrutura antes e após prensagem da porcelana e termociclagem foi aceita. Neste trabalho o gap marginal (vertical e horizontal) não aumentou após a prensagem da porcelana, cimentação e ciclagem termomecânica. Esse resultado contradiz o estudo de Hung et al. (1990), que concluiu que o gap marginal aumentou após a cimentação e a termociclagem. Por outro lado, corrobora com sua afirmação de que coroas metalocerâmicas 
apresentam adaptação significativamente melhor que coroas obtidas por outros sistemas cerâmicos. Outro fato a se considerar é que o recobrimento estético teoricamente não é o responsável para melhorar a adaptação da peça protética.

Nesse trabalho, a avaliação anterior à ciclagem foi realizada com a infraestrutura sem recobrimento de porcelana. Assim, pode-se sugerir que a aplicação do recobrimento estético não alterou a adaptação marginal das próteses. Os resultados desse trabalho sugerem que, mesmo após a simulação de dois anos de uso das próteses, não houve falha na cervical. Microtrincas, lascamentos e fraturas não ocorreram na região cervical, mesmo nos grupos com infraestruturas em zircônia. Durante a ciclagem não houve decementação, desaperto de parafusos e grandes fraturas da porcelana e infraestrutura. Ocorreram apenas trincas e lascamentos da porcelana de cobertura em alguns corpos de prova, porém na região oclusal da porcelana, e que não atingiram a infraestrutura. $\mathrm{O}$ grupo em que foi verificada maior ocorrências dessas fraturas foi o Lava, com 6 corpos de prova fraturados, seguido pelo grupo controle com 5, e os grupos ZirNeo e TiNeo com apenas dois corpos de prova fraturados. Falhas ocorridas na porcelana de cobertura utilizando a técnica convencional de aplicação estão diretamente relacionadas à diferença no coeficiente de expansão térmica da zircônia e, também, no rápido resfriamento da restauração quando removida do forno de queima da porcelana.

Complicações técnicas ocorrem continuamente após a instalação das próteses devido à fadiga e pelas tensões geradas nos materiais selecionados, sendo que estes eventos nornalmente não levam a falhas na prótese e no implante, mas são significantes em relação ao número de reparos e sessão de manutenção, tempo e custo para o profissional e o paciente (Papaspyridakos et al., 2012). Trincas ou fratura da cerâmica de cobertura são um dos principais problemas relacionados com restaurações metal free confeccionadas com 
infraestrutura em zircônia (Al-Amleh et al., 2010; Heintze e Rousson, 2010; Papaspyridakos e Lal, 2013).

A hipótese que não há diferença entre a adaptação interna (axial e oclusal) antes e após prensagem da porcelana e ciclagem termomecânica foi parcialmente aceita. Houve diferença nos M (ZirNeo e Lava) para a desadaptação axial e para desadaptação interna oclusal houve diferença nos pilares PM (TiNeo e Co) e para os pilares M (ZirNeo e Lava). Os valores da desadaptação interna para os grupos com esses materiais $(\mathrm{CoCr}$, Zir e $\mathrm{NiCr})$ diminuíram o que pode ter acontecido devido à contração dos materiais sob alta temperatura da prensagem da porcelana de recobrimento estético. Os menores valores de desadaptação foram encontrados para o grupo TiNeo, que teve valores próximos de 0 para a desadaptação interna axial.

Considerando a desadaptação interna, há muita divergência quanto à espessura da linha de cimentação em próteses cimentadas. A Associação Dentária Americana (ADA) Especificação $\mathrm{n}^{\mathrm{o}}$. 8 estabelece que a espessura da película de cimento para restaurações cimentadas deve ser de 25 a $40 \mu \mathrm{m}$. No entanto, desajustes marginais dentro deste intervalo raramente são alcançados clinicamente. Quanto maior a desadaptação marginal e a exposição da linha de cimentação, maior a taxa de dissolução do cimento. Jacobs e Windeler (1991) afirmaram que linhas de cimento são inevitáveis em prótese fixa, porque sempre vai existir algum grau de discrepância marginal devido à dissolução do cimento no meio bucal. Por isso, a cimentação adesiva seria preferível ao assegurar maior retenção e adaptação marginal, garantindo maior resistência à fratura (Piascik et al., 2009).

Segundo Reich et al. (2005) a precisão da adaptação de uma restauração produzida usando a tecnologia CAD/CAM é influenciada pelo processo de escaneamento, desenho no computador, fresagem e efeitos da contração do material. A zircônia pode ser utilizada em blocos pré-fabricados parcialmente sinterizados, que são utilizados para produzir restaurações 
aumentadas para compensar a contração de sinterização final. Fresagem de blocos totalmente sinterizados pode produzir restaurações mais precisas, mas está associada a grande desgaste das brocas de fresagem e demanda muito tempo de trabalho. Embora programas de computador sejam usados para compensar essa diferença e garantir um ajuste preciso, não é certo que a contração pode ser controlada tão eficientemente em próteses mais extensas. Isso pode ter ocorrido nesse trabalho e a maior desadaptação interna oclusal ter ocorrido devido à contração própria do material.

Neste contexto, é importante salientar que a instalação de uma prótese implantossuportada não passiva com aumento do microgap vertical pode induzir tensões mais elevadas para as estruturas de suporte e contribuir para complicações mecânicas e biológicas segundo Tiossi et al., 2012. No entanto o trabalho desses autores foi com próteses parafusadas e este com próteses cimentadas.

Além disso, a quantidade e a qualidade de tecido ósseo ao redor dos implantes são de fundamental importância para garantir a excelência dessa modalidade de tratamento reabilitador, haja vista que a perda óssea pode levar à sua instabilidade (Ciftci e Canay, 2000).

Foi verificada a influência no padrão de distribuição de tensões nas infraestruturas e no tecido ósseo por meio de estudo in vitro por correlação de imagens digitais. É importante ressaltar que todo estudo in vitro apresenta limitações que devem ser consideradas durante a interpretação dos resultados (Shirakura et al., 2009). A validade dos resultados obtidos a partir de métodos numéricos também deve ser cuidadosamente analisada (Natali et al., 2006), uma vez que depende da precisão com a qual a geometria, propriedade dos materiais, condição de interface, suporte e carregamento, estão de acordo com a realidade clínica (Meijer et al., 1993).

A hipótese de que não há diferença na distribuição de tensões nos implantes nos quatro grupos foi parcialmente aceita. Não houve diferença significante entre a distribuição de 
tensões entre os implantes PM e $\mathrm{M}$ de cada grupo. Porém, houve diferença nos implantes $\mathrm{M}$ entre os grupos ZirNeo e Lava. Avaliando os valores da distribuição de tensões em toda a região do implante, verificou-se maior diferença de tensões em função dos grupos na região do molar. Isso pode ser justificado pela maior mesa oclusal desse dente, o que pode aumentar a probabilidade de forças laterais, fora do longo eixo do dente, pela própria decomposição das forças geradas pelo contato das vertentes das cúspides em oclusão. Observou-se que, comparando tanto a distribuição de tensões em todo o implante quanto somente na região cervical, o grupo ZirNeo teve maiores valores de tensão que o grupo Lava. Como esse grupo teve o pilar em zircônia cimentado sobre o link metálico, existiu um novo componente intermediário entre pilar e implante o que pode ter melhorado a distribuição de tensões no osso.

A distribuição de tensões foi maior na região cervical dos implantes, comparado à região apical, o que pode explicar a maior incidência de perda óssea nessa região para implantes com conexão em hexágono externo. Existem diversos fatores que contribuem para a perda óssea no primeiro ano de instalação dos implantes (Oh, 2002; Qian, 2012). Os implantes cone Morse estão sendo muito usados e difundidos com o intuito de minimizar essa perda óssea marginal. Nesse trabalho foram utilizados implantes de hexágono externo por serem, ainda, os mais utilizados mundialmente.

Estudo envolvendo simulação computacional que comparou o desempenho da transmissão de tensões entre próteses implantossuportadas cimentadas x parafusadas, mostrou que as próteses parafusadas contribuem para o aumento da tensão nos implantes (Papavasiliou et al., 1996). A literatura ainda é controversa quanto à melhor forma de retenção da coroa protética em próteses implantossuportadas. Nissan et al. (2011) compararam o sucesso em longo prazo e as complicações envolvendo restaurações implantossuportadas parafusadas e cimentadas em pacientes parcialmente edêntulos. Verificaram que os resultados em longo 
prazo para as restaurações cimentadas foram superiores aos das parafusadas, clínica e biologicamente. Contudo, em acompanhamento clínico de 10 anos de próteses cimentadas e parafusadas unitárias (Vigolo et al., 2012), não foram encontradas evidências de comportamento clínico diferente quanto à perda óssea marginal e dos tecidos moles periimplantares.

A hipótese de que não há diferença na resistência à fratura das próteses dos quatro grupos foi rejeitada. Houve diferença entre o grupo TiNeo e os demais, sendo que o grupo TiNeo apresentou os maiores valores de resistência. É bem sabido que a resistência de próteses fixas depende das propriedades do material, largura, extensão, forma e posição dos conectores, bem como da forma do pôntico, da técnica de confecção, do acabamento da superfície das coroas e do método de cimentação.

Semelhantemente ao trabalho de Sundh e Sjogren (2006), nesse trabalho as fraturas foram localizadas entre o ponto de carga e um dos conectores. As formas de propagação de trincas eram, na maioria, oblíquas através do conector e pôntico. A localização da fratura ocorreu nas regiões mesial ou distal do pôntico.

Nesse trabalho os menores valores foram maiores que $500 \mathrm{~N}$. Dentre os grupos analisados, a resistência à fratura do TiNeo $(2.134 \mathrm{~N})$ foi maior que a dos demais, e a menor resistência foi do grupo ZirNeo $(1.362 \mathrm{~N})$. O grupo TiNeo teve maior resistência à fratura potencialmente devido à sua maior higidez, comparada com a dos outros grupos, que tiveram mais ocorrência de lascamento da porcelana de cobertura em consequência da ciclagem termomecânica. A infraestrutura em $\mathrm{Co}-\mathrm{Cr}$ pode ter ajudado no aumento da resistência à fratura do grupo TiNeo. Tem sido relatado que a força média de oclusão no adulto é de cerca de 400 a $800 \mathrm{~N}$ na região molar, $300 \mathrm{~N}$ na região de pré-molar e de $200 \mathrm{~N}$ na região anterior. As médias de todos os grupos ficaram acima desses valores, o que sugere que todos os grupos suportariam bem as cargas mastigatórias na região posterior da boca em oclusão fisiológica 
normal. Ressalta-se, de qualquer modo, a importância do ajuste oclusal para a obtenção de melhores resultados.

Entre os grupos metálicos, TiNeo e Co, observou-se resistência à fratura significativamente maior para o grupo TiNeo. Além de maior resistência, esse grupo teve como vantagem a utilização de uma infraestrutura fresada pelo sistema CAD/CAM, diferentemente daquela do grupo controle, que foi fundida e soldada. Enquanto na fundição há inequivocamente maior interferência humana, no sistema CAD/CAM há maior possibilidade de se ter maior rigor por ser um sistema mais evoluído tecnologicamente. Entretanto, o acompanhamento do escaneamento e desenho no computador das estruturas Lava, bem como algumas intercorrências com o sistema Neodent digital, demostraram que a interferência do operador ainda altera o resultado final da estrutura. Apesar de ambos os sistemas serem operados por técnicos bem treinados, nenhum era dentista ou técnico em prótese dentária, e havia maior dificuldade para o esclarecimento correto das características de uma prótese fixa, dificultando o estabelecimento da necessidade de alguma correção por nós sugerida. Portanto, entre fundir e utilizar a tecnologia CAD/CAM, nos casos em que o material permite essa escolha, é possível afirmar que o método tradicional de fundição, desde que se trabalhe com um bom técnico em prótese dentária, ainda é uma boa escolha. Os pilares fundidos nesse trabalho apresentaram resultados satisfatórios.

Segundo Triwatana (2012), a resistência à fratura depende de vários fatores, tais como: tipos de testes e suas condições, morfologia e dimensões da peça testada; por isso é difícil utilizar esses parâmetros para comparar os resultados entre os diferentes estudos ou materiais. Nesse trabalho utilizamos metodologia descrita anteriormente (Bakeman et al., 2015) para facilitar a comparação entre os trabalhos.

Há evidências de que o espaço excessivo de cimento poderia ser relacionado a falhas do material de revestimento (Rekow e Thompson, 2005). Além disso, Tuntiprawon e Wilson 
(1995) observaram que o aumento da espessura de cimento em coroas de cerâmica pura reduziu a resistência à fratura. Neste trabalho observou-se que o problema da porcelana, apesar de toda evolução, continua sendo a friabilidade e lascamento. Os avanços estéticos da zircônia monolítica e sua possível utilização sem necessidade de recobrimento com a porcelana deve melhorar a desvantagem de friabilidade das próteses metal free.

A análise sob microscopia eletrônica de varredura permitiu verificar que, em todos os grupos, os componentes: implantes, pilares, parafusos de pilares e prótese parcial fixa, estavam adequadamente relacionados. Não houve nenhuma fratura de implante e pilar. Apenas uma fratura de parafuso do pilar foi observada. Duas fraturas de infraestrutura, sendo ambas em zircônia, 1 do grupo Lava e outra do grupo ZirNeo. Em todos os grupos foi observada ocorrência de inclusão de ar no cimento, na região do orifício do parafuso.

Sugere-se que a propagação da linha de fratura ocorreu a partir da região do pôntico, local de aplicação da carga. Dos 40 corpos de prova examinados somente 2 tiveram fratura na infraestrutura, sendo que ambas eram de zircônia (1 ZirNeo e 1 Lava). Houve pequena ocorrência de fratura (1 fratura em cada 10 corpos de prova), nenhuma nos grupos metálicos (TiNeo e Co). Apesar de todos os avanços dos materiais cerâmicos, o metal continua sendo o padrão ouro com relação à resistência, tanto o fundido (grupo Co) quanto o usinado em laboratório pelo sistema CAD/CAM (grupo TiNeo). Nota-se, em algumas fotomicrografias, que houve propagação da falha, iniciada na cerâmica, para a interface cerâmica/zircônia, também sugerindo que a cerâmica de recobrimento, inclusive quanto à adesão à zircônia, pode ser considerada como um ponto crítico a ser observado.

O grupo Lava por necessitar de um link metálico para cimentação do pilar em zircônia tinha duas áreas de cimentação: uma da zirconia do pilar ao link metálico e outra da prótese fixa à zircônia de cada pilar. A cimentação ao link metálico ocorreu no laboratório, pelo responsável pelo sistema CAD/CAM. O espaço de cimentação não foi homogêneo e a 
linha de cimentação se apresentou aumentada, o que pode ter ocorrido devido a falha na manipulação e inserção do cimento no interior do pilar em zircônia ou a um erro no escaneamento do link metálico, desenho/fresagem da estrutura de zircônia no computador ou excessivo desgaste no interior da zircônia para adaptação ao link. No trabalho de Reich et al. (2005), em que avaliaram a adaptação marginal e interna de prótese parcial fixa posterior totalmente em cerâmica utilizando três sistemas CAD/CAM (Digident, Cerec e Lava) e compararam os resultados aos de próteses metalocerâmicas convencionais, a opção de erro da fresagem da estrutura pôde ser descartada, já que afirmam que o sistema Lava é capaz de calcular satisfatoriamente a contração de sinterização da zircônia.

Dessa forma podemos inferir que a prensagem da porcelana e a termociclagem mecânica não influenciou os resultados da desadaptação marginal e melhorou a adaptação interna. O grupo usinado pelo sistema Neodent digital em zircônia teve maior concentração de tensão na região cervical podendo ter maior perda óssea nessa região. O grupo TiNeo foi o que mais resistiu a fratura. Entre fresar em zircônia pelo sistema Neodent digital ou Lava, o sistema Lava distribuiu melhor a tensão ao longo do implante, porém teve maiores valores de desadaptação interna. Entre fresar em titânio ou confeccionar a prótese pelo sistema convencional, melhor fresar.

Novos estudos, inclusive com maior controle da interferência humana devem ser desenvolvidos para testar a potencial superioridade dos sistemas CAD/CAM sobre métodos mais tradicionais de confecção de pilares e infra e supraestruturas de próteses, convencionais ou sobre implantes. De qualquer modo, sugere-se que a utilização do sistema CAD/CAM anuncie, quem sabe, o fim da era das fundições odontológicas, ainda realizadas quase da mesma maneira que no início do século XX, o que não condiz com o avanço tecnológico atualmente à disposição do cirurgião-dentista. 

7. Conclusão 

Dentro dos limites desse trabalho in vitro, e de acordo com as hipóteses propostas:

1. Houve diferença significante na adaptação marginal pilar/implante entre os materiais e sistemas CAD/CAM;

2. Não houve diferença significante na adaptação marginal (vertical e horizontal) pilar/infraestrutura entre os materiais e sistemas CAD/CAM quando considerados antes e após prensagem do revestimento estético cerâmico e ciclagem termomecânica. Houve diferença quanto aos espaços internos (axial e oclusal);

3. Houve diferença significante na adaptação marginal (vertical e horizontal) entre antes e após ciclagem termomecânica para os diferentes materiais e sistemas CAD/CAM;

4. Houve diferença significante na adaptação interna (espaços axial e oclusal) entre antes e após ciclagem termomecânica para os diferentes materiais e sistemas CAD/CAM;

5. Houve diferença significante na distribuição das tensões, na região cervical do molar, entre os diferentes materiais e sistemas CAD/CAM;

6. Houve diferença significante na resistência à fratura das próteses fixas implantossuportadas obtidas com os diferentes materiais e sistemas CAD/CAM. 

ReFERÊECIAS 1

${ }^{1}$ Estilo Vancouver (De acordo com o International Committee of Medical Journal Editors, e baseado no padrão ANSI, adaptado pela U.S. National Library of Medicine. Disponível em: http://www.ncbi.nlm.nih.gov/bookshelf/br.fcgi?book=citmed) 

Abduo J. Fit of CAD/CAM Implant Frameworks: A Comprehensive Review. J Oral Implantol. 2014 Dec;40(6):758-766.

Aglietta M, Iorio Siciliano V, Blasi A, Sculean A, Brägger U, Lang NP, Salvi GE. Clinical and radiographic changes at implants supporting single-unit crowns (SCs) and fixed dental prostheses (FDPs) with one cantilever extension. A retrospective study. Clin Oral Implants Res. 2012 May;23(5):550-555.

Al-Amleh B, Lyons K, Swain M. Clinical trials in zirconia: a systematic review. J Oral Rehabil. 2010 Apr;37(8):641-52.

Alkumru H, Hullah WR, Marquis PM, Wilson HJ. Factors affecting the fit of porcelain jacket crowns. Br Dental J. 1988 Jan;164(2):39-43.

Andreiuolo R, Gonçalves AS, Dias KRHC. A zircônia na Odontologia Restauradora. Rev. bras. Odontol. 2011 Jan-Jun;68(1):49-53.

Andreiuolo RF, Sabrosa CE, Dias KR. Dual-scan technique for the customization of zirconia computer-aided design/computer-aided manufacturing frameworks. Eur J Dent. 2013 Sep;7(Suppl 1):S115-8.

Bakeman EM, Rego N, Chaiyabutr Y, Kois JC. Influence of Ceramic Thickness and Ceramic Materials on Fracture Resistance of Posterior Partial Coverage Restorations. Oper Dent. 2015 Mar-Apr,40(2):211-7.

Barbosa GA, Bernardes SR, das Neves FD, Fernandes Neto AJ, de Mattos Mda G, Ribeiro RF. Relation between implant/abutment vertical misfit and torque loss of abutment screws. Braz Dent J. 2008;19(4):358-63.

Beuer F, Edelhoff D, Gernet W and Naumann M. Effect of preparation angles on the precision of zirconia crown copings fabricated by CAD/CAM system. Dent Mater J. 2008 Nov;27(6):814-820. 
Beuer F, Aggstaller H, Edelhoff D, Gernet W, Sorensen J. Marginal and internal fits of fixed dental prostheses zirconia retainers. Dent Mater. 2009 Jan;25:94-102.

Beuer F, Naumann M, Gernet W, Sorensen JA. Precision of fit: zirconia three-unit fixed dental prostheses. Clin Oral Investig. 2009 Sep;13(3):343-9.

Blanes RJ, Bernard JP, Blanes ZM, Belser UC. A 10-year prospective study of ITI dental implants placed in the posterior region. II: Influence of the crown-to-implant ratio and different prosthetic treatment modalities on crestal bone loss. Clin Oral Implants Res. 2007 Dec;18:707-714.

Borba M, Cesar PF, Griggsc JA, Bona AD. Adaptation of all-ceramic fixed partial dentures. Dent Mater. 2011 Dec;27:1119-1126.

Chen HY, Hickel R, Setcos JC, Kunzelmann KH. Effects of surface finish and fatigue testing the fracture strength of CAD/CAM and pressed-ceramic crowns. J Prosthet Dent. 1999 Oct;82(4):468-75.

Cibirka RM, Nelson SK, Lang BR, Rueggeberg FA. Examination of the implant-abutment interface after fatigue testing. J Prosthet Dent. 2001 Mar;85(3):268-275.

Ciftci Y, Canay S. The effect of veneering materials on stress distribution in implantsupported fixed prosthetic restorations. Int J Oral Maxillofac Implants. 2000 Jul-Aug;15:571582.

Elias CN, Santos C. Próteses cerâmicas produzidas por usinagem CAD/CAM. Implant News. 2010;7(2):263-6.

Fanhmy. Bond Strength, microhardness, and core/veener interface quality of an all-ceramic system. 2010;19:95-102.

Gonzalo E, Suarez MJ, Serrano B, Lozano JF. Marginal fit of zirconia posterior fixed partial dentures. Int J Prosthodont. 2008 Sep-Oct;21(5):398-9. 
Gratton DG, Aquilino SA, Stanford CM. Micromotion and dynamics fatigue properties of the dental implant-abutment interface. J Prosthet Dent. 2001 Jan; 85(1):47-52.

Guazzato M, Proos K, Quach L, Swain MV. Strength, reliability and mode of fracture of bilayered porcelain/zirconia (Y-TZP) dental ceramics. Biomaterials. 2004 Sep;25(20):50455052.

Guess PC, Att W, Strub JR. Zirconia in Fixed Implant Prosthodontics. Clin Implant Dent Relat Res. 2012 Oct;14(5):633-645.

Harish V, Ali SAM, N J, Ifthikar M, Senthil S, Basak D, Huda F, Priyanka. Evaluation of Internal and Marginal Fit of Two Metal Ceramic System - In Vitro Study. J Clin Diagn Res. 2014 Dec;8(12):ZC53-6.

Heintze SD, Rousson V. Survival of zirconia- and metal-supported fixed dental prostheses: a systematic review. Int J Prosthodont. 2010 Nov-Dec;23(6):493-502.

Heymann HD, Bayne SC, Sturdevant JR, Wilder Jr AD, Roberson TM. The clinical performance of CAD/CAM-generated ceramics inlays. A four year study. J Am Dent Assoc. 1996 Aug;127(8):1171-81.

Hung SH, Hung SK, Eick JD, Chappell RP. Marginal fit of porcelain-fused-to-metal and two types of ceramic crown. J Prosthet. Dent. 1990 Jan;63(10:26-31.

Jacobs MS, Windeler AS. An investigation of dental luting cement solubility as a function of the marginal gap. J Prosthet Dent. 1991 Mar;65(3):436-42.

Jemt T. In vivo measurements of precision of fit involving implantsupported prostheses in the edentulous jaw. Int J Oral Maxillofac Implants 1996 Mar-Apr;11(2):151-158.

Kano SC, Binon PP, Curtis DA. A classification system to measure the implant-abutment microgap. Int J Oral Maxillofac Implants. 2007 Nov-Dec;22(6):879-85. 
Karatasli O, Kursoglu P, Çapa N, Kazagoglu E. Comparison of the marginal fit of different coping materials and designs produced by computer aided manufacturing systems. Dent Mater J. 2011;30(1):97-102.

Katsoulis J, Mericske-Stern R, Rotkina L, Zbaren C, Enkling N, Blatz MB. Precision of fit of implant-supported screw-retained 10-unit computer-aided-designed and computer-aidedmanufactured frameworks made from zirconium dioxide and titanium: an in vitro study. Clin. Oral Impl. Res. 2014 Fev; 25(2):165-174.

Katsoulis J, Muller P, Mericske-Stern R, Blatz MB. CAD/CAM fabrication accuracy of longvs. short-span implant-supported FDPs. Clin. Oral Impl. Res. 2015 Mar;26:245-249.

Khraisat A, Hashimoto A, Nomura S, Miyakawa O. Effect of lateral cyclic loading on abutment screw loosening of na external hexagon implant system. J Prosthet Dent. 2004 Apr;91(4)326-34.

Kohorst P, Junghanns J, Dittmer MP, Borchers L, Stiesch M. Different CAD/CAM processing routes for zirconia restorations: influence on fitting accuracy. Clin Oral Investig 2011 Aug;15(4):527-36.

Kollar, A., Huber, S., Mericske, E., Mericske-Stern, R. Zirconia for teeth and implants: a case series. Int J Periodontics Restorative Dent. 2008 Oct;28(5): 479-487.

Krasanaki ME, Pelekanos S, Andreiotelli M, Koutayas SO, Eliades G. X-ray microtomographic evaluation of the influence of two preparation types on marginal fit of CAD/CAM alumina copings: a pilot study. Int J Prosthodont. 2012 Mar-Apr;25(2):170-2.

Li J, Fok AS, Satterthwaite J, Watts DC. Measurement of the full-field polymerization shrinkage and deph of the cure of dental composite using digital image correlation. Dental Mater. 2009 May;25(5):582-8.

Lins L, Bemfica V, Queiroz C, Canabarro A. In vitro evaluation of the internal and marginal misfit of CAD/CAM zirconia copings. J Prosthet Dent. 2015; 113:205-211.

McLean JW, von Fraunhofer JA. The estimation of cement film thickness by an in vivo technique. Br Dent J 1971;131:107-11. 
Meijer HJ, Starmans FJ, Bosman F, Steen WH. A comparison of three finite element models of an edentulous mandible provided with implants. J Oral Rehabil. 1993 Mar;20(2):147-157.

Moretti Neto RT, Hiramatsu DA, Suedam V, Conti PCR, Rubo JH. Validation of an experimental polyurethane model for biomechanical studies on implant-supported prosthesis - compression tests. J Appl Oral Sci. 2011 Jan-Fev;19(1):47-51.

Natali AN, Pavan PG, Ruggero AL. Evaluation of stress induced in peri-implant bone tissue by misfit in multi-implant prosthesis. Dent Mater 2006 Apr;22(4):388-395.

Nissan J, Narobai D, Gross O, Ghelfan O, Chaushu G. Long-term outcome of cemented versus screw-retained implant-supported partial restorations. Int J Oral Maxillofac Implants. 2011 Sep-Out;26(6):1102-1107.

Oh TJ, Yoon J, Misch CE, Wang HL. The causes of early implant bone loss: myth or science? J Periodontol. 2002 Mar; 73(3):322-33.

Pak HS, Han JS, Lee JB, Kim SH, Yang JH, J. Influence of porcelain veneering on the marginal fit of Digident and Lava CAD/CAM zirconia ceramic crowns. J Adv Prosthodont. 2010 Jun;2(2):33-8.

Papaspyridakos P, Chen CJ, Chuang SK, Weber HP, Gallucci GO. A systematic review of biologic and technical complications with fixed implant rehabilitations for edentulous patients. Int J Oral Maxillofac Implants. 2012 Jan-Fev;27(1):102-110.

Papaspyridakos P, Lal K. Computer-assisted design/computer-assisted manufacturing zirconia implant fixed complete prostheses: clinical results and technical complications up to 4 years of function. Clin Oral Implants Res 2013;24(6):659-665.

Papavasiliou G, Kamposiora P, Bayne SC, Felton DA. Three-dimensional finite element analysis of stress-distribution around single tooth implants as a function of bony support, prosthesis type, and loading during function. J Prosthet Dent 1996 Dec;76(6):633-640. 
Pelekanos S, Koumanou M, Koutayas SO, Zinelis S, Eliades G. Micro-CT Evaluation of the Marginal Fit of Different In-Ceram Alumina Copings. Eur J Esthet Dent. 2009; 4(3):278-292.

Piascik JR, Swift EJ, Thompson JY, Grego S, Stoner BR. Surface modification for enhanced silanation of zirconia ceramics. Dent Mater. 2009 Sep;25(9):1116-21.

Qian J, Wennerberg A, Albrektsson T. Reasons for marginal bone loss around oral implants. Clin Implant Dent Relat Res. 2012 Dec;14(6):792-807.

Reich S, Wichmann M, Nkenke E, Proeschel P. Clinical fit of all-ceramic three-unit fixed partial dentures, generated with three different CAD/CAM systems. Eur J Oral Sci 2005 Apr;113(2):174-9.

Rekow D, Thompson VP. Near-surface damage - a persistente problem in crowns obtained by computer-aided design and manufacturing. Proc Inst Mech Eng H 2005 Jul;219(4):233-43.

Romeo E, Storelli S. Systematic review of the survival rate and the biological, technical, and aesthetic complications of fixed dental prostheses with cantilevers on implants reported in longitudinal studies with a mean of 5 years follow-up. Clin Oral Implants Res. 2012 Oct;23 Suppl 6:39-49.

Sahin S, Çehreli MC. The significance of passive framework fit in implant prosthodontics: current status. Implant Dent 2001;10(2):85-92.

SAS Institute Inc., SAS/STAT® User's Guide, Version 9, Cary, NC: SAS Institute Inc., 2003. Schall R. Estimation in generalized linear models with random effects. Biometrika. 1991;78(4):719-727.

Seo D, Yi Y, Roh B. The effect of preparation designs on the marginal and internal gaps in Cerec3 partial ceramic crowns. J Dent. 2009 May;37(5):374-82.

Shirakura A, Lee H, Geminiani A, Ercoli C, Feng C. The influence of veneering porcelain thickness of all-ceramic and metal ceramic crowns on failure resistance after cyclic loading. $\mathbf{J}$ Prosthet Dent. 2009 Fev;101(2):119-127. 
Sundh A, Sjogren G. Fracture resistance of all-ceramic zirconia bridges with differing phase stabilizers and quality of sintering. Dental Mater 2006 Aug;22(8):778-784.

Tiossi R, Lin L, Rodrigues RC, Heo YC, Conrad HJ, de Mattos Mda G et al. Digital image correlation analysis of the load transfer by implant-supported restorations. J Biomech. 2011 Apr;44(6):1008-1013.

Tiossi R, Lin L, Conrad HJ, Rodrigues RC, Heo YC, de Mattos Mda G et al. Digital image correlation analysis on the influence of crown material in implant-supported prostheses on bone strain distribution. J Prosthodont Res. 2012 Jan; 56(1): 25-31.

Tossi R, Falcão-Filho H, Aguiar Júnior FA, Rodrigues RC, Mattos M da G, Ribeiro RF. Modified section method for laser-welding of ill-fitting cp $\mathrm{Ti}$ and $\mathrm{Ni}-\mathrm{Cr}$ alloy one-piece cast implant-supported frameworks. J Oral Rehabil. 2010 May;37:359-363.

Triwatana P, Nagaviroj N, Tulapornchai C. Clinical performance and failures of zirconiabased fixed partial dentures: a review literature. J Adv Prosthodont 2012 May, 4(2):76-83.

Tuntiprawon ML, Wilson PR. The effect of cement thickness on the fracture strength of allceramic crowns. Aust Dent J. 1995 Feb;40(1):17-21.

Vásquez VZ, OsKan M, Kimpara ET. Evaluation of interface characterization and adhesion of glass ceramics to commercially pure titanium and gold alloy after thermal and mechanical loading. Dental Mater. 2009 Feb;25(2):221-31.

Vigolo P, Mutinelli S, Givani A, Stellini E. Cemented versus screw-retained implantsupported single-tooth crowns: a 10-year randomised controlled trial. Eur J Oral Implantol. 2012;5(4):355-364. 

Anexos 



\section{ANEXO 1: Adaptação marginal pilar/implante pré-teste}

Tabela 1: Valores da adaptação marginal entre pilar/implante $(\mu \mathrm{m})$.

\begin{tabular}{cccccccc} 
TiNeo PM & ZirNeo PM & Lava PM & Co PM & TiNeo M & ZirNeo M & Lava M & Co M \\
\hline 4,78 & 7,33 & 7,04 & 10,24 & 8,50 & 6,68 & 2,58 & 11,64 \\
5,14 & 7,62 & 3,25 & 7,02 & 5,85 & 6,91 & 5,18 & 7,14 \\
6,20 & 8,19 & 5,88 & 6,55 & 5,67 & 8,15 & 5,27 & 5,97 \\
7,09 & 7,49 & 4,65 & 5,71 & 6,60 & 6,10 & 4,04 & 7,51 \\
4,78 & 8,00 & 4,65 & 4,41 & 6,38 & 6,56 & 4,91 & 4,29 \\
7,80 & 8,33 & 4,56 & 8,93 & 5,49 & 6,91 & 3,42 & 10,71 \\
6,02 & 8,50 & 5,00 & 5,60 & 7,46 & 7,09 & 6,40 & 5,95 \\
6,42 & 8,15 & 4,21 & 7,87 & 5,67 & 6,73 & 4,82 & 6,67 \\
4,83 & 7,97 & 15,21 & 5,12 & 6,20 & 8,33 & 9,54 & 6,56 \\
4,96 & 9,23 & 4,04 & 6,07 & 4,61 & 7,97 & 3,68 & 7,62 \\
4,78 & 7,33 & 7,04 & 10,24 & 8,50 & 6,68 & 2,58 & 11,64 \\
5,14 & 7,62 & 3,25 & 7,02 & 5,85 & 6,91 & 5,18 & 7,14 \\
\hline
\end{tabular}




\section{ANEXO 2: Adaptação marginal vertical pilar/infraestrutura}

Tabela 2: Valores da adaptação vertical entre infraestrutura-pilar PM antes da prensagem da porcelana e ciclagem $(\mu \mathrm{m})$.

\begin{tabular}{cccc}
\hline TiNeo & ZirNeo & Lava & Co \\
\hline 88,81 & 48,44833 & 31,41 & 20,81 \\
113,6267 & 93,70167 & 49,46917 & 35,18833 \\
48,27833 & 158,765 & 75,60167 & 29,06833 \\
13,4825 & 119,6825 & 70,50667 & 14,65417 \\
33,88667 & 18,64833 & 49,82583 & 91,76333 \\
74,97583 & 32,38833 & 102,2258 & 36,3225 \\
30,78917 & 17,525 & 46,60333 & 33,91 \\
41,30833 & 46,81333 & 44,59167 & 35,1375 \\
48,42 & 18,11917 & 66,88917 & 48,03333 \\
28,40917 & 16,7 & 85,13167 & 37,03083 \\
\hline
\end{tabular}


Tabela 3: Valores da adaptação vertical entre infraestrutura-pilar Mo antes da prensagem da porcelana e ciclagem $(\mu \mathrm{m})$.

\begin{tabular}{cccc}
\hline TiNeo & ZirNeo & Lava & Co \\
\hline 74,8075 & 71,39833 & 39,19167 & 17,67167 \\
73,68583 & 76,76417 & 93,915 & 21,5525 \\
82,325 & 240,2275 & 31,66917 & 47,4775 \\
77,48833 & 131,1217 & 130,7617 & 26,97 \\
79,66917 & 58,08333 & 95,92 & 22,19667 \\
42,90167 & 53,96583 & 138,59 & 26,27167 \\
60,25 & 29,4325 & 90,3875 & 68,86 \\
102,0358 & 75,70083 & 177,7058 & 19,05 \\
68,41083 & 89,69625 & 126,6083 & 20,91833 \\
22,16417 & 62,58167 & 131,7467 & 34,2975 \\
\hline
\end{tabular}




\section{ANEXO 3: Adaptação marginal horizontal pilar/infraestrutura}

Tabela 4: Valores da adaptação horizontal entre infraestrutura-pilar PM antes da prensagem da porcelana e ciclagem $(\mu \mathrm{m})$.

\begin{tabular}{cccc}
\hline TiNeo & ZirNeo & Lava & Co \\
\hline 15,14583333 & $-4,528333333$ & 17,01833333 & 0 \\
$-0,834166667$ & 2,025 & 11,21916667 & 2,025 \\
$-35,58833333$ & 25,70833333 & 1,591666667 & 1,4325 \\
25,78 & $-30,31916667$ & 26,07583333 & 0 \\
5,455 & $-1,1775$ & 12,53166667 & $-12,89166667$ \\
$-2,115833333$ & 0 & 0,4783333333 & 0 \\
3,905833333 & 0 & 25,69666667 & 0 \\
2,045833333 & 0,593333333 & 15,53916667 & 0 \\
0 & 2,864166667 & 33,69166667 & $-0,5925$ \\
0 & 0 & 25 & 11,63333333 \\
\hline
\end{tabular}


Tabela 5: Valores da adaptação horizontal entre infraestrutura-pilar Mo antes da prensagem da porcelana e ciclagem $(\mu \mathrm{m})$.

\begin{tabular}{cccc}
\hline TiNeo & ZirNeo & Lava & Co \\
\hline$-8,0225$ & 3,905833 & $-10,03$ & 0 \\
$-6,47$ & 2,864167 & 13,8125 & 5,729167 \\
$-2,56167$ & $-13,9742$ & $-2,9025$ & $-5,72167$ \\
12,99083 & $-15,2617$ & 1,4325 & $-6,74083$ \\
1,364167 & 16,58833 & 22,32167 & $-14,0975$ \\
$-0,54333$ & $-46,1667$ & 28,99 & 2,865 \\
6,075833 & 10,70167 & 54,48333 & $-14,155$ \\
0,178333 & 0,330833 & 20,04583 & 4,296667 \\
0 & $-9,26917$ & 32,2475 & 0 \\
8,931667 & $-1,84083$ & 33,02417 & $-4,29667$ \\
\hline
\end{tabular}




\section{ANEXO 4: Adaptação interna pilar/infraestrutura}

Tabela 6: Valores da adaptação interna axial entre infraestrutura-pilar PM antes da prensagem da porcelana e ciclagem $(\mu \mathrm{m})$.

\begin{tabular}{cccc}
\hline TiNeo & ZirNeo & Lava & Co \\
\hline 0 & 90,2225 & 42,4775 & 48,455 \\
0 & 68,7425 & 55,7775 & 151,3875 \\
0 & 107,96 & 62,44 & 23,2625 \\
0 & 134,4425 & 70,395 & 33,42 \\
0 & 51,5575 & 62,42 & 57,03 \\
0 & 85,9275 & 65,885 & 86,7675 \\
0 & 34,3725 & 88,865 & 37,165 \\
0 & 25,78 & 64,695 & 90,65 \\
0 & 66,155 & 85,93 & 25,78 \\
0 & 63,1275 & 86,715 & 60,1525 \\
\hline
\end{tabular}


Tabela 7: Valores da adaptação interna axial entre infraestrutura-pilar Mo antes da prensagem da porcelana e ciclagem $(\mu \mathrm{m})$.

\begin{tabular}{cccc}
\hline TiNeo & ZirNeo & Lava & Co \\
\hline 0 & 71,0175 & 54,2025 & 32,2125 \\
0 & 63,175 & 64,9725 & 95,05 \\
0 & 177,52 & 78,61 & 21,485 \\
0 & 65,6725 & 56,55 & 53,285 \\
0 & 37,82 & 117,7675 & 40,6525 \\
0 & 25,0425 & 71,44 & 60,15 \\
0 & 24,275 & 71,6075 & 32,055 \\
0 & 48,31 & 55,7675 & 73,735 \\
0 & 8,595 & 71,345 & 150,3725 \\
0 & 28,9575 & 57,25 & 36,15 \\
\hline
\end{tabular}


Tabela 8: Valores da adaptação interna oclusal entre infraestrutura-pilar PM antes da prensagem da porcelana e ciclagem $(\mu \mathrm{m})$.

\begin{tabular}{cccc}
\hline TiNeo & ZirNeo & Lava & Co \\
\hline 348,19 & 197,565 & 81,935 & 75,7475 \\
397,435 & 167,5575 & 134,185 & 123,2475 \\
397,92 & 341,41 & 253,74 & 154,81 \\
146,255 & 417,5275 & 171,555 & 201,33 \\
209,54 & 223,7325 & 188,9175 & 211,2975 \\
335,765 & 227,7075 & 176,15 & 171,855 \\
146,3425 & 214,9825 & 146,255 & 118,8775 \\
175,2125 & 219,41 & 215,485 & 64,4475 \\
104,0525 & 199,295 & 283,88 & 232,0025 \\
116,91 & 169,6875 & 118,385 & 167,8625 \\
\hline
\end{tabular}


Tabela 9: Valores da adaptação interna oclusal entre infraestrutura-pilar Mo antes da prensagem da porcelana e ciclagem $(\mu \mathrm{m})$.

\begin{tabular}{cccc}
\hline TiNeo & ZirNeo & Lava & Co \\
\hline 34,7125 & 163,5025 & 82,0825 & 54,885 \\
135,03 & 134,2425 & 39,41 & 30,7725 \\
58,6775 & 172,655 & 179,44 & 116,6975 \\
68,7425 & 279,88 & 124,5925 & 89,11 \\
123,115 & 169,92 & 57,7325 & 41,625 \\
158,655 & 202,2975 & 218,065 & 137,485 \\
30,77 & 116,4275 & 73,98 & 58,245 \\
33,2125 & 159,18 & 250,7225 & 120,4925 \\
0 & 169,6025 & 165,1775 & 150,3725 \\
42,9625 & 136,8825 & 90,4825 & 112,06 \\
\hline
\end{tabular}


ANEXO 5: Adaptação marginal vertical pilar/infraestrutura, pós-teste

Tabela 10: Valores da adaptação vertical $(\mu \mathrm{m})$ entre infraestrutura/pilar PM após a prensagem da porcelana e ciclagem termomecânica.

\begin{tabular}{cccc}
\hline TiNeo & ZirNeo & Lava & Co \\
\hline 54,81833 & 29,51167 & 65,75917 & 26,05833 \\
98,9375 & 42,48583 & 66,35167 & 104,2975 \\
70,51833 & 151,4683 & 51,98167 & 15,7975 \\
83,32333 & 133,2683 & 51,02083 & 32,25667 \\
46,76417 & 23,82083 & 32,38833 & 28,77917 \\
82,975 & 62,38917 & 76,25667 & 40,1 \\
20,9 & 10,115 & 32,83083 & 39,60833 \\
23,3525 & 25,9325 & 64,3775 & 15,52667 \\
29,41917 & 125,815 & 60,37833 & 66,2225 \\
24,72083 & 37,20667 & 474,5808 & 21,2125 \\
\hline
\end{tabular}


Tabela 11: Valores da adaptação vertical $(\mu \mathrm{m})$ entre -infraestrutura/pilar $M$ após a prensagem da porcelana e ciclagem termomecânica.

\begin{tabular}{cccc}
\hline TiNeo & ZirNeo & Lava & Co \\
\hline 83,29 & 58,985 & 52,4 & 19,07958 \\
71,89667 & 23,205 & 117,2925 & 25,19083 \\
96,51417 & 70,6925 & 91,65 & 49,3225 \\
6,620833 & 120,4442 & 73,2075 & 15,53333 \\
76,90917 & 45,4475 & 68,62667 & 57,345 \\
35,11 & 93,63833 & 42,05833 & 102,985 \\
64,86 & 25,17083 & 48,0875 & 59,1275 \\
48,16167 & 91,16083 & 66,42 & 14,75333 \\
38,44 & 54,47417 & 166,5475 & 57,835 \\
14,66083 & 73,90583 & 133,6975 & 33,52583 \\
\hline
\end{tabular}




\section{ANEXO 6: Adaptação marginal horizontal pilar/infraestrutura, pós-teste}

Tabela 12: Valores da adaptação horizontal $(\mu \mathrm{m})$ entre -infraestrutura/ pilar PM após a prensagem da porcelana e ciclagem termomecânica.

\begin{tabular}{cccc}
\hline TiNeo & ZirNeo & Lava & Co \\
\hline 28,68667 & $-0,35583$ & 11,82917 & 0 \\
79,73167 & 0 & 1,79 & 0 \\
29,9225 & $-2,7275$ & 11,19833 & 0 \\
55,23833 & 6,020833 & 5,455833 & 0 \\
29,81833 & 0 & 1,685 & 0 \\
2,501667 & 3,1825 & 20,31 & 0 \\
3,553333 & 0 & 19,86167 & 3,905 \\
8,186667 & 0 & 7,024167 & 0 \\
9,0925 & $-2,22083$ & 5,433333 & 11,12583333 \\
1,4325 & $-4,09083$ & 0 & 0 \\
\hline
\end{tabular}

Tabela 13: Valores da adaptação horizontal $(\mu \mathrm{m})$ entre -infraestrutura/ pilar M após a prensagem da porcelana e ciclagem termomecânica.

\begin{tabular}{cccc}
\hline TiNeo & ZirNeo & Lava & Co \\
\hline 1,1575 & 7,723333333 & 1,301666667 & 0 \\
7,401666667 & 0 & 4,9725 & 0 \\
$-49,98583333$ & 0 & $-3,7741666667$ & $-3,4575$ \\
46,0325 & 0 & $-2,464166667$ & 0 \\
23,65416667 & 0 & 0 & 0 \\
$-3,015$ & $-6,560833333$ & 31,03833333 & 0 \\
$-10,5525$ & 0 & 20,04408333 & 2,910833 \\
0 & 0 & $-0,401666667$ & 0 \\
4,774166667 & $-1,301666667$ & $-2,7275$ & $-11,2642$ \\
0 & $-1,364166667$ & 1,591666667 & 29,7375 \\
\hline
\end{tabular}




\section{ANEXO 7: Adaptação interna pilar/infraestrutura, pós-teste}

Tabela 14: Valores da adaptação interna axial $(\mu \mathrm{m})$ entre prótese fixa - pilar PM após a prensagem da porcelana e ciclagem termomecânica.

\begin{tabular}{cccc}
\hline TiNeo & ZirNeo & Lava & Co \\
\hline 0 & 0 & 32,6825 & 31,62 \\
0 & 24,62 & 45,15 & 145,5725 \\
0 & 43,7 & 72,305 & 27,6875 \\
0 & 269,9775 & 38,4275 & 19,94 \\
0 & 32,48333 & 49,9825 & 35,6225 \\
0 & 58,06 & 58,9525 & 23,015 \\
0 & 156,685 & 56,8025 & 37,1825 \\
0 & 34,0175 & 69,1175 & 67,575 \\
0 & 38,095 & 44,175 & 65,2875 \\
0 & 43,8075 & 145,89 & 24,7425 \\
\hline
\end{tabular}


Tabela 15: Valores da adaptação interna axial $(\mu \mathrm{m})$ entre -infraestrutura/pilar $M$ após a prensagem da porcelana e ciclagem termomecânica.

\begin{tabular}{cccc}
\hline TiNeo & ZirNeo & Lava & Co \\
\hline 0 & 71,795 & 15,9425 & 35,41 \\
0 & 9,615 & 20,465 & 64,215 \\
0 & 27,74 & 37,105 & 77,5575 \\
0 & 28,085 & 48,0175 & 18,14 \\
0 & 4,0925 & 19,9975 & 52,1025 \\
0 & 11,525 & 43,5675 & 38,6925 \\
0 & 3,4375 & 21,56 & 24,6175 \\
0 & 16,525 & 27,745 & 57,84 \\
0 & 31,27 & 50,3275 & 100,7775 \\
0 & 22,3175 & 27,3875 & 29,7375 \\
\hline
\end{tabular}


Tabela 16: Valores da adaptação interna oclusal $(\mu \mathrm{m})$ entre -infraestrutura/pilar PM após a prensagem da porcelana e ciclagem termomecânica.

\begin{tabular}{cccc}
\hline TiNeo & TiNeo & TiNeo & TiNeo \\
\hline 225,7275 & 225,7275 & 225,7275 & 225,7275 \\
295,935 & 295,935 & 295,935 & 295,935 \\
289,2725 & 289,2725 & 289,2725 & 289,2725 \\
116,8975 & 116,8975 & 116,8975 & 116,8975 \\
132,1 & 132,1 & 132,1 & 132,1 \\
263,095 & 263,095 & 263,095 & 263,095 \\
55,2275 & 55,2275 & 55,2275 & 55,2275 \\
17,185 & 17,185 & 17,185 & 17,185 \\
29,3375 & 29,3375 & 29,3375 & 29,3375 \\
47,26 & 47,26 & 47,26 & 47,26 \\
\hline
\end{tabular}


Tabela 17: Valores da adaptação interna oclusal $(\mu \mathrm{m})$ entre -infraestrutura/pilar M após a prensagem da porcelana e ciclagem termomecânica.

\begin{tabular}{cccc}
\hline TiNeo & ZirNeo & Lava & Co \\
\hline 161,59 & 0 & 34,2525 & 26,1525 \\
122,66 & 64,3925 & 17,49 & 4,5225 \\
76,57 & 19,4625 & 106,435 & 127,7825 \\
141,1675 & 71,98 & 27,9325 & 0 \\
49,9025 & 32,74 & 63,7 & 72,7425 \\
12,89 & 58,5325 & 100,3475 & 178,39 \\
82,3675 & 14,1725 & 0 & 53,9025 \\
18,115 & 36,055 & 35,5275 & 69,44 \\
15,095 & 61,47 & 114,34 & 165,4675 \\
0 & 48,085 & 59,83 & 41,3475 \\
\hline
\end{tabular}




\section{ANEXO 8: Tensão nos implantes (CID)}

Tabela 18: Valores da tensão (Exx) em toda região dos implantes pelo método da Correlação de Imagens Digitais:

\begin{tabular}{|c|c|c|}
\hline Corpo de prova & $\mathbf{P M}$ & $\mathbf{M}$ \\
\hline TiNeo 1 & $-310,361$ & $-295,312$ \\
\hline TiNeo 2 & $-523,48$ & $-425,02$ \\
\hline TiNeo 3 & $-469,924$ & $-245,959$ \\
\hline TiNeo 4 & $-251,548$ & $-288,283$ \\
\hline TiNeo 9 & $-383,089$ & $-418,21$ \\
\hline ZirNeo 13 & $-607,945$ & $-479,179$ \\
\hline ZirNeo 14 & $-621,035$ & $-479,179$ \\
\hline ZirNeo 17 & $-355,746$ & $-876,255$ \\
\hline ZirNeo 18 & $-261,521$ & $-491,319$ \\
\hline ZirNeo 20 & $-392,675$ & $-576,713$ \\
\hline Lava 23 & $-523,17$ & 351,5811 \\
\hline Lava 25 & $-224,228$ & $-503,547$ \\
\hline Lava 27 & $-207,23$ & $-347,489$ \\
\hline Lava 28 & $-225,213$ & $-220,016$ \\
\hline Lava 30 & $-293,021$ & $-245,801$ \\
\hline Co 31 & $-417,134$ & $-304,468$ \\
\hline Co 32 & $-439,073$ & $-304,468$ \\
\hline Co 33 & $-372,367$ & $-289,355$ \\
\hline Co 37 & $-342,427$ & $-380,272$ \\
\hline Co 40 & $-489,688$ & $-326,19$ \\
\hline
\end{tabular}


Tabela 19: Valores da tensão (Exx) na região cervical dos implantes pelo método da Correlação de Imagens Digitais:

\begin{tabular}{|c|c|c|}
\hline Corpo de prova & PM & $\mathbf{M}$ \\
\hline TiNeo 1 & 102,5861 & 71,55325 \\
\hline TiNeo 2 & $-49,0685$ & $-21,1287$ \\
\hline TiNeo 3 & 163,3886 & 110,5765 \\
\hline TiNeo 4 & $-124,851$ & 98,5627 \\
\hline TiNeo 9 & $-87,266$ & $-96,7428$ \\
\hline ZirNeo 13 & $-94,7037$ & $-110,768$ \\
\hline ZirNeo 14 & $-80,8532$ & $-110,768$ \\
\hline ZirNeo 17 & $-34,5922$ & $-75,1523$ \\
\hline ZirNeo 18 & 8,307461 & 23,27444 \\
\hline ZirNeo 20 & 48,43131 & $-92,473$ \\
\hline Lava 23 & 187,48 & 229,182 \\
\hline Lava 25 & $-42,5905$ & $-0,76452$ \\
\hline Lava 27 & 142,7893 & 90,82153 \\
\hline Lava 28 & 314,6613 & 79,76782 \\
\hline Lava 30 & 272,2911 & $-149,951$ \\
\hline Co 31 & $-205,575$ & $-42,4815$ \\
\hline Co 32 & 60,95727 & $-93,6069$ \\
\hline Co 33 & 270,4866 & 22,42917 \\
\hline Co 37 & 278,1807 & 56,27558 \\
\hline Co 40 & 11,6894 & 75,38218 \\
\hline
\end{tabular}


Tabela 20: Valores da tensão (Exx) na região apical dos implantes pelo método da Correlação de Imagens Digitais:

\begin{tabular}{|c|c|c|}
\hline Corpo de prova & $\mathbf{P M}$ & $\mathbf{M}$ \\
\hline TiNeo 1 & $-134,472$ & $-110,435$ \\
\hline TiNeo 2 & $-162,913$ & $-256,847$ \\
\hline TiNeo 3 & $-116,022$ & $-83,3683$ \\
\hline TiNeo 4 & $-133,613$ & $-116,167$ \\
\hline TiNeo 9 & $-206,791$ & $-211,015$ \\
\hline ZirNeo 13 & $-381,462$ & $-316,304$ \\
\hline ZirNeo 14 & $-384,272$ & $-316,304$ \\
\hline ZirNeo 17 & $-193,319$ & $-533,291$ \\
\hline ZirNeo 18 & $-81,2287$ & $-235,132$ \\
\hline ZirNeo 20 & $-145,808$ & $-367,321$ \\
\hline Lava 23 & $-199,973$ & $-88,0514$ \\
\hline Lava 25 & $-159,42$ & $-277,699$ \\
\hline Lava 27 & $-26,7173$ & $-182,353$ \\
\hline Lava 28 & $-8,57139$ & $-78,4323$ \\
\hline Lava 30 & $-28,5906$ & $-169,413$ \\
\hline Co 31 & $-287,47$ & $-396,807$ \\
\hline Co 32 & $-137,598$ & $-174,224$ \\
\hline Co 33 & $-41,5491$ & $-131,485$ \\
\hline Co 37 & $-37,3168$ & $-180,242$ \\
\hline Co 40 & $-200,272$ & $-148,231$ \\
\hline
\end{tabular}




\section{ANEXO 9: Resistência a fratura}

Tabela 21: Valores da resistência à fratura $(\mathrm{N})$ de cada corpo de prova:

\begin{tabular}{ccccc}
\hline Corpos de prova & TiNeo & ZirNeo & Lava & Co \\
\hline $\mathbf{1}$ & 3838,33 & 1313,39 & 1639,52 & 1299,56 \\
$\mathbf{2}$ & 2687,35 & 1900,82 & 1780,41 & 1406,96 \\
$\mathbf{3}$ & 1849,58 & 792,16 & 1151,44 & 2549,27 \\
$\mathbf{4}$ & 2676,48 & 607,37 & 1139,26 & 1187,54 \\
$\mathbf{5}$ & 1682,01 & & 1626,65 & 1090,39 \\
$\mathbf{6}$ & 1015,18 & 1031,58 & 1991,79 & 1064,85 \\
$\mathbf{7}$ & 1812,79 & 2311,93 & 1350,99 & 1362,48 \\
$\mathbf{8}$ & 1848,17 & 1701,45 & 1635,38 & 542,79 \\
$\mathbf{9}$ & 2225,67 & 925,91 & 1104,78 & 1564,91 \\
$\mathbf{1 0}$ & 1712,32 & 1676,86 & 762,85 & 2401,87 \\
\hline
\end{tabular}

